\title{
Selján Péter
}

The Role of Foreign Intervention in the Balance of Power System of the Greater Middle East:

The Case of Iraq 

Institute for International, Political and Regional Studies

Department of International Relations

Supervisors:

Dr. Csicsmann László, Ph.D.

Associate Professor

Dr. Rostoványi Zsolt DSc, Ph.D.

Professor

2021

(C) Selján Péter

ALL RIGHTS RESERVED 

International and Security

Studies Doctoral Program

The Role of Foreign Intervention

in the Balance of Power System

of the Greater Middle East:

The Case of Iraq

Doctoral dissertation

Selján Péter

Budapest, 2021 

This dissertation is dedicated to my parents. 



\begin{abstract}
The number of major civil wars declined significantly during the 1990s, however, the improving trends of violent conflict has been reversed during the last decade. The Middle East has long been among the most conflict-prone regions, and the centrally located Iraq is one of the countries most affected by conflict. Iraq has been effectively a battleground since the USled invasion in 2003. However, Baghdad has been in focus of US national security policy since the 1979 Iranian Revolution, which resulted in a shift of the regional balance of power.

The main question of this exploratory study is whether a foreign military intervention can induce a notable shift in the regional balance of power through the redistribution of the national capabilities among states in the system? The structure of this doctoral dissertation is as follows: Chapter One contains the introduction and the overview of the research project. Chapter Two offers an overview of trends and approaches of armed conflict, describes the concept and the various definitions of foreign intervention, and shows the relationship between external intervention and civil war. Chapter Three proceeds with the overview of the balance of power theory, starting with the various meanings of the term and the possible applications of the concept. It also outlines the different balancing behaviors, the process of alliance formation, the operation of a balance of power system, and the methodological challenges of measuring power. Chapter Four provides an overview of foreign interventions in Iraq from 1990 to 2014 from a balance of power perspective. Chapter Five outlines the current regional balance of power system. Chapter Six concludes the doctoral dissertation with our conclusions.

The balance of power is a variously defined theory and a controversial realist concept. However, its application as a tool of theoretical analysis remains valid. Seeing the history of external interventions targeting Iraq and their impact on national capabilities, it can be concluded that an external intervention is capable to shape or even change how a regional balance of power system operates. However, this is not only due to its impact on national capabilities, but also to its influence on threat perception, which is an important driver of alliance formation.
\end{abstract}





\section{Table of Contents}

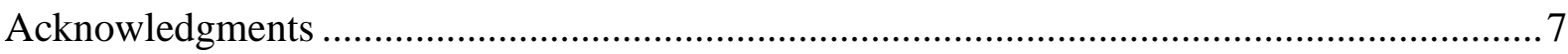

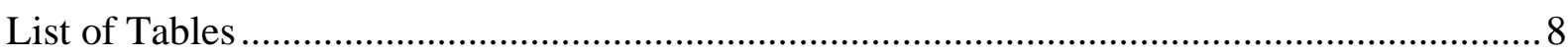

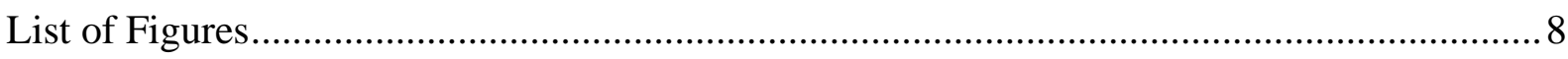

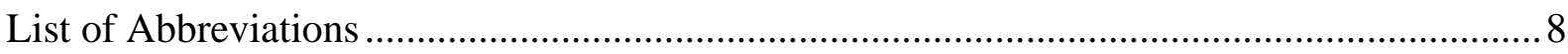

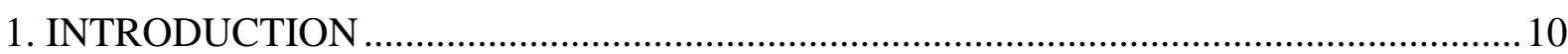

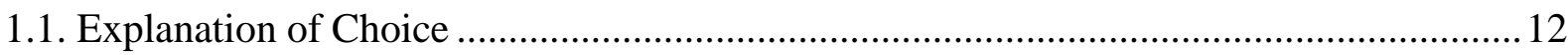

1.2. Research Problem, Time Frame, and Case Selection .................................................. 15

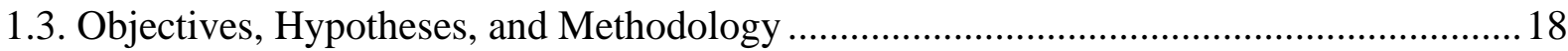

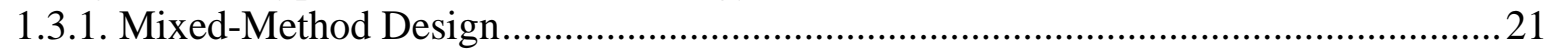

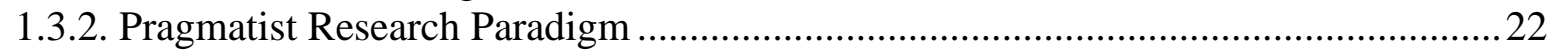

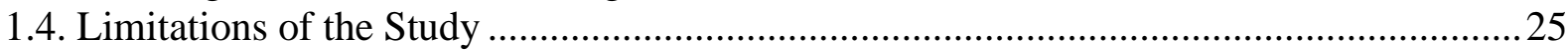

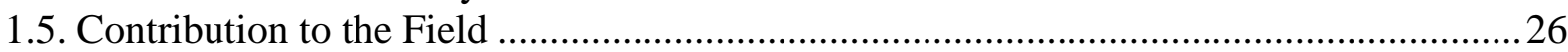

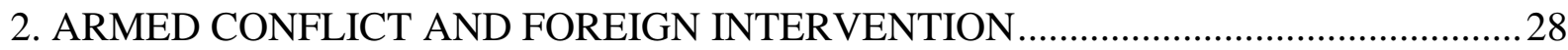

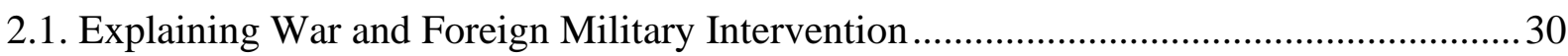

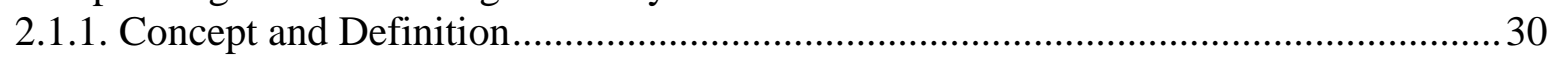

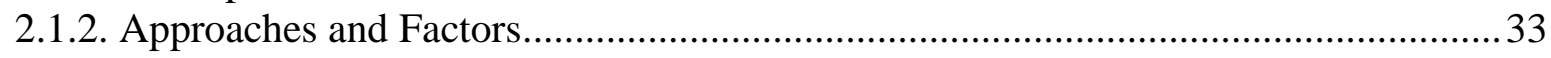

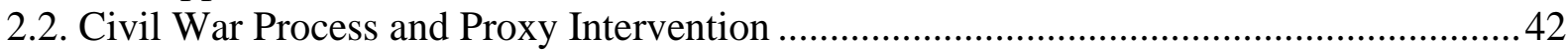

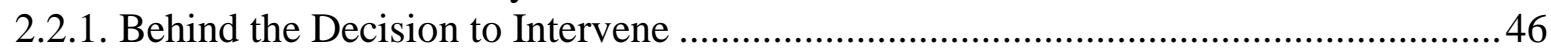

2.2.2. Impact of External Intervention on Civil War ...................................................... 47

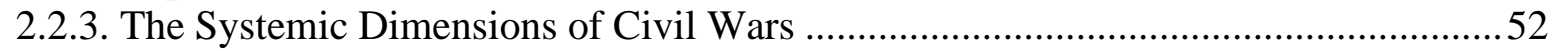

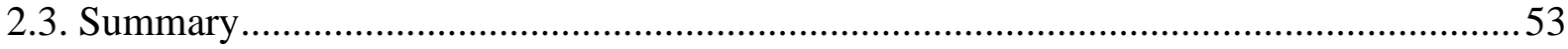

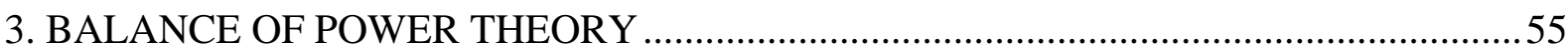

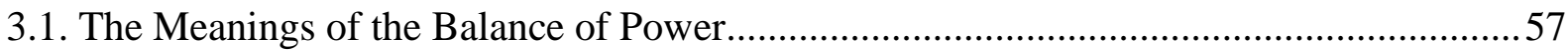

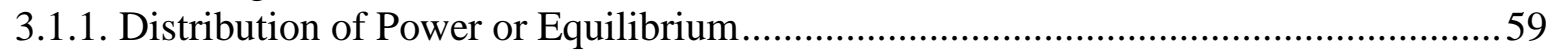

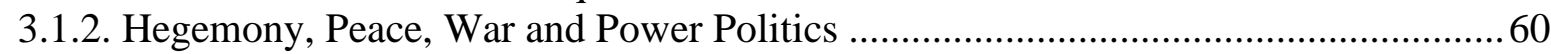

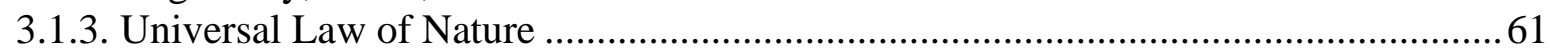

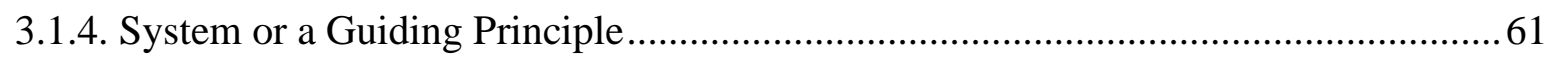

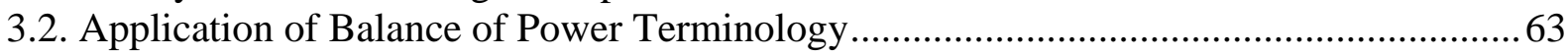

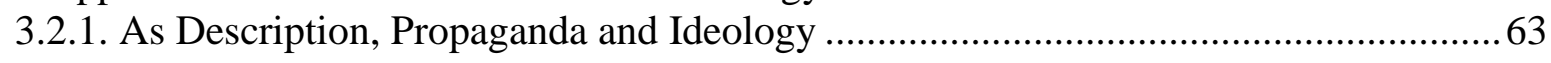

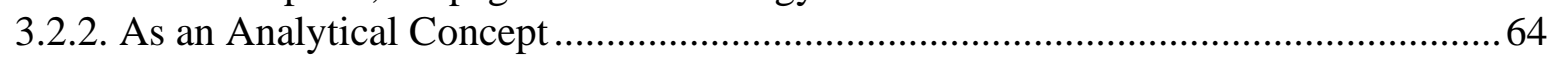

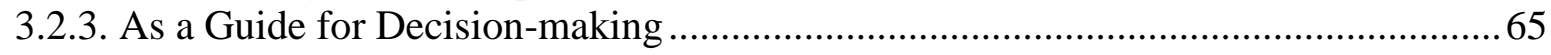

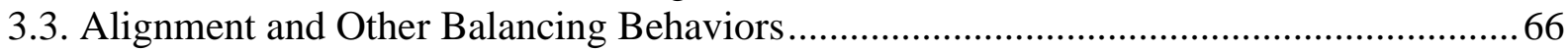

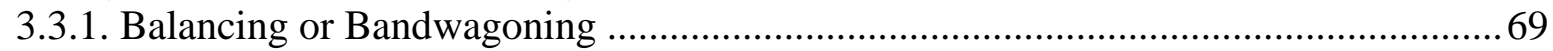

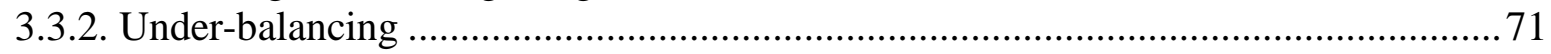



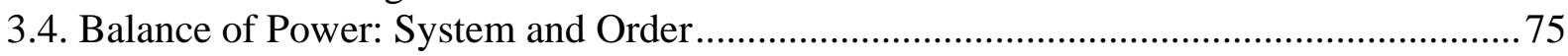

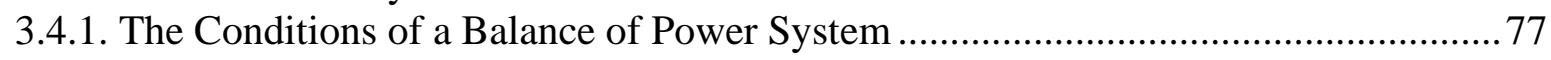

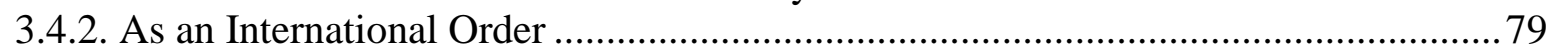

3.5. Measuring Balance, the Redistribution of Power, and Alliance Formation ...................... 80

3.5.1. Balance of Power, Collective Security and Power Transition.................................. 82

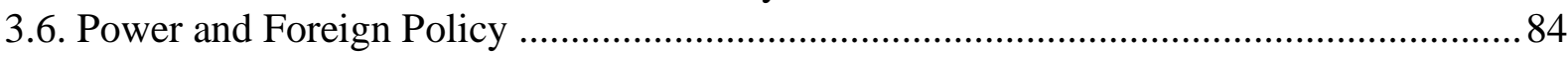

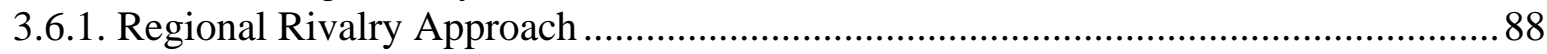






\section{FOREIGN INTERVENTIONS IN IRAQ FROM A BALANCE OF POWER}

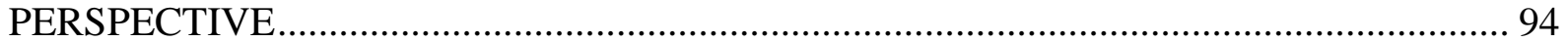

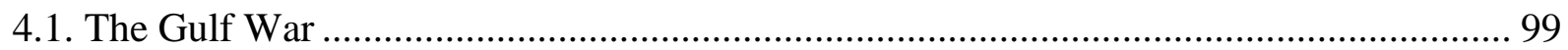

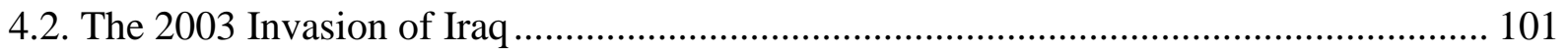

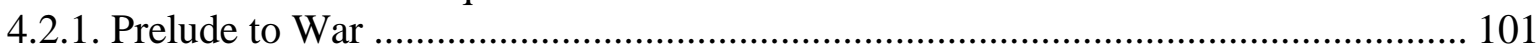

4.2.2. From Regime Change to State Collapse .............................................................. 102

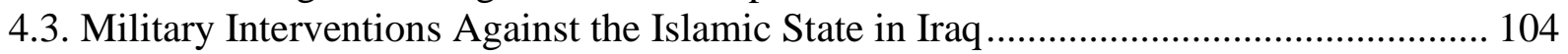

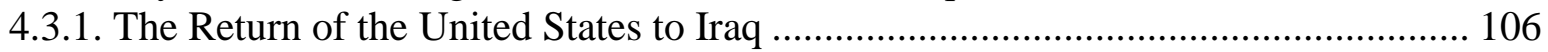

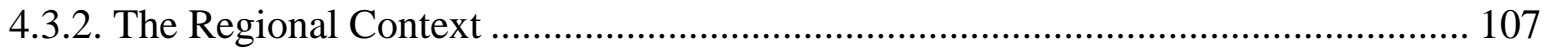

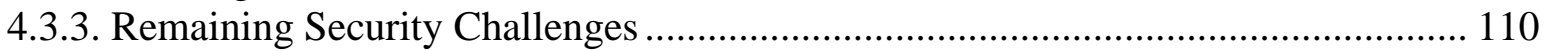

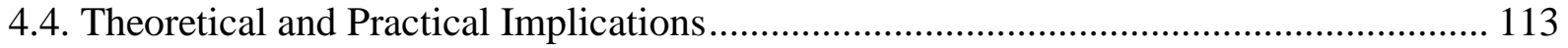

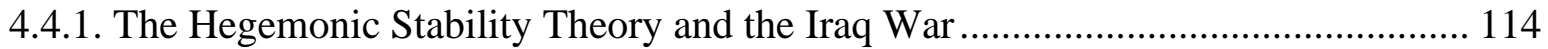

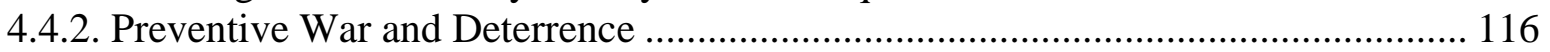

4.4.3. Balance of Power Theory and Growing Uncertainty ............................................ 119

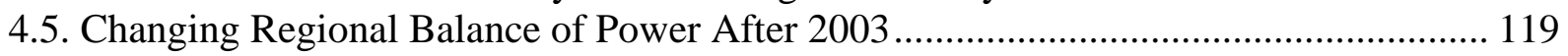

4.5.1. Opposing Iran's Growing Influence ................................................................ 121

4.5.2. A Potential Anti-Iranian Alliance with Israel and Saudi-Arabia ........................... 123

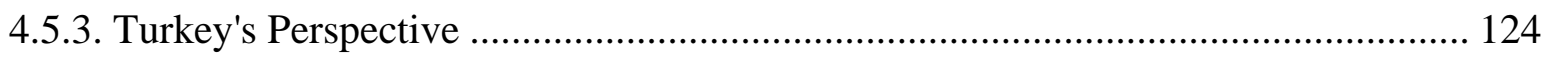

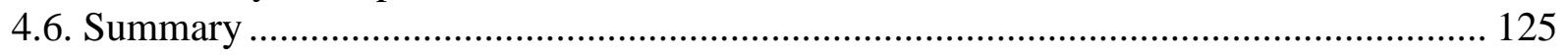

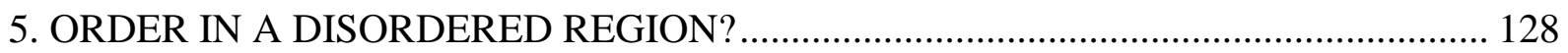

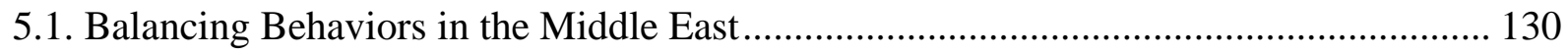

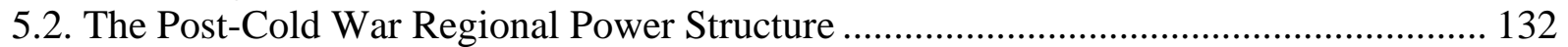

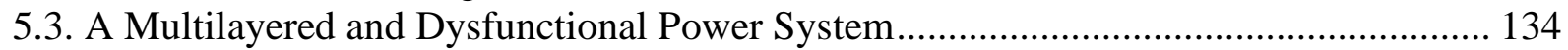

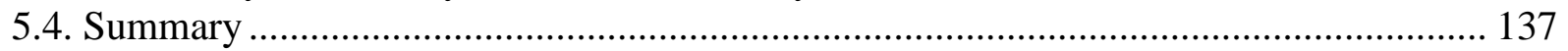

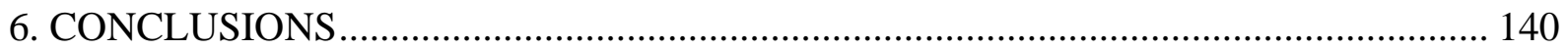

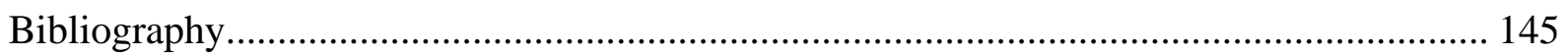

List of the Author's Related Publications ............................................................................ 170

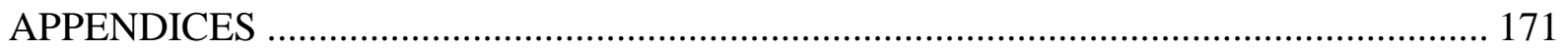



A.1.1. Correlates of War Project: Militarized Interstate Disputes, 1816-2010................. 171



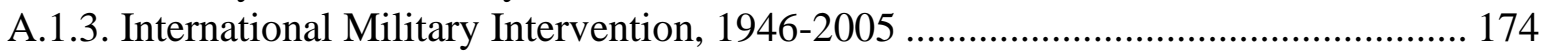

A.1.4. Interventions During Political Instability, 1957-2007 .......................................... 178

A.1.5. Uppsala Conflict Data Program: Organized Violence, 1989-2017 ......................... 181

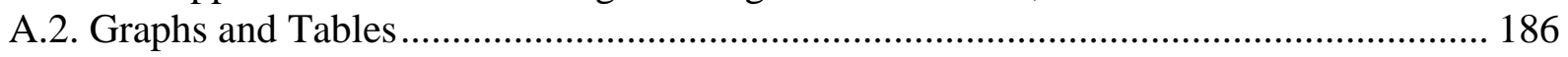




\section{Acknowledgments}

It would be impossible to identify all the professors, colleagues, and students who in some way influenced my thinking and my research process during these years in which this doctoral dissertation was conceived. However, I do not want to deviate from the customary practice of expressing gratitude and naming some of those individuals who have made significant contributions to my studies and my research process.

I am very grateful to Professor Kaiser Ferenc, who become my supervisor many years ago to help me participate in the biennial Scientific Student Conferences. Thanks to his support, I was able to write and submit 5 papers to these conferences, and I learned a lot through these events, expanding my knowledge further. I would also like to thank N. Rózsa Erzsébet, who showed me direction and helped me to understand regional issues better. Special thanks to my supervisors, Csicsmann László and Rostoványi Zsolt, who undertook the task to help me with my doctoral research project. Their thoughts and arguments enriched my thinking during these years and helped me to constantly move forward with my research.

I also wish to address my thanks to the Zrínyi Miklós National Defense University (now University of Public Service), where I studied five years as a security policy student, and where for the first time I had the opportunity to write publications in peer-reviewed academic journals. Special thanks to the researchers of the Institute for Strategic and Defense Studies (ISDS), particularly to Csiki Tamás and Háda Béla, who have also supported me in recent years, and without their help I certainly would not have been able to publish regularly.

I wish to thank the Corvinus University of Budapest as well, and especially Kaponyi Erzsébet for allowing and encouraging me to continue my studies in the field of International Relations, as I returned to this area in 2016 right after I have just graduated as a paramedic. The university staff at Corvinus was always very supportive, and I will be always grateful for their help which allowed me to pursue my research project while I was working part-time as a health care professional in the Hungarian Army Medical Center, and later as a Paramedic with the National Ambulance Service.

I wish to express my gratitude to my family, because I would not have been able to complete my studies without their constant support. Special thanks to Selján Gábor, my twin brother, who has been my main supporter during these years, while he was pursuing his own doctoral research project at Corvinus. 


\section{List of Tables}

- Table 1. Military Interventions by Powerful States, 1990-2003 (p. 17)

- Table 2. Foreign intervention and proxy war definitions (p. 32)

- Table 3. US military interventions in Iraq since 1990 (p. 98)

- Table 4. Interventions by Major Powers, Non-Major Powers and International Organizations, 1946-2005 (p. 178)

- Table 5. Interventions by Region, 1946-2005 (p. 178)

- Table 6. CINC scores of Iraq: A comparative table of pre-intervention and postintervention periods (p. 186)

- Table 7. CINC-score comparison table (p. 188)

- Table 8. Strategic international military interventions targeting Iraq, 1989-2005 (p. 191)

- Table 9. IMI Dataset variables explained (p. 192)

\section{List of Figures}

- Figure 1. Threat-perception scale (p. 21)

- Figure 2. Regional FSI-score comparison graph, 2006-2020 (p. 108)

- Figure 3. Regional CINC-score comparison graph, 1990-2012 (p. 120)

- Figure 4. International Military Interventions, 1946-2005 (p. 177)

- Figure 5. Regional CINC-score comparison graph, 1945-2012 (p. 187)

\section{List of Abbreviations}

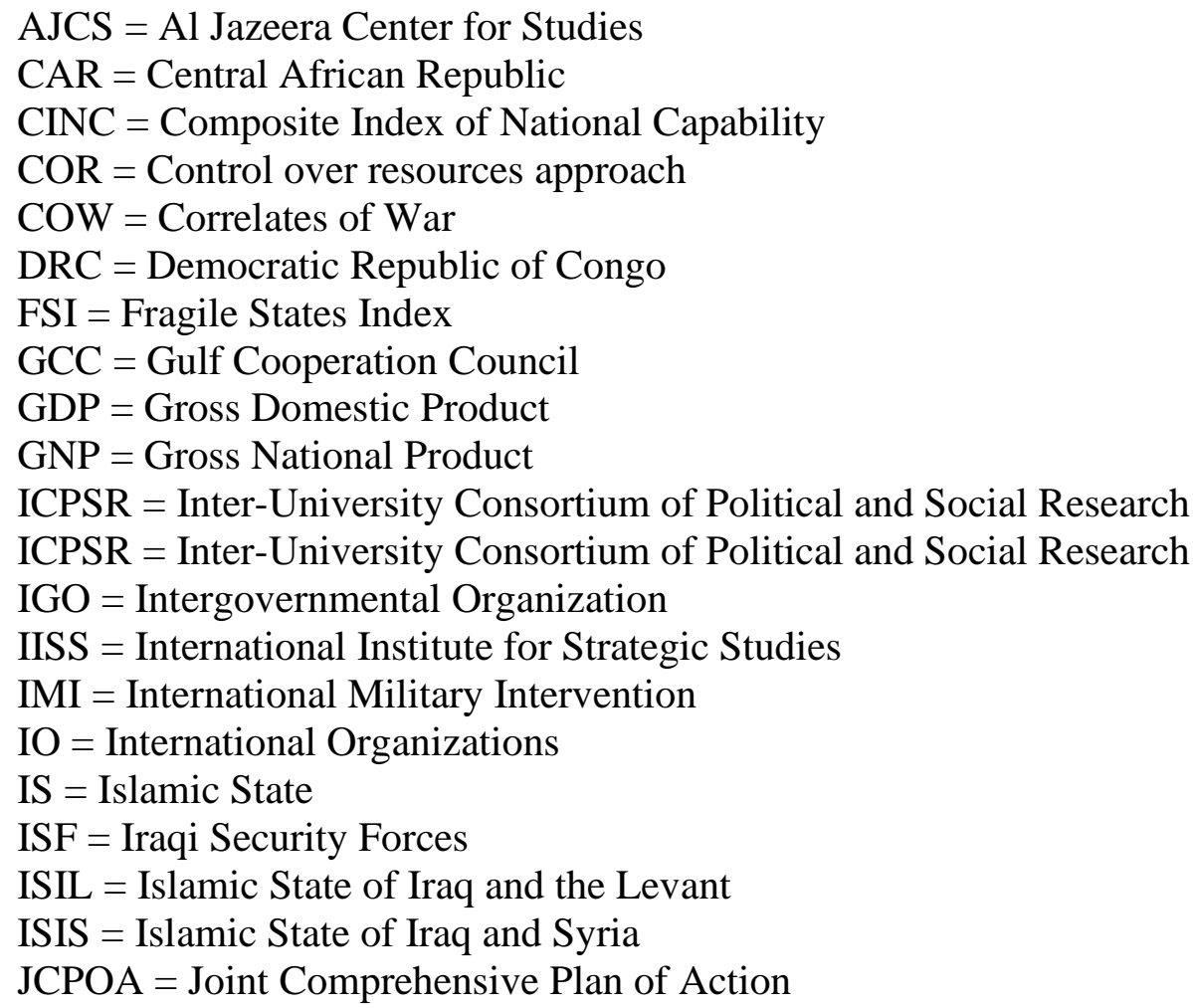


$\mathrm{KRG}=$ Kurdish Regional Government

MID = Militarized Interstate Dispute

MIPS $=$ Military Intervention by Powerful States

NMC $=$ National Material Capabilities

OAU $=$ Organization of African Unity

ODA = Overseas Development Assistance

PRIE = Politically Relevant International Environment

PRIO = Peace Research Institute Oslo

$\mathrm{SDF}=$ Syrian Democratic Forces

$\mathrm{UAE}=$ United Arab Emirates

UCDP $=$ Uppsala Conflict Data Program

UNUCPR = United Nations University - Centre for Policy Research

USA $=$ United States of America 


\section{INTRODUCTION}

"It must be remembered that 'negative findings' are not to be dismissed as useless. In a field [...] with many scholars - not to mention practitioners - quite sure that they understand the system around them, a little evidence for agnosticism can be quite salutary. It is true, of course, that we must act every day despite the paucity of our knowledge, and hope that our judgements and predictions will be correct. But better, it seems to me, that we act fully aware of our limited knowledge, rather than in sublime, but ill-founded, confidence."

(Singer 1977:577)

"Thinking is also research." (Hedley Bull)

Foreign military intervention seems one of the ultimate instruments of forceful foreign policy and is becoming a determining phenomenon of world politics in the $21^{\text {st }}$ century. Especially in Central Asia and the Middle East, where since the beginning of the so-called Arab Spring one external military intervention follows another. We can see this happening in some countries struggling with civil wars and armed conflicts like Libya, Syria, Yemen, and Iraq. The empirical literature on foreign military intervention has made considerable progress in the last few decades identifying the causes and consequences of military intervention, but we still have much to learn about the subject. Where and when states use armed forces is frequently interpreted in terms of international norms. However, there is serious disagreement as to whether the norms governing the use of force are primarily due to international law or balance of power.

According to realist thinking, where and when a state uses armed forces is primarily affected by the opportunities and obstacles afforded by the recognized distribution of power among states in the international system. From a liberal perspective, state behavior on the international stage now appears to challenge the validity of the classical balance of power theory. It seems that now the process of globalization, increasing institutionalism, economic interdependence and other factors are transforming world politics and international relations. However, non-state actors are ready to challenge the international order built around the power of nation-states, and, while states are often reluctant to cooperate with one another, they are standing side-by-side against the threat of international terrorism. Meanwhile, the preponderant power of the United States has failed to generate a balancing behavior. 
Therefore, many are skeptical whether the traditional notions of balance of power might still apply in contemporary international relations. The bulk of the criticism of the theory has focused on its methodological and empirical weaknesses, and on the failure of its proponents to predict the timing in which balance of power occurs. However, realists think that balance of power dynamics still operate in some way, and that hard balancing continues at the regional level, particularly where protracted conflicts are, while soft balancing and asymmetric balancing are occurring almost everywhere.

The history of the Middle East region is dominated by protracted armed conflicts, rivalries, civil wars, and foreign interventions. Foreign powers are traditionally highly involved in the Middle East because of its natural resources, its strategic location, their alliances in the region and their various security and economic interests. There is a constant power competition in the region, which can be balanced by the intervention of great powers to prevent the formation of a regional hegemony. States also tend to bandwagon with a global hegemon that regularly intervenes in the region, which can create a situation where revisionist states and non-state actors are likely to be kept contained. In this sense, a regional system is neither totally anarchic, nor fully autonomous because of the influence of great powers, which means it actually depends on the great powers of the international arena. In other words, only when great powers disengage from a region is an autonomous regional system able to form, and until then, balancing at the regional level takes place primarily through great-power alliances with local actors.

This research project is an attempt to fill the gap in the scientific literature through looking for the link between foreign intervention and changes in a balance of power system or the change of the system itself. The aim of this study is to find out, whether a foreign military intervention can induce significant shifts in a regional balance of power system. In addition, this research includes questions related to the impact of interventions on alliance formation, threat perception, and non-state actor activities. To identify the relationship between the impact of the interventions and shifts in the balance of power, this study provides an overview of the foreign military interventions in Iraq since the end of the Cold War, traces the changes in the national capabilities and the strategic landscape, and highlights the connections.

This first introductory chapter of the dissertation contains the description of the overall research design, stating the topic and the aims of the study in more detail, while also provides a brief literature review. The introduction also offers an explanation of choice, describes the research area, the time frame, outlines the methodology of the study and points out its limits. Finally, it covers the contribution to the field as well. Chapter Two and Three contain together 
the literature review. The former is intended to outline the concept of foreign intervention, while the latter one offers an overview of the balance of power theory and provides the widely used interpretations of the theory as well. The aim of the literature review is to define the theoretical cores of both subjects and to identify the gap that needs to be addressed. Chapter Four contains the case study of Iraq with the description of the foreign interventions targeting Iraq from 1990 to 2014, including the Gulf War, the 2003 US-led invasion, and the international response against the Islamic State as well. In addition, it also outlines the implications of these external interventions, highlighting the significant changes in the regional balance of power. Chapter Five describes the current balance of power system of the Middle East.

The final chapter briefly summarizes how this research project extended existing knowledge in this subject area, and how the results can impact future scholarly research, theory, and policymaking, emphasizing why the research problem worth investigating. At the end of the study the sources used in composing this paper have been listed, referencing only the literature that have been used or cited in the footnotes. A list of the author's related publications and appendices have also been provided.

\subsection{Explanation of Choice}

In recent years there seems to be a growing interest in the changing balance of power of the region, however, little research has been dedicated to the theory's applicability at the regional level, especially in the Middle East. The competitive relations between Iran and Saudi Arabia today seem to reflect the operation of the balance of power theory, although the ongoing transformation of the region towards a new regional political order is mostly driven by the socalled Arab Spring and the protracted civil wars.

The Middle East is a geographical region that has been of great importance in history. ${ }^{1}$ Due to its strategic location, it is a natural land bridge, connecting the continents of Asia, Africa, and Europe. It was the site of some of the world's earliest civilizations and the birthplace of three world religions - Judaism, Christianity, and Islam. In recent decades, its

\footnotetext{
${ }^{1}$ The Middle East has always been a very vague term, in which countries were added and removed depending on the context. Our research area as the Greater Middle East and North Africa includes countries from West-Africa to India (including Iran, Israel, Turkey, Afghanistan, and Pakistan). In this regard, we use the term of Middle East not as a merely geographical term to describe a region that lies between Asia and Africa, but more as a political one, as was introduced by George W. Bush in 2004. Zeev Maoz' (1996) concept of a “politically relevant international environment" (PRIE) can also be applied in this context. Maoz defined a state's PRIE as those states to which it is geographically contiguous as well as the major, or regional powers. Similarly, Enterline (1998) argues that the "geographic neighborhood" of a new regime has important consequences for the regime's subsequent involvement in interstate conflict.
} 
huge oil reserves have made the Middle East region more important than ever before. The significance of this region is clear when one deals with the questions of war, peace, power, and influence that have traditionally been at the center of the discipline of International Relations since conflicts in developing countries of the Middle East continue unabated. The current regional trends point to the increasing importance of the Middle East in matters of international security as well. To better understand the causes of conflicts in the Middle East, and to find possible solutions for them, we must first have a better understanding of the region itself.

The centrally located Iraq, which occupies the historical region of Mesopotamia (often referred to as the cradle of civilization), has been a battleground since the US-led military intervention ousted Saddam Hussein in 2003. The mainly Shia-led governments that have held power since have struggled to stabilize the country amid the growing sectarian violence. Iraq has the world's fifth-largest reserves of crude oil, however, the country's unsettled security environment made efforts futile to rebuild its shattered economy.

The United Nations University Centre for Policy Research (UNUCPR) published an occasional paper in March 2017, which provides insights into major trends in violent conflict and analyses the implications of these trends for international actors engaged in conflict prevention and management. According to the data, major civil wars - those with over 1,000 battle deaths per year and involving at least one state actor - declined by about $72 \%$ from 1990-2003. This trend, however, has been dramatically reversed over the past decade, with the number of major civil wars since then rising from 4 to 11 in 2015 . The last time the number of major civil wars was higher was in 1992 (Einsiedel 2017:2). ${ }^{2}$

Minor civil wars were also on the rise, standing at 38 in 2015, which was the highest number since $1994 .^{3}$ It must be noted that the sharp increase since 2014 has been largely driven by the expansion of the Islamic State of Iraq and Syria (ISIS) and its affiliates, which were involved in conflicts in 3 countries in 2014 and 12 in 2015 (Melander, Pettersson \& Themnér 2016:727-742). With the rise of intrastate conflict, the number of battle deaths has also grown significantly. From 2011 to 2015, there has been a six-fold increase in battle deaths in major civil wars, which in 2015 stood at 90,000, making 2014 and 2015 the deadliest years on the battlefield since the end of the Cold War. The rise in battle deaths since 2011 was due to two major factors: the lethality of conflicts in the Middle East, Syria in

\footnotetext{
${ }^{2}$ The eleven civil wars include Afghanistan, Iraq, Nigeria (2x), Pakistan, Somalia, Sudan, Syria (2x), Ukraine, Yemen.

${ }^{3}$ An armed conflict qualifies as minor civil war if results in at least 25 battle deaths per year, and if there is at least one state actor involved.
} 
particular, and the expansion of jihadist groups, such as ISIS, al-Qaeda and their affiliates. However, this data fails to capture "indirect deaths", which are caused by the consequences of conflict and significantly surpass the number of battle deaths (Einsiedel 2017; Krause 2016:113-126).

In regard of civil war relapse, it must be noted that the causes of civil war tend to be multiple and complex, and the specific dynamics of each case are unique. However, earlier studies highlighted the central importance of weak institutions as the key structural cause that create the conditions for conflict and violence, particularly in combination with political and economic exclusion. Quantitative studies indicate that countries that have experienced regime change, sudden changes in the degree of democracy, or recent independence are especially conflict prone. Moreover, civil wars tend to exacerbate the conditions that helped cause them in the first place. This may explain the finding of the 2011 World Development Report that $90 \%$ of the civil wars since 2000 occurred in states that had experienced a civil war in the previous 30 years (World Bank 2011:3).

The nature of conflicts is also changing, as armed conflicts are becoming more intractable and less conducive to political settlement. Three developments can be named which significantly complicate the endeavors of international actors in conflict management, such as: (1) the impact of organized crime as a major stress factor; (2) the increasing internationalization of civil war, that is the increase in military involvement of external actors in civil wars which renders conflicts more difficult to solve; and (3) the growing presence of jihadist groups in modern conflict settings (Einsiedel 2017:4).

In regard of the impact of organized crime, it is worth noting that during the Cold War, many civil wars were fueled by superpower support to rebel forces in "third world" proxy conflicts. As external state support decreased, armed non-state groups increasingly engaged in the shadow economy. This trend continues even today, and the growing ability of armed groups and other non-state actors to tap into global illicit markets, and their deepening involvement in criminal activities are dramatically affecting conflict dynamics. Furthermore, the significant rise of internationalized civil wars is another trend of recent years that makes conflict even more intractable. In 1991, 4\% of conflicts were internationalized, that is other states intervened militarily on one or both sides. By 2015, this number had multiplied ten-fold to $40 \%$. This is a concerning trend because research shows that when external interventions in domestic conflicts do not lead to a rapid military victory, they are likely to make internal conflicts deadlier and longer. The significant rise in jihadist violence in modern conflict settings is another phenomenon of particular concern. Since 2010, there has been a substantial 
rise in the number of Salafi-jihadist fighters. Accompanying this trend has been an almost tenfold increase since 2003 in the number of fatalities from terrorist attacks. It must be emphasized that only four groups were responsible for $74 \%$ of all these deaths: ISIS, Boko Haram, al-Qaeda, and the Taliban. And the sharp rise in deaths has been due to a large number of fatalities in a handful of conflict-affected countries: Iraq, Nigeria and Afghanistan (Einsiedel 2017:4-6).

The theory of balance of power is regularly mentioned during discussions of the worrying trends of armed conflict and the internationalized civil wars in the Middle East. But despite being a frequently mentioned and cited theory, it is still a controversial, widely debated and variously defined realist concept. The "new balance of power of the Middle East" appears often even in the daily press in different contexts, which shows the growing popularity of the balance of power concept in recent years. But the term "balance of power" is still far from being free from theoretical confusion. With all this in mind, the question arises for researchers of International Relations as to whether the theory of the balance of power can help to understand the latest political developments in the region. Even if the theory may no longer be applicable or may be just of limited application, it may still be subject to further development.

\subsection{Research Problem, Time Frame, and Case Selection}

Foreign interventions have become the most common phenomena of the international relations of the $21^{\text {st }}$ century. From a certain point of view, they can be catalysts of the redistribution of power capabilities among states in regional systems, similarly to major wars as Ikenberry described it in his book 'After Victory'. According to Ikenberry, the most important characteristic of interstate relations after a major war is that a new distribution of power suddenly emerges, creating new asymmetries between powerful and weak states (Ikenberry 2001:23-29; Danilovic 2002:71-97). ${ }^{4}$ Especially in the broader Middle East region, where in the recent years one military intervention follows another, while we still do not have comprehensive knowledge on their role in regional balance of power systems, their complex effects, and long-term consequences.

\footnotetext{
${ }^{4}$ In his book, 'After Victory', Ikenberry states that "the best place to look for the sources of order among industrial democracies is the situation after wars, when order takes shape". The question of how to create and maintain order in a world of sovereign states is a fundamental problem of international relations. In the cases of major wars, serious changes can occur within the international system, when the old order has been destroyed by war and newly powerful states try to reestablish basic organizing rules and arrangements. (Ikenberry 2001:2329).
} 
Is it possible that a foreign intervention, or a rival intervention, can be viewed as another kind of balancing behavior adopted by members of a regional balance of power system, thus can be considered a 'balancing' or a 'balance of power intervention'? In this case, a balance of power intervention is a caused/dependent variable, rather than an explaining/independent one? Or is it possible that an intervention can be both an explaining and a caused variable at the same time? Or all this depends on the intervener's identity and policy objectives? Then, which one is more common? And what does 'balancing intervention' or 'balance of power intervention' even mean in such a context? Maybe the case is more complex than a simplified balance of power perspective would suggest. However, a thorough analysis of the recent history of the Middle East region and the current political trends is essential to find answers to these kinds of questions.

There has never been agreement on a precise definition of the Middle East. Historically, the region includes the lands that were formerly part of the Ottoman (Turkish) Empire plus Persia (modern Iran). Thus, the area occupied by the modern-day nations that emerged from the breakup of the Ottoman Empire, together with Iran, would come close to what we generally mean by the Middle East. An earlier term, the Near East, was at one time in common use. It usually referred to lands in the Balkan Peninsula of southeastern Europe that were also once under Ottoman rule, in addition to territory now considered part of the Middle East. The core of the Middle East region today consists of the countries of Southwest Asia and the African nations of Egypt and Libya. Tunisia, Algeria, and Morocco are sometimes also included in the region. Even Afghanistan and Sudan are occasionally included. ${ }^{5}$ Our research area as the Greater Middle East and North Africa includes countries from West-Africa to India (including Iran, Israel, Turkey, Afghanistan, and Pakistan). In this regard, we use the term of Middle East not as a merely geographical term to describe a region that lies between Asia and Africa, but more as a political one, as was introduced by George W. Bush in $2004 .^{6}$

The time frame of the research is focused of the period from the end of the Cold War until 2014. There were many foreign interventions during the Cold War period and even after 1991, and the available scientific datasets on conflict provide sufficient data for the project up until 2012. For instance, just the Military Intervention by Powerful States (MIPS) dataset

\footnotetext{
${ }^{5}$ It worth to note that, if one applies the widely used, however still controversial concept of the 'regional security complex', Afghanistan can be included in the research as well, which helps to elucidate the region's security dynamics, and, to evaluate the balance of power order of the Middle East.

${ }^{6}$ The Middle East has always been a very vague term, in which countries were added and removed depending on the context.
} 
provides detailed data on 126 American, British, Chinese, French, and Russian uses of military force against both state and non-state targets between 1946 and 2003. In the International Military Intervention (IMI) dataset 1116 cases were coded from 1946 to 2005 altogether. However, choosing such a wide time frame would result a too large scope for the project, which is better to be avoided. Thus, we prefer a narrow time frame from the collapse of the Soviet Union, until the start of the Arab Spring in 2012, backed up with a brief historical background covering the Cold War period. In order to identify those cases that must be included in the project, a case-selection criterion was defined. For this purpose, we applied the variables of the IMI and the MIPS datasets ${ }^{7}$, and selected the strategic or large-scale ${ }^{8}$ interventions for further evaluation. According to the MIPS dataset, the five great powers carried out a total of 19 military interventions between 1990 and 2003, seven of which were carried out by the United States against the Iraqi government and Saddam Hussein's regime (see Table 1.), which is sufficient reason for an Iraq case study.

\section{Table 1. Military Intervention by Powerful States, 1990-2003}

(Sullivan \& Koch, 2018)

\begin{tabular}{|c|c|c|c|c|}
\hline MP & Target & Location & Start date & End date \\
\hline USA & Iraqi government (Hussein) & Saudi Arabia & 14-Aug-1990 & 28-Feb-1991 \\
\hline USA & Iraqi government & Kuwait & 16-Jan-1991 & 28-Feb-1991 \\
\hline USA & Iraqi government & Iraq & 6-Apr-1991 & 19-Mar-2003 \\
\hline FRN & Habre rebels & Chad & 1-Dec-1991 & 7-Jan-1992 \\
\hline USA & Iraqi government & Iraq & 27-Aug-1992 & 19-Mar-2003 \\
\hline USA & Warring clans & Somalia & 3-Dec-1992 & 4-May-1993 \\
\hline USA & Somali Natl Alliance (Aidid) & Somalia & 4-May-1993 & 31-Dec-1993 \\
\hline RUS & Rebels in breakaway republic & Chechnya & 1-Jan-1994 & 30-Apr-1996 \\
\hline USA & Haitian regime (Cedras) & Haiti & 19-Sep-1994 & 31-Mar-1995 \\
\hline USA & Iraqi government (Hussein) & Kuwait & 14-Oct-1994 & 21-Dec-1994 \\
\hline CHN & Taiwan & Taiwan Strait & 21-Jul-1995 & 25-Mar-1996 \\
\hline USA & Bosnian Serbs & Bosnia & 30-Aug-1995 & 21-Sep-1995 \\
\hline FRN & FR mercenaries/ coup leaders & Comoros & 15-Sep-1995 & 15-Oct-1995 \\
\hline USA & China & Taiwan & 8-Mar-1996 & 25-Mar-1996 \\
\hline FRN & Army mutineers & CAR & 23-May-1996 & 2-Jun-1997 \\
\hline USA & Iraqi government (Hussein) & Kuwait & 3-Sep-1996 & 19-Mar-2003 \\
\hline USA & Iraqi government & Iraq & 1-Feb-1998 & 20-Dec-1998 \\
\hline USA & Federal Republic of Yugoslavia & Yugoslavia & 24-Mar-1999 & 10-Jun-1999 \\
\hline USA & Taliban regime & Afghanistan & 7-Oct-2001 & 31-Mar-2002 \\
\hline
\end{tabular}

\footnotetext{
${ }^{7}$ The MIPS dataset provides thorough data on interventions conducted by five major powers (or the five permanent members of the UN Security Council, namely the United States, the United Kingdom, China, France, and Russia) since the end of World War II. It defines military intervention as a use of armed force that involves the official deployment of at least 500 regular military personnel. For the IMI dataset on strategic international military interventions targeting Iraq between 1989 and 2005 see Table 8. on page 191. For the variables of the IMI dataset see Table 9. on page 192.

${ }^{8}$ A military intervention can be considered large-scale if more than 10,000 ground troops were deployed or, in case of an air campaign, a no-fly zone was established.
} 


\subsection{Objectives, Hypotheses, and Methodology}

This exploratory research project attempts to answer the following questions related to foreign interventions, undertaking both quantitative and qualitative means:

1. Can a foreign military intervention induce notable shifts in the regional balance of power through the redistribution of the national capabilities among the states in the system during the postwar period?

a) Can a foreign military intervention directly or indirectly change a balance of power system through its impact on alliance formation, tightening or loosening existing alignments among the actors?

b) Is there any relationship between foreign military interventions and changes in the threat perception of a state or statesman?

c) Does foreign military intervention lead to increasing non-state actor activities in the target-country due to the decreasing national capabilities of that state?

The main hypothesis and the sub-hypotheses of this research are as follows:

H1. A large-scale foreign military intervention can lead to decreased levels of national capabilities for the target country due to increasing conflict intensity, which can result in changes of the relative power status of other states in the regional balance of power system.

a) A 'balance of power intervention' or 'balancing intervention' can have an effect on regional alliance formation, changing the tightness of existing alliances or pave the way for a new one.

b) Foreign military interventions can influence the threat perceptions of ruling elites.

c) Decreased levels of national capabilities lead to a more anarchical system, which can lead to the rise of non-state actors within the target country and in its proximity.

To answer these questions, first and foremost, two pieces of information are required. On the one hand, foreign military intervention must be defined. On the other hand, changes in the balance of power system must be identified, presuming that the theory itself still applies to the region. We consider a foreign military intervention as a political use of military force in an active attempt to influence the behavior of other actors. Some events did not involve the hostile introduction of ground troops in large numbers, and some are rather obscure. A more inclusive definition of foreign military intervention can be applied to gain a more thorough understanding of the subject. In this research project we review cases of foreign intervention targeting Iraq from 1990 until 2014, using the above mentioned IMI and MIPS datasets.

A fairly reliable measurement of national power is also needed to answer these questions. The 'control over resources' (COR) approach is the most widely used and accepted one for measuring and studying power and national capabilities (Singer \& Small 1966:236- 
282; Modelski 1974). The most frequently used indicators of national power are military expenditures, the size of armed forces, the Gross National Product (GNP), and population. The COR approach assumes that control over resources can be converted into control over actors or events. However, it is not always certain that actors will be able to use resources which are nominally under their control, and it is not always clear what types of resources should be included in a general measure of power. Additionally, the focus on national power precludes the consideration of the role of non-state actors in determining the outcome of conflicts (Hart 1976).

One way to measure national power is to apply the Composite Index of National Capability (CINC) ${ }^{9}$ dataset from 1816 to 2012, which is a statistical measure of national power created by David Singer for the Correlates of War project in 1963 (Singer, Bremer \& Stuckey 1972:19-48; Singer 1988:115-132). It uses an average of percentages of world totals in six different components, which represent demographic, economic, and military strength. ${ }^{10}$ More recent studies tend to use this score, because it better represents state power than Gross Domestic Product (GDP) or GNP solely. Another complementary source of data to measure anarchic patterns of states is the Fragile States Index by The Fund for Peace, which is based on a conflict assessment framework - known as "CAST" - that was developed by FFP for assessing the vulnerability of states to collapse. ${ }^{11}$ For a comparative analysis the data of the indices can be examined with the help of graphs, while changes in the regional balance of power due to external intervention can be evaluated by process tracing.

There are two options for identifying changes in national capabilities. One way is to take the CINC score received by the target nation in two years prior to the year of the intervention and compare it to the rating received in the two years after the year of intervention. The post-intervention rating can be subtracted from the pre-intervention score to

\footnotetext{
${ }^{9}$ The Composite Index of National Capability (CINC) score aggregates the six individual measured components of national material capabilities into a single value per state-year. The CINC reflects an average of a state's share of the system total of each element of capabilities in each year, weighting each component equally. In doing so, the CINC will always range between 0 and 1. " 0.0 " would indicate that a state had $0 \%$ of the total capabilities present in the system in that year, while " 1.0 " would indicate that the state had $100 \%$ of the capabilities in a given year (and by definition that every other state had exactly $0 \%$ capabilities in that year.) See also: The Correlates of War Project, National Material Capabilities (v5.0), http://www.correlatesofwar.org/datasets/national-material-capabilities.

${ }^{10}$ These components are total population, urban population, iron and steel production, primary energy consumption, military expenditure, and military personnel ratios.

${ }^{11}$ The CAST framework was designed to measure this vulnerability in pre-conflict, active conflict and postconflict situations. The methodology uses both qualitative and quantitative indicators, relies on public source data, and produces quantifiable results. Twelve conflict risk indicators are used to measure the condition of a state at any given moment. The indicators provide a snapshot in time that can be measured against other snapshots in a time series to determine whether conditions are improving or worsening. See more at http://fundforpeace.org/fsi/ .
} 
obtain a final rating (see Table 6.). The larger this number, the greater the decrease in the share of national capabilities while a negative result would mean a positive change, that is an increase in national capabilities. However, this method has its own limits. The result requires careful additional evaluation, since a decrease in national capabilities not necessarily means that a change in the balance of power occurred as well. The data cannot be evaluated correctly without a context, which can help to put everything into a perspective, and in this regard, graphs can make the interpretation much easier for us (see Table 7. and Figure 5.).

According to Organski and Kugler (1980:16), "the major mechanism through which the balance of power system is maintained is the making and unmaking of alliances". Moreover, they note that in the balance of power model, changes are the results of alliances. ${ }^{12}$ Thus, in addition to the evaluation of interventions and changes in national capabilities, alliance formation processes also must be investigated. Bruce Bueno de Mesquita (1975) provides indicators which are measures of changes in alliance behavior. According to his argumentation, if alliances tighten, and interaction among alliance groups decreases, such behavior may be taken as an indication that statesman perceive the environment as presenting a threat to the security and/or the power position of their countries and are preparing to fight. On the other hand, the loosening of alliances can be taken as an indication that similar elites have judged the danger to have passed or to have been a false alarm, and peace should continue. From this perspective, wars are still possible even when alliances loosen, but the frequency of their occurrence should be low, and they should be presumed to be the result of miscalculation (Organski \& Kugler 1980:39; De Mesquita 1975:207).

The degree of tightness or discreteness in the alliance system is not as important as the shifts in these arrangements. Increasing tightness makes clearer to leaders which states are likely to fight with them and which against them, and thus makes possible more accurate estimations of what resources will be available to them and their enemies if a war breaks out between them. In this sense, there is a link between threat perception, the tightness of alliances, and the decision whether to fight, hence alliance behavior is taken to measure threat. Organski and Kugler offer a method for measuring alliance behavior, which was developed from an original scale built from four types of alliance: defense pacts, mutual nonaggression pacts, ententes, and no alliances at all. Using the tightness and looseness of alliances, they

\footnotetext{
12 "The rule is simple: a nation can influence the balance of power in its own favor by allying itself with other nations and by adding to its own capabilities those of its allies. Other means are available if a nation wishes to improve its power position. [...] But the least costly and most certain way for a nation to improve its power position is to combine its strength with that of friends or to break the coalitions of adversaries." (Organski \& Kugler 1980:16; 24).
} 
developed a simple eight-point scale (see Figure 1. below) that reflects both degree of commitment and the direction of change in commitment (Organski \& Kugler 1980:38-41).

Figure 1. Threat-perception scale

(Organski \& Kugler 1981:41)

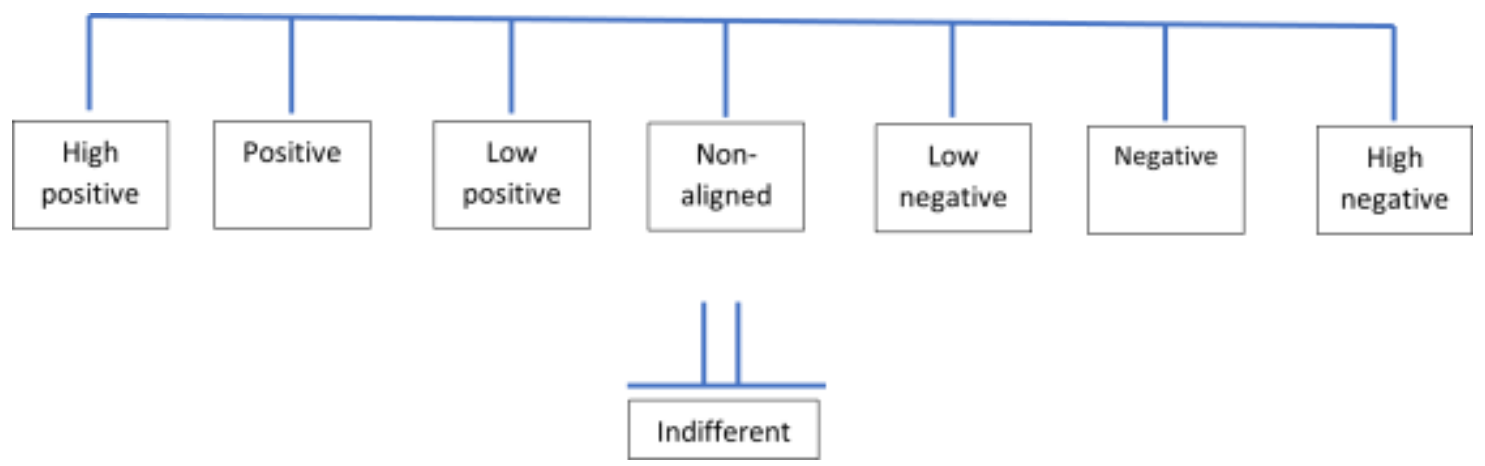

According to Organski and Kugler, a positive position on the scale means that there has been a change in the tightness of alliances between the two actors, and that each of the actors has increased its alliance commitments with other nations with whom the second nation in the pair also has alliances. On the other hand, a position on the negative end of the scale means a cutting of ties with the other state and with its allies. They coded point on the scale stretching from nonaligned to positive as nonhostile, and all of the points stretching from the center to the negative pole as hostile. The "indifferent" position is for nations which do not have and never have had any ties with any nation in the system. Therefore, this position got situated outside the scale, and it can be occupied only by nations outside the system (Organski \& Kugler 1980:41-42).

\subsubsection{Mixed-Method Design}

This study follows a mixed-method research design, combining a descriptive design (a case study) with a quantitative (correlational) element to formulate a holistic interpretative framework. The mixed-method design can utilize the existing data, while at the same time it can test a grounded theory approach to describe and explain the phenomenon under study. Mixed-method designs are usually applied to investigate complex research problems, since this way the researcher is not constrained by the application of only one method. As a matter of fact, with this approach, the strengths of one method can be used to overcome the weakness of another. Moreover, it may generate new insights that a single methodological approach would not reveal. 
The exploratory case study on Iraq attempts to provide an in-depth analysis of the research problem, applying some statistical methods and a comprehensive comparative inquiry. The case study method can help to evaluate whether the balance of power theory actually applies to the contemporary regional system. This element of the research design makes also possible to understand this complex issue through a detailed contextual analysis of a limited number of interventions and their relationships. In addition, a case study allows to apply various methodologies and to rely on a variety of sources to investigate the given research problem, while it can extend existing knowledge or confirm earlier research findings. To examine real-life situations and provide basis for the application of concepts and theories, a case study method seems adequate.

\subsubsection{Pragmatist Research Paradigm}

In the academic discipline of International Relations, there are two kinds of fundamental controversies. There are debates over substantive issues, which are also embodying conceptual ones, and debates over methodological issues. The latter became prominent in the 1950s and 1960s, during the 'behavioral revolution' in American political science, when behavioralists argued that IR should be placed on a foundation of 'scientific' analysis. Behavioralists believe that social science is not so different from natural science, that interdisciplinary studies among the social sciences can be conducted, and the same analytical methods can be applied in both areas. They argue that the individual person is the basic unit of analysis, politics is only one aspect of the behavior of people, and political behavior can be examined at the personal level, the social level, and the cultural level. In the focus of the study of political behavior is the roles of people in social structures, and the central social structure is the political system itself. This behavioral approach seeks to transform political science into social science by applying the scientific standards of natural sciences, with the aim of collecting data which can lead to scientific explanation. This requires scientific methodology and attitude, in order to make possible to provide empirical explanations of political behavior. A scientific study of this kind requires precise research designs, methodology and analysis to produce verifiable empirical propositions (Jackson \& Sørensen 2010:279).

One of the earliest examples of this behavioral approach was Kaplan's 'system analysis' to distinguish between different kinds of international state systems: the 'balance of power' system; the loose and the tight bipolar systems, the universal international system, the hierarchical international system, and the Unit Veto International System. Kaplan argues that states act in a 'balance of power' system, which is characterized by different patterns of 
behavior, and actions of states that lead to certain patterns of alignment in the system which the theory can predict (Kaplan 1957:21-53). ${ }^{13}$ Kaplan's system analysis later proved to be wrong in many ways. His 'balance of power' system received its harshest scientific critique from Waltz (1979:50-59). However, the logic of empirical analysis later became widespread among scholars who are seeking objective knowledge. This academic orientation later has come to be known as positivism, and its methodology is still widely criticized (Jackson \& Sørensen 2010:278-281).

There is also the traditional, or classical methodological approach of IR, which does not have an explicit methodology, it does not frame hypotheses and test them, or apply a formal apparatus of research. It does not even gather and organize data. It views the international system as highly complicated, thus difficult to understand, and it rejects the view that there can be one correct scientific analysis of international politics. According to the classical approach, science is a matter of experience in the practice of scholarship, not a matter of methods, models, and statistics. It is a matter of becoming a careful and critical observer of international relations. One of the great defenders of this approach is Hedley Bull, who argued that the activity of research basically involves thinking on a topic, and the most important thing in carrying out research is not scientific methodology, it is knowledge of substance. ${ }^{14}$ Classical scholars call attention to the limitations of IR scholarship, which they see as an imperfect field of study which cannot give definitive answers to complex questions of international relations. In sum, these two approaches hold different conceptions of the world - ontology - and fundamentally different ideas of the best way to gain knowledge of the world - epistemology (Jackson \& Sørensen 2010:284).

Positivist methodology is the legacy of behavioralism, as it views the international world as having regularities and patterns that can be explained if the correct methodology is properly applied. It argues that observation and experience are keys to constructing and judging scientific theories, which should consist of empirical propositions that are logically related and can be tested against evidence to confirm or refute the whole theory (Nicholson 1996:128-146). According to Waltz, whether a theory is a positivist empirical theory can be

\footnotetext{
${ }^{13}$ According to Kaplan: States 1.) Act to increase capabilities but negotiate rather than fight. 2.) Fight rather than pass up an opportunity to increase capabilities. 3.) Stop fighting rather than eliminate an essential national actor. 4.) Act to oppose any coalition or single actor which tends to assume a position of preponderance with respect to the rest of the system. 5.) Act to constrain actors who subscribe to supranational organizing principles. 6.) Permit defeated or constrained essential national actors to re-enter the system as acceptable role partners ... Treat all essential actors as acceptable role partners (Kaplan 1957:21-53).

14 “'Thinking is also research' was a saying adopted by him. The principal stages in this process were listing the central questions, defining the relevant concepts and drawing distinctions, and examining the principal considerations." (Holbraad in: Miller \& Vincent 1990:193).
} 
determined by a test involving six questions, which indicate the conditions that IR theories should be able to meet to count as scientific or empirical. Waltz notes that these conditions may be difficult to meet in practice since the world is not an isolated laboratory where variables can be excluded or controlled (Waltz 1979:13; Jackson \& Sørensen 2010:284-285).

Neorealism is often seen as the essence of positivism and behavioralism in International Relations, however, positivism is broader than neorealism. Nicholson (1996) argues that there are two general research programs of positivism in IR: a program of quantitative research, and a program of rationale choice analysis, such as game theory. Since positivists are seeking to establish verifiable empirical generalizations, they are inclined to employ quantification. On the other hand, the approach of the rational choice theory is based on logic, rather than strictly quantitative measures (Jackson \& Sørensen 2010:286).

In International Relations post-positivism rejects the scientific methods of positivism, arguing that the empiricist observation of natural sciences cannot be applied to the social sciences, since it is the people who construct and constitute the international world, hence it is a human arrangement. One of the several approaches of post-positivist methodologies is critical theory, according to which the international system is a specific social construction of the powerful states, and as such it can be changed. Critical theorists believe that knowledge cannot be neutral because it is produced from the social perspective of the analyst, thus it is obviously biased. One leading critical theorist, Robert Cox (1981) argued that effectively all IR theories are biased. ${ }^{15}$ However, if that is the case, we will not be able to tell whether a theory is good or not in academic terms, because we are all biased. Another post-positivist approach, the postmodernist thinking similarly argues that social science is not neutral, and there is no such thing as object reality or truth, since everything that human beings are involved in is subjective (Jackson \& Sørensen 2010:289; Smith 1997:181).

Considering this fundamental issue of methodological divide in IR, we believe it is better to avoid the choice between extremes of the positivist and the post-positivist methodology. We proceed on a middle ground instead. This exploratory research project aims for results accomplished by employing both a positivist approach with a quantitative method (scores and indices) and a post-positivist/constructivist approach with a qualitative method (case study). Combining these approaches and methods, this study falls into the category of mixed-methods, following a pragmatist paradigm.

\footnotetext{
${ }^{15}$ According to Robert Cox: "Theory is always for someone and for some purpose." (1981:128)
} 


\subsection{Limitations of the Study}

There are certain limitations and pitfalls of this research project which must be mentioned. First, there is a lack of recent and up-to-date comprehensive data on interventions, especially in regard of the Middle East. Existing datasets could be updated to include the latest events, or a new, focused dataset could be composed with all the latest cases in the Middle East, such as the Saudi-Arabian-led military intervention in Yemen, the Russian and the Turkish interventions in Syria, the American involvement in the Syrian Civil War and the US-led international military intervention against ISIS. However, considering that such an effort would require thorough data collection and coding, not to mention a reliable validating process, this project could not undertake such a demanding task. Second, relying solely to applying the CINC score system and FSI datasets, in cases of foreign interventions in civil wars the negative effect of interventions on the level of national capabilities cannot be unequivocally separated from the negative impact of the internal civil conflict itself. Third, it must be kept in mind that scholars use different data collections to test their ideas, and the utilization of different sources can produce incompatible results.

The lack of a proven adequate methodology for evaluating national power and anarchic patterns may result in the researcher failing to notice or misinterpreting the initial changes in power capabilities and state-vulnerability that occur within the regional balance of power system. Appreciating the true basis of national power may require not merely a detailing of tangible military assets, but also an assessment of other, intangible elements. The traditional approaches to measuring power sought to rank order the status of countries in terms of their capacity for war, charting the hierarchy of capabilities in the international system. The various indices can be distinguished in terms of the number of variables they use, and each index differs from the others in terms of the number of countries assessed, the time frames and the complexity of their formulas. However, single-variable measures of power can be just as effective as more complex indices for purposes of rank ordering countries. And it should be also kept in mind that most traditional indices fail to incorporate qualitative factors that describe state capacity. With all this in mind, developing a universal hierarchy of national power capabilities is not an objective of this research. We see national power as the capacity of a country to pursue strategic goals through purposeful action, as defined by Tellis et al. (2000:4). In this regard, utilization of the datasets of the Correlates of War Project (COW) and the Fragile States Index (FSI) can provide the basis of the evaluation of changes in the regional balance of power systems. 
It must be noted that applying multiple methods is risky and melting them together in the design can be challenging for any researcher. In addition, the likelihood of conflicting results or ambiguous findings can increase, thus drawing a valid conclusion can be challenging as well. One disadvantage of this approach is that a complex research design can become even too complex, thus reporting findings can require a well-oriented narrative, which poses another challenge.

A case study design has its drawbacks too. One of them is that the study of a particular case may bias a researcher's interpretation of the findings. Moreover, a case study is not to facilitate assessment of cause and effect relationships, while it must be also kept in mind that vital information may be missing hampering correct interpretation. It must be noted that the case may not be representative of the problem being investigated, moreover, depending on the selection criteria, the selected case can represent such a unique phenomenon, that the findings interpretation can apply only to the particular case.

\subsection{Contribution to the Field}

This exploratory research project intends to shed light on the role of external military intervention in a regional balance of power system. So far, no research has been done to address this problem, investigating the relationship between external intervention and changes in a regional power-balance order. This project aims to fill this gap in the scientific literature on the role of foreign intervention in the international system, from the perspective of the theory of balance of power.

This study is also an attempt to begin to develop an understanding of the non-state actors directly or indirectly targeted by military intervention, and to theorize about diverging patterns and effects of foreign military intervention across the Middle East. We do not have enough knowledge on how interventions affect various non-state actors and their relationships with others. Developing theory to understand these relationships and gathering data to evaluate such a theory helps to develop our knowledge further and gain new insights on foreign military intervention and regional order.

This research project contributes to the development of the IR literature, while the analysis of the effect of external intervention from a balance of power perspective provides a new viewpoint for researchers and policymakers and adds to the popular discussion on intervention. Regardless of whether the results will be able to influence the direction of 
further studies on these subjects, we recommend this study to everyone who is interested in the Middle East, issues of foreign military interventions, or the theory of balance of power. 


\title{
2. ARMED CONFLICT AND FOREIGN INTERVENTION
}

\author{
"The deeper one delves into the literature on intervention, the \\ more incredulous one becomes." (Rosenau 1969:149). \\ "Intervention, like surgery, is not an evil in itself, but it must \\ be applied sparingly and with consummate skill." \\ (Rosenau 1969:157)
}

In recent decades, civil wars ${ }^{16}$ have become the most recurrent form of conflict, and most of them are characterized by the active involvement of foreign actors, another state, coalition, or a non-state actor (Einsiedel 2017). The impact of foreign interventions has been studied by scholars of IR from many aspects. However, academic research in which international military interventions constitute a main explanatory/independent variable are sparse. In terms of lessons of the "War on Terror" in Afghanistan (2001-2021) ${ }^{17}$ and the Iraq War (2003-2011) there are studies on radicalization, increasing transnational terrorism, the intervention's effect on nation building and education, the human rights issues and on other political, economic and social questions. Most of the existing research are dedicated to three aspects of the effects of foreign interventions: democratization, human rights, and conflict intensity. The impact of foreign interventions on the national capabilities of target nations and the role of foreign intervention in the operation of a regional balance of power system is still under-researched.

Foreign military intervention directs modern international armed conflict. It seems the ultimate instrument of forceful foreign policy. Power politics and nuclear paralysis theories offer fundamentally different views of who is primarily responsible for the scope and frequency of international armed conflict. Theories of power politics generally assume that all states resort to military force as often as their interests command and their resources permit. On the other hand, the theory of nuclear paralysis assumes that military force has lost much of its traditional utility for great powers in the nuclear age due to their fear that armed conflict might expand to nuclear war. However, according to Tillema, during the Cold War most great

\footnotetext{
${ }^{16}$ According to the Uppsala Conflict Data Program (UCDP) and International Peace Research Institute's (PRIO) definition, a civil war involves at least 25 battle-related deaths in a conflict between a government and an internal armed opposition.

${ }^{17}$ Under a peace agreement with the Taliban reached in 2020 after almost a two decades long war, the US military has begun its final withdrawal from Afghanistan in 2021. President Biden announced in April 2021 that US forces would be out of the country by September 11, the 20th anniversary of the 9/11 terrorist attacks that propelled the United States into its long war in Afghanistan. There were approximately 3,500 U.S. troops, 7,000 NATO and allied forces, and 18,000 contractors in Afghanistan in April 2021. Alongside the United States NATO forces were about to withdraw as well since many countries in the coalition are dependent on American support (Gibbons-Neff 2021).
} 
powers, including China, France, the United Kingdom, and the United States, have each intervened more frequently than nearly all other states, consistent with the view of power politics theory. On the other hand, great powers as a group are responsible for only a minority of all foreign military interventions, and especially the nuclear superpowers, in particular the United States and the Soviet Union, contributed much less often to international armed conflict than presumably they were able, which is consistent with the nuclear paralysis perspective (Tillema 1989:179-182).

Where and when states use armed forces is frequently interpreted in terms of international norms. However, there is serious disagreement as to whether the norms governing the use of force are primarily due to international law or power. The debate on the role of power versus the role of law is an endless one in IR. According to the realist thinking, where and when a state uses armed forces is primarily affected by the opportunities and obstacles afforded by the recognized distribution of power among states in the international system (Bull 2002; Hoffmann 1971:35-66; Morgenthau \& Thompson 2006). On the other hand, many scholars of international law and organization assert that legal rules also channel international use of military force. As Tillema and Wingen (1982) note it, international law and naked power cohabit in international relations. Law conditions statesmen's expectations of one another's normal behavior thus helps to regularize international interaction. However, there is no higher authority to enforce law upon resisting sovereign states, therefore leaders rely upon national power to help protect and advance national interests, and the measure and calculation of power is also a guide to wise foreign policy. At issue is whether the world depends in part upon international law or solely upon the balance of power. As Tillema and Wingen point out, the problem is that most studies of military intervention reflect either exclusive realism or exclusive legalism. This is so in part because realists and lawyers tend to focus upon different aspects of intervention, while differences of methodology also salient (Tillema \& Wingen 1982:223). ${ }^{18}$

\footnotetext{
${ }^{18}$ Tillema and Wingen in regard of the relationship of international law and military intervention conclude that after World War II each great power professed support for the United Nations Charter, but none has always obeyed a strict interpretation of its rules restricting use of military force. Military intervention by major states is nevertheless consistent with apparent norms of both international law and power. For instance, each major power has consistently and prudently avoided intervening with armed forces in lands where another major power has visible military commitments (Tillema \& Wingen 1982:221-223, 240).
} 


\subsection{Explaining War and Foreign Military Intervention}

\subsubsection{Concept and Definition}

In the simplest form, military intervention as a specific form of intervention is defined as "the beginning of blatant acts of military force in another country". The term "intervention" has been used to mean many things, including interference in domestic and foreign affairs, and almost any act of influence among sovereign states (Tillema \& Wingen 1982:223). As Rosenau once noted, notwithstanding the extensive literature on intervention, there appears to be no agreement whatsoever on the phenomena designated by the term (Rosenau 1969:152). Tillema and Wingen specify military intervention to be the beginning of military acts by the official armed forces of one state beyond its own borders and within the territory of another country (Tillema 1973:3). In addition, they note that there is a tacit understanding among states that military intervention is considerably different from lesser forms of intervention, since military intervention is a more blatant trespass than lesser forms of intervention, such as covert operations, military aid, and diplomatic or economic penetration. Moreover, it is more provocative than mere military shows of force or violent acts at sea (Tillema \& Wingen 1982:223).

According to Rosenau, a major result of the many definitional options is that some tend to merge two or more of them and, in effect, end up by defining intervention as any action whereby one state has an impact upon the affairs of another. Thus, in the literature there are discussions of military interventions, propaganda interventions, economic interventions, diplomatic interventions, and ideological interventions, among others. Rosenau notes, that the height of definitional vagueness is occasionally reached when inaction is regarded as intervention. In addition, however loosely or precisely intervention may be defined, its use as an analytic concept is further complicated by the various distinctions that are sometimes drawn in terms of the identity of the intervening actor or the nature of affairs into which the intervening actor intrudes (Rosenau 1969:153-154). For instance, Falk distinguishes five types of intervention (unilateral, counter-, collective, regional, and universal), and argues that the differences among them are sufficient to generate different normative and legal structures for evaluating their application (Falk 1964:40-41).

Obviously, the concept of intervention still suffers from a lack of definitional clarity. Since different authors prefer different definitions and interpret their evidence differently, the "essence" of intervention is highly variable, with what is essential for one scholar being

peripheral for another. However, as Rosenau emphasizes, science deals exclusively with 
observables - with phenomena that can be measured, and thus who engage in scientific inquiry must operationalize their definitions before they proceed to make empirical observations. To operationalize a concept is to specify the operations that one performs in order to observe the phenomena that it encompasses. Another challenge is that the central process of intervention - influence - is so difficult to measure. However it may be defined, intervention involves modifications of the behavior of persons and groups in the target nation that would not have occurred if the intervening state had not engaged in interventionary activities. Intervention succeeds when the intended alterations occur, and it fails when they do not. The production of intended impacts (influence) is thus both the main purpose and the process of intervention. However, the measurement of influence is among the most troublesome problems of political analysis. It not only involves tracing of changes in political behavior, but it also requires linking the changes to a specific set of actors who sought to evoke them, while there is always the possibility that the behavior deemed to represent intended impacts would have occurred even in the absence of efforts to produce it (Rosenau 1969: 155, 159-160).

Intervention may be differently conceptualized, but it does refer to empirical phenomena and these do constitute a central problem of world affairs. The scientifically oriented analyst, however, cannot dismiss interventionary phenomena as too difficult. He must confront the theoretical challenge of explaining such primary international processes as intervention. His definition must be broad enough to identify those phenomena that are generally associated with the term, and yet not so broad it fails to distinguish them from other aspects of international affairs. A scientific approach to foreign military intervention requires a formulation that is more accurate than the common-sense usage of the term, which allows for any action directed toward another nation to be regarded as intervention. It must be bear in mind that intervention would lose its utility as an analytic concept if its operationalization allowed for too broad interpretations, thus a fairly restricted definition must be developed. However intervention may be defined in the scientific literature, and irrespective of what perspective it is approached from, two characteristics are usually associated with behavior classified as interventionary. One is what might be called the convention-breaking character of interventions, and the other is their authority-oriented nature. Military interventions are perhaps the most unequivocal departures from conventional patterns and, they may also be the most frequent form of intervention throughout history. In some sense, interventions are very much the product of the perceptions, calculations, and decisions that occur within decisionmaking circles. It is worth to note that leaders and their staffs do not act in a vacuum, they 
operate in an international context and they do have some view of what is a desirable state of affairs abroad and what actions support or hinder its realization. Therefore, while pressure for or against interventions may not arise in the domestic environment, developments in the foreign environment can be perceived to alter the structure and functioning of the international system to such a degree that decision-makers feel compelled to consider whether an intervention is in order. In summary, as filtered through the individual variables, systemic variables can be highly potent as sources of the perceptions, calculations, and decisions that lead to the implementation of military intervention (Rosenau 1969:160-167).

Accordingly, our definition of external interventions is adapted from Regan et al. and Rosenau, where external interventions are convention-breaking political, economic, or military actions in a country targeting the authority structures of the country (in support of the government, opposition or neutral) in order to influence the balance of power between the parties or have an effect on the conflict process. The intervener can be a state or non-state party but must be foreign to the country (Regan, Frank \& Aydin 2009:135-146; Rosenau 1968:165-176). In defining international military intervention, we can also follow Pearson and Baumann (1993) in which interventions are referred to as the movement of regular troops or forces of one country into the territory or territorial waters of another country, or forceful military exploits by troops already stationed by one country inside another (Pearson \& Baumann 1993). See Table 2. below for a summary of the definitions.

\section{Table 2. Foreign intervention and proxy war definitions}

\begin{tabular}{|c|c|}
\hline Source & $\begin{array}{l}\text { The beginning of military acts by the official armed forces of one state beyond } \\
\text { its own borders and within the territory of another country. }\end{array}$ \\
$\begin{array}{c}\text { Tillema \& Wingen (1982) } \\
\text { Opema (1989), }\end{array}$ & $\begin{array}{l}\text { Operations undertaken directly by a state's regular military forces within } \\
\text { foreign lands in such a manner as to risk immediate combat, hence war, if they } \\
\text { encounter resistance. }\end{array}$ \\
\hline $\begin{array}{c}\text { Regenau (1968), } \\
\text { Regan et al. (2009) }\end{array}$ & $\begin{array}{l}\text { Convention-breaking political, economic, or military action in a country } \\
\text { targeting the authority structures of the country (in support of the government, } \\
\text { opposition or neutral) in order to influence the balance of power between the } \\
\text { parties or have an effect on the conflict process. The intervener can be a state } \\
\text { or non-state party but must be foreign to the country. }\end{array}$ \\
\hline $\begin{array}{c}\text { Pearson \& Baumann (1993) } \\
\text { International Military } \\
\text { Intervention Dataset }\end{array}$ & $\begin{array}{l}\text { The movement of regular troops or forces (airborne, seaborne, shelling, etc.) } \\
\text { of one country into the territory or territorial waters of another country, or } \\
\text { forceful military action by troops already stationed by one country inside } \\
\text { another, in the context of some political issue or dispute. }\end{array}$ \\
\hline $\begin{array}{c}\text { Sullivan \& Koch (2009) } \\
\text { Military Intervention by } \\
\text { Powerful States Dataset }\end{array}$ & $\begin{array}{l}\text { A use of armed force that involves the official deployment of at least } 500 \\
\text { regular military personnel to attain immediate-term political objectives } \\
\text { through action against a foreign adversary. }\end{array}$ \\
\hline
\end{tabular}


An international conflict between two countries in a third country.

Proxy war and proxy intervention according to Deutsch (1964), and Mumford (2013a-b)
A way of conflict where one state uses proxies in indirect engagements through secret destructive operations against the other.

A conflict that takes place indirectly and secretly in another country, using proxies.

\subsubsection{Approaches and Factors}

There are two major approaches to conflict and the use of force that have framed much empirical research over the past decades: (1) the interstate rivalry framework and, (2) the bargaining model of war. These two broad theoretical frameworks still do not, of course, capture the totality of our knowledge on the use of foreign military force (Pickering \& Mitchell 2017:3-4). According to the rivalry approach, a relatively small number of states account for the majority of the forceful interactions in the international system, and among the main reasons behind the use of force against one another is the history of past conflict (Diehl \& Goertz 1988:103-122; Thompson \& Dreyer 2012). Past tensions are important factors because they produce an atmosphere full of mistrust, which often presents attempts at peaceful conflict resolution and lays the basis for future conflict. Earlier studies have shown that former disputes between rivals make later disputes more likely and that a growing number of disputes makes an outbreak of war more likely (Colaresi \& Thompson 2002:11751198; Hensel 1994:281-297).

Over the past decade, the bargaining model has grown more prevalent. According to this model, low-level uses of force are thought to be rational attempts to obtain information about opponents. The proponents of the bargaining model argue that force may be necessary because statesman have strategic reasons to bluff about their military capabilities, and costly action may compel rivals to reveal information about their strategic competencies and determination (Fearon 1994:577-592). In addition, empirical research has highlighted a wide variety of structural factors that may operate independently from bargaining and rivalry but may also inform each of these approaches. According to Thompson, the probability that interstate force will be used tends to rise as the number of such structural factors increases in each context (Thompson 2003:455).

Fearon in his 'Rationalist Explanations for War' notes that while wars are costly, nonetheless they still recur, and this is one of the main reasons we study it (Fearon 1995). Earlier studies attempted to give an explanation with three types of argument. One can argue that state leaders are sometimes or always irrational because they are biased, thus they tend to neglect the costs of war or to misunderstand how their decisions will produce it. In addition, 
one can argue that the decision makers who order war enjoy its benefits but not pay the costs, which are paid by soldiers on the field and ordinary citizens. Finally, according to the third argument even rational leaders who consider the risks and costs of war may end up fighting nonetheless. Fearon refers to the arguments of the third sort as "rationalist explanations for war", which could just as well be called "neorealist explanations" (Fearon 1995:379-380). Scholars who studied the origins of wars often have concluded that war can be a rational alternative for leaders who are acting in their state's interest, simply because they find that expected benefits of war sometimes outweigh the expected costs. In addition, neorealism is thought to advance or even to depend on rationalist arguments about the causes of war, thus, if no rationalist explanation for war is theoretically or empirically reasonable and tenable, then neither is neorealism. In this case, the causes of war would lie in the defects of human nature itself rather than in the international system, as argued by neorealists (Fearon 1995; Waltz 1979; Jervis 1978:167-214; Walt 1987).

As Fearon argues, it is not enough to say that under anarchy nothing stops states from using force, or that anarchy forces states to rely on self-help, which generates mutual suspicion and can lead to armed conflict. And neither do miscalculation, deterrence failure, preventive and preemptive considerations, or free-riding in alliances amount to theoretically coherent rationalist explanations for war. Fearon asserts that none of the principal rationalist arguments holds up as an explanation because none addresses the central puzzle, that is that war is costly and risky, so rational states should have incentives to find negotiated solutions that all would prefer to the gamble of war. The standard rationalist arguments fail either to explain adequately what prevents leaders from reaching bargains that would avoid the costs and risks of armed conflict. A coherent rationalist explanation for war must show why states are unable to locate an alternative outcome that both would prefer to a war (Fearon 1995). ${ }^{19}$

Most historians and political scientists who study war agree that while a few wars may have been unwanted by the leaders who brought them about, most wars were simply wanted, and the leaders involved viewed war as a costly but worthwhile gamble (Blainey 1988;

\footnotetext{
${ }^{19}$ In the literature, there are five rationalist arguments accepted as tenable on the causes of war: (1) anarchy; (2) expected benefits greater than expected costs; (3) rational preventive war; (4) rational miscalculation due to lack of information; and (5) rational miscalculation or disagreement about relative power. Emphasizing that neither argument explains what prevents rational leaders from using diplomacy or other forms of communication to avoid such costly miscalculations, Fearon proposes three general mechanisms as explanations. First, rational leaders may be unable to locate a mutually preferable negotiated settlement due to private information about relative power/capabilities or resolve and incentives to misrepresent such information. Second, rationally led states may be unable to arrange a settlement that both would prefer to war due to commitment problems. Third, states might be unable to locate a peaceful settlement both prefer due to issue indivisibilities (Fearon 1995:381 382).
} 
Howard 1984). Additionally, many believe that wanted wars are easily explained from a rationalist perspective. Wanted wars occur when no negotiated solution exists that both sides would prefer to the gamble of armed conflict. It is an entirely possible situation between states led by rational leaders who consider the costs and risks of fighting. On the other hand, unwanted wars take place despite the existence of settlements both sides preferred to conflict. In this case, the question is, what prevents states in a dispute from reaching an ex-ante agreement that avoids the costs they know will be paid ex-post if they go to war? (Fearon 1995:283-284)

The rationalist arguments of anarchy, preventive war, and positive expected utility are the most common employed arguments in the literature in this regard, however, they do not address the question directly. The anarchical nature of the international system is routinely cited as a root cause of war. Waltz argued that "war occurs because there is nothing to prevent it" (Waltz 1959:188). Fearon argues that the standard framing of the argument is not enough to explain why wars occur and recur. ${ }^{20}$ According to the preventive war argument, if a declining power expects it might be attacked by a rising power in the future, then a preventive war in the present may be rational. These kind of preventive war arguments, however, do not consider whether the rising and declining powers could construct a bargain, that would leave both sides better off than a costly and risky preventive war would. The third argument of positive expected utility states that war may occur when two states each estimate that the expected benefits of fighting outweigh the expected costs (De Mesquita 1985). This argument, however, typically fails to address the question of how or under what conditions it can be possible for both states to prefer the costly gamble of war to any negotiated settlement (Fearon 1995:383-386).

The other two, commonly employed rationalist explanations of war (private information and incentives to misrepresent) directly address the question, why might states fail either to find or to agree on an outcome to avoid the costs and risks of war. According to one of the explanations, a state's leaders may rationally overestimate their chance of military victory against an adversary, so producing a disagreement about relative power that only war can resolve. The other argues that rationally led states may lack information about an adversary's willingness to fight and so may challenge in the mistaken belief that war will now

\footnotetext{
${ }^{20}$ This argument focuses on the fundamental difference between domestic and international politics. Within a well-ordered state, the government has the monopoly of organized violence. In contrast, in international relations no agency exists that can credibly threaten reprisal for the use of force to settle disputes. Without such a credible threat, war will sometimes appear the best option for states that have conflicting interests (Fearon 1995:384).
} 
follow. Fearon asserts that the cause of war cannot be simply lack of information, but whatever it is that prevents its disclosure (Fearon 1995:390-391).

It is worth mentioning that according to Geoffrey Blainey's argument "wars usually begin when two nations disagree on their relative strength", and if states agree on relative power, they are very unlikely to go to war against each other. He explains disagreements about relative power as a consequence of human irrationality, and he also suggests that emotional commitments could irrationally bias leaders' military estimates (Blainey 1988:246, 254).

In addition, it must be noted that since we all aware of that the world is a very complex place, military analysts in different states understandably could reach different conclusions about the likely impact of different technologies, doctrines, and tactics on the expected course of battle. State leaders might have private information about militarily relevant factors, and if a state has more reliable information about any important factor, then its estimate of the probable course of battle may differ from that of an adversary. Furthermore, in case of bounded rationality, leaders or military analysts with the same information might reason to different conclusions about the likely course of war because of differential ability to cope with complexity of the problem (Fearon 1995:392-395).

\subsubsection{Domestic Factors: Institutions and Diversionary Incentives}

At the domestic level two structural factors have been considered to be important in regard of the use of force: (1) the impact of domestic institutions and (2) diversionary incentives. The different domestic political institutions have long been claimed to either hamper or facilitate leader's decisions to use military force. The most well-known argument of these claims is democratic peace theory, while others have found evidence of an autocratic peace (Pickering 2002:293-324; Peceny \& Beer 2003:339-342).

In the last three decades several studies have attempted to assess the potentially varying conflictual tendencies of democratic and non-democratic regime types. In regard of democracies, studies have analyzed whether presidential or varieties of parliamentary systems tend to have greater proclivity to use military force abroad (Ireland \& Gartner 2001:547-568; Reiter \& Tillman 2002:810-826). The predisposition of non-democratic governments to use foreign military intervention has not been analyzed in such a detail, however, the literature on the subject has increased over the past decades. The current evidence suggests that autocratic political systems that more closely resemble democracies are more cooperative and less prone to use military force abroad than those that are more dictatorial (Lai \& Slater 2006:113-126; 
Mattes \& Rodríguez 2014:527-538; Weeks 2012:326-347). Personalist regimes seem to use military force abroad more frequently than single-party and military regimes. Moreover, personalist regimes also tend to pursue reckless foreign policies because there are few reliable checks on leaders' power. However, they may be less likely than single-party and military regimes to send soldiers abroad in response to domestic political or economic pressures, that is to use diversionary force. ${ }^{21}$ It is worth to note that one school of thought argues that domestic economic structures, such as capitalist economies or contract intensive economies, have greater explanatory power than political arrangements, and some combination of domestic political and economic structures seems likely to offer the most explanatory power in the future (Hegre 2014:159-172).

Considerable research has been done on the diversionary incentive to use foreign military force. Most of the literature now seem to suggest that diversionary military force is used only under certain conditions, which are still unknown (Levy \& Mabe 2004:65-83; Oakes 2012). Early attention focused on regime type, while more recent work suggests that other domestic considerations, such as a state's extractive capacity and its ethnic composition, and certain characteristics of the target state may also shape the predisposition to use diversionary force (Kisangani \& Pickering 2011:1021-1046; Pickering, Kisangani 2005:2343; Oakes 2012:7-8). In addition, research has begun to study the effects of diversionary force on the domestic factors that prompt it. According to recent studies, it remains unclear whether diversionary force works in the way leaders anticipate (DeRouen 2000:317-328; Kisangani \& Pickering 2009:483-515).

\subsubsection{Interstate Factors}

Pickering and Mitchell in their summary article, Empirical Knowledge on Foreign Military Intervention, provide a basic overview of the primary structural conditions at the interstate level that lead to the use of force, noting that substantial research has been dedicated to these factors. According to the list of Pickering and Mitchell, the interstate factors are the following: (1) proximity; (2) territorial concerns; (3) power capabilities; (4) alliances; (5) economic interdependence; (6) intergovernmental organization (IGO) membership; (7) and colonial history (Pickering \& Mitchell 2017:9).

Proximity and territorial disputes are well known structural conditions influencing decisions to use force. Earlier research suggests that as the number of land border a state has

\footnotetext{
${ }^{21}$ Diversionary force means that leaders dispatch soldiers abroad with the intention of diverting the attention of politically relevant groups away from domestic problems. (Pickering \& Mitchell 2017:6; Pickering \& Kisangani 2010:477-493).
} 
increases the likelihood that it will use force rises as well. Disputed territory also substantially increases both the chances that military force will be used and the odds of an escalation to war (Souva \& Prins 2006:183-200; Diehl \& Goertz 1988:103-122; Vasquez \& Henehan 2001:123-138). Additionally, proximity can further increase the likelihood of escalation when combined with other structural causes, such as alliances or rivalry, and as territory becomes more valuable the chance that force will be used rises even further. In contrast, border agreements significantly reduce the risks that force will be employed between states (Rasler \& Thompson 2006:145-167; Owsiak 2012:51-66).

Measures of national military capabilities are also often presumed to influence statesman's decisions to use military force against weaker states to increase the probability of success and to reduce the possibility of retaliation. However, as Pickering and Mitchell note, empirical evidence on this supposition remain inconsistent. Some studies suggest that disputes between states with roughly symmetrical capabilities have a higher probability of escalation. On the other hand, there are studies with contradictory findings. In addition, some argue that rapid changes in capabilities also influence the chances that military force will be used (Moul 2003; Bennett \& Stam 2003).

There are mixed findings in the literature also in regard of alliances. Some argue that defensive alliances may deter attackers, and that alliances that settle territorial claims may solidify peace (Fang, Johnson \& Leeds 2014). Conversely, others argue that offensive and neutrality pacts can increase the probability that interstate force will be used (Gibler \& Vasquez 1998). There is no doubt, that further analysis is needed in this regard, to help us understand the impact of specific types of alliances during certain historical periods.

Economic interdependence is also among the interstate factors, which is often assumed to influence the use of military force. The research findings are nevertheless inconsistent again, with some studies arguing that interdependence reduces the probability that force will be used (Kinne 2012), while others find that trade partners use force against one another in asymmetric relationships (Gartzke \& Westerwinter 2016). Another research suggests that export similarity may lead to conflict regardless of interdependence levels. According to Bell and Long, rising levels of interdependence may reduce the probability that military force is used over territorial disputes, but it may have negligible impact on decisions to use force over existential issues, such as regime survival (Bell \& Long 2016).

Many analyses include membership in intergovernmental organizations, arguing that shared IGO membership may reinforce the bargaining approach by providing a communication channel for shared information that reduces the probability for states to use 
force. However, the impact of certain type of IGO membership also remains contested. Some scholars argue that IGO membership decreases conflict predispositions (Russett, Oneal \& Davis 1998), while others find that it increases such inclination or has little effect (Boehmer, Gartzke \& Nordstrom 2004). Anderson, Mitchell, and Schilling (2016), for instance, assert that IGO membership had a conflict-reducing effect during the Cold War period, but a conflict-increasing effect after the collapse of the Soviet Union.

Shared history may also lead one country to intervene into another. According to some studies, former colonial powers seem significantly more likely to use military force in their former colonies than in other countries (Pickering \& Peceny 2006:539-560). In a recent study, Chacha and Stojek argue that colonial ties have significant explanatory power even when controlling for commonalities between the intervener ant the target nation (Chacha \& Stojek 2016:42-62).

\subsubsection{International Factors and Regional Conditions}

System-level theories and empirical tests were prevalent through the 1980s, but since then the scientific literature rather focused on dyadic theories and tests of interstate and domestic structural factors. Thus, in the last few decades system-level factors that might explain patterns in the use of military force has remained under-researched. Furthermore, system-level theories such as power transition theory, tend to focus on system-changing events, particularly full-scale wars among great powers in the international system, paying little attention to lowscale uses of military force. However, the distribution of power in the international system highlighted by these theories is an important context for understanding the use of military force during a specific time period. By and large, research regarding the relation between system-level dynamics and the use of force remains limited (Pickering \& Mitchell 2017:11).

According to Rosenau, certain systemic/international variables seem likely to be especially potent as sources of interventions for those decision-makers which are predisposed to undertake such behavior. Three systemic variables appear likely to have a high potency in this regard: (1) the basic structure of the international system; (2) the degree to which ideological rivalry sustains the structure; (3) and the stability of the nations that compromise the system. As Rosenau describes, by the basic structure of the international system is meant the degree to which the capability for affecting the conduct of international affairs is distributed or concentrated within the system. He notes that a balance of power structure involves a greater distribution of national capabilities than a bipolar structure. The more dispersed the structure of the international system, the less the likelihood that it can be rapidly 
and radically changed by a single development. Thus, leaders are less likely to succumb to the temptation to engage in convention-breaking behavior the less capabilities are concentrated in the system. On the contrary, foreign military intervention seems more likely to occur the more tightly the system is structured. In a tight system a potential shift in the alliances and ties of a nation will seem more threatening to other nations than would be the case in a loosely structured era of world politics. ${ }^{22}$

Additionally, the type and degree of ideological conflict that marks the international system both shapes its structure and is in turn channeled by the distribution of national capabilities. When ideological rivalry is intense, leaders are more likely to consider the possibility of directly influenced governmental changes abroad. For the more future plans are seen to be at stake in international politics, the more are decision-makers likely to allow their personal tendencies to become involved in their perceptions and calculations, and thus the more will they be ready to undertake convention-breaking behavior (Rosenau 1969:168).

The third systemic variable is the stability of nations in the system. The weaker are the authority structures of foreign nations, the more likely it is that convention-breaking attempts to preserve or alter them will be employed. Rosenau argues that this is perhaps the most potent of all the systemic variables, since whatever their individual differences, world-leaders everywhere are likely to be particularly sensitive to the stability of foreign governments.

According to Rosenau:

"While publics may be unconcerned about authority structures abroad, those responsible for the maintenance of a favorable international environment will be constantly alert to any sudden changes that may alter the personnel and orientations of foreign governments. Aside from the consequences of war, the major turning points in world politics occur when old regimes collapse and are replaced by new ones with substantially different policies." (Rosenau 1969:168).

The less the stability the greater their readiness to break with tradition and undertake unconventional efforts to avert the dangers of, or to seize advantages in the unstable situations. This point is particularly important in regard of the developing states ${ }^{23}$ or Third World countries, since the developing nations are by definition burdened with unstable and delicate authority structures, as they are undergoing rapid economic, social, and political change. Therefore, the international system appears likely to be characterized by a

\footnotetext{
${ }^{22}$ Rosenau makes a reference to Kaplan, noting that these hypotheses were stimulated by him, and his work is indeed rooted in a scientific mode of analysis, while his conclusions about intervention are derived not from moral, legal, or strategic considerations, but from a theoretical model of the international system (Rosenau 1969:167-168; Kaplan 1964:92-121).

${ }^{23}$ Pickering and Kisangani (2006:366) identified developing states as those "whose annual real Gross Domestic Product (GDP) per capita is less than 50 percent of the highest real GDP per capita in the international system". Their approach is similar to that employed by Reuveny and Thompson (2004:5-24).
} 
preponderance of unstable subsystems. In his work, Rosenau concludes that incidences of intervention seem likely to occur at greater rather than a lesser rate in the future, and the developing countries appear destined to be the primary focus of this form of international behavior (Rosenau 1969:168-169).

In the last few decades foreign intervention has been of increasing significance as a problem of international security. Among earlier research we can find a few focusing on the rise of intervention from a regional perspective. In the 1980s, MacFarlane pointed out that military intervention has become increasingly common in Africa. According to him, the discussion of intervention is incomplete without attention to its regional context, to its local origins and impacts. In his paper, he addresses the regional causes of intervention and its implications for regional security, from the perspective of African states. His analysis focusses on member states of the Organization of African Unity (OAU). MacFarlane argues that intervention is at least as much a symptom of more basic regional problems (political and social fragmentation, economic decay, progressive differentiation in the distribution of power) as it is a cause of regional instability in its own right (MacFarlane 1984:127-129).

According to MacFarlane, in accounting for the increasing number of interventions in Africa during the Cold War period, a number of external factors were of great importance, such as the transfer of superpower competition to the periphery of the international system, the deterioration in relations between East and West, and the growing insecurity of South Africa. In addition, regional instability favors intervention by both regional and extra-regional actors, because states which are divided internally have difficulty in mounting resistance to external intervention, and parties to internal conflicts seek outside assistance against their rivals. When their survival is at stake, they promote escalation of their external benefactor's involvement. As MacFarlane emphasizes, "in this sense, internal conflict provides an entry point for outsiders interested in influencing the policy choices of the state in question", thus intervention in Africa is not so much a cause of regional insecurity as it is a manifestation of more profound problems (MacFarlane 1984). ${ }^{24}$

It is worth noting that those suffering from internal instability are not only potential targets. They are also potential interveners since regimes often attempt to compensate for their incapacity to cope with pressing internal problems and for their illegitimacy in the eyes of their own publics by success in foreign policy. In addition, regimes may attempt through

\footnotetext{
${ }^{24}$ According to MacFarlane (1984:130, 130-134), there are at least three fundamental problems of African security: (1) political fragmentation; (2) catastrophic economic performance; (3) and the growing regional disparity in military and other forms of power.
} 
interventions to preempt or to hinder efforts by outsiders to take advantage of or to exacerbate internal instability. In regard of the impact of intervention on African regional security, governments in the region frequently condemn intervention maintaining that its impact on regional security is negative, and it is itself a security problem rather than a solution to problems of security. This conclusion is based upon several judgments with respect to the effect of foreign interventions: that intervention both prolongs and intensifies the conflict which provoked it, increasing the number of casualties and refugees and the level of destruction in the target state; that it therefore hinders economic development; that it erodes national sovereignty; and that it is politically destabilizing for the target country (MacFarlane 1984:133-134, 136).

\subsection{Civil War Process and Proxy Intervention}

Scholars argue that foreign intervention is central to the civil war process, which is characterized by the duration of hostilities and the type of outcome (Balch-Lindsay \& Enterline 2000). ${ }^{25}$ Earlier research suggests that external interventions can be decisive in the evolution of civil wars and that foreign interventions have a different effect on the duration of a conflict and civil war outcomes (Dixon 2013). According to the research results of BalchLindsay, Enterline and Joyce (2008:345), third-party intervention decreases the time until the supported group achieves military victory. In addition, foreign intervention on both the government and opposition sides increases the time until a negotiated settlement can be reached.

The research on the role of third parties in the last decades divided into three roughly defined research agendas: (1) the causes of foreign interventions in civil wars, (2) the effect of foreign interventions on civil war outcomes, and (3) the effect of external intervention on the duration of civil wars. Balch-Lindsay, Enterline and Joyce note that third parties are central to the civil war process insomuch as even decisions by third parties not to intervene overtly in a civil war has meaningful consequences for the manner in which civil wars evolve. They studied this issue further by assuming that foreign intervention in civil wars manifests itself in three ways: (1) external intervention on behalf of the government of the civil war state; (2) external intervention on behalf of the opposition group challenging the government; (3)

\footnotetext{
${ }^{25}$ Scholars have argued that civil wars are not discrete events but rather processes, which are subject to conditions and factors that vary across the duration of the conflict, as, for instance, one side in the conflict begins to prevail on the battlefield, while foreign actors intervene and depart the conflict. (Balch-Lindsay $\&$ Enterline 2000:621).
} 
simultaneous third-party interventions on behalf of both the government and opposition sides (Balch-Lindsay, Enterline \& Joyce 2008:348-349).

Scholars agree that foreign intervention on the side of the government alters a government's decision calculus, just as a third-party intervention on the side of an opposition group influences the behavior of the opposition as well. The presence of third-party support on the government's side helps it to minimize the rent it extracts from its citizens to fund its civil war effort, as well as shore up political support, while greater military, economic, and political capability increases the chances of winning militarily. On the other hand, foreign intervention on the side of the opposition forces facilitates the ability of the opposition to impose costs on the government. An opposition supported by a third-party is more likely to challenge the government with a capable military threat, thereby increasing the opposition's chances of achieving victory. In summary, foreign support increases the likelihood that a combatant will more easily win the conflict militarily. In regard of balanced intervention, some would suggest that the continued high cost of fighting a civil war, as well as the low probability of winning, increases the attractiveness to the combatants of ending a civil war in a negotiated settlement. Thus, following the logic of Zartman's hurting stalemate, negotiated settlements should occur more rapidly under conditions of balanced foreign intervention (Balch-Lindsay, Enterline \& Joyce 2008:349-350; Zartman 2000:225-250).

Others suggest that third parties are central to the issue of when and how civil wars are likely to end, since third parties are strategic and self-interested actors. Civil wars provide windows of opportunity for external actors to pursue their national security interests, which are not necessarily benign. Foreign actors, for instance, are often interested in exploiting the natural resources of the civil war state or weakening a potential rival state by supporting continued armed conflict. As Balch-Lindsay, Enterline and Joyce (2008) note, their review of the case study literature on interstate conflict bolsters the contention that although the degree of third-party involvement varies, external intervention in civil wars is nearly ubiquitous. ${ }^{26}$

\footnotetext{
${ }^{26}$ After laying out the theoretical foundations of their inquiry into the effect of third parties on civil war process, Balch-Lindsay, Enterline and Joyce discusses the logic underlying some additional causal factors such as: (1) separatist issues, (2) civil war costs, (3) bargaining reputation, (4) economic development, and (5) democracy. Regarding the effect of separatist issues there is an argument according to which separatist civil wars should be more amenable to negotiated settlement, because separatist claims, by definition, do not require the government to relinquish power over the entire territory encompassed by the civil war state, and there are also incentives for a separatist group to prefer a negotiated settlement to military victory. However, according to the logic of another argument, since separatist demands challenge the very basis of state sovereignty and territorial integrity, governments are extremely reluctant to surrender their right to determine policy within the geographic boundaries of their states. Not to mention the government fear that allowing one region to gain autonomy establishes precedent for subsequent separatist demands (Balch-Lindsay, Enterline \& Joyce 2008:350-352; Balch-Lindsay \& Enterline 2000:618).
} 
The increasing importance of foreign intervention as a means of foreign policy is indicated by the rising number of military interventions in civil wars by external actors. In some cases, smaller intervening states are seen to have acted as the proxy of a major power. It is often assumed that civil war, as a matter of fact, invites military intervention from outside the country. Several research attempts have been made earlier to provide evidence of the extent to which the surrounding countries have tended to intervene on one side or the other (Kende 1977:59-67; Singer \& Small in: Kegley \& McGowan 1979:89-115). On the other hand, it has been argued that the traditional way of intervening is now outdated, since it has become more and more hazardous for a country to invade with its own troops a neighboring country. Earlier studies suggest that military intervention will take place more and more in an indirect way, that is a certain external actor who wishes to try to influence the outcome of an internal conflict will rather choose to employ subversion, to supply arms to the combatants, provide help in training and advisors and the like. Thus, it can stay away or at least it can pretend to stay away from the actual warfare. In addition, this way it can also cope with the international consequences of its involvement more easily (Dunér 1981:353-361).

As Dunér puts it, one way of intervening indirectly is to let someone else do the work for you. The country which intervenes as a 'tool' of another state is mostly called a 'proxy'. According to Dunér, if all the examples of proxy intervention discussed in the scientific literature should be collected together, the list would probably be a very long one (Dunér 1981:355). However, there can be considerable disagreement between different experts as to how various cases should be evaluated. It is also must be noted that there are also authors who object the whole idea of proxy relationships and who think it is in itself misleading (Kende 1978:227-241).

Defining 'proxy' is not an easy task. Dunér identifies various dimensions which seems to be relevant in this respect. He argues that the first circumstance which appears to be important is the interests of various parties of the conflict, since to some observers, a proxy intervention appears to be a manifestation of the interest of major power (A) but not of that of the proxy (B). It is also possible that both parties have an interest in the intervention. As Dunér notes, as interest in this connection must relate to something else than power, it will therefore have to be interpreted as some kind of joint interest between the parties or a compatibility of interests at least. Furthermore, Dunér argues that the material relationships between $\mathrm{A}$ and $\mathrm{B}$ also appears to be important, and he points out the tendency to insert into the proxy concept the circumstance that A provides B with material support intended for the actual intervention, and in some cases, B is even dependent on this support. However, an 
essential element of all discussions of proxy relationships is the question of whether $\mathrm{A}$ exercised influence or power, that is, B is submissive to A, thus cannot resist its demands, or just simply accept its directions. The relationship between A and B can also manifest itself in the coordination of activities, which means that there can be a division of labour or some accord, so that the implementation of the intervention or its success is dependent on the actions of both parties. Dunér also brings up for discussion the fact that a relationship between A and B expresses asymmetry in some sense. In summary, Dunér picked three dimensions, from which it is possible to formulate sufficient criteria of definition: (1) compatibility of interests; (2) material support; (3) power (Dunér 1981). ${ }^{27}$

According to previous studies, there appears to be a clear connection between foreign intervention and increased defense spending and weapons procurement in contiguous states. Thus, intervention in this sense is a major contributor to region-wide trends in size of forces, military expenditure, and arms procurement. In addition, the increasing incidence of intervention in the late 1970s and early 1980s in Africa reflects an erosion of the normative basis of interstate relations in the region. ${ }^{28}$ MacFarlane argues that the increasing frequency of intervention in Africa suggests that regional actors are increasingly willing to seek military assistance from external actors, and the increasing numbers of interventions not only reflect but foster the erosion of the previously mentioned normative basis, since, in the absence of a supranational authority capable of enforcing rules, compliance is based upon mutual interest and upon the expectation that others will comply (MacFarlane 1984:143-147).

MacFarlane (1984) notes that while it was argued earlier that generalization with respect to intervention and the intensity and duration of military conflict was disputable, it appears that the involvement of the great powers complicates the attempt to resolve the political issues underlying hostilities by stimulating the interest of and counteraction by rival actors. This adds an additional dynamic of conflict to regional crises and renders them even

\footnotetext{
${ }^{27}$ According to Dunér, whether or not a state has acted as a proxy can best be regarded as a question of whether it has been subjected to the exercise of power by some other state; whether it has been pressured to intervening. Dunér suggests an interpretation, according to which a proxy intervenes on account of the positive or negative sanctions (or threats of sanctions) which are directed against it, and without such sanctions the intervention would not occur. Positive sanctions' means rewards, for instance, transfers of resources. Categorizing the status of an intervener Dunér outlined a diagram, where the phenomenon of intervention has been divided up into four different cases as follows. Proxy 1: receives (is dependent on) material support and pressured to intervene; proxy2: does not receive (is not dependent on) material support and pressured to intervene; partner: receives (is dependent on) material support and not pressured to intervene; autonomous actor: does not receive material support and not pressured to intervene (Dunér 1981:355-358).

${ }^{28}$ According to MacFarlane, among the most important norms were: (1) non-interference in the internal affairs of African states; (2) non-recourse to force in inter-African relations; (3) non-recourse to extra-regional military assistance in the resolution of regional disputes (i.e., African solutions to African problems); (4) respect for the territorial status quo established by the colonial powers (MacFarlane 1984:146; Zartman 1967:545-564).
} 
more intractable than they might otherwise be. In short, intervention by aligned regional powers or by outside forces on one side or the other of the great power competition tends to embroil local conflicts in broader regional, or even global rivalries. MacFarlane concludes that the intrusion of global variables into regional conflicts makes conflict resolution even more difficult (MacFarlane 1984:147-149).

\subsubsection{Behind the Decision to Intervene}

Despite the recent resurgence of policy interest in civil wars, this type of conflict is not a new feature of the international system. Besides their prevalence and intractability, the historical record of the international system shows frequent overt and covert third party intervention in intrastate conflicts. In addition, while states intervene in internal conflicts with some regularity, earlier research suggests that in doing so external actors pursue a range of goals (Regan 1996:336-359; 2000). Balch-Lindsay and Enterline (2000:616-619) point out in their work that the impact of third party interventions on the evolution of intrastate conflicts/civil wars is often a function of the involvement of other third parties/external actors. They argue that third party interventions are interdependent and exhibit "system-like" qualities and note that there is sufficient evidence to suggest that a relationship obtain between civil wars and interstate behavior. As they describe, the literature underlines the notion that the impact of individual third parties on the evolution of civil wars occurs within the context of conditions internal and external to the civil conflict itself. Moreover, individual third party intervention are interdependent with the behavior and interventions of other third parties.

Earlier studies suggest that many of the same factors that influence decisions to use military intervention as a policy tool outside of the context of civil war also impact the decision to send troops into active zones of civil conflict. During the Cold War, most military interventions occurred where the intervening state had previously established visible military commitments, however, this has not been true of all interventions (Tillema \& Wingen 1982:240). Adjacent or nearby countries, allies and rivals, and former colonial powers tend to intervene into ongoing civil wars. In addition, bilateral trade ties also influence civil war intervention on the side of the government, and the probability that a state will intervene increases markedly when a rival state has deployed armed forces into the country. However, the impact of rivals may not apply to the post-Cold War period. Other studies argue that transnational ethnic affinities, even linkages between marginal ethnic groups in the intervener and the target country may also increase the probability of external intervention. Religious ties are also important motivating factors behind the decision to intervene into ongoing civil 
wars. Evidence suggest that intervening states tend to have populations that have similar religious ties as targeted groups in civil war states, and external intervention seems to be set in motion on behalf of religious minorities more often than in case of any other minorities. ${ }^{29}$

It is worth noting that some studies suggest that characteristics of the civil conflict itself can also affect intervention decisions. Empirical evidence shows that third parties are more likely to intervene in intense civil conflicts with high casualty rates, however, the probability of military intervention decreases if other third parties have intervened already and failed to achieve their goals. Furthermore, regional considerations can also influence intervention decisions. External interveners often come from the same region as the affected state, and one of their main motivations is to prevent the regional escalation of civil conflict (Aydin 2010:47-66; Kathman 2011:847-876).

In regard of political characteristics of the intervening state, some evidence suggests that democratic states are more likely to deploy soldiers to defend co-ethnics within civil wars than autocracies, while autocratic states seem to tend to support rebels when such non-state actors control exploitable resources. In case of democratic states, media coverage of civil conflicts may also help to drive foreign interventions (Koga 2011:1143-1166; Bell, Frank \& Macharia 2013:646-671).

\subsubsection{Impact of External Intervention on Civil War}

There are mixed findings in the empirical literature on the impact of external interventions on civil war. There seems to be a consensus or understanding on that interventions on the side of rebels increase the probability of rebel victory, while biased interventions in favor of the government do not seem to have a similar impact, maybe because interventions on the governments side may only be necessary as a last resort in a critical situation. Possibly the only example in which pro-government interventions improve the government's chance of victory is when government forces do not have the much needed capability advantage over rebel forces, thus national armed forces benefit from the additional firepower of external troops. However, one-sided interventions may increase the time required to reach some sort of settlement to the conflict. The applied tactics of either side can also affect the duration of the conflict. It also must be emphasized, that foreign interventions also alter the chances that the conflict will spill over to neighboring states. Studies suggest that pro-government interventions tend to reduce diffusion, while pro-rebel interventions increase diffusion, partly

\footnotetext{
${ }^{29}$ Findley \& Teo (2006:828-837); Stojek \& Chacha (2015:228-242); Daxecker (2011:543-565); Mullenbach \& Matthews (2008:25-52); Nome (2012:747-771); Fox, James \& Li (2009:161-186).
} 
by increasing the capabilities and transnational activities of insurgents (Sullivan \& Karreth 2015:269-288). ${ }^{30}$

In the last few years more research on interventions has investigated the effectiveness of intervention and its role in conflict resolution and maintaining peace. Ricardo Real P. Sousa dedicated one chapter of his Ph.D. dissertation to the effect of external interventions on conflict intensity (Sousa 2014). ${ }^{31}$ Based on the balance of capability model, in his research Sousa explored conflict intensity levels and conflict-intensity changes, with a new dataset on external interventions for Africa for the period between 1989 and 2010. Sousa confirmed that partisan, military, and economic interventions increase conflict intensity, whereas neutral or diplomatic interventions have no such effect (Sousa 2014:136). According to Sousa, the impact of foreign interventions can be evaluated by looking at a conflict's duration, which mostly depends on the objective and type of the intervention. ${ }^{32}$ According to research taken on the objectives of interventions, unilateral/one-sided interventions can improve the chances of success for the supported side (Balch-Lindsay, Enterline \& Joyce 2008:345-363). In terms of types of interventions there are research indicating that military and economic interventions tend to prolongate conflicts. Studies on the economic and political determinants of civil wars have revealed that once a civil war has started, its termination depends critically on the balance of military capability between the government and the rebels. This balance is similarly important in all armed conflicts as well (Elbadawi \& Sambanis 2000; Regan 2002:55-73).

According to ripeness theory, when the parties of a conflict find themselves locked in a situation from which they cannot escalate to victory and this deadlock is painful to both of them - although not necessarily in equal degrees or for the same reasons -, they seek a way out. In a situation like this, if one party can gain superiority somehow over the other, maybe by a foreign intervention by its patron, that can improve its chances for military victory, which increases the other sides willingness to negotiate (Zartman 2000:225-250).

MacFarlane describes the argument concerning intervention and the intensity and duration of conflict as follows:

\footnotetext{
${ }^{30}$ See also Gent (2008:713-735); Brandt et al. (2008:415-434); Linebarger \& Enterline in: Mason and Mitchell (2016:93-108); Peksen \& Lounsbery (2012:348-374).

${ }^{31}$ Conflict intensity is the count of battle deaths per month. Sousa also included other variables, such as previous levels of conflict intensity, population, GDP per capita, level of democracy, existence of natural resources (oil, gas), Overseas Development Assistance (ODA) score (Sousa 2014:124-125).

${ }^{32}$ Intervention targets can be biased and partisan, when in support of the government or opposition, or neutral, when not intended to change the balance of capabilities of the parties. Intervention types can be grouped into military, economic, and diplomatic interventions as well as missions by the UN and other actors.
} 
"In theory, the introduction of well-equipped units of an external power increases the quantity of firepower deployed and often alters the quality of conflicts through the deployment of technologically more sophisticated weapons systems. Moreover, such intrusions can prolong a conflict, in that appeals for more considerable support often come from local actors close to exhaustion. Finally, intervention may bring counterintervention in support of other parties to the conflict." (MacFarlane 1984:137)

Patrick Regan (2002:71) also examined the proposition, that taking sides in a conflict is an important determinant in the ability to end wars. He concludes that intervention is not an effective or reliable conflict management tool, as conflicts experiencing intervention last longer on average than those without intervention, regardless of when those interventions occur during the conflict and on whose behalf. However, unilateral interventions tend to increase the duration of civil conflict by a very small margin, compared to multilateral interventions.

It is also worth noting that foreign military intervention also tends to elicit counterinterventions. As Lounsbery, Pearson and Talentino (2011:233) put it, a target state potentially has both enemies and friends, and occasionally, rival states may act militarily to counter previous intervention moves, resulting in what has been referred to as "counterintervention" or "rival interventions." By escalating the conflict or increasing the number of states trying to affect the outcome, competitive or multiple interventions might set the stage for long-term destabilization of the target country. In civil conflict interventions, Regan finds that conflicts experiencing counterinterventions last longer than those without, as counterinterventions appear to provide enough power to all parties to continue the fight. ${ }^{33}$

\subsubsection{Conflict Intensity and Economic Development}

There are also cases in which intervention at a level sufficient to determine the outcome of a conflict terminated hostilities or drastically reduced their scale far earlier than would otherwise have been the case. As a result, generalizations regarding intervention and conflict intensity and duration are suspect. However, the argument concerning effects on economic development draws from that with regard to the intensity and duration of conflict. The more intense a civil war is, the greater the destruction. However, if the assumption concerning the relationship between foreign intervention and the intensity and duration of conflict is uncertain, so too are its implications concerning the impacts of intervention on economic development. As MacFarlane notes, in specific instances, the impacts of intervention on economic activity can go either way, while in some cases, foreign intervention has no obvious

\footnotetext{
${ }^{33}$ On the effect of unilateral and multilateral military intervention on conflict duration see Regan (2002:71) and Pickering \& Kisangani (2006:366).
} 
economic effects. In this regard, again, it seems that there is not any justification for broad generalization at this point about the impact of foreign intervention (MacFarlane 1984:137139).

\subsubsection{Sovereignty, Security, and Stability}

It is worth to note that according to the general view intervention compromises national sovereignty and self-determination, since foreign military meddling on behalf of a party to a civil war creates a relationship of dependency such that the local client is incapable of independent action in internal and international affairs where his interests or preferences diverge from those of his patron. In this sense, as MacFarlane (1984:139-140) puts it, “intervention constitutes a new kind of colonialism". In some instances, this may be true, however, there are cases where the regime has benefited considerably from intervention with the support of a great power. Additionally, such influence is not permanent. The removal or disappearance of the threat causing intervention removes the source of a regime's dependence, thus weakening the source of foreign influence. Moreover, in some cases intervention may preserve and enhance sovereignty rather than eroding it.

In regard of the question of political stability, according to MacFarlane (1984), some cases in Africa suggests that in the short term, intervention may be stabilizing or destabilizing in intent and consequences. In the longer term, military intervention is unlikely to enhance a target state's stability. Foreign military intervention may bring military victory for one of the parties to a civil conflict, however, so long as the political and social roots of the conflict which caused intervention are not addressed, the solution will remain at best a temporary one, which is full of dangers of deeper involvement for the external actor. In addition, external interference may in fact reduce the likelihood of conflict resolution. Intervention and a sustained foreign role in defending a government against its internal opposition may discredit that government in the eyes of the people, which comes to see the regime as an instrument of a foreign power and as betraying the nation which it supposed to serve. It may even undermine further the legitimacy upon which the stability of a government rests. However, it must be noted that it is not necessarily the case that foreign intervention will have these impacts. Occasionally, it may set the stage for longer term stability by removing threats to popular and legitimate regimes. Moreover, external intervention and sustained military presence need not to discredit an incumbent government. Whether intervention has this impact depends on, for instance, the demeanor of foreign personnel, the degree of economic benefits to the target state, the performance of the incumbent government in meeting the 
economic and social needs of the population, the effectiveness of the opposition in mobilizing public opinion, and so on. Thus, it would appear that it is neither easy nor very productive to generalize about intervention and its impact on security. Intervention in Africa and in the Middle East is not a homogeneous phenomenon (MacFarlane 1984:141-143).

Lounsbery, Pearson, and Talentino published an article in Democracy and Security in 2011 on unilateral and multilateral military interventions and their effects on stability and security, in which they highlight that international military interventions are increasingly being judged primarily on their effects on the target country itself. In other words, success and failure are determined by the conditions interventions create and/or leave behind on the ground. In addition, as they note, intervention in a different, multilateral form and with different goals (to end a conflict, establish security, relieve humanitarian crisis, and provide room for political transformation and rebuilding) is now viewed as a legitimate and sometimes even necessary means of impacting state sovereignty. As the authors put it, "it is clear that stability and security are the goals of intervention in any era, though whose stability and security is somewhat at issue" (2011:229). They emphasize that during the Cold War it was the intervener's and allies' stability and security that mattered most. However, after the collapse of the Soviet Union, the trend shifted, which means that external military intervention is now expected to contribute to the stability and security of the target state. The authors emphasize this specifically, noting that this distinction is important because it makes stability and security more difficult to measure, since they depend both on domestic political and social dynamics in the target state as well as regional power balances. With this in mind, to evaluate contemporary intervention, they attempt to look beyond how the act and its outcome affect the intervener and international power competition, and examine how they affect the target state itself, which approach has received little attention so far (Lounsbery, Pearson \& Talentino 2011:227-229).

The article of Lounsbery et al. poses three questions regarding the effect of intervention on target states, which together constitute what is often referred to as the prospect for target "stability": 1.) does foreign military intervention composition (multilateral or unilateral) matter in terms of target state impact? 2.) does intervention help or hinder the development of democratic processes? And 3.) does it improve the target state's quality of life and economic prospects, thereby relieving local conflicts and tensions that may lead to further violence? The authors analyze a data set on all foreign military interventions into developing countries during the period 1960-2002, introducing a new approach to evaluating the 
cumulative effect of intervention across time in subsequent years (Lounsbery, Pearson \& Talentino 2011:230).

\subsubsection{The Systemic Dimensions of Civil Wars}

There has been little effort to conceptualize civil wars and foreign interventions as intrastateinterstate relationships, some earlier research suggested alternative levels of analysis that capture the system-like security interests of states. For example, Buzan and Waever (2003) introduced the notion of a "regional security complex" to capture the environment that political leaders consider when developing security policy. Earlier, in his study of the security policy of Third World states, Robert Rosh (1988) introduced the concept of "security webs", which he defines as the geographic neighborhood that encompasses a state and conditions the state's domestic and foreign policies. Later Maoz (1996) has incorporated Rosh's idea into his own concept of a "politically relevant international environment" (PRIE). Maoz defined a state's PRIE as those states to which it is geographically contiguous as well as the major, or regional powers. Similarly to Maoz's proposition, Enterline argues that the "geographic neighborhood" of a new regime has important consequences for the regime's subsequent involvement in interstate conflict.

The literature provides a solid basis for the claim that civil wars do not occur in isolation, but rather are embedded in the international system. Balch-Lindsay and Enterline (2000:619-620) found the overlapping concepts of "security web," "politically relevant international environment," and "geographic neighborhoods" to be helpful in conceptualizing behavior in civil wars specifically for the following three reasons.

1. These concepts stress the importance of considering the geographic and strategic environment within which a civil war is embedded, keeping in mind that proximity is a decisive factor at the interstate level that influences decisions to use force. The literature also suggests that the characteristics of civil wars are partly a function of their interstate environment.

2. Security webs underline the complex interdependence that exists in every civil war. Earlier case studies stress that foreign actor behavior is often motivated and sustained by the choices of other external actors, and action and reaction in civil wars are really complex.

3. In addition, security webs underline the dynamic properties of interstate environments. Changes in the political systems or leadership in states bordering a state experiencing a civil war might affect the course of an ongoing civil war. 


\subsection{Summary}

Although balance of power is largely a game for the major powers, smaller states have conducted a range of significant foreign military interventions. Moreover, as a matter of fact, small states initiated the bulk of foreign military interventions in both the Cold War and postCold War eras. Most likely third-party military intervention will be the most common type of the use of armed force in the coming decades. Moreover, non-state actors seem to be one of the largest threats to international security, while they also appear to be one of the primary targets of state use of force.

According to data on armed conflicts in 2018, the Middle East is still among the most conflict-prone regions, and while the overall decrease in fatalities supports the claim that conflict deaths are in decline and that the world is increasingly peaceful, the number of nonstate conflicts has increased. In 2016 and 2017, most of the non-state conflicts in the Middle East took place in Syria. Despite the overall decline, violence in Iraq and Afghanistan escalated in 2017, with Afghanistan experiencing its most violent year in the post-Cold War period and Iraq its second most violent year. In addition, many intrastate conflicts in the recent years were internationalized at some point, and it is also worth noting that the United States was involved in more conflicts as a secondary warring party than any other country in 2017 (Pettersson \& Eck 2018).

In the last decades scholars have generated substantial empirical knowledge on the motivating factors and the impacts of foreign military intervention, however, there are still notable gaps in our understanding. On the one hand, relatively little attention has been dedicated to periodicity and regional variations. As Pickering and Mitchell (2017) note, a sustained effort to theorize about why patterns and impacts of foreign military intervention deviate across regions has been lacking. It is possible, that state capacity, border fixity and norms vary roughly along regional lines, and these factors may systematically influence the use of armed force across borders. On the other hand, it is worth noting that today many of our measures for external military interventions and their targets remain imperfect. Most of them are binary, indicating whether an intervention occurred or not and whether it was in support of the government or not. However, interventions can target non-state actors and still be categorized as being either pro- or anti-government. We do not have reliable data on such targets, thus we do not have information on how foreign interventions affect various non-state actors and their relations. Pickering and Mitchell consider this "arguably the most crucial missing link" between the theory and data on intervention and outcomes. Furthermore, more 
refined categorizations of military intervention itself is needed. There are many types of military intervention, however, few studies capture variation in scale or intention across interventions (Pickering \& Mitchell 2017:17-18).

Leader's perceptions and decision-making processes are also among the underresearched factors, however, leader perceptions of structural conditions may be more important for determining foreign policy decisions than the actual structural conditions themselves (Keller 2005). Keller and Foster $(2012 ; 2016)$ argue that leaders who believe that they can have a decisive influence on events are more prone to use military force abroad for domestic reasons. They also demonstrate that leaders who do not view the world as complex, or who have low cognitive complexity, are more prone to react to stimuli with military force than those who have high levels of cognitive complexity. Thus, cognitively complex leaders are more likely to consider all policy options and to carefully weigh the risks. They may ultimately choose to use military force, but they will not do it without a thorough review of the evidence and alternatives (Foster \& Keller 2014).

Wars have several direct and indirect consequences, short and long-term effects on countries and societies. The economy may suffer devastating impacts during and after a foreign military intervention. Everyday activities of communities are disrupted, and property may be damaged. This can result in a decrease of the national capabilities, while non-state actors on the sidelines of the conflict can take advantage of the weakening state authority to thrive. In political science, the term 'power vacuum' is used to describe a situation like this, when a government has no identifiable central power or authority. The physical analogy suggests that in a power vacuum, other actors (e.g. insurgents, terrorist organizations, proxies) will show up to fill the vacuum as soon as it is created, as has happened in Iraq (MacAskill \& Burkeman 2003; Chulov 2012; Brown 2018).

In international relations theory, the concept of anarchy means that there is no superior power within a system that would be able to enforce rules. However, this does not mean that anarchy always results in chaos and the unrestricted use of violence. Effective governments have a monopoly on the legitimate use of violence. But, in anarchical systems, there is no such monopoly. This means that there is no central agency that would ensure peace or uphold order. The units within an anarchical system must perform these tasks on their own. In case of a foreign intervention that had a debilitating effect on the target country's national capabilities, the destruction can result in an anarchical system where there is no monopoly on the use of force and the non-state actors can rise freely. 


\title{
3. BALANCE OF POWER THEORY
}

\begin{abstract}
"Now, if we turn to the Oxford English Dictionary, we find that "balance" itself is a word whose various meanings are collected under twenty different heads. The word "of" has sixty-three similar headings, and "power" eighteen. I leave it to mathematicians to calculate how many different meanings can by permutation and combination be extracted from three words together; but I believe the number runs to many thousands. I merely mention that fact to indicate the amount of confusion which may underlie the use of a phrase. Like "liberty," "independence," the "freedom of the seas" or the straits, the balance of power may mean almost anything." (Pollard 1923:58)

"We have been using the term balance without defining it, as if everybody knew what it meant. In fact, it is not far from the truth to say that nobody knows what it means."

(Vernon Van Dyke 1957:219) ${ }^{34}$
\end{abstract}

Balance of power has been the basis of realist international relations theory. According to realists, states maintain security and stability at the systemic level mainly through balancing. ${ }^{35}$ The traditional theory is predicted on four assertion that are also claimed in political realism, which is not just a scientific research program, it is also a political philosophy or worldview, which is pessimistic about the capacity of human reason to create a world of peace and harmony (Schweller 1997:927). The four assertation are as follows:

1. The international system is anarchic, there are no central governing authority.

2. States seek to survive as independent entities.

3. Power or positional competition is a determining factor of international politics. ${ }^{36}$ Hegemony is sought by the power whose expanding capabilities compel it to broaden its national interests and thereby seek more power to protect its increasing assets.

4. When one state attempts to become dominant, threatened states will form defensive coalitions to acquire appropriate military capabilities through internal or external sources (Paul 2005:51).

\footnotetext{
${ }^{34}$ Claude (1962:22) cited Van Dyke (1957:219).

${ }^{35}$ According to Wagner, an international system is stable if the independence of all the actors in it is preserved. (Wagner 1986:546).

${ }^{36}$ It is important to note that what really counts is not the states' absolute capabilities but how they perform relative to their opponents. In such situations, a change in the absolute capability of any actor has important effects not only for that player but also for the other contestants in the system. Thus, positional competition is therefore a zero-sum game: a gain or loss for one player becomes a corresponding loss or gain for the opponent(s) (Schweller 1997:928).
} 
A balance of power order is organized around the principle of anarchy, in which there is no topmost authority (Waltz 1979:88-93). In a condition of anarchy, sovereign states do not stand in any fixed, hierarchical relation with one another, and incentives exist for states to balance. Security/survival is the fundamental goal of states, and because of uncertainty, states will be very sensitive to their relative power position. When powerful states emerge, secondary states will rather seek protection in countervailing coalitions of weaker states than risk domination. Alliances emerge as temporary coalitions of states formed to counter the concentration of power (Schweller 1997:928). As the distribution of power shifts, coalitions will shift as well. ${ }^{37}$

Waltz contrasts balancing with "bandwagoning". ${ }^{38}$ According to him, as we can see in domestic politics, once a leader is finally selected, the losers tend to bandwagon, to support the winning leader (Waltz 1979:126; Wolfers 1962:122-124). In international politics, bandwagoning means the emergence of a "world hegemony". In anarchy, the only effective way to contain the rising power of another state is to combine with other weaker states to resist domination. This is the logic of balance within anarchy that gives shape to international order. Hegemonic order is also based on the distribution of power among states, but the relations of power and authority are defined by the organizing principle of hierarchy. Balance of power and hegemonic orders are both creatures of the international distribution of power. Balancing orders reflect to the prevailing distribution of power, which is driven by the fundamental interest that states have to maintain their position and not to be dominated by a hegemonic state. In contrast, hegemonic orders are established and maintained by the concentration of unchecked power (Ikenberry 2001:23-29).

Many believe that realism and the balance of power is now obsolete. Critics usually argue that, although the realist concepts of anarchy, self-help, and power balancing may have been appropriate in the past, the conditions have changed and better ideas, revised or entirely different theories have taken over their places. As Waltz (2000) emphasizes, if the conditions that a theory contemplated have changed, the theory no longer applies. Changes of the system really would alter the international political system in such a way, that old theories would no longer be relevant. However, changes in the system would not do that, even though withinsystem changes take place all the time. Changes in the structure of the system are distinct from changes at the unit level. The introduction of nuclear weapons, for instance, was the

\footnotetext{
${ }^{37}$ On the balance of power theory see also Wight in Butterfield \& Wight (1968:149-176), Gulick (1982), Claude (1962:3-93; 1989:77-85), and Snyder (1997).

${ }^{38}$ Schweller defines bandwagoning as "any attempt to side with the stronger". Walt redefined bandwagoning as

"alignment with the source of danger" (Schweller 1997:928).
} 
greatest change that have occurred at the unit level. Nuclear weapons definitely change the way some states provide for their own security, but they have not altered the anarchic structure of the international political system. Really significant changes take place, for example, when the number of great powers reduces to two or one (Waltz 2000:5-6).

A key assumption derived from realist theory is that international politics reflects the distribution of national capabilities. Another core assumption is that the balancing of power by some states against others recurs as realist theory predicts that balances disrupted will one day be restored. Waltz (2000:27) notes that "as nature abhors a vacuum, so international politics abhors unbalanced power. Faced with unbalanced power, some states try to increase their own strength, or they ally with others to bring the international distribution of power into balance." Unbalanced power, whoever wields it, is a potential source of real threat to other states.

There is a legitimate expectation, according to which, after victory in a great war a new balance of power will form, since victories in major wars leave the balance of power altered. The winner emerges as a dominant power, which means that the international equilibrium is broken, and theory suggests that its restoration can be expected. According to Waltz $(2000: 30,37)$, theory enables one to say that a new balance of power will form but not to say when, since national and international conditions determine that. At the same time, balancing is not universal and omnipresent. A dominant power may suppress balancing, and whether or not balancing takes place also depends on the decisions of leaders.

\subsection{The Meanings of the Balance of Power}

The balance of power is one of the most familiar theories of IR, however, it remains an elusive, endlessly debated and variously defined realist concept even today. ${ }^{39}$ The fact that the "new balance of power of the Middle East" appears more and more often, not only in the scientific literature, but in the daily press in different contexts shows the renaissance of the concept in recent years. However, it must be noted that the term "balance of power" is not free from theoretical confusion. Pollard (1923:51-64) suggested that the number of uses of the phrase approaches many thousands. ${ }^{40}$ As Haas (1953:442) has already emphasized, it is

\footnotetext{
${ }^{39}$ See for instance Vasquez and Elman (2003); Paul, Wirtz, and Fortmann (2004); Sheehan (2007).

40 The original conception of balance implies two things balanced against each other, as in a pair of scales. Balance comes from the classical Latin 'bilanx' (=two-scaled) through the late Latin 'bilancia' (=a pair of scales). Mathematicians call this a simple balance, which means in international affairs two states equally balanced against each other. When three or more powers becomes involved in the balance, that is a multiple balance. Two centuries ago, the balance of power usually meant the balance of power in Europe. Today, the
} 
defined differently and used in varying senses, and it is the focal concept in several distinct theories of international relations. Wight (1968) discussed nine meanings of the balance of power concept, capturing most of the variation in usage. That is why the clarification of the verbal and applied meanings of the "balance of power" phrase is necessary at this point, since they vary in accordance with the intentions of users. Some argue that this concept holds the key to understanding modern history, while others are convinced that it never had any actual historical existence at all. Gulick (1943:14-15), for instance, states that the origin of the modern development of the balance of power coincided with the growth of the present state system. He considers the theory as having a definite historical reality but as being fallacious, because it cannot efficiently realize policy aims.

Haas (1953:444) points out that the use of both the term and the theory is not free from semantic difficulties, citing the findings of Alfred Stern (1923), according to which the term initially is used to describe an objective state of affairs, while in the next moment it implies a guide to the making of foreign policy. In one instance it means an equality of power, in the next a slight superiority. Thus, the meaning of the term is obscured by the varying intentions of writers employing it. These diverse usages have given rise to several attempts to classify both the meaning of the term and the theories behind them. Bucher (1887), for example, investigated its philological meanings, and Kaeber (1906) analyzed the content of numerous formulations of the theory, among others. Still, the precise meaning of the term is in dispute, and there is no agreement on the classification of the various meanings and their theoretical implications.

Morgenthau and Thompson (2006:125, 134-135) state that the term may carry the following meanings: (1) a policy aimed at bringing about a certain power distribution; (2) a description of any actual state of affairs in international politics; (3) an approximately equal distribution of power internationally; and (4) a term describing any distribution of political power in international relations. In this respect, the theory of balance of power acquires the significance of a universal law of history (Haas 1953:445).

On the other hand, Quincy Wright (1964:743-766) differentiates between a "static balance of power" and a "dynamic" one, arguing that a static balance is "the condition which accounts for the continued coexistence of independent governments in contact with one another", while a dynamic balance "characterizes the policies adopted by governments to maintain that condition." This means, that the static balance exists automatically, and the 
dynamic policy can be adopted only after conscious thought. Wright claims that the static sense of the definition has enjoyed a large measure of historical application, while under contemporary conditions the entire theory has ceased to applicable as a whole.

One of the more common meanings of the term "balance of power" is the mere factual description of the distribution of political power in the international scene at any one time. However, in another sense, the term can be interpreted as a theoretical principle, acting as a guide to foreign policy-making in order to avoid the preponderance of any one state. Assuming that almost all states guide their policies by this principle, a general system of balance of power can be formed. Such a system may take the form of two or more competing power blocs and it may include a balancer state. In addition to this, the term has frequently been used to describe a political equilibrium, such a distribution of power that each major state is the approximate equal of every other. On the other hand, the term is commonly used to connote the opposite of the equilibrium, and then it comes to be identical with a notion of hegemony. Others insist on the presence of the "natural law" of the balance of power, implying that the search for hegemony by one state will inevitably be met by a coalition of all other states. Also, balance of power very frequently means power politics in general (Haas 1953:446-447).

According to Schweller (2016:3-4), among the various meanings of the term "balance of power" there are:

1. the even distribution of power;

2. the principle that power ought to be evenly distributed;

3. the existing distribution of power as a synonym for the prevailing political situation;

4. the principle of equal aggrandizement of the great powers at the expense of the weak;

5. the principle that our side ought to have a preponderance of power to prevent the danger of power becoming evenly distributed;

6. the situation that exists when one state possesses the special role of the balancer and thereby maintains an even distribution of power between two rival sides;

7. and the inherent tendency of international politics to produce an even distribution of power.

\subsubsection{Distribution of Power or Equilibrium}

The simplest and most commonly found use of the term "balance of power" can be found in plain descriptive statements. In this usage, the term merely means the distribution of power, without suggesting any "balancing" of weights. It can also imply an exact equilibrium of power between two or more contending states. This interpretation takes no account of the possible existence of a similar relationship between contending groups within a state. However, Lasswell (1965) argued that the domestic political process offers a parallel 
spectacle, furthermore, he established a relationship between the domestic and international balancing process by describing connection between various societal groups in one state, working with or against certain other groups in the opposing state or in the "balancer" state (Haas 1953:447-449).

\subsubsection{Hegemony, Peace, War and Power Politics}

Some analysis leads to the meaning of balance of power equivalent to hegemony. Nicholas Spykman (1942) for instance understood the balance of power as implying a search for hegemony. He argued that all states seek a hegemonial position and therefore are in more or less continual conflict with each other. However, this can never be stable since statesmen do not seek "balance" but hegemony. As Spykman emphasizes: "The truth of the matter is that states are interested only in a balance which is in their favor. Not an equilibrium, but a generous margin in their objective. There is no real security in being just as strong as a potential enemy; there is security only in being a little stronger" (Spykman 1942:21-25). As Haas notes, in this sense, should equilibrium be reached at one point, it would be wiped out by the search for slight superiority (Haas 1953:450).

Some analysts believe that balance of power is identical with peace and stability. Francis Gould Leckie (1817:4, 242, 292, 303), for instance, recommended that feudal succession law be abolished, and Europe go in for colonization in Africa and America, thus creating a "stable balance of power." Olof Höijer (1917) also used the term in this sense, arguing that whenever the powers decided peace has to be maintained a true balance of power existed (Haas [1953] cited Höijer [1917:52-59]). It also must be mentioned that occasionally we can find writers using the term "balance of power" as being synonymous with war, intervention, competition, and instability (Haas 1953:450-451).

According to some authors the politics of power and the balance of power can be merged into one concept, that says that state survival in a competitive international world demands the use of power uninhibited by moral considerations, thus the balance of power comes to mean any power combination to stop "aggression". In this meaning the use of the term "balance of power" signifies the over-all power position of states in an international arena dominated by power politics, thus balance of power here is identical with the general process of power politics (Haas 1953:451-452). 


\subsubsection{Universal Law of Nature}

Balance of power has been traditionally treated as a law of nature, assuming that the universe is like a "gigantic mechanism, a machine or a clockwork, created and kept in motion by the divine watchmaker" (Morgenthau \& Thompson 2006:197). The idea of the balance of power arose during the Renaissance as a metaphorical concept borrowed from other fields, and wherever it was applied, balancing was interpreted as a law of nature, the basis of concepts viewed as generally appealing and socially beneficial (Vagts 1948:82-101). The original view of balancing behavior as a response driven by a law of nature still dominates most discussions of how the theory operates. As Hans Morgenthau wrote: "The aspiration for power on the part of several nations, each trying either to maintain or overthrow the status quo, leads of necessity to a configuration that is called the balance of power and to policies that aim at preserving it" (Schweller [2004] quoted Morgenthau \& Thompson [2006:163]). ${ }^{41}$

According to John Bassett Moore (1924:310), balance of power is merely a manifestation of the instinct of "self-defense", which so often manifests itself in aggression. The starting point of these interpretations is the assumed inevitable and natural struggle among states for preponderance, and the equally natural resistance to such attempts. Schuman (1941:281) argues that there is a tendency for all revisionist states to line up against the ones anxious to conserve the status quo, and Morgenthau \& Thompson (2006) similarly state that the "imperialistic" states tend to line up against those defending the status quo, producing a balance in the process. In this context, the balance of power struggle is part of the system and tends toward its preservation by avoiding the hegemony of a single member. In this kind of general dialectic of power relationships balances of power play an important role, however, no balance is permanent, actually it is subject to change in any moment. Thus, it guarantees neither peace nor law, moreover, it implies war and its own destruction whenever a former counterweight state acquires enough power to challenge the balance which it was called upon to maintain (Haas 1953:455).

\subsubsection{System or a Guiding Principle}

In contrast to the formulation of the balance of power as a universal law, where the emphasis is on the unconscious and unplanned behavior of statesman, in the formulation of the balance of power as a system of political organization and a guide to policy-making, emphasis is on the conscious and deliberate decision-making. According to Fay (1934:395-99), the balance

\footnotetext{
${ }^{41}$ Schweller also cited Waltz (2000), Layne (1997), Wolfers (1962), and Mearsheimer (2001), emphasizing that realists often invoked the same "law of nature" metaphor to explain opportunistic expansion (Schweller 2004:163).
} 
of power as a system and guide means "such a 'just equilibrium' in power among the members of the family of nations as will prevent any of them from becoming sufficiently strong to enforce its will upon the others." Gooch (1939:78) described the balance of power as "the determination, partly conscious and partly instinctive, to resist by diplomacy or arms the growth of any European state at once so formidable and so actually or potentially hostile as to threaten our liberties". 42

These definitions are in close agreement with some of the classical statements of the balance of power, interpreted as a guide to statesman on how to prevent any other actor from acquiring enough power to threaten their state in any way. David Hume also understood the balance of power in this sense, suggesting the existence of a multi-state system, dominated by competition and hostility among the members. According to him, statesman made good policy when they checked in time the growth of a state potentially able to threaten them all and made bad policy when they ignored this guiding principle, and they did not enter into alliances and coalition wars due time (Hume in: Hume \& Miller 1777:337-338). This guide merely tells statesman to prevent the growth of any state which is potentially able to threaten their own state. As Haas (1953:457) notes, there is diplomatic evidence to support this statement, since some leaders have actually made their decision to go to war on just these grounds. ${ }^{43}$

If all the states are to base their policies on the prescription of the balance of power, a "system" would come about in the sense that the least movement toward hegemony by one would immediately result in the coalition of the other states into an opposing alliance. As Haas (1953:457-458) describes the constant readiness to do just that and the necessary vigilance to prevent any one state's hegemony would in themselves produce this system of the balance of power. The earlier interpretations of the balance of power contented themselves with the so-called simple balance, while the later interpretations introduced the notion of the complex balance, where more than two states, plus satellites, were postulated. In a system as such, the necessity for preserving the freedom of all from the lust for dominance by any one was thought to involve the setting into motion of various weights and counterweights on all sides. As Haas (1953:458) mentions, this system is related to the idea of the "balancer", which was introduced into the theory by British writers during the seventeenth century.

\footnotetext{
${ }^{42}$ Haas (1953:455) quoted Fay (1934:395-99) noting that this is a particularly British understanding of the balance of power.

${ }^{43}$ Haas mentioned the policy of William III in going to war against France in 1701 as an example (1953:457).
} 


\subsection{Application of Balance of Power Terminology}

After the analysis of verbal applications of the balance of power, which has resulted in the introduction of eight distinct meanings which the term may carry, the application of the terminology must be discussed. Perhaps the use to which these meanings may be put bears even more significance than the varying interpretations themselves, since the application of the term by its proponents vary with their theoretical and practical preoccupations.

Haas (1953:459) attempted to correlate the application of various usages of the term "balance of power" with the intentions of its users and distinguished four areas of intention: (1) a purely descriptive; (2) a conscious or unconscious propagandistic; (3) an intention of using the term as an analytical concept in the development of a theory of international relations; (4) and an intention of using it as a guide to foreign policy-making. Thus, the breakdown of the "balance of power" term into eight distinct verbal meanings can be categorized into four possible applications, without inferring that among these classifications there is one which alone is of general value and applicability when it comes to the analysis of international relations. Each meaning and intention must be considered separately in terms of the given context, even though meanings and intentions may change along with the context, either in compliance with the author's intent or in defiance of his idea. It must be kept in mind that the loose terminology of the term can be easily exploited, which is why the "balance of power" had tended to become a catchall phrase to accommodate whatever policies writers wanted to endorse. Hence, some caution with respect to meanings and intentions is always necessary.

\subsubsection{As Description, Propaganda and Ideology}

When discussing international affairs journalists often resort to the term "balance of power" without any theoretical or analytical purpose. In most cases the meaning to be conveyed to the audience merely implies "distribution" of power, rather than "balance". Sometimes the descriptive use of the term implies more than a mere distribution of power, it can come to mean "equilibrium" or even "hegemony" or "preponderance" of power. As Haas (1953:460) pointed out, "when users' intentions go beyond that of mere description, clarity of thought and purpose may be seriously jeopardized". The clear definition of the term "balance of power" and its precise understanding becomes especially important when it is used for propagandistic purposes or as an ideological phrase, and according to Haas, the meanings of "balance" as being identical with either "peace" or "war" fall into this category, and sometimes the term becomes no more than merely a convenient catchword to concentrate 
individual attentions into a generally acceptable form. In these cases the balance of power is invoked in such a way as to serve as the justification for policies that actually are not related to balancing anything.

"Propaganda assumes the dishonest use of facts and the distortion of concepts devised on intellectually sincere grounds. It implies conscious and deliberate falsification. Ideology, as defined by Mannheim, however, postulates belief in a set of symbols which, even though they may be "false" objectively, still characterize the total myth system of social groups and are essential to the spiritual cohesion of a ruling group which would lose its sense of control if it were conscious of the "real" state of affairs." (Haas 1953:460)

Justi (1758:60; cited by Haas [1953:463]) in his essay criticized the balance of power, concluding that this theory is nothing, but the ideological justification adopted by statesmen eager to hide their real intentions. As a matter of fact, the distinction between the propagandistic and ideological uses of the term "balance of power" is a thin one.

\subsubsection{As an Analytical Concept}

In opposition of the propaganda-oriented application of the "balance of power" there is the analysis-oriented intention of the user, when the term employed as a tool of theoretical analysis, however in this case as well as in other field of intentions several of the verbal meanings of the term can be applied. Even as a tool of analysis the term has been used to mean "power politics", "equilibrium", "hegemony" and a "universal law" of international relations. Nevertheless, as Haas (1953:465) noted, it is in this area of intentions that the balance of power rose to the status of a theory of IR in the first place. Some found the balance of power equal to power politics or realpolitik generally since the struggle for selfpreservation in the state of nature implies the formation of alliances and mutually antagonistic blocs, and power politics are the only observable pattern in which balancing is an integral process.

Additionally, the concept of evenly balanced power or "equilibrium" has been frequently applied as a tool of analysis, arguing that any increase in coercion potential of one power will always bring corresponding increases on the part of its competitors, so a rough equality of power will always prevail. Continuing the thought further results in the application of the balance of power concept as implying the search for hegemony. Spykman (1942:22) argued that the search for power by sovereign states is an end in itself, since conflict is the only regular or systemic pattern in relations between state units, thus statesmen seek a margin of safety in superiority of power and not in mere equality of power. Therefore, the search for 
equilibrium essentially is the search for hegemony, and the balance of power as an analytical concept becomes another term for the search for preponderance of power by all actors.

However, Morgenthau \& Thompson (2006), and Schuman (1941) go beyond the characterization of equilibrium and hegemony, developing a thesis that it is inherent a multistate system based on sovereignty to engage in mutually hostile policies, and in the process of search for balanced power it is a natural choice of policy to form blocs and counter-blocs to prevent the formation of hegemony. The group of revisionist states will always line up against the group of states devoted to the maintenance of the status quo in a way that approximate balance results. This is the pattern, which attains the quality of a historical law, and its characteristic does not necessarily assume a conscious intention of the statesmen to balance power with power. Statesmen may be consciously motivated by balancing notions, however, their policies which they would most logically pursue would be consistent with the balance of power. Otherwise, they do not make logical policy and thereby go against proven and generalized modes of conduct (Haas 1953:468).

\subsubsection{As a Guide for Decision-making}

Besides the analytical application, there is an idea according to which the balance of power should be a guiding principle for decision-making on the part of statesman. According to this argument, international relations are pictured as being in the Hobbesian state of nature, where survival dictates the formation of alliances among those states committed to preserving the balance against the state allegedly seeking domination. In this sense, the balance is a conscious guide dictating the rules of survival, since in the "system" of states tied together by mutual interdependence the search for hegemony of a single member is an attack upon the whole organic unit. Basically, such a system is based on the continued independence of all members and their common will to resist the search for hegemony by any other state. Thus, the balance of power is inherent in the system itself and acts as a set of rules or a "guide" dictating the proper policies for preventing the formulation of hegemony. In this sense, the balance of power can be considered as an international institution vital to the preservation of the status quo, and as the ad hoc regulating mechanism of the system.

Based on this logic of the balance of power theory, Gentz (1806:1-8) made interesting comments on the right to intervene in the domestic affairs of other states. He argued that ideological antipathy for internal changes elsewhere did not in themselves constitute a ground for balance of power intervention, unless such changes had the necessary consequence of 
upsetting the balance of power. ${ }^{44}$ In this sense, intervention in domestic developments of other states is legal if the balance of power is really threatened by the changes in the system (Haas 1953:468-471).

\subsection{Alignment and Other Balancing Behaviors}

The question of alliance formation is also a key issue of IR. Alliances are usually viewed as a response to threats, but there is still disagreement on what that response will be. Glenn Snyder (1997:192) has even remarked that "alliances have no meaning apart from the adversary threat to which they are a response". Previous studies on alliances outlined the most important hypotheses of alliance formation and explored their policy implications, however, important questions remain open. ${ }^{45}$

The term "alliance" in its broadest sense refers to a formal or informal relationship of security cooperation between two or more states, involving mutual expectations of policy coordination on security issues under certain conditions in the future. The realist perspective dominates the theoretical literature on alliance formation (Barnett \& Levy 1991:371). There is a wide agreement that alliances' primary motivation is to enhance state security in the face of some immediate or future external threat, and that ideological and domestic interests are of secondary importance. In this sense, states form alliances mainly to enhance their capabilities through combination with others, which helps to deter a potential aggressor and avoid an unwanted war, or to prepare for a successful war if deterrence fails, or to increase one's influence in a high-threat environment or maintain a balance of power in the system (Morgenthau \& Thompson 2006:175; Liska 1962:12; Holsti, Hopmann \& Sullivan 1985:4-14; Walt 1987). ${ }^{46}$ However, this capability aggregation model of international alliances has several limitations, such as its failure to emphasize (1) the trade-offs that states make between arms and alliances in their security policies, (2) the impact of domestic economic and political

\footnotetext{
${ }^{44}$ As Sheehan (1996:271) argues, the eighteenth century has been described as 'the golden age of the balance of power', since no other period in history has seen the balance of power concept embraced so strongly by governments and broadly accepted as being the basic organizing principle of international relations. According to Sheehan, Britain was the 'balancer' of the eighteenth century European state-system, which means that Britain maintained a balance of power to prevent the emergence of a dominant power. Sheehan notes that the balancer state achieves this purpose through a flexible foreign policy characterized by support for the weaker great power against the stronger. This requires a willingness to go to war in defense of the balance if necessary.

${ }^{45}$ For instance, McGowan and Rood (1975:859-870) tested Kaplan's (1957) "theory" of the balance of power system, asking the question: "Did European alliance behavior in this [19 ${ }^{\text {th }}$ century] period conform to Kaplan's theoretical expectations of a random alliance process?" They found that their data strongly support their hypotheses and concluded that Kaplan's theory has great credibility.

${ }^{46}$ It is also worth to note, that while some alliances can increase a nation's security, it is also true that some alliances will add nothing at all to a nation's security or even reduce its security by making it more vulnerable than before (Altfeld 1984:525).
} 
factors on these trade-offs, and (3) the value of alliances as sources of military and economic resources as well as security guarantees. ${ }^{47}$ Barnett and Levy (1991:371-372) emphasize that the state generally has alternative policy instruments for dealing with external security threats, such as internal mobilization of military resources. Traditional balance of power theories have acknowledged the potential trade-off, however, little attention has been given to the question of the conditions under which a state pursues one strategy rather than the other. ${ }^{48}$

External alliance formation and internal resource mobilization each have advantages and disadvantages. Alliance formation is more flexible since an alliance can be formed quickly to provide security guarantees in response to an immediate threat and can be discarded later if necessary. In addition, it can bring a rapid infusion of funds and other resources, such as military expertise and equipment. Furthermore, the external resources can benefit either the economy as a whole or certain supporters of the regime and can be used for internal and external security purposes as well. The benefits can also include prestige if a small state aligns with a powerful one. However, alliances involve some potential costs and risks, including abandonment by an ally that fails to fulfil its commitment, entrapment in a war and loss of autonomy (McGinnis 1990:124). Although the internal mobilization of military resources avoids these risks, there are several reasons why states, especially in the Third World, might turn to alliance formation when responding to a security threat, such as lack of resources, problems with their extraction or with the access to those, decreasing political support and stability (Barnett \& Levy 1991:374-378). ${ }^{49}$

Balancing is a frequently used term in IR, but it remains an ambiguous concept. Thus, the conceptual ambiguity of the theory extends to its core concept of "balancing", which is still a precisely undefined term. Some talk about soft balancing, others have added strategic balancing and asymmetrical balancing ${ }^{50}$, while still others talk about economic and ideological balancing. According to T. V. Paul (2004), "soft balancing involves tacit balancing short of formal alliances. It occurs when states generally develop ententes or limited security understandings with one another to balance a potentially threatening state or a rising power" (Paul, Wirtz \& Fortmann 2004:2-3). Schweller (2004) offers his own definition

\footnotetext{
${ }^{47}$ On the capability aggregation model see Morgenthau \& Thompson (2006), Gulick (1982) and Walt (1987).

${ }^{48}$ According to Waltz (1979), "external" balancing through alliances is more common in multipolar systems, while "internal balancing" through arms production is more common in bipolar systems.

${ }^{49}$ Low levels of military expenditure may actually benefit the economy, and as more economic resources are devoted to the military more of the state's other goals must be sacrificed (McGinnis 1990:122).

50 "Asymmetric balancing refers to efforts by nation-states to balance and contain indirect threats posed by subnational actors such as terrorist groups that do not have the ability to challenge key states using conventional military capabilities or strategies" (Paul, Wirtz \& Fortmann 2004:3).
} 
of balancing centered on military capabilities, which some would refer to as hard balancing as opposed to soft balancing:

"Balancing means the creation or aggregation of military power through either internal mobilization or the forging of alliances to prevent or deter the occupation and domination of the state by a foreign power or coalition. The state balances to prevent the loss of territory, either one's homeland or vital interests abroad. [...] Balancing only exists when states target their military hardware at each other in preparation for a possible war. If two states are merely building arms for the purpose of independent action against third parties, we cannot say that they are engaged in balancing behavior." (Schweller 2004:166) ${ }^{51}$

Balancing and underbalancing can be broken down into four additional categories. The first is appropriate balancing, which occurs when the target is a really dangerous aggressor that cannot or should not be appeased and the state's military capabilities are indispensable to counterbalance the rising state's power. The second category is overbalancing or inappropriate balancing, which triggers an arms race because the target is mistakenly perceived as an aggressor, instead of a defensive state seeking only to enhance its security (Jervis 1976). The third is non-balancing, which can have many forms, such as buckpassing, bandwagoning, appeasement, engagement, distancing, or hiding, and which may also be underbalancing behaviors. All these policies are rational when the state is thereby able to avoid war. The fourth category is underbalancing, which occurs when the state does not balance or does so inefficiently, that it brings about a war that could have been avoided or makes the war costlier. In this sense, underbalancing is the opposite mistake of overbalancing. When the state under-balances, it either misperceives the intentions of the rising power or does not adopt proper policies to protect itself for reasons of domestic politics (Schweller 2004:167-168).

The variation in the way states respond to similar changes in their external environment turns on the preferences of relevant actors and the unique structural characteristics of society and government that constitute constraints and opportunities for these actors. The probability that a state will balance is a function of the preferences of political elites and social groups, which means that on the part of the actors there has to be "willingness" and "ability to balance". The balancing theory proposed by Schweller (2004) presents an elaborate causal chain of how policy adjustments to changes in relative power occurs. ${ }^{52}$

\footnotetext{
${ }^{51}$ Timing of a state's response is also a determining factor of whether some action can be considered as balancing or not. As Jack Levy asserted, "it would not be balancing if war is forced on the potential balancer by a direct military attack by the aggressor" (Schweller 2004:166; 1994:135; Levy in: Vasquez \& Elman 2003:135). 52 With his analytic framework, Schweller emphasizes that "statecraft is also a consequence of (1) elites' preferences and perceptions of the external environment, (2) which elites' preferences and perceptions "matter"
} 


\subsubsection{Balancing or Bandwagoning}

According to Walt (1985), when entering an alliance, states may either balance, that is ally in opposition to the source of danger, or bandwagon, in other words ally with the state that poses the major threat. ${ }^{53}$ Therefore, "if balancing is more common than bandwagoning, then states are more secure because aggressors will face combined opposition. [...] But if bandwagoning is the dominant tendency, then security is scarce because aggression is rewarded" (Walt 1985:4). Walt discussed each hypothesis and indicated how they should be revised, then concluded that states form alliances to balance against threats rather than bandwagon with them.

As the balancing hypothesis claims, states join alliances to protect themselves from states or coalitions whose growing power could pose a threat. In this sense, states risk their own survival if they do not curb a potential hegemon before it is too late, and the decision to ally with the dominant power would require deep trust in its benevolence. Simply put, it is safer to join the weaker side to avoid being dominated by those who are stronger (Gulick 1982:61-62). Furthermore, joining the vulnerable side increases the new member's influence, since the weaker side has greater need for assistance. ${ }^{54}$

Despite the evidence that history provides in support of the balancing hypothesis, the belief in the bandwagoning hypothesis - that states will tend to ally with rather than against the dominant power - is common as well. Walt (1985:7-8) found that it seems that states are attracted to strength, which means that the more powerful a state is the more likely others are to ally with it, while a decline in relative power will result one's allies to opt out from the alliance at least, or even to defect to the other side. Walt offers two possible motives to bandwagoning, which may be adopted as a form of appeasement. A state may align with the dominant power to avoid an attack on himself, or to share the spoils of victory. In the first case, bandwagoning is a defensive strategy, while in the second, it is an offensive policy choice.

in the policymaking process, (3) the domestic political risks associated with certain foreign policy choices, and (4) the variable risk-taking propensities of national elites." Then he offers four unit-level variables to explain variation in state responses to threats: elite consensus, government or regime vulnerability, social cohesion, and elite cohesion. Unlike standard balance of power theory in which states respond in a timely and systematic way to dangerous changes in relative power, Schweller proposed the following causal chain: „Changes in relative power $\rightarrow$ elite consensus about the nature of the threat and the degree of elite cohesion $\rightarrow$ mobilization hurdles as a function of regime vulnerability and social cohesion $\rightarrow$ continuity or change in foreign policy" (Schweller 2004:169-170).

${ }^{53}$ We use the terms "balancing" and "bandwagoning" as Walt (1985) and Waltz (1979) use them. Arnold Wolfers (1963) uses a similar terminology in his essay.

${ }^{54}$ As Kenneth Waltz (1979:127) put it: "Secondary states, if they are free to choose, flock to the weaker side; for it is the stronger side that threatens them." 
Since balancing is alignment with the weaker side, while bandwagoning is alignment with the stronger, they are usually composed solely in terms of power. ${ }^{55}$ For instance, Waltz's balance of power interpretation is focusing exclusively on the distribution of capabilities (Waltz 1979:102-128). According to Walt (1985), this view is flawed, because it ignores the other factors that leaders will consider when identifying potential threats and allies. He argues that power is not the only factor behind such foreign policy decisions, and it is more accurate to say that states will ally with or against the most threatening power. States may balance by allying with other strong states if a weaker power is more dangerous for other reasons. Walt also lists and describes the most important factors that must be considered in order to assess the level of threat that states may pose, such as (1) aggregate power; (2) proximity; (3) offensive capability; and (4) offensive intentions, which can produce either a balancing or a bandwagoning response. All these factors or sources of threat must be considered by statesmen when making alliance choices, since all of them are likely to play a role. ${ }^{56}$

It is worth to note that, as Walt notes:

"The desire to balance against regional threats has inspired most Middle Eastern states to align with one or the other superpower, just as the superpower rivalry itself made the Soviet Union and the United States willing to support these regional clients. In the same way, the threat from revolutionary Iran has provoked the formation of the Gulf Cooperation Council, led by Saudi Arabia." (Walt 1985:16)

The conventional realist wisdom, described by Walt, that balancing is more prevalent than bandwagoning has been challenged by several times in the last decades. Schroeder (1994:117) asserted that states have bandwagoned with or hidden from threats far more often than they have balanced against them. Schweller (1994:93) also have claimed that bandwagoning behavior is prevalent among revisionist states, because their alliance choices are driven more by the search for profit than security. ${ }^{57}$ Moreover, Powell (1999:196) finds that "balancing is relatively rare in the model. Balances of power sometimes form, but there is no general tendency toward this outcome. Nor do states generally balance against threats.... States frequently wait, bandwagon, or, much less often, balance."

Nevertheless, Walt never claimed that bandwagoning never occurs, actually, he named three conditions that may increase the generally low tendency for states to bandwagon. He

\footnotetext{
55 Alignment occurs when a state closely cooperates with another state in order to achieve mutual security goals (Duncan \& Siverson 1982:511-538).

${ }^{56}$ Discussing aggregate power, Walt asserts that the greater a state's total resources the greater a potential threat it can pose to others. That is why Walter Lippmann and George Kennan defined the goal of American grand strategy to be preventing any single state from controlling the combined resources of industrial Eurasia, and they advocated intervention on whichever side was weaker when seemed necessary (Walt 1985:8-13).

${ }^{57}$ Schweller looked at how unthreatened states respond to opportunities in their environment and found that bandwagoning is a common form of behavior, especially among dissatisfied states. (Schweller 1997:929).
} 
argued that especially weak states will be more likely to bandwagon because their vulnerability and their lack of capabilities, they are more likely to opt for the winning side (Rothstein 1963:11). Furthermore, weak states are more likely to bandwagon when allies are simply unavailable, when there is no possibility of external assistance, to align with the threatening power may be chosen as a last resort. Walt $(1985: 11,17)$ also points out that, these two factors can help explain why great powers are every now and then able to create spheres of influence. ${ }^{58}$

"Although strong neighbors will balance, small and weak states in close proximity to great power are the most likely candidates for bandwagoning. Because they will be the first victims of an attack, because potential allies may be scarce or distant, and because they lack the capabilities to stand alone or alter the balance significantly, accommodating a neighboring great power may occasionally make more sense.” (Walt 1985:18)

Waltz (2000) argues that structural theory, and the theory of balance of power that follows from it, do not lead one to expect that states will always engage in balancing behavior. Balancing is a strategy for survival. He notes, that to argue that bandwagoning represents a behavior more common to states than balancing has become a bit of a craze. According to him, whether states bandwagon more often than they balance is an interesting question, however, to draw a qualitative conclusion from a quantitative result is a mistake. Waltz (2000:38) emphasizes, that states try various strategies for survival, and balancing is one of them, while bandwagoning is another.

Thus, of the two hard-balancing instruments (arms buildups and alliance formation), the alignment of smaller states with opponents of the most powerful state is more common (Liska 1957:34-41; Hoffmann 1968:507; Claude 1962:56). Great powers form coalitions to build both their defensive and deterrent capabilities, and to dissuade hegemonic power from becoming too strong or threatening. Weaker states, in contrast, join coalitions to gain respect from members of their group. According to structural realists, balancing recurs in international politics as a lawlike phenomenon (Waltz 1979:126-128).

\subsubsection{Under-balancing}

There have been many instances in international politics when threatened countries have failed to recognize a clear and present danger or simply not reacted to it or have responded in inadequate ways. Schweller (2004:159-160) calls this behavior "underbalancing", which runs contrary to the core prediction of structural realist theory, that threatened states will balance

\footnotetext{
${ }^{58}$ A sphere of influence is created, when a threat from proximate power leads to bandwagoning, since small states bordering a great power may be so vulnerable that they choose to bandwagon rather than balance.
} 
against dangerous accumulations of power. According to Schweller, there were many examples in history of underbalancing. For instance, during the Napoleonic Wars, the American Civil War, the German hegemony over Europe in the late $19^{\text {th }}$ century or the 1930 s, when none of the great powers balanced against Nazi Germany. Instead, they bandwagoned, buck-passed, appeased, or adopted ineffective half measures in response to the growing German threat, and a similar reluctance to check unbalanced power characterized most interstate relations since 1945. As Schweller notes, a survey of state behavior during the Cold War finds new instances of balancing behavior, except the US-Soviet bipolar rivalry. Holsti (1998:106) argues that alliances are notable by their absence in most areas of the Third World, as balances of power, since the search for continental hegemony is also rare.

Schweller (2004:161-163) asserts, that since most states of the Eurocentric domain from which balance of power theory was derived and largely tested can resist its logic, the theory is certainly not akin to a law of nature, it is rather underspecified. According to him, the main question is, what are the necessary conditions for the proper operation of the balance of power? For Schweller, the main problem is realism's assumption of states as coherent actors, since when states are divided at the elite and societal levels, they are less likely to behave in accordance with the balance of power preconditions. He notes, that from the policymaker's perspective, balancing superior power and filling power vacuums hardly appear as laws of nature, these behaviors emerge through the political process as a product of debate and consensus building instead. As Spykman (1942) argues, political equilibrium is neither a gift of gods nor an inherently stable condition, it is a result of the active intervention of statesman. "States cannot afford to wait passively for the happy time when a miraculously achieved balance of power will bring peace and security. If they wish to survive, they must be willing to go to war to preserve a balance against the growing hegemonic power of the period." (Schweller [2004] quoted Spykman 1942:25)

As it has been already mentioned, the broader phenomenon of underbalancing behavior includes buck-passing, distancing, hiding, waiting, appeasement, bandwagoning, and ineffective half measures. A segment of realist literature focuses on buck-passing, which is a form of underreaction to threats by states which attempt to free ride on the balancing efforts of others. There are two basic explanations for this behavior. Some argue that great powers under multipolarity will pass the balancing buck when they perceive a defensive advantage. Others claim that buck-passing occurs primarily in balanced multipolar systems, among great powers that are geographically isolated from the threatening state. Schweller argues, instead, 
that whether states balance against threats is not primarily determined by systemic factors but rather by the domestic political process (Schweller 2004:166; Barnett \& Levy 1991:369-395).

\subsubsection{Omnibalancing}

As Steven R. David (1991) pointed out, the alignment decisions of Third World countries is not well understood, and the balance of power is particularly inadequate as an explanation of Third World alignments because it does not take into account the unique characteristics of these regions. David offers an alternative to the classical balance of power with the introduction of the theory of omnibalancing, which draws upon some of the main assumptions of the balance of power while adding some additional elements. It agrees with the key assumption of balance of power, that threats will be resisted, but considers the fact that the statesman of Third World countries need to counter all threats. Thus, omnibalancing considers internal and external threats to the leadership, providing an alternative understanding of why Third World countries align as they do and also provides some explanation for a range of Third World behavior (David 1991:233-256).

According to the balance of power theory, as it has been discussed previously, states align to protect themselves against the power of or threats from other states in order to prevent any other state or group of states from achieving preponderance, recognizing that the emergence of a hegemonic power would ultimately threaten their own survival (Walt 1987:21-26; Claude 1962:64-65). In this sense, the determinants of alignment are the external threats that states face. Waltz (1979:102-128), Morgenthau and Thompson (2006:183-193) base their balance of power theory on the capabilities of states, arguing that the greater the capability of a state, the greater the threat it poses to other states. Accordingly, internal threats are usually not considered relevant in influencing alignments in most balance of power writings, as Holsti, Hopmann and Sullivan (1985) concluded, based on their survey of the scientific literature.

David (1991:235) notes that many balance of power theorists argue that their theory holds for the states of the Third World as well, however, they base their work on the experience of states outside the Third World. Walt (1987:13-14) even asserts that his theory is supported by the experiences of states in the Middle East, although he modifies the balance of power theory to focus on threats, instead of power, from other states. According to Waltz (1979:121), Morgenthau and Thompson (2006:228) one can expect the balance of power theory to prevail whenever states seeking to survive and expand their power in an anarchic order. 
On the other hand, David (1991:235-236) argues that while the essence of balance of power theory is correct, the conditions of the Third World states require another theory of alignment that applies primarily to the Third World. He offers three repairs of the balance of power theory. David asserts that leaders of states will appease, that is align with secondary adversaries to focus their resources on primary adversaries, since the threatened leadership has no other choice than align with one threat to address the other. ${ }^{59}$ This often results in appeasing other states in order to counter the more immediate and dangerous domestic threats. Thus, Third World leaders appease the international allies of their domestic opponents. Additionally, since the main goal of Third World leaders is to stay in power, they tend to protect themselves at the expense of the interests of the state. Since many contemporary Third World states are very susceptible to coups and revolutions, the regime in power may find a close relationship with a great power very useful in obtaining the resources it needs to stay in power (McGinnis 1990:124).

As David describes the theory of omnibalancing:

"It incorporates the need of leaders to appease secondary adversaries, as well as to balance against both internal and external threats in order to survive in power. This theory rests on the assumptions that leaders are weak and illegitimate and that the stakes for domestic politics are very high - conditions that are much more common in the Third World than elsewhere. It assumes that the most powerful determinant of alignment is the drive of the Third World leaders to ensure their political and physical survival." (David 1991:236)

As David puts it, omnibalancing is framed in opposition to balance of power, however, it shares much of its realist arguments, claiming that international politics is about power, interests and rationality, and accepting that the world is characterized by international anarchy, that interests are bound to conflict, that the use of force is always an option, and that survival is the most important issue. It also assumes that the laws of politics have their roots in human nature, in this instance, emphasizing the importance of the desire of Third World leaders to survive. The main difference between balance of power and omnibalancing is that the latter asserts that internal threats must be taken into consideration in addition to focusing on external threats and capabilities, and that the leadership of the state rather than the state itself should be used as the level of analysis. ${ }^{60}$

Supporters of the balance of power maintain that the prevalence of internal threats in the Third World generally does not invalidate the theory. Waltz (1979) for instance argues

\footnotetext{
${ }^{59}$ For instance, the United States and Great Britain's alignment with the Soviet Union during World War II against Germany.

${ }^{60}$ David offers two examples for the superiority of omnibalancing for explaining Third World Alignment: Mengistu's alignment with the Soviet Union and Sadat's alignment with the United States (David 1991:236-237, 245-251).
} 
that violence and the use of force to deal with it occur as often within states as between states, which means that neither the occurrence of violence nor the use of force can be used as a standard by which to distinguish domestic from international politics. He asserts that the distinction is marked by the government's monopoly on the legitimate use of force instead (Waltz 1979:103-104, 94). On the other hand, David (1991) argues that Waltz's analysis is problematic in case of Third World alignment, as the notion of a legitimate government protecting its citizens from private acts of violence often does not apply: "for large groups of people in the Third World the government is neither legitimate nor a protector" (David 1991:251).

However, it can be argued that it does not matter whether the assumptions of balance of power are true as long as the theory based on those assumptions accurately predicts what occurs. That is, so long as balance of power theory accurately predicts the behavior of Third World states, it remains a valuable theory for the Third World. Some have also argued that although many states in the Third World do not follow the commands of balance of power when aligning, that does not mean that the balance of power theory should lose value. As Waltz (1979:94) claims, "so long as the major states are the major actors, the structure of international politics is defined in terms of them." Considering this, since the major states are not Third World states, their behavior is apparently not sufficient to invalidate theories of international politics (Waltz 1979:37-38; David 1991:251-253).

\subsection{Balance of Power: System and Order}

Claude published a book in 1962 in which he analyzed, criticized, and compared the three leading theoretical approaches to management of power: balance of power, collective security, and world government. In his book, he gave balance of power a mixed review. Later, in 1989 he published an essay re-evaluating these traditional approaches to the ordering of relationships among states. As Claude (1989) notes, advocates of balance of power often fail to distinguish between balance of power as a situation of equilibrium and as a system of states engaged in competitive manipulation of power relationships among themselves. Furthermore, theorists exhibit a disturbing ambiguity both about the result to be expected from a successfully operating balance of power system and about the means by which such a system achieves those results.

Claude argues that while it is generally agreed that a successful system preserves the integrity of the multistate system by preventing any ambitious state from becoming a 
hegemon, and maintaining stability and order, however, this not means that the maintenance of international peace is a criterion of the effectiveness of a balance of power system. On the other hand, the main goal of a balance of power system is to preserve the independence of its member states, which may sometimes require resort to war. As Claude (1989:78) puts it: "The value of peace is subordinate to that of security, and war may represent not the breakdown but the working of the system." In this regard, the relatively small wars can be described as necessary features of the balancing process or at wars as minor failures of a mechanism that concentrates on the main goal of preserving the stability of the system. This claim suggests that balance of power theory is concerned mainly with the rivalries and clashes of great powers and the massive military conflicts that threaten to destroy the entire multistate system (Claude 1989:77-78).

"Balance of power enjoys the great advantage of being a system that, in its fundamentals, relies upon what we might describe as the instinctive behavior of rational persons undertaking to manage the external relations of states enveloped in a multistate environment. It calls upon states to 'do what comes naturally' - to be wary of powerful neighbors, to check the rise of ambitious ones, to pose a countercoalition against a hostile combination, to avoid provocation by acting moderately, etc. Balance of power is the traditional system, and the fallback system, precisely because it is first of all a description of how states tend to behave; a multistate system tends to function as a tolerable anarchy because states spontaneously act to preserve themselves by controlling each other. In contrast to collective security, which calls upon states to abandon such 'natural' habits as forming alliances and discriminating between threats that have a direct and those that have a remote impact and to adopt the view that their own safety can be secured only if they give priority to world order, balance of power treats world order as a happy by-product of the urge of states to defend their own security, individually or in combination with allies." (Claude 1989:83)

So, alongside the ambiguity of the meanings of balance of power there is the question what can be expected from a successfully operating balance of power system. As Schweller (2016) asserts, the ultimate goal of balance of power is not the maintenance of international peace and stability, rather it is to preserve the integrity of the multistate system by preventing any ambitious state from becoming a hegemon, because states are not to be trusted with excessive power, which threatens all members of the system. Thus, increases in power therefore must be checked by countervailing power, by building arms (internal balancing) and forming alliances (external balancing). ${ }^{61}$ The general principle of action of the balance of power is when any state or coalition becomes or threatens to become too powerful, other states should recognize this as a threat to their security and respond by taking measures to enhance their military power. This counterbalancing process is thought to be the central

\footnotetext{
${ }^{61}$ Arms expenditures and alliance relationships are the two major security policy instruments available to states (Morgenthau \& Thompson 2006:181).
} 
operational rule of a balance of power system. However, there is disagreement how the process works in practice (Schweller 2016:4-5).

According to Claude (1962:43-51), there are three types of balance of power systems. First, there is the automatic version, which is self-regulating and spontaneously generated. Second, there is the semi-automatic version, whereby a balancer has to regulate the system. Third, there is the manually operated version, wherein statesman and diplomats carefully manage the affairs of the units in the system, which is consistent with the British School's conception. ${ }^{62}$

According to Organski and Kugler (1980:16), one important feature of the balance of power system is that it is homeostatic (ultra-stable). In maximizing their own power positions, states group themselves in the kind of balances that tend to keep the system stable. If the equilibrium is disturbed, the system favors adjustments that will return it to equilibrium. If this process cannot reallocate the power sufficiently to obtain a roughly equal distribution among the major actor in the system, then a balancer state will step in on the weaker side to redress the balance.

\subsubsection{The Conditions of a Balance of Power System}

Schweller (2016) offers nine conditions, which can be jointly sufficient to bring about an effectively performing balance of power system. These are the following:

1. at least two actors in the system;

2. cautiousness from the part of its members;

3. readiness, being fully prepared;

4. a general tendency for standing by the weaker or less threatening side;

5. having power projection capabilities;

6. war must be a legitimate tool in the system;

7. alliance formation processes must be unhindered;

8. members must pursue moderate war aims, and

9. there must be proportional compensations for all parties.

Regarding the number of actors, for a balance of power to exist, there must be at least two states that seek to survive under the anarchic conditions of the international arena, where the world lacks any supreme authority. States in a balance of power system act in ways that maximize their relative gains and avoid or minimize their relative losses. Schweller asserts that states must be watchful and sensitive to changes in the distribution of capabilities with respect to actual or potential rivals and with regard to one's allies because the state must be

\footnotetext{
${ }^{62}$ According to the English School, states consider balance as a collective good, since the role of great power comes with the responsibility to maintain the balance of power. Bull (2002:106) argues that the balance of power is a conscious goal of the system as a whole.
} 
able to recognize any deteriorating situation on either side and to take the necessary steps. As Gulick (1982) points out, states must not only be aware of any changes in the balance of power, but they must also be able to respond to them accordingly. Hence, "policy must be continually readjusted to meet changing circumstances if an equilibrium is to be preserved" (Gulick 1982:68). In addition, in a conflict states must join the less threatening side. According to Waltz (1979:127), as it has been discussed already, states flock to the weaker side, since the stronger side is what threatens them. Structural realists argue that the most powerful state will always appear threatening because the pervasive uncertainty. However, as Walt's balance of threat theory says states rather flock to what they perceive as the less threatening side, whether it is the stronger or weaker. ${ }^{63}$ It is important to note that as Schweller argues "it is not necessary that every state or even a majority of states balance against the stronger or more threatening side. Balancing behavior will work to maintain equilibrium or to restore a disrupted balance as long as the would-be hegemon is prevented from gaining preponderance [....]. What matters is that enough power is aggregated to check preponderance" (Schweller 2016:7; 1997:927-930).

Additionally, states must be able to project power through offensive military capabilities, and war must be a legitimate tool of statecraft since balancing behaviors are preparations for war (Jervis 1985:60). It must be emphasized here, that the outbreak of war does not disconfirm, but in most cases, supports the theory, as the balancing of power rests on the expectation that states will settle their differences by fighting (Lasswell 1965). Furthermore, an effectively operating balance of power system requires continuous and unhindered alliance formation, which means that states must be able to align with other states freely, on the basis of power considerations, despite of the preexisting "alliance handicaps" (Jervis 1985:60) ${ }^{64}$ For a balance of power system to operate states should pursue moderate war aims and avoid eliminating main actors, since "an equilibrium cannot perpetuate itself unless the major components of that equilibrium are preserved" (Gulick 1982:72-73). Finally, in a balance of power system, proportional aggrandizement can maintain an existing equilibrium among the great powers through the prevention of any great power from making unfair relative gains at the expense of the others (Schweller 2016:9).

According to Jervis (1985), the balance of power is characterized by a pattern, according to which, states are restrained only externally, by what others are doing, or by the

\footnotetext{
${ }^{63}$ According to Stephen Walt (1985:9), threat is a combination of aggregate power, proximity, offensive capability, and offensive intentions.

${ }^{64}$ For more on the term of alliance handicaps see Liska (1962).
} 
anticipation of what others will do if they act against the others' interests. Under the balance of power, several restraints are revealed: no state gains preponderance, wars remain limited, unconditional surrenders are rare, the territory of losing states is not divided up among the winners, and the looser is soon reintegrated into the system. As Jervis points out, these restraints emanate from the clashing self-interests of the individual member states. They are aware of the fact that today's enemy may be tomorrow's ally, thus it is not in their interest to be too harsh with the defeated state. Moreover, since each member of the winning coalition worries about the excessive growth in its partner's power, there may be competition among the allies. The results of such competitive dynamics remain restrained as states block each other's ambitions in order to maintain their own power, however, since there is no escape from international anarchy, the security dilemma ${ }^{65}$ is the main force that drives the system (Jervis 1985:59). However, international anarchy and the security dilemma make cooperation difficult among sovereign states. ${ }^{66}$

Jervis (1985) asserts that the balance of power normally maintains itself. Individual states rise and fall, but the system usually continues. But sometimes, after a major war fought to contain a potential hegemon, this continuity fails, and a concert system arises. Such wars undermine the assumptions of a balance of power system and alter the perceived payoffs in such a way that facilitate cooperation. Jervis argues that most scholars would agree that the following four assumptions are necessary to the operation of a balance of power system:

1. there must be several, at least two actors of relative equal power;

2. all states must want to survive;

3. states must be able to ally with each other;

4. war must be a legitimate instrument of statecraft.

According to Jervis (1985:60-61), concert systems form after a large war against a potential hegemon because such a conflict alters the last two assumptions and increases the incentives to cooperate.

\subsubsection{As an International Order}

According to Schweller (2016:9-10), a system exhibits order when its objects are related to one another according to some pattern, which means that their relationship is not miscellaneous but accords with some observable principle. That is, order emerges when things display a high degree of predictability, when there are patterns that follow some consistent logic, while disorder is a condition of randomness. The degree of order is partly a

\footnotetext{
${ }^{65}$ For more on the security dilemma see Herz (1950:157-180) and Wolfers (1962:83-90).

${ }^{66}$ For more on the problems of cooperation under anarchy see Jervis (1978:167-214) and Keohane (2005).
} 
function of stability, which is the property of a system that causes it to return to its original condition after it has been disturbed form a state of equilibrium. On the other hand, instability is when mild disturbances produce major disruptions that prevent the original condition form being restored. As Schweller notes, complex and delicately balanced systems tend to be unpredictable.

There are different types of international order according to the amount of order displayed; whether the order is deliberate or unintended; and the types of mechanisms that provide order. On one hand, there is purposive order. On the other hand, international order is an unintended recurrent pattern to which the system and its members exhibit conformity, however, it was not deliberately designed to serve their goals. Thus, in the latter case international order is spontaneously generated and self-regulating. As Schweller (2016) argues, the classic example of this spontaneously generated order is the balance of power, which arises though none of the states may seek equality of power, since their actions produces the unintended consequence of a balance of power. Thus, the actors are constrained by a system that is the unintended consequence of their coactions. Therefore, the operation of a balance of power system is automatic and can be predictable, if states seek power and security as they must in an anarchic order, in order to survive and thrive in a self-help realm. ${ }^{67}$

However, balance of power systems do not always function properly and predictably, since balancing can be late, uncertain or inadequate. Schweller emphasizes that balancing problems typically occur when states seek to opt out of a balance of power system but then fail to replace it with a functioning alternative. In such a case, the result is that a default, spontaneously formed balance of power system eventually emerges but is not accomplished as efficiently as it otherwise would have been (Schweller 2016:11).

\subsection{Measuring Balance, the Redistribution of Power, and Alliance Formation}

Measuring the power of states or coalitions precisely is not an easy task, especially if someone intends to do a detailed assessment. A rough but reliable comparison of alliance systems can be obtained by considering the following factors: population, gross national product, size of armed forces, and defense expenditure (Knorr 1975; Cline 1975; Baldwin

\footnotetext{
${ }^{67}$ There are three types of international orders: (1) A negotiated order is a rule-based, highly institutionalized order, ensuring that the hegemon will remain engaged in managing the order but will not exercise its power erratically (Pax Americana, and Pax Britannica in the $19^{\text {th }}$ century). (2) An imposed order is a non-voluntary order among unequal actors, intentionally designed and operated by a hegemon, whose power is unchecked (Soviet satellite system). (3) A spontaneously generated order is an automatic or self-regulating system, which is an unintended consequence of actors seeking only to maximize their power (18the century Europe). (Schweller 2016:10-11; Betts 1992.).
} 
1979). Alliance members can be categorized either by the existence of a formal security treaty or by the presence of a significant level of security cooperation between the ally and the great power in question. Then, the distribution of capabilities between these two systems can be calculated.

Balance of power primarily refers to the relative power capabilities of great powers, thus fighting power is the power to be measured. In determining what power capabilities must be included, context is very important. According to Moul (1989:103), an accurate assessment of the balance of power between those in conflict must include (1) their military capabilities, (2) their political capacity to extract and apply those capabilities, (3) the capabilities and reliability of commitments of allies and possible allies, and (4) the basic features of the political geography of the conflict. While the exact components of any particular power capability index will vary, they typically include the following measures: territorial size, total population, size of armed forces, defense expenditures, overall and per capita size of the economy (GNP), technological development (steel production, fossil fuel consumption), value of international trade, government revenue, political will and competence, combat efficiency and the like (Schweller 2016:5).

Moul (1989) examined critically some measures of power capabilities used in systematic empirical studies of great power conflict since the Congress of Vienna in 18141815. By the balance of power, Moul referred simply to the relative power capabilities of great power rivals and opponents, roughly equal or not, in the event of war between them. He defined power, as the ability of state A to do something which state B would prefer that it not do, emphasizing that power is a relationship, not a thing (Dahl 1957:201-215). Moul offered two basic and two general principles to be used to distinguish good measures of power from poorer ones. First, the context is crucial. Second, the best measure of fighting power is the direct measure of the fight itself. War sorts great powers into ordered categories of victor and defeated. Otherwise, estimates of the balance of power are just estimates. The third principle is Ockham's razor. According to Moul, an argument that one index of power capabilities is better that another is cogent if the index is simple rather than complex, that is, dependent on complicated calculations which allow errors to occur and multiply. Moul's fourth principle is that the index values should accord with judgements of historians who have examined the balance of power of specific great powers at specific times (Moul 1989:101-103). 
Moul applied these principles to Wayne Ferris's (1973) attempt to construct a measure to compare the power capabilities of all states. ${ }^{68}$ Then discussed the use of GNP as the measure of power among great powers ${ }^{69}$, and the Correlates of War composite capability index. Moul's discussion of power capabilities indices ends with a variation of the Correlates of War index considered better than the others. It is worth noting here that the indices, considered by Moul are incomplete measures of balance of power, since they do not include alliance formations, political capacity to use their power capabilities, or notable features of political geography such as location and distance. The differences in the measurement of power capabilities, and of errors made in the assessment of balance of power because essential features are not considered, could result in a mixture of findings. However, as Moul noted, much can and should be done with the inherently rough measurement of balances of power. Or, as Moul quoted Lord Keynes: "It is better to be vaguely right than to be precisely wrong" (Moul 1989:102). As Moul argues:

"Whatever the numbers on material capabilities, they should not be used as they are in order to test balance of power arguments. To be relevant to the arguments, the quantitative evaluations must be qualified. Whatever 'the balance of power' might mean, it involves alliances. Alliances, and the possibilities of alliance, can change the balance of power. Alliances also can alter, and be altered by, the political geography of great power conflict. There is no 'the balance of power'; there can be many. To repeat: context is crucial, and numerical assessments of fighting power should vary with the interstate context." (Moul 1989:115) $)^{70}$

\subsubsection{Balance of Power, Collective Security and Power Transition}

Organski and Kugler (1980) argued that accurate observations are needed on the power possessed by all nations in the system, if someone intends to explain why major wars begin at the first place. It has long been believed that the outbreak of armed conflicts is connected to changes in the power structure of the international order, that is changes in power are considered causae belli. ${ }^{71}$ Analysts and scholars are still in dispute over the question of whether estimates of an adversary's capacities are more important than information on the

\footnotetext{
${ }^{68}$ Ferris constructed an index which, in his words, 'provides scores on the capabilities of nearly all states in the system relative to nearly all other states' during the period 1850-1966. However, the context of any balance of power is ignored in his index. The failure of this index may also be the result of very complicated calculations which allow much room for statistical error. Ferris constructed his index with six variables often listed as components of power capabilities: land area, total population, government revenue, defense expenditures, value of international trade, and the size of armed forces (Ferris 1973:58; Moul 1989:103-107).

${ }^{69}$ Gross national product is the aggregate market value of goods and services produced in an economy during a specific period of time. Organski and Kugler (1980:51-53) used the GNP statistics as the single index of power capabilities, arguing that this is the best generally available measure of national power. They argue that there is no empirical advantage to be had by using the Correlates of War measure of power capabilities in place of GNP.

${ }^{70}$ Moul also notes that index values should also vary with domestic political capacity, and if a great power were in the midst of a civil war, any index value would mislead fundamentally (Moul 1989:115).

${ }^{71}$ If one state gains significantly in power, its improved position relative to that of other nations frightens them and induces them to try to reverse this gain by war (Organski \& Kugler 1980:13).
} 
intentions of its leaders. It is worth to note that neither estimates of a state's changes in power capabilities nor the bellicosity of its elites can alone account for the entire process that leads one nation to war against another.

In previous studies three models have been deployed in an effort to relate specifically different distributions of power to the outbreak of war or the preservation of peace. First, the balance of power model suggests that when power is more or less equally distributed among great powers or members of major alliances peace will ensue. In contrast, as large asymmetries become apparent in the distribution of power capabilities, the probability of war increases markedly. That is, equality of power is conducive to peace, while an imbalance of power leads to war, and the stronger party is the likely aggressor. The major mechanism through which the balance of power system is maintained is alliance formation (Organski \& Kugler 1980:13-15, 17).

The second model, called collective security, requires that all members of the system move against the aggressor. The main difference between the former and the latter systems is that while peace is largely unintended consequence of an effectively operating balance of power system, in the collective security system, peace is the direct and explicit aim of all its members, aside from the aggressor. Additionally, the collective security model assumes that alliances are the major method by which the necessary imbalance of power between aggressive and peaceful nations is to be affected. In this regard, the collective security and the balance of power models are as one (Organski \& Kugler 1980:17-18).

The third model evolved from the conception of the power transition. According to this model, an even distribution of power capabilities between contending groups of states is likely to increase the probability of war, and peace is preserved best when there is an imbalance of national capabilities between disadvantaged and advantaged nations. This model insists that the main differences in the distribution of international power are rooted in the different capacities of states to utilize their own power resources. Additionally, the model asserts that the source of war is to be found in the differences in size and rates of growth of the members of the international system (Organski \& Kugler 1980:19-20).

The balance of power and collective security models argue that changes in the system are results of alliances. The units of the system do not change, they just simply combine in different ways, and the different distributions are the result of these combinations. Thus, a state can influence the balance of power in its own favor by allying itself with other nations and by adding to its own capabilities those of its allies. Additionally, it can also arm and even fight for this purpose. However, the least costly and most certain way for a state to improve 
its power capabilities is to combine its strength with that of others. In contrast, the power transition model assumes that the major source of power for a nation is its own socioeconomic and political development. Furthermore, it is worth to note that alliances cannot form or broken up that easily. For the several states that represent the great powers of the international system, there are many possible but wildly implausible alliance combinations. Most of them are not plausible because the socioeconomic and politicoideological ties that bind nations together seem to be more important than the considerations of power advantage (Organski \& Kugler 1980:24-25).

To test the keystone proposition of the models, that the distribution of power is associated with war and peace, Organski and Kugler (1980:28-30) developed their own framework. First, they come up with readily usable measures of national capabilities. Second, they defined explicitly the way the changes in the distribution of power are to be indexed. Third, they made clear which powers represent the actors in a given system. Fourth, they had to identify which wars the measured changes in power are supposed to explain. Additionally, what the models aim to explain are major wars, so another problem was to define what constitutes a major war. Moreover, since all three models suggest that changes in the power distribution are not coded in the same way by different ruling elites, there must be an acceptable measure for showing whether the elites interpreted the changes in the power structure preceding wars as not threatening or threatening. Because a friend's power gains are not disturbing, but the newly won power of an adversary may be seen by many as a warning sign.

Organski and Kugler (1980:40-42) also developed measures of alliance behavior from an original scale built from four types of alliances: defense pacts, mutual nonaggression pacts, ententes, and no alliances at all. Clearly, formal defense pacts were considered the greatest commitment between states, while no alliance represented the least. In addition, measures of associations were used to estimate the degree of tightness within each cluster in relation to the others. They developed a simple eight-point scale, using the tightness and looseness of alliances, that reflects both degree of commitment and the direction of change in commitment.

\subsection{Power and Foreign Policy}

According to neoclassical realists, the scope and ambition of a country's foreign policy is driven by its place in the international system and specifically by its relative material power 
capabilities. ${ }^{72}$ Furthermore, they argue that the impact of such power capabilities on foreign policy is indirect and complex, because systemic pressures must be translated through intervening variables at the unit level. Neoclassical realists also argue that relative material power establishes the basic parameters of a country's foreign policy. ${ }^{73}$ However, they emphasize that there is no perfect transmission belt linking material capabilities to foreign policy behavior. As Gideon Rose (1998:146-147) puts it, foreign policy choices are made by political leaders and elites, and so it is their perceptions of relative power that really matter, not the actual quantities of resources. Thus, neoclassical realists believe, understanding the links between power and policy requires close examination of the contexts within which foreign policies are formulated and implemented.

Scholars have long debated what causes states to adopt certain kinds of foreign policies. The most common approach has been Innenpolitik theory, which argues that internal factors such as political and economic ideology, national character, and socioeconomic structure determine what foreign policy choices statesman will make. There are many variants of this Innenpolitik approach, each favoring a different domestic independent variable, but they all share the common assumption that foreign policy is best understood as the product of a country's internal dynamics (Zakaria in: Brown, Lynn-Jones \& Miller 1995; Moravcsik 1997). However, pure unit-level explanations still have difficulty accounting for why states with similar domestic systems often act differently in the foreign policy field and why different states in similar situations often act alike. Scholars have generated two theories of foreign policy, offensive and defensive realism, to avoid the problem of Innenpolitik. Offensive realism assumes that international anarchy is malevolent, security is scarce, and states try to achieve it by maximizing their relative power advantage. Thus, rational states are prone to take actions that can lead to conflict with others. According to offensive realists, a state's relative capabilities and its external environment will be easily translated into foreign policy. In contrast, defensive realists assume that international anarchy is more benign, security is plentiful, thus rational states can often afford to be relaxed, since external threats are rare. Moreover, such states usually respond to these threats by balancing against them (Rose 1998:148-149).

\footnotetext{
72 Gideon Rose (1998:146) uses the term "neoclassical realism”, emphasizing that there is no simple, straightforward classical realism. The term realism covers different authors in regard of assumptions, objectives, and methodologies. Neoclassical realism is the fourth school of foreign policy theories along with Innenpolitik, offensive realism and defensive realism.

${ }^{73}$ In Thucydides' formula: "the strong do what they can and the weak suffer what they must." (Rose [1998:146] quoted Strassler [1996:589]).
} 
However, according to neoclassical realists, Innenpolitik theories are misguided, because if there is any single, dominant factor shaping nation's foreign policies, it is their relative material power, and so this should be in the focus of foreign policy analysis. Defensive realism is misguided also, for a similar reason, because its emphasis on countries' responses to threats neglects the fact that one's perceptions of threat are partly shaped by one's relative material power. As Rose notes, by making relative power their main independent variable, the neoclassical realists are forced to choose sides in the debate about just how that concept should be defined and operationalized (Rose 1998:150-151).

It is important to note that instead of assuming that states seek security, neoclassical realists assume that states respond to the uncertainties of international anarchy by seeking to control and shape their external environment. The neoclassical realist school argues that states are likely to want more rather than less external influence and pursue such influence on the extent that they are able to do so. Thus, the central prediction of neoclassical realism is that the relative amount of material power resources of a state will shape their foreign policies, that is, as their relative power rises states will seek more influence abroad, and as it falls their actions and ambitions will be scaled back accordingly. However, neoclassical realists argue that a theory of foreign policy limited to systemic factors alone is bound to be inaccurate, which is why offensive realism is also misguided. As they say, the analysis must include how systemic pressures are translated through unit-level intervening variables such as threat perceptions and domestic state structure. Therefore, neoclassical realists argue that international reality is socially constructed and that "anarchy is what states make of it", occupying a middle ground between pure structural theorists and constructivists. Neoclassical realists assume that there is something like an objective reality of relative power, however, they do not assume that states necessarily apprehend that reality accurately on a daily basis (Rose 1998:152-153; Wendt 1992:391-425).

In the 1980s Robert Gilpin (1999:22-23, 94-95), Paul Kennedy (1989) and Michael Mandelbaum (1993) all used relative power as the ordering principle for studies of international politics over several centuries, arguing that beneath the apparent chaos of events there are substantial regularities. Later Aaron L. Friedberg (2010) and Melvyn P. Leffler (2007) traced precisely how a shift in relative power led to a shift in the foreign policy of a particular country. Leffler successfully demonstrated how changing capabilities helped to drive policymakers' perceptions of external threats, interests, and opportunities. After them, the neoclassical realists pick up where they left off. In his study of US foreign policy in the late nineteenth century, Fareed Zakaria argued (2001:3) that the behavior of building large 
armies, entangling in politics beyond borders, and seeking international influence stems from the tendency of states to use the tools at their disposal to gain control over their environment (Rose 1998:155-157).

Neoclassical realists argue that the international distribution of power can drive countries' behavior only by influencing the decisions of statesman, and all-time foreign policy analysts must explore in detail how each country's decisionmakers actually understand their situation (Jervis 1976). Leffler (2007) and Wohlforth (1993) provide a comprehensive view of the United States' and the Soviet Union's foreign policies from the beginning of the Cold War to its end, arguing that ultimately changing relative power is the driver of threat perceptions. However, as they point out, tracing the connections between power and policy is more difficult than it might seem. As Wohlforth notes, "rapid shifts in behavior may be related to perceived shifts in the distribution of power which are not captured by typical measures of capabilities" (Wohlforth 1993:294-307). Additionally, Zakaria (2001:39-40) and Christensen (1996:20-22) emphasize that gross assessments of the international distribution of power are inadequate, because national leaders may not have easy access to a country's total material power resources. Thus, Zakaria argues that because foreign policy is made by governments, what really matters is state power, instead of national power. ${ }^{74}$ In addition, Christensen offers a general model that considers both increase in power and increase in threat as factors that are able to drive active foreign policies.

It is worth noting that, as Rose (1998:161-164) pointed out, analysts wanting to understand any particular case need to do justice to the full complexity of the causal chain linking relative material power and foreign policy outputs. Realism states that systemic forces and relative material power shape state behavior. However, who cannot move beyond the system will have difficulty explaining most of what happens in international relations. Neoclassical realists favor beginning intellectually at the systemic level then trace precisely how relative power is translated and operationalized into the behavior of state actors (George in: Lauren 1979; George \& McKeown 1985). Furthermore, neoclassical realists insist that significant area expertise is critical for an accurate understanding of countries' foreign policy behavior. The theory's basic concepts can be simple and generalizable, but, as Christensen (1996:248) put it, "the application of the approach to any given country requires a great deal of knowledge about the nation in question." $" 75$

\footnotetext{
${ }^{74}$ State power is that part of national power the government can extract for its purposes (Zakaria 2001:9).

75 A research on how perceptions matter can require, for instance, foreign language capabilities and archival research, knowledge of how specific institutions operate in a given country (Christensen 1996:248).
} 
The neoclassical realist school methodologically calls for an emphasis on theoretically informed narratives that trace how relative material is translated into the behavior of decisionmakers. This approach can enlighten the behavior of countries in many regions of the world during different historical periods. However, the link between objective material power capabilities and policymakers' assessment of them remains obscure. Nevertheless, national power capabilities must be capable to have an impact on foreign policy (Rose 1998:168-169).

\subsubsection{Regional Rivalry Approach}

The topic of arms acquisitions and alignments and their connections to regional and global conflicts is too broad to tackle in its full complexity. However, there is extensive literature on specific regional conflicts and arms races. McGinnis (1990:111-135) developed a formal decision model of a simplified regional rivalry system in which two states are engaged in a long-standing competition over regional issues that could escalate to war. There are several regional powers who command significant military power within their own region, and while none of them are among the major global powers, their behavior often has great significance for international relations. Among contemporary examples are North-South Korea, IndiaPakistan, and Iran-Saudi Arabia. These regional rivalries take place within the wider context of competition among the great powers, since regional powers can dramatically increase their own security by gaining access to the arms transfers, military aid, and diplomatic and military support of one or more of them. ${ }^{76}$ On the other hand, each great power strives for better position for any global conflict by obtaining military and intelligence bases at strategic locations throughout the world and to otherwise wield influence in various regions. This sets the stage for mutually beneficial cooperation between regional and great powers (McGinnis 1990:111-112).

The fundamental premise of McGinnis' analysis is that the same realist principles that have proven useful in the analysis of Great Power behavior can also be applied to regional rivalries. As McGinnis put it, the security policy makers of regional powers choose their arms acquisitions and alignments to advance their state's security, while their actions are guided by "regime interest", that is the need to maintain sufficient domestic support to keep their power. The simplification of treating the state or its ruling regime as a unitary rational actor facilitates a comprehensive examination of the relationships among the various components of security policy. As McGinnis notes, many analysts continue to rely on the unitary rational state

\footnotetext{
${ }^{76}$ Under "great powers" we are referring to the United States, Russia, China, the United Kingdom and France due to their political and economic dominance of global affairs.
} 
assumption because it is analytically convenient, it helps focus analysis on the conflicts of interests between states that are central to all security rivalries, and it focuses attention on the tradeoffs that confront top decision makers. Additionally, he argues that the rational choice model provides an effective representation of the fundamental logic underlying the political dilemmas confronting the decision makers of regional rivals. Thus, his paper develops a rational choice model of the decision calculus of regional powers as they deal with the danger of their regional rival by exploiting the opportunities of access to the military resources of the global powers (McGinnis 1990:112-113).

A formal military alliance clearly indicates alignment, and the stationing of great power's troops at military bases in the regional power's territory is usually an important manifestation of that alignment (Harkavy 1982). Guaranteed access to strategically important resources could also reflect alignment, as could the regional power's votes in the UN General Assembly (Moon 1983; 1985). Obtaining access to a global power's military resources is presumed to be the primary rationale for regional power alignment (McGinnis 1990:118).

McGinnis analysis focuses on the security threat posed by each member of a pair of regional rivals, while all other security threats are considered exogenous to the system of regional rivalry. In his model, each regional power's perceived sense of security is simply a function of its own military capability and that of its rival. Therefore, each state feels more secure the larger its own military capability and the smaller that of its rival. Furthermore, a regional power's military capability is a function of its military expenditures, arms imports, and any diplomatic and military support it receives from its alignment partner. The precise relationship between the contributions of arms and alignments in the production of military capability is not specified by McGinnis. In this model, alignment concessions can have a direct effect on a regional power's perceived level of security, for instance, a regional power's behavior is affected by the level of confidence that its global power patron would come to its aid in any regional crisis (McGinnis 1990:119-120).

McGinnis concludes that if arms acquisitions and alignments are indeed closely related, then any statistical analysis of the military expenditures and arms imports of regional powers must also include data on their alignment behavior. However, such political variables are the most difficult to operationalize, and multiple measures would be necessary to capture the different manifestations of alignment concessions in different regions and different historical eras. As McGinnis asserts, explaining changes in behavior would be a more appropriate focus for empirical research than mere categorization of regional behavior. Analysis of the dynamics of regional rivalry would require the deduction of consequences 
more feasible to empirical verification. Additionally, it would be desirable to integrate the determinants of global power behavior into his model, rather than leaving them as exogenous sources of highly abstract arms and aid access constraints (McGinnis 1990:129-130).

\subsection{Summary}

Even today, three basic questions are at the focus of controversies about the balance of power. The most fundamental is whether the competitive behavior of states leads to some sort of international stability or equilibrium. The second is whether an equal or an unequal distribution of power among states is necessary for the existence of such an equilibrium. Finally, the third is what number of major states is optimal for the stability of the system (Wagner 1986:546).

After the end of the Cold War, many scholars have come to the conclusion that realism and the balance of power are now obsolete, as a growing body of IR literature contends that now it is just a relic of the Cold War period (Lebow 1994, Vasquez 1997). ${ }^{77}$ According to liberal critics, international politics has been changed as democracy extends further, as interdependence increases, and institutions strengthen. Thus, many are wondering if balance of power still operates in the contemporary world at the global level. Rhodes (2004) claims that today, balancing behavior makes no sense in a world without trinitarian wars and the belief that any state, if too powerful and unchecked by other states, threatens the sovereignty of all other states, since nuclear arsenals assure great powers of the ultimate invulnerability of their sovereignty.

The concept of balance of power is still one of the most influential theoretical ideas of IR, which has attracted more scholarly effort than any other single proposition about international politics. It's core meaning, that hegemonies do not form in multistate systems because perceived threats of hegemony over the system generate balancing behavior by other leading states in the system, still appears to be central to contemporary policy debates (Levy 2004). Even though the unipolar structure of the current international system is different from the multipolar world in which balancing theory emerged, many share Kenneth Waltz's view that "hegemony leads to balance..." (Waltz 1993:77). However, some argue that a systematic effort to evaluate the core balancing proposition in international systems (other than modern Europe and its global successor) is missing from the body of balance of power scholarship. In

\footnotetext{
${ }^{77}$ Many critics emphasize that evidence of a balancing coalition forming against the United States to countervail its power or threatening behavior is conspicuously absent. T. V. Paul (2005:47) argues that since the end of the Cold War, major powers such as China, France, Germany, India, and Russia have mostly abandoned traditional "hard balancing" at the systemic level.
} 
their research, Wohlforth et al. (2007) expanded the domain in which balance of power theory can be evaluated, and reported findings from eight new case studies on balancing and balancing failure in different international systems that comprise over 2000 years of international politics in the Middle East, the Mediterranean region, South and East Asia, and Central and South America. Their findings concerning both systemic outcomes and state behavior directly contradict the core hypothesis of balance of power that balancing behavior prevents systemic hegemony. They argue that this evidence undermines the widespread belief that balancing is a universal empirical law in multi-state systems and the tendency to assign explanatory precedence to the balance of power theory (Wohlforth et al. 2007:156; Vasquez \& Elman 2003).

Wohlforth et al. cannot even list all of the versions of balance of power in their article, thus, their focus is on the core or foundational proposition of the theory, which drives expectations that balancing behavior or a new balance of power should emerge in the contemporary international system. As they describe:

"This version of balance of power theory posits that because units in anarchic systems have an interest in maximizing their long-term odds on survival (security), they will check dangerous concentrations of power (hegemony) by building up their own capabilities (internal balancing), aggregating their capabilities with those of other units in alliances (external balancing), and/or adopting the successful power-generating practices of the prospective hegemon (emulation)." (Wohlforth et al. 2007:157)

This theory was derived from the case of Europe between the $17^{\text {th }}$ and $20^{\text {th }}$ centuries, but its core balancing proposition is usually stated in universal terms applicable to any anarchical system, that is, any system comprising autonomous political units with armed forces that control territories and which wish to survive. However, according to Wohlforth et al., there are three major part of social science literature which predict systemic impediments to balancing, even if one accepts the core assumptions of the balance of power:

1. The theory of collective goods predicts chronic free-riding and a consequent undersupply of external balancing via alliance formation (Olson 1971; Rosecrance 2003).

2. The new institutionalism in economics, sociology, and political science generates the expectation that increasing returns, path dependence, barriers to collective identity change, and other factors will raise the real costs and thus lower the supply of internal balancing via domestic self-strengthening reforms (North 2002; Powell \& DiMaggio 1991; March \& Olsen 1989; Schweller 2006).

3. Research of decision-making would predict pervasive uncertainty ex ante concerning the identity and severity of the hegemonic threat that would exacerbate the other system- and unit-level barriers to balancing (Gilovich, Griffin \& Kahneman 2002; Tversky, Kahneman \& Slovic 1982). 
Furthermore, the theoretical propositions discussed by Wohlforth et al. yield three countervailing expectations about great-power behavior (Wohlforth et al. 2007:159):

1. Efforts to form effective balancing alliances will frequently fail due to collective action problems.

2. Political obstacles inside states will frequently lead to failures to emulate powergenerating innovations by potential hegemons.

3. Uncertainty about which power poses the greatest threat of hegemony will frequently impede or prevent efforts to balance.

Additionally, Wohlforth et al. (2007:160-176) offer seven narratives to test the universalistic version of the balance of power theory, such as the ancient Near Eastern System (900-600 BCE), the Greek City-State System and Persia (500-330 BCE), the Eastern Mediterranean System (300-100 BCE), the ancient Indian System (500-200 BCE), the ancient Chinese System (656-221 BCE), the East Asian System (1000-1800 CE), and finally the American Systems (1300-1600 CE). Three of their findings radically revise the conventional wisdom derived from modern balance of power theory concerning anarchic great power systems. They find that systemic outcomes are inconsistent with the theory, and causal processes predicted by competing theories systematically overwhelm balancing. States did engage in internal and external balancing to try to oppose the rise of almost every hegemon, however, in almost all cases behavior predicted by the theory of collective goods and new institutional theory undermined the effectiveness of balancing. Additionally, in some cases uncertainty about which state presented the main hegemonic threat undermined balancing either independently or in conjunction with the problems of free-riding and domestic institutional rigidity. Furthermore, a major explanation for prevention of unipolarity or hegemony is not balancing but limits on the putative hegemon's ability to cumulate power (Wohlforth et al. 2007:176-178).

Many critics emphasize that evidence of a balancing coalition forming against the United States to countervail its power or threatening behavior is conspicuously absent (Lieber \& Alexander 2005). Paul (2005) argues that since the end of the Cold War, major powers such as China, France, Germany, India, and Russia have mostly abandoned traditional hard balancing at the systemic level. ${ }^{78}$ However, according to Wohlforth (2004), non-liberal states such as Russia and China are incapable of balancing US power since they cannot find allies to join them in such an effort. Other liberal states, such as France and Germany, do not perceive

\footnotetext{
78 "Hard balancing" includes countervailing alliances and arms buildups, while "soft balancing" involves the formation of limited diplomatic coalitions, diplomatic bargaining, within international institutions (Paul 2005:47).
} 
the need to counterbalance the United States because they do not consider its growing power a threat (Owen 2001, Kupchan 1998, Schweller 2004). Ikenberry $(1999,2007)$ asserts that other states have eschewed traditional balancing because of their ability to influence American foreign policy through institutions. According to economic liberals, interdependence and globalization disincline major powers from engaging in balance of power politics, because they are linked by trade, investment, and commercial flows with the United States, thus they fear that military competition with it could set back their economies (Mansfield \& Pollins 2009). In contrast, realists contend that the United States will eventually be balanced by one or more states with matching capabilities (Waltz 2000, Layne 2004). And, according to Paul, if balancing implies restraining the power and threatening behavior of the hegemonic actor, strategies other than military buildups and alliance formation should be included in balance of power theory (Paul 2005:71). 


\title{
4. FOREIGN INTERVENTIONS IN IRAQ FROM A BALANCE OF POWER PERSPECTIVE
}

\begin{abstract}
"In the final analysis, the champion of balance of power is a relaxed Realist, one whose message runs somewhat like this: You want order and stability in international relations? Well, do not worry about it too much." (Claude 1989:85)
\end{abstract}

The 2003 invasion of Iraq by the US-led coalition was based on false US and UK allegations that Baghdad was developing weapons of mass destruction (WMD) and that Saddam Hussein and his regime therefore presented a serious security threat for the international community (Borger 2004). The conflict later escalated into an "anti-occupier" insurgency (2003-2006) emerged to oppose the Western military forces and the post-invasion Iraqi government (Fisher \& Wong 2004). The United States officially withdrew from the country in 2011, but soon became re-involved in 2014 after then President Barack Obama ordered United States forces to be dispatched to the region, this time at the official invitation of the Iraqi government in response to offensives in Iraq conducted by ISIS (Arango, Schmidt 2011; Collinson 2014). On 8th of August, the United States began airstrikes against ISIS positions in Iraq (Roberts \& Ackerman 2014). Later, in coalition with the United States, nine countries have also conducted airstrikes on ISIS in the country. These airstrikes have been coordinated with ground warfare by Kurdish and Iraqi government forces against the Islamist group. The USled airstrikes escalated over the next years, resulting in massive territorial gains by the Iraqi Security Forces (ISF). This culminated in a battle at Mosul (between 16 October 2016 and 20 July 2017) in which ISIS's territorial capital in Iraq was recaptured (Arango \& Gordon 2017). By December 2017, following the final major military operation of the Iraqi Civil War with the objective of completely expelling ISIS from its last strongholds in the country, the Islamist organization had no remaining territory in Iraq. Then-Prime Minister Haydar alAbadi declared victory against ISIS while continuing operations against the group's residual presence in rural areas (Coker \& Hassan 2017).

Also, in late 2017, Abadi responded to an independence referendum held by the Kurdish Regional Government (KRG) by ordering Iraqi forces to take control of disputed territories across central and northern Iraq that were previously occupied and governed by Kurdish forces (Solomon \& Sheppard 2017). Parliamentary elections were held on 12 May 
2018, and five months later the Shiite Adil Abdul-Mahdi, former oil minister was selected as prime minister by the Kurdish Barham Salih, who was elected as president by Iraq's parliament (Salim \& El-Ghobashy 2018).

To understand Iraq's current situation, we must go back in history and take a closer look at decades of US policy in the region. In the last decades there were many interventions, sanctions, covert CIA operations and even regime change. Where else could we start than in 1958 with an Iraqi coup d'état - which is also called as the 14 July Revolution, - when the British-installed monarchy was overthrown by Abd al-Karim Qasim, a popular Iraqi army general who set about to nationalize oil, normalize relations with the Soviet Union, and implement sweeping agrarian and social reforms (Morris 2017). ${ }^{79} \mathrm{He}$ took power as Prime Minister of the newly established Iraqi Republic, until the next coup d'état of Iraq in 1963, when he was overthrown and killed in the Ramadan Revolution, also referred to as 8 February Revolution (Cockburn 1997). In the next, this time bloodless coup of Iraq (in the 1986 July 17 Revolution), the Arab Socialist Ba'ath Party rose to power, starting the period of the Ba'athist Iraq (1968-2003) which began with high economic growth and soaring prosperity, but ended with stagnation (Hirst 1968; Devlin 1991:1396-1407).

Saddam Hussein played a key role in these coups. He formally rose to power in 1979, although he had already been the de facto head of state for several years. He suppressed the Shia and Kurdish movements which sought to overthrow the government or gain independence and stayed in power during the Iran-Iraq War (1980-1988) and the Gulf War (1990-1991), until in 2003, a coalition led by the United States invaded Iraq to depose him. ${ }^{80}$ After the invasion, Saddam's Ba'ath party was disbanded, and elections were held (Morris 2003). In 2006, Saddam was convicted by an Iraqi court of crimes against humanity related to the 1982 killing of 148 Iraqi Shiite and sentenced to death (Semple 2006). He was executed on 30 December 2006 (Santora, Glanz \& Tavernise 2006).

This short summary of the last few decades of Iraq's history is by no means a thorough one, but rather an overview and a reminder of the role the US has played in the politics of Iraq and the region for over half a century. The long history of Western influence, the foreign interventions, and covert operations makes an interesting case for those students of IR who have a special interest in the Middle East. According to our already mentioned case-selection criteria, the Gulf War (Operation Desert Storm, 17 January 1991 - 28 February 1991), the

\footnotetext{
${ }^{79}$ See the original article in JPEG at https://uploads.guim.co.uk/2017/07/25/iraq1958.jpeg [Accessed 4 May, 2021].

${ }^{80}$ For more on how Hussein could stay in power see Quinlivan (1999).
} 
2003 invasion of Iraq (Operation Iraqi Freedom, 19 March 2003 - 18 December 2011), and the American-led intervention in Iraq against ISIS (15 June 2014 - present) provides us with three cases for comparative analysis from a balance of power perspective, although the latter one is still not included in any of the intervention datasets discussed earlier (for the list of US military interventions in Iraq since 1990 see Table 3.).

The United States has been involved politically and militarily in the Middle East for many decades now. Though the American public in general is against wars and overseas military commitments, in February 2020 Americans have deemed the Middle East as the most important region to US security interests. Moreover, most of them said the US military presence in the Middle East should be maintained or even increased, which is partly due to the perception of rising Iranian influence (Smeltz \& Kafura 2020). Direct American engagement in the region probably will continue in the coming decades, since the United States has a number of core interests in the region, such as preventing the rise of a regional hegemon, stopping nuclear proliferation, thwarting terrorist attacks, ensuring access to oil, and protecting regional allies. The United States wants to avoid a situation where a single state can be so strong that it can dominate the region and could not be balanced by its neighbors in the Middle East alone, which would present a wider security challenge for the international community (Al-Istrabadi \& Ganguly 2018:223-226). ${ }^{81}$ According to the 2018 National Defense Strategy the US military's objectives in the Middle East are maintaining a favorable regional balance of power, deterring aggression, denying safe haven to terrorists, preventing hostile powers from dominating the region, keeping energy markets stable and trade routes secure, defeating terrorists, and countering Iranian malign influence (Mattis 2018).

Iraq has been in focus of US national security policy since the 1979 Iranian Revolution. The overthrow of Iran's Shah Reza Pahlavi and the establishment of the Islamic Republic shifted the regional balance of power. This was the turning point, when a former US ally against the Soviet Union become a hostile state. Just one year after the Iranian Revolution, Saddam Hussein attacked Iran, and the United States supported the Iraqi armed forces during the eight years long war. By the time the war ended in 1988, Saddam Hussein and the United States have become inapt informal allies. The US has fought the Iraqi Army twice in the past thirty years, which - aside from the British Army - is one of the two armies in the world that have fought in three major conventional wars in the past four decades. ${ }^{82}$ The 1980-1988 IranIraq War, the 1991 Gulf War, and the 2003 invasion of Iraq have had serious regional

\footnotetext{
${ }^{81}$ See the importance of the access to oil and the issue of nuclear proliferation.

82 The United Kingdom fought in the 1982 Falklands War, the 1991 Gulf War, and the 2003 invasion of Iraq.
} 
consequences. For the United States, Iraq can be considered as the main battleground for regional influence against Iran. Iraq is the fifth-largest oil producer in the world, and its instability directly affects the US economy. The Islamic State emerged from Iraq, and it is also central to the competition with Russia and China in the region (Connable 2020).

This chapter proceeds as follows: the first subchapter provides a historical background with a short overview of the 1980-1988 Iran-Iraq War, then outlines the 1991 Gulf War. The second subchapter analyzes the history of the 2003 invasion of Iraq, focusing on its causes, circumstances, and consequences, with particular reference to changes in the strategic environment. Next, the third subchapter assesses the interventions against the Islamic State in Iraq (ISIS) ${ }^{83}$, summarizing the US reengagement in Iraq in the framework of the international response, the regional context of the fight against ISIS, and the remaining security challenges after the military defeat of the jihadist group. The fourth subchapter provides a summary of the theoretical implications of the 2003 invasion of Iraq and draws a lesson from the case of ISIS. The last subchapter offers an overview of the changing regional balance of power after 2003. Finally, the chapter concludes with a summary.

\footnotetext{
${ }^{83}$ The Islamic State is also referred to as ISIS, for the Islamic State of Iraq, or the Islamic State of Iraq and Syria; ISIL, for the Islamic State of Iraq and the Levant; or Daesh, which is the abbreviation of the Arabic fort both names. We refer to the group as Islamic State for the sake of simplicity, mentioning it's previous form and name when necessary.
} 
Table 3. US military interventions in Iraq since $1990^{84}$

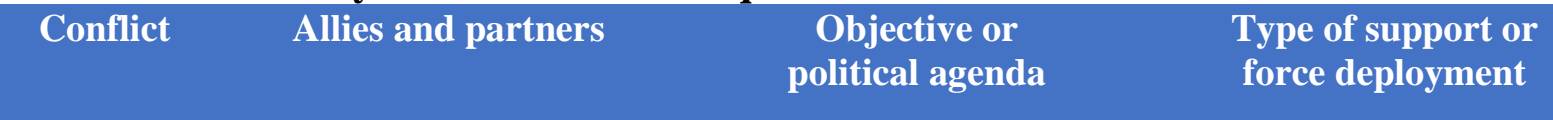

\begin{tabular}{|c|c|c|}
\hline $\begin{array}{l}\text { Gulf War } \\
\text { Aug 2, } \\
1990-\text { Feb } \\
28,1991\end{array}$ & $\begin{array}{l}\text { Coalition forces of the } \\
\text { United States, United } \\
\text { Kingdom, Saudi Arabia, } \\
\text { Egypt, and France. } \\
\text { With the authorization of } \\
\text { the United Nations Security } \\
\text { Council (Resolution 678). }\end{array}$ & $\begin{array}{l}\text { Restoration of the status } \\
\text { quo and the regional } \\
\text { balance of power after Iraq } \\
\text { invaded Kuwait. }\end{array}$ \\
\hline $\begin{array}{l}\text { Iraqi no- } \\
\text { fly zones } \\
\text { March 1, } \\
1991 \text { - } \\
\text { March 20, } \\
2003\end{array}$ & $\begin{array}{l}\text { The United States, United } \\
\text { Kingdom, and France } \\
\text { initiated the establishment } \\
\text { of the zones (Australia, } \\
\text { Belgium, the Netherlands, } \\
\text { Saudi Arabia, Turkey, and } \\
\text { Italy were supportive). }\end{array}$ & $\begin{array}{l}\text { To protect the Kurdish } \\
\text { minority in the north } \\
\text { (northern no-fly zone) and } \\
\text { the Shia Muslims in the } \\
\text { south (southern no-fly } \\
\text { zone). }\end{array}$ \\
\hline
\end{tabular}

\begin{tabular}{|c|c|c|}
\hline $\begin{array}{l}\text { Invasion of } \\
\text { Iraq } \\
\text { March 20, } \\
2003- \\
\text { May 1, } \\
2003\end{array}$ & $\begin{array}{l}\text { Coalition forces of the } \\
\text { United States, the United } \\
\text { Kingdom, Australia, } \\
\text { Poland. } \\
\text { Supported by Italy and the } \\
\text { Netherlands. }\end{array}$ & $\begin{array}{l}\text { The stated goal was "to } \\
\text { disarm Iraq of weapons of } \\
\text { mass destruction, to end } \\
\text { Saddam Hussein's support } \\
\text { for terrorism, and to free } \\
\text { the Iraqi people." The aim } \\
\text { was rather to launch a } \\
\text { process of democratization } \\
\text { and regional transformation } \\
\text { through a regime change in } \\
\text { Iraq. }\end{array}$ \\
\hline
\end{tabular}

\begin{tabular}{|c|c|c|c|}
\hline $\begin{array}{l}\text { Post- } \\
\text { invasion } \\
\text { Iraq War } \\
\text { May } 1, \\
2003- \\
\text { December } \\
18,2011\end{array}$ & $\begin{array}{l}\text { Coalition forces led by the } \\
\text { US, UK, Australia, Spain, } \\
\text { and Poland. } \\
\text { Combined Joint Task Force } \\
7 \text { (June } 2003 \text { - May 2004) } \\
\text { Multi-National Force - Iraq } \\
\text { (May } 2004 \text { - December } \\
\text { 2009) }\end{array}$ & $\begin{array}{l}\text { To contribute to the } \\
\text { maintenance of security in } \\
\text { Iraq, preventing terrorism, } \\
\text { and protecting the territory } \\
\text { of Iraq. To help the Iraqi } \\
\text { people to complete the } \\
\text { political transition, and to } \\
\text { facilitate Iraq's } \\
\text { reconstruction. }\end{array}$ & $\begin{array}{l}\text { There were more than } \\
160,000 \text { US troops in Iraq } \\
\text { in October } 2007 \text { (peak). } \\
\text { The number of British } \\
\text { forces decreased to } 4,100 \text { in } \\
\text { May 2009. Other allies and } \\
\text { coalition partners } \\
\text { contributed with additional } \\
\text { troops, in smaller numbers. }\end{array}$ \\
\hline $\begin{array}{l}\text { Fight } \\
\text { against } \\
\text { ISIL in } \\
\text { Iraq } \\
\text { (2014- } \\
\text { present) }\end{array}$ & $\begin{array}{l}\text { US-led coalition: } \\
\text { - Combined Joint Task } \\
\text { Force, Operation Inherent } \\
\text { Resolve; } \\
\text { - Global Coalition to } \\
\text { Counter the Islamic State of } \\
\text { Iraq and the Levant. }\end{array}$ & $\begin{array}{l}\text { The stated objective: to } \\
\text { "degrade, and ultimately } \\
\text { destroy ISIL through a } \\
\text { comprehensive and } \\
\text { sustained counter-terrorism } \\
\text { strategy." }\end{array}$ & $\begin{array}{l}\text { More than 4,000-4,500 US } \\
\text { troops in Iraq, } 500 \text { soldiers } \\
\text { for training, } 7,000 \\
\text { contractors. } \\
\text { Massive coalition air } \\
\text { campaign, with } 75-80 \% \text { of } \\
\text { attacks conducted by the } \\
\text { US military. }\end{array}$ \\
\hline
\end{tabular}

${ }^{84}$ Collings 2019; BBC News 1998; Associated Press 2008; BBC News 2011. 


\subsection{The Gulf War}

In the Gulf region, Iran was the most powerful state in the 1970s, partly due to its population which was approximately three times that of $\operatorname{Iraq}^{85}$, and due to its vast oil reserves. In addition, it must be noted that during this period Tehran received support from the United States. Hence Iraq could not defy Iran's regional dominance at this time, while Tehran was putting pressure on Baghdad, and used the Iraqi Kurdish minority to incite unrest against Saddam's regime. The Shah's ouster in 1979 was a fortunate development for Saddam, and he even tried to build good relations with Iran's new revolutionary leaders. However, the Supreme Leader of Iran, Ruhollah Khomeini was determined to extend his revolution across the region, and wanted to start with Iraq, using the Iraqi Kurdish and Shiite populations again to instigate a revolt against Saddam, and tried to execute even targeted assassinations. Saddam launched a limited war against Iran on September 22, 1980, with the aim to capture territories along the Iraq-Iran border, and not to remove Khomeini from power. In this sense, a weaker state tried to resist the hegemonic goals of its stronger neighbor, who wanted to change the status quo. The war lasted for eight years, and it claimed many lives. Iraq received support from foreign powers, such as the United States, Kuwait, Saudi Arabia, and France, who were determined to prevent the spread of the Islamic Revolution. As Mearsheimer and Walt assessed, considering Saddam's perspective the Iran-Iraq War was "an opportunistic response to a significant threat" (Mearsheimer \& Walt 2009).

After the Iran-Iraq War ended, Iraq's economy remained badly damaged in its aftermath, and continued to decline in the following years. Iraq's economic hardships were getting worse, as Kuwait refused to give Iraq a loan and to write off Baghdad's debts. However, Saddam believed that Iraq deserves aid because of its help in protecting Kuwait and the Gulf region from Iran's attempt to export its Islamic Revolution. Moreover, Kuwait was overproducing its OPEC quotas, decreasing oil prices, and reducing profits. Saddam tried to solve these economic challenges through diplomacy, but his efforts turned out to be futile. Around July 1990, he concluded that he would have to use force, and he approached the United States to find out what Washington's most probable reaction will be if he proceeds with his plan. It seems that the United States unintendedly gave Iraq a green light to invade Kuwait, which is what it did in early August 1990, clearly violating international law. The United State opposed the invasion and organized a military intervention to restore the status

\footnotetext{
${ }^{85}$ Iran's population changed from 28.5 million to 38.6 million, while Iraq's growth from 9.9 million to 13.6 million during the 1970s.
} 
quo and the regional balance of power. But as Mearsheimer and Walt pointed out, in this case, Saddam's decision to invade Kuwait was not irrational, and deterrence did not fail, since it was never even attempted. As they argue, Saddam chose to use force because he was facing a huge challenge and he had reasons to believe that his military action would not provoke serious opposition or retaliation (Mearsheimer \& Walt 2009).

So, two years after the Iran-Iraq War, the United States entered into a war against the Iraqi Army that it had supported before, as in August 1990, Saddam Hussein attacked Kuwait. The United States deployed more than 500,000 troops, providing the core of the coalition forces. After a month of airstrikes and a short ground invasion the Iraqi forces withdrew. It is important to note here, that the core of the Iraqi Army survived the Gulf War and retained its capability to pose a threat to American interests in the region under Saddam Hussein's rule. This partly contributed to the decision to maintain a US military presence in the Middle East (Connable 2020:4-5).

After the end of the Cold War, the liberation of Kuwait was the first major military operation by the United States, and as a result Iraq has emerged as a priority issue for US foreign policy. The overall assessment of this military intervention was positive, as it was approved by the United Nations Security Council, allowing the United States to play a decisive role in resolving a conflict with significant domestic and international support. ${ }^{86}$ However, Robert Tucker and David Hendrickson viewed the Gulf War negatively, and watched with concern the direction of US foreign policy and the development of the global role of the United States. In 1992, they published a book by courtesy of the Council on Foreign Relations, in which Tucker and Hendrickson pointed out that the easy success of the Iraq War could easily plunge the United States into "imperial temptation." In their view, after this "positive experience" it may be much easier for Washington to decide that the United States prefers to use military force over other, probably more suitable means of crisis management (Tucker \& Hendrickson 1992:15-16).

Following the defeat of 1991, Saddam Hussein's main goal was the survival of his regime. According to John Gee (2006:225), survival also meant that Saddam "had to be ready to bow to superior force", even if he had to abandon fundamental principles. As Gee notes, this meant sanctions could have been effective in disarming Iraq and ensuring that Saddam Hussein could not pose a threat to the region. But in the end, they proved ineffective for the

\footnotetext{
${ }^{86}$ The United Nations Security Council Resolution 678 gave time Iraq until 15 January 1991 to withdraw from Kuwait and empowered states to use "all necessary means" to force Iraq out of Kuwait after the deadline. This SC resolution was the legal authorization for the Gulf War, as Iraq did not withdraw by the deadline (United Nations Security Council Resolution 678, 1990).
} 
United States in terms of a desired regime change. Tucker and Hendrickson's prediction was eventually fulfilled by the neoconservatives and the Republicans (Andor, Tálas \& Valki 2004:35-36).

\subsection{The 2003 Invasion of Iraq}

The 2003 Iraq War can be seen as a continuation of the 1990-1991 Gulf War. Actually, some note that from 1991 through 2003, the United States was effectively in a low-intensity conflict with Iraq, since Washington applied economic sanctions, established two no-fly zones ${ }^{87}$, deployed additional forces to deter Iraqi aggression, and even fired missiles into Iraq (Connable 2020:4-5). The 2003 Iraq War has had wide implications, not just for the Middle East region but beyond, in world politics. The 2003 invasion of Iraq marked a major deviation from the international norms that have been governing international affairs since 1945 . This military action was the first preemptive war in a century, and it was the first war waged on the basis of intelligence reports, which later turned out to be false. Its implications are wide and raising issues that are ranging from the questions regarding the role of the United Nations, the relevance of international law, the goals of the war on terror and the concept of military intervention. After almost twenty years of the downfall of Saddam Hussein, the major longterm consequences of this foreign military invasion are visible for the stability of the Middle East, but it had implications for the study of International Relations as well (Fawn \& Hinnebusch 2006).

\subsubsection{Prelude to War}

Following the terror attacks of September 11, 2001, the Bush administration decided to embark on regime change in Iraq and used the issue of weapons of mass destruction (WMD) to justify and secure international support for the war. The most influential advocates of a war for regime change in Iraq were the neoconservatives, who came into power with the election victory of George W. Bush in 2001. After 1991, neoconservatives regularly criticized the end of the Gulf War. By the late 1990s, they were strongly suggesting that the United States return to the unresolved problem and remove Saddam Hussein from power in another war (Andor, Tálas \& Valki 2004:36). So, the Iraq War was effectively a predetermined war, which was decided relatively soon in Washington, not long after the 9/11 terror attacks.

\footnotetext{
${ }^{87}$ Until 2003, there were two no-fly zones (NFZs) over Iraq, established by the United States, United Kingdom, and France after the Gulf War of 1991. The United States said the zones were intended to protect the northern Kurdish minority (in the Northern NFZ) and the southern Shiite Muslim community (in the Southern NFZ).
} 
In an interview with Ron Suskind, Paul O'Neill, Bush's secretary of the treasury who was removed from the government in 2003, revealed that President Bush had already raised a plan to attack Iraq right at the first meeting of the newly formed National Security Council (Leung 2004; Krugman 2004). ${ }^{88}$ The Secretary of Defense, Donald Rumsfeld in February 2001 specifically recommended a "regime change" in Iraq, that would serve for the transformation of the entire Middle East, seven months before the 9/11. Later, on September 11, 2001, several members of the president's senior staff advocated military action against Iraq within hours of the terror attacks, including Rumsfeld, Deputy Secretary of Defense Paul Wolfowitz, and Vice President Dick Cheney (Woodward 2002; Clarke 2004). So, the question of invading Iraq was on the agenda in the Bush administration right after 9/11, and the final decision was surely made by 19 January 2002, the date of the President's State of the Union address (Andor, Tálas \& Valki 2004:58).

President George W. Bush later asserted that Iraq was a key front in the "war on terrorism" $"$, while critics argued that the invasion had actually turned Iraq into a terrorist heaven and just made US troops even better targets in the region (Stern 2003). The removal of Saddam Hussein was followed by a long occupation, a violent insurgency, and a challenging state building process. All of this becomes even more confusing once one takes into account that allegedly Hussein Kamil, Saddam Hussein's son-in-law after his defection in 1995 has already told Western intelligence agencies that Iraq's WMDs had been secretly destroyed earlier. However, the neoconservative political leaders in the Bush administration decided to disregard this testimony, because nothing could deter Washington from the war it had already determined upon (Kristof 2003).

\subsubsection{From Regime Change to State Collapse}

Saddam Hussein consolidated the Iraqi regime's autonomy from society after 1979 by building a set of powerful state institutions and breaking organized resistance to the Baathist rule. As a result, there was no functioning civil society under Saddam's government. However, Saddam managed to retain power not only by relying on force. The most important institutional pillars of his regime (secret police, the Republican Guard, and the administrative elite) were well paid. Furthermore, it must be noted that by the time of the Gulf War, economic investments raised Iraq's development among the best in the region. Those who were ready to cooperate with the regime were given rewards and well-paid jobs. But

\footnotetext{
${ }^{88}$ For Paul O’Neill's account see Suskind (2004).

${ }^{89}$ George W. Bush made misleading and even false statements about the Iraqi threat on several occasions, most notably on his State of the Union Address in 2003 (The Washington Post 2003).
} 
eventually, the two wars and a decade of sanctions had a devastating impact on the Iraqi state and its society (Gee 2006:225-226).

Due to the Iran-Iraq War, the Gulf War, and the sanctions (1990-2003), Saddam had to change his strategy of rule. Until 2003, the effects of the government's policies and the sanctions together led to hyperinflation and increasing poverty rates. The state welfare system collapsed, and the well-educated middle class has become impoverished. As the sanctions began to take effect in the 1990s, state institutions started to decline. The government had to cut funding for the armed forces and police, and state bureaucracy was also weakened. The state institutions that were supposed to be inherited by the invading US forces after they reached Baghdad were effectively on the verge of collapse by April 2003. Civil servants have fled, their offices were looted and burned. Thus, the subsequent state building process has been far more costly than it was anticipated before (Dodge 2006:211-212).

In the aftermath of the war, US planners anticipated an easily manageable state reform. However, the collapsed state institutions made the task of building a new and stable political order much more complex for the occupying forces. They wanted to minimize the role of former Baathists in the new government, but as Toby Dodge (2006:220) noted, the deBaathification, the dissolution of the army and the expulsion of civil service administrators markedly hindered the restoration of government services and law and order. According to Dodge, the central problem that hampered the occupation was an "acute lack of knowledge about the country". The occupying forces relied on a small group of Iraqi exiles, who they hoped would eventually become the basis of Iraq's new governing class. But this reliance was not without problems either (Dodge 2006).

In addition, economic reconstruction has been mishandled as well. The infrastructure of the country was in a poor condition already as a consequence of war and sanctions since the late 1980s. Following the US-led invasion, water supplies remained unreliable in many areas. Electricity in Baghdad was not available for more than twelve hours in a day, while most of the country had electricity supply for less than three hours. In contrast, ten months before the invasion, Baghdad had reliable electricity supply. Moreover, the inadequate electricity services caused additional problems in regard of fuel distribution because pumps stopped working due to the power outages (Gee 2006:230). ${ }^{90}$

\footnotetext{
${ }^{90}$ After the war, in October 2003, a debate erupted over whether the Pentagon had ignored the results of research conducted by the State Department under the framework of The Future of Iraq Project. The State Department predicted several problems that would arise after the war, such as the security of energy supply, the power vacuum, the deteriorating security environment, poor public security, and so on (Schmitt \& Brinkley 2003).
} 
After the Iraqi invasion, many realist thinkers condemned the war, arguing that a proper operationalization of the national interest was perverted by ideology and special interests in the decision making and policy processes. Their argument partly referred to the Powell Doctrine that said the United States should not get involved in a war unless there is a clear and present threat to US national security (LaFeber 2009). Indeed, the realist school cannot afford an adequate explanation for the 2003 invasion of Iraq, because what happened is more or less that some devoted neoconservative policymakers managed to capture US foreign policy and followed their own special interests, rather than national ones. However, it should not be surprising to anyone that decision makers tend to view the world in a way that corresponds to their interests (Hinnebusch 2007:210-211).

\subsection{Military Interventions Against the Islamic State in Iraq}

Although the US-led military intervention (preventive war) easily overthrew Saddam Hussein's government, one consequence of this regime change was the development of a nationwide insurgency. In the wake of the 2003 invasion, a power vacuum emerged which pitted the three main ethno-sectarian groups, the Sunni Arabs, Shia Arabs, and the Kurds against each other to achieve political control. Since the Sunnis lost the most in this situation, they came to form the core of the insurgency, while the majority Shia population got the dominant position in the new government. ${ }^{91}$ In addition, the Kurdish minority at last was able to play an important role in the political process and was given a chance to consolidate its effective autonomy in northern Iraq (Johnston et al. 2016:13).

One prominent figure of the insurgency was Abu Musab al-Zarqawi, whose goal was to establish a Sunni Islamic government and spread it further. ${ }^{92}$ A US air strike killed Zarqawi in 2006, but his group known as al-Qaeda in Iraq (AQI) continued to develop, and soon has evolved to the Islamic State of Iraq (ISI). ${ }^{93}$ The region and the international community had to face a "new" terrorist threat, after the AQI/ISI extended its rule to territories in Iraq and Syria,

\footnotetext{
${ }^{91}$ According to the CIA World Factbook, the ethnic groups in Iraq are as follows: Arab 75-80\%, Kurdish 1520\%, other 5\% (1987 government estimate). Religions: Muslim (official) 95-98\% (Shia 64-69\%, Sunni 29-34\%), Christian $<1 \%$. The data is available here: https://www.cia.gov/the-world-factbook/countries/iraq/\#people-andsociety.

${ }^{92}$ We can trace back the story of the Islamic State to 1999, when the Jordanian jihadist, Abu Musab al-Zarqawi (Ahmad Fadeel al-Nazal al-Khalayleh) was released from prison (The New York Times 2006).

${ }^{93}$ The original core of AQI which later became ISI came from the foreign fighters of Abu Musab al-Zarqawi's group called Jama'at al-Tawhid wal-Jihad, which was formed in Jordan in the late 1990s. During the insurgency in Iraq, the group operated under several different names. AQI was officially formed in October 2004, when Zarqawi's group aligned with the larger al-Qaeda movement (Kirdar 2011). It is important to note that the main difference between ISI and AQ is that the former one wants to realize an Islamic state right away, whereas alQaeda wants to slowly build the state up. The two groups differ from each other in other important ways as well, and they have developed differently from 2006 (Andersen 2017:17).
} 
and established affiliations throughout the Middle East. After a "forced temporary withdrawal" into a limited terrorist campaign in northern Iraq the regional events favored ISI, thus it was finally able to make a come-back, and soon developed its organization even further. ${ }^{94}$ While the United States was about to leave Iraq and fully withdraw its forces in December 2011, a civil war broke out in Syria, deepening the sectarian divisions of the Syrian population (Johnston et al. 2016). Some ISI fighters went into Syria in 2011 to fight under the alias of Jabhat al-Nusra ${ }^{95}$, but due to differences of the two group's leadership they split up. In April 2013, ISI changed its name to the Islamic State in Iraq and al-Sham (ISIS, or the Islamic State of Iraq and Syria, or the Islamic State of Iraq and the Levant), and from this point, the group were fighting on its own in Syria. ISIL managed to expand its force in Iraq, while antigovernment protests erupted in Anbar. In June 2014, as ISIL fighters were getting closer to Mosul, the Iraqi Army retreated, letting ISIL to capture the city. After this important conquest, the jihadist group renamed itself again, this time to Islamic State (IS), and proclaimed a caliphate with its leader Abu Bakr al-Baghdadi as the caliph (Bunzel 2015). ${ }^{96}$

In 2014, the Islamic State controlled about a third of Iraq's territory. In this year, prime minister Nouri al-Maliki was forced to step down and Haider al-Abadi became his successor. Since then, Abadi could declare a military victory over the Islamic State in December 2017, and parliamentary elections were held again in May 2018, leading to the transfer of power from Haider al-Abadi to Adil Abdul-Mahdi. However, in October 2019 antigovernment protests have erupted, people took to the streets to express their anger at endemic corruption, high unemployment, dire public services, and foreign interference. The social unrest has become the largest since the US-led invasion in 2003, and the heavy-handed responses by the government security forces - which killed hundreds of protesters - soon

\footnotetext{
${ }^{94}$ From 2006, the formation of the Sunni Awakening movement in Anbar province began to undercut ISI's support and later proved so effective against the jihadist group that the movement got integrated into the formal Iraq Security Forces structure as police forces. In addition, the US-led coalition eventually acknowledged that their strategy was not working, and George W. Bush decided to make some important changes. The new strategy become known as the "surge". The combination of the Awakening movement and the coalition surge operations finally proved successful in degrading ISI as the organization suffered dramatic losses between 2006 and 2008 (Johnston et al. 2016:17-23). By the summer of 2010, ISI was on the verge of total defeat, but the onset of the Syrian civil war and the actions of the Maliki government changed its fortunes. The withdrawal of the Syrian armed forces from the Sunni-majority regions on the east of the country provided more ground to the jihadist group. In addition, Maliki's government refused to pay the salaries of former Awakening fighters, thus some experienced and vengeful insurgents rather went back to ISI (Martin 2018:108; Andersen 2017:17-18).

95 After ISI decided to take part in the Syrian insurgency, Abu Bakr al-Baghdadi sent Abu Muhammad al-Julani to Syria in August 2011 to form a group there, which later became known as Jabhat al-Nusra. Within a short time, al-Nusra became one of the strongest militias among the Syrian opposition forces (Andersen 2017:19). ${ }^{96}$ The former leader of AQI/ISI, Omar Abu al-Baghdadi had been killed in 2010 and replaced by Abu Bakr alBaghdadi who had been released from an American prison in Iraq in 2009. The new leader managed to turn ISI into an insurgent army which became a serious threat to the region (Andersen 2017: 19-20).
} 
forced Mahdi to resign (BBC News 2019). In May 2020, the former director of the Iraqi National Intelligence Service, Mustafa al-Kadhimi became Iraq's new prime minister, following nearly six months of political negotiations, after two previous nominees failed to secure enough support among cabinet ministers. Kadhimi assumed office in the middle of serious upheavals in Iraq, such as continuing protests, falling oil prices, and the COVID-19 pandemic (Al Jazeera 2020). Though the positive developments raised hopes that Iraq is finally moving toward stabilization, the Iraqi state still faces many challenges (Clausen 2019). The Islamic State indeed suffered a military defeat in recent years, however, most of the underlying conditions that facilitated its rise in the first place remain the same.

\subsubsection{The Return of the United States to Iraq}

The "sudden rise" of the Islamic State in Iraq and Syria in the summer of 2014 came as a surprise for many. ${ }^{97}$ In just a matter of weeks, ISIS fighters inflicted heavy losses on the Iraqi and Syrian forces, Syrian rebel groups, the Kurdish Peshmerga ${ }^{98}$, and minority groups from Mosul to Aleppo. The international and regional responses to this regional security threat were slow initially, but as the goals and fighting capabilities of ISIS became more apparent, the United States and its allies assembled an international coalition to stop the Salafi jihadist organization. Due to their competing interests under the new geopolitical conditions, key regional actors, such as Saudi Arabia, Iran, and Turkey were even slower in developing their own strategies against ISIS (Banai 2018:151-152).

The international response to the rise of ISIS has been carried out by the US-led Global Coalition against Daesh ${ }^{99}$, which was formally established in December 2014 with the mission to "degrade, and ultimately destroy ISIS through a comprehensive and sustained counterterrorism strategy" and is composed of eighty-three partner nations (Hudson 2014). ${ }^{100}$

\footnotetext{
${ }^{97}$ Some note that there were many warning signs suggesting that a new terrorist threat could soon emerge in the Middle East, long before ISIS captured Mosul in June 2014. The political situation in Iraq and the Arab Spring in 2011 was alarming enough for many. However, the politicians, the news media and the intelligence community overlooked these developments and expressed confidence that the Iraqi government could keep everything under control (Andersen 2017:12-14).

${ }_{98}$ The Kurdish Peshmerga was an important ally of Iraqi government in the fight against the Islamic State, however, they take their orders from the Kurdistan Regional Government (KRG), not from Baghdad (Okuducu 2016).

${ }^{99}$ For more on the coalition see https://theglobalcoalition.org/en/.

${ }^{100}$ It is worth to note that since 2014 , the Iraqi government has authorized several states to undertake military action against ISIS on its territory. In 2014 Baghdad issued requests asking for assistance from the international community to help defeat the Islamic State. Intervention by invitation has been recognized as the sole valid legal basis for all foreign interventions in Iraq. According to Karine Bannelier-Christakis (2016), all these interventions against ISIS in Iraq confirm the purposed-based approach of intervention, which means that if the purpose of the intervention on request of the government does not violate the principle of self-determination, then normally such interventions is legal.
} 
The military campaign has been carried out mainly by air units and has been led by the United States through Operation Inherent Resolve (OIR). It must be noted that Russia, China, Iran, and Syria have stayed away from this coalition. Instead, they have formed parallel coalitions of their own in pursuit of their own interests in the region with their rational calculations in mind, while there are differences even within the US-led coalition, particularly in case of Saudi Arabia and Turkey (Banai 2018). Sunni-majority Arab states have seen ISIS as largely an unpleasant buffer against an aspiring regional hegemon, namely Iran, while the Iranian leadership and its Shia Arab allies in Iraq, Lebanon, Syria, and Yemen view ISIS as "bait by Sunni countries designed to weaken Iran's influence" in the Arab world (Banai 2018:159).

The United States regional interests (preventing hegemony, nuclear proliferation, terrorist attacks, protecting allies) provide a background for the most prominent regional threat, which is the rise of the Islamic State of Iraq and Syria. Though ISIS poses a significant threat only to secondary American regional interests (such as regional peace and stability and the promotion of democracy), and it suffered a military defeat in recent years, the conditions that facilitated its rise remain almost unchanged. It is also worth to note, that as Peter Krause points out, "ISIS is not simply a terrorist group", it is rather like a state, a transnational insurgency, and a revolutionary movement at once, which makes the fight against it even more complicated (Banai 2018:157; Krause 2018:223-224).

\subsubsection{The Regional Context}

According to Curtis Ryan (2015:18-23), the regional response to ISIS must be evaluated in the context of successive destabilizing events which altered the regional order, namely the 2003 invasion of Iraq, the popular uprisings of the so called Arab Spring, and the authoritarian responses to them (to map the anarchic patterns caused by these factors see how the regional FSI-scores changed in Figure 2.). The 2003 Iraq War left in its wake a broken state along sectarian and ethnic lines, beset by terrorism and external meddling by foreign actors. This environment provided a great opportunity for al-Qaeda in Iraq to transform itself to a jihadi terrorist organization pursuing the establishment of an Islamic State in Iraq under the leadership of the Jordanian Abu Musab al-Zarqawi. After Zarqawi’s death, Abu Bakr alBaghdadi took over the leadership of ISI and took advantage of the increased sectarianism in Iraq and the civil war in Syria to found ISIS. As the former US military adviser David Kilcullen put it, there would be no ISIS without the 2003 invasion of Iraq (Dearden 2016). 
Figure 2. Regional FSI-score comparison graph, 2006-2020

(Source: https://fragilestatesindex.org)

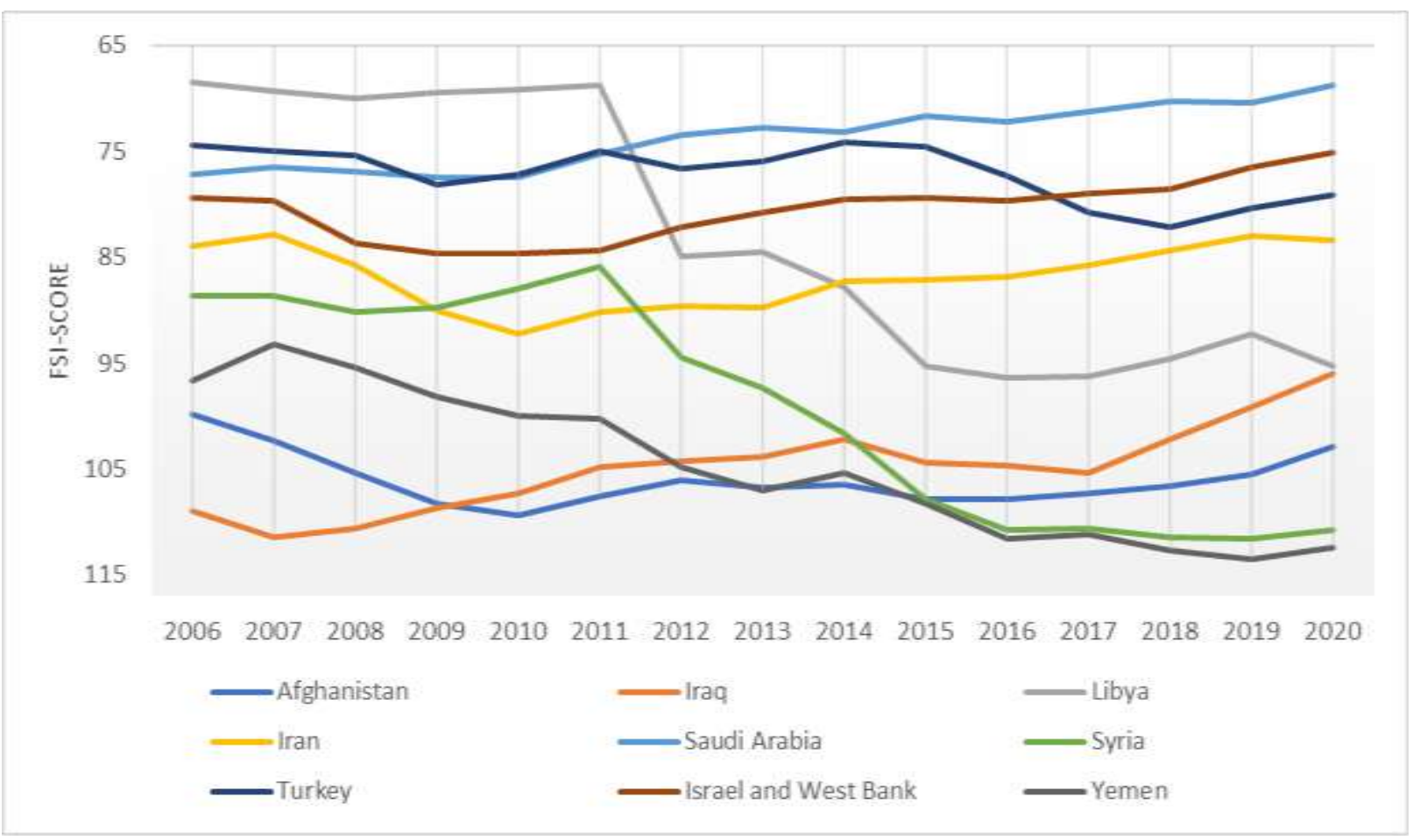

Note: increasing FSI-scores indicates worsening, while decreasing scores indicates improvement. The vertical axis has been inverted from top to bottom for easier interpretation.

Another important consequence of the invasion of Iraq was that Iran found itself in a volatile strategic environment which propelled Tehran to step up as the guardian of Shia interests in the region, and to get involved more deeply in the internal politics of Arab countries as a major regional power, as it did for instance in Bahrein, Iraq, Yemen, Syria, and Lebanon. In this context, Iran played a major role in supporting Shia political parties and militias in Iraq after the invasion. The aftermath of the 2003 invasion of Iraq provided the Islamic Revolutionary Guard Corps (IRGC) with new objectives, including the development of political, economic, and military ties with Shia parties, economic entities, and militias, mainly to the detriment of Sunni and Kurdish communities. From this aspect, Iran's response to ISIS has been consistent with its strategic objectives. As long as ISIS could not pose any serious danger to the status quo in Iraq and Syria, Iran would not risk a conflict with a jihadist terrorist organization. ${ }^{101}$ Similarly, Russia's intervention in the Syrian conflict from 2015 has been consistent with Moscow's strategic objectives in the region, one of which has been to prop up the regime of Bashar al-Assad as a bastion against the American and NATO forces

\footnotetext{
${ }^{101}$ Iran has been Baghdad's most significant regional ally in the fight against ISIS. Tehran provided financial, technical, and logistical support to the Iraqi government. From the summer of 2014, Tehran has also intervened in the conflict directly, conducting air strikes against ISIS targets and deploying infantry and armor in coordination with the Kurdish forces and the Iraqi Army (Martin 2018:105).
} 
into its sphere of influence. Thus, Russia's military campaign against ISIS has provided a good excuse to carry out its strategy under the pretense of the fight against terrorism (Banai: 2018:160-161).

However, Iran's growing influence in the region has alarmed some Sunni Arab states, especially the members of the Gulf Cooperation Council (GCC). ${ }^{102}$ From their point of view, Iran's support of Shia political parties and movements in the Arab world, and its nuclear program pose a serious threat to the regional order. Since the establishment of the Islamic Republic in 1979, the GCC countries have benefited from the Arab-dominated regional order, which has been upset in the 2000s. The aftermath of the 2003 invasion of Iraq and the wave of Arab uprisings across the region in 2010 and 2011 - which resulted in the collapse of Iraq, Syria, Yemen, and Libya -, changed the regional order and the strategic landscape tremendously. In addition, the adoption of the Iran nuclear deal (Joint Comprehensive Plan of Action, JCPOA, 2015) ${ }^{103}$ also led to increasing anxiety in Arab capitals about the potential rapprochement of the United States and Iran, since Washington and Tehran's enmity has worked to the advantage of the Arab states in recent decades. As Saudi Arabia mobilized its resources to counterweight the political change in the region and Iran's influence, the situation gradually escalated into confrontations with Iran's proxies, which can be seen particularly in Yemen and Bahrain (Darwich 2018; Friedman 2012). This is important because the inconsistent responses of Arab nations to ISIS must be evaluated considering the intense rivalry and sectarianism between Iran and Saudi Arabia. If any of the regional actors, Tehran or Riyadh would be able to exploit ISIS to diminish the regional influence of its opponent, then they would have no incentive to destroy the terrorist organization. However, since ISIS cannot be controlled, and a wildly spreading jihadist militant group could end up being a serious destabilizing factor for all the regional actors, the Arab states and Iran are also better to stay wary to avoid such a scenario. Meanwhile, for Saudi Arabia and its Sunni allies, balancing Iran's regional ambitions remain the upmost priority, which comes even more evident in light of the formation of the Saudi-led Islamic Military Alliance to Fighting

\footnotetext{
${ }^{102}$ The member states of the Gulf Cooperation Council are Saudi Arabia, Kuwait, the United Arab Emirates, Qatar, Bahrein, and Oman.

${ }^{103}$ The Iran nuclear deal was reached under former US President Barack Obama in Vienna on 14 July 2015, between Iran and China, France, Russia, the United Kingdom, the United States, Germany, and the European Union. Tehran agreed to limit its nuclear activities and allow in international inspectors in return for the lifting of economic sanctions. However, in May 2018, former US President Donald Trump unilaterally abandoned the deal and reinstated sanctions targeting Iran. Later Iran suspended commitments under the agreement and has since breached the nuclear activity beyond the limit allowed in the 2015 deal. Trump's successor, President Joe Biden has pledged to revive the deal. Negotiations to bring the United States and Iran back into the nuclear deal began in 2021 (Al Jazeera (2021b)
} 
Terrorism (IMAFT) in December 2015 (Alghafli 2018), which was established in response to the Iranian government's World Against Violence and Extremism WAVE initiative that was launched in 2013 (Trifunov 2013; Banai 2018:162-163).

We need to mention here another regional player, namely Turkey. The Syrian civil war and the rise of ISIS as a quasi-state between Syria and Iraq have created one of the worst humanitarian crises of all times, partly at the borders of the NATO-member Turkey. However, for Ankara, the most important aspect of the Syrian conflict and the fight against ISIS was the involvement of Syrian and Iraqi Kurdish fighters along its southern border. While the Kurds in Syria managed to restrain ISIS, Turkey was worried about the success of the People's Defense Forces or YPG militias and the revival of separatist aspirations in their own Kurdish community. For this reason, Ankara has used the threat of ISIS to fight against the decades-long insurgency led by the Kurdish Workers party (PKK), and has directed air strikes at PKK camps in northern Iraq, under the cover of the US-led coalition against ISIS. Furthermore, Turkey has participated in the arming and training of opposition groups such as the Free Syrian Army (FSA), and even some jihadist factions like Jabhat al-Nusra. In the light of all this, as Hussein Banai (2018:163-164) put it, it can be said that even a brief look at regional dynamics reveals complex, multi-layered, intersecting, and contradictory security and political priorities for all actors involved. Without addressing the conflicting interests of major powers in the region, ISIS may be defeated militarily, but transnational jihadist terror will not end, and ISIS's core ideology will survive. The destruction of ISIS can only come as a result of wider international commitment to end the civil wars in Syria and in Yemen, and honest efforts made to start a regional reconstruction project, that would serve as the basis for cooperation between competing states (Banai 2018).

\subsubsection{Remaining Security Challenges}

As earlier studies concluded, the rise of ISIS was rooted in the collapse of order in the wake of the 2003 Iraqi invasion and the fall of Saddam Hussein, since the overthrow of his regime left state institutions severely weakened (Dodge 2012). The de-Baathification as a strategy proved to be the wrong choice, since it effectively weakened the capacity of the Iraqi state bureaucracy, increased disenfranchisement, and mainly served as a political tool to silence political opponents, even years later (Sissons \& Al-Saiedi 2013). Nouri al-Maliki secured control of key institutions for himself following a similar logic, which resulted in divided state structures along ethno-sectarian party lines, paving the way for the rise of Islamic State 
in Iraq and the Levant in 2014. ${ }^{104}$ The use of the quota-based political power-sharing muhasasa system (introduced in Iraq after the US-led invasion in 2003), instead of transparency and a meritocratic recruitment process, has in fact become the basis of a system of nepotism and corruption. ${ }^{105}$ Which explains why the public sector remains ineffective even today.

The war in Iraq in 2003 and the disbandment of the armed forces led to the creation of a security vacuum, as no functioning state institutions remained after the collapse of the regime. Instead, there has been an increase in armed non-state actors, which in many cases have been supported by external actors, including former Baathists, Sunni Islamist groups and Shia groups as well (Dodge 2012). In addition to fighting American forces, these groups also embarked on ethno-sectarian violence led by Abu Musab al-Zarqawi and his group which joined al-Qaeda. These developments underpinned the subsequent rise of ISIS, but also point out that Iraq's current problems are not due to the strengthening of ISIS, but rather to the weakness of the Iraqi security sector and the proliferation of armed non-state actors, which has a deeper historical background (Clausen 2019:12).

Although the Islamic State no longer poses an existential threat to the Iraqi state, the jihadist terrorist organization remains capable of carrying out terrorist attacks, hence should be treated as a continuous security threat in the coming years. It is also worth to note, that as long as the brutality of IS and its ability to carry out attacks makes it a relevant concern in Iraq, the broader challenge remains the Iraqi Security Forces' lack of monopoly of violence. In this regard, the influence, and capabilities of the Popular Mobilization Forces or PMFs which consist of a coalition of militias, including more than fifty groups that mobilized after Grand Ayatollah Ali as-Sistani issued a fatwa in June 2014 calling Iraqis to join to the fight against ISIS -, pose a huge challenge for the Iraqi state (Clausen 2019:13-14). ${ }^{106}$

It must be noted, that the PMFs are dominated by Shia groups, which can be divided into three main factions based on their allegiances to Ayatollah Ali Khamenei, Ayatollah Ali

\footnotetext{
${ }^{104}$ Some noted that many of ISIS's most stunning military successes in Iraq can be attributed to Maliki's efforts to consolidate his influence over the armed forces. He replaced the competent professionals with often inexperienced and corrupt loyalists, who were prone to abandon their soldiers upon the first threat of an attack (Moubayed 2015:113-114; Andersen 2017:18-19).

105 The muhasasa system is a power-sharing system between the three main ethno-sectarian groups in Iraq, the Shias, the Sunnis, and the Kurds. Though it was introduced in Iraq after the US-led invasion in 2003 in attempt to provide proportional government representation among the ethno-sectarian groups, many Iraqis believe the system is deeply flawed and must be overhauled (Ibrahim 2019).

106 The Iraqi government established the Popular Mobilization Forces (al-Hashd al-Shaabi) in June 2014, which served as an umbrella organization of various militias. The PMF officially report to the Iraqi prime minister. But many asserted that they actually have been taking orders from Tehran via Qasem Soleimani, the commander of the Iranian Revolutionary Guard Corps, until he was killed in a US drone strike at the Baghdad International Airport in January 2020 (Weiss \& Hassan 2016:240).
} 
al-Sistani and Muqtada al-Sadr (Mansour \& Jabar 2017). Albeit the PMFs contributed significantly to the fight against ISIS, their continuous presence is a consequence and a reminder of the Iraqi state failure. This led to a situation where the PMFs with ties to Tehran are the strongest, and where Iran is gradually becoming the most influential foreign actor in Iraq (Clausen 2019:14; Mansour \& Jabar 2017:13; Litvak, Landau \& Kam 2018:46). ${ }^{107}$ This is particularly important because, as Maria-Louise Clausen (2019) notes, PMFs in Iraq are security and political actors at the same time, with substantial influence. While they are formally subject to government control, in fact they are more like a weakening factor for the Iraqi state (Connable 2020:23; Malik 2017). However, it is very difficult to challenge these PMFs because they provide livelihoods to many poor and marginalized people. As Clausen (2019) concludes, the fragmentation and politicization of the security sector will continue to pose a huge challenge to Iraq's future stabilization. The Islamic State continues to be able to carry out attacks, while the PMFs remain only formally controlled by Baghdad, hence they can maintain their independence and keep increasing their political influence (Clausen 2019:15-16; 33-34). As Johnston et al. (2016:7) pointed out, the Islamic State is one of the major current threats to regional stability in the Middle East, and its story is a good example of how militant organizations can exploit disorder within one state to advance territorial goals. ISIS can be considered the product of Iraq's historical experiences, since decades long authoritarian rule, sectarian conflicts, militarism, war, and foreign interventions produced the environment that favored the emergence of ISIS's precursors and its rapid rise (Martin 2018).

The catalyst of the initial rise of al-Qaeda in Iraq and its evolvement into ISIS was the ramping up of the insurgency in Iraq (between 2004 and 2006), and the outbreak and further escalation of the Syrian civil war (between 2011 and 2014). According to Krause, polarization and violence helped the most to create new political grievances against the government and open a vacuum for ISIS to fill with its own governance. Thus, the United States and its allies must work to end regional civil wars of which many have become proxy wars as part of a new Arab Cold War, to lessen the polarization and the sectarianism that feeds ISIS (Ryan 2012). Furthermore, to ensure that the Islamic State will not rise again, the regional powers need to improve their governance (Krause 2018:236-240). The key regional players must also work together to establish realistic spheres of influence in the region and a power-sharing agreement. As Krause (2018:241) put it, "the sobering costs of endless proxy wars that go nowhere and help strengthen a common threat like ISIS should help [...] move toward a more

\footnotetext{
107 The commanders of the three largest militias, 'Asa'ib Ahl al-Haq, the Badr organization, and Kata'ib Hizbullah are considered Iranian proxies in Iraqi politics (Mansour \& Jabar 2017:12-15).
} 
stable regional order". Similarly, Hussein Banai (2018:157) noted that "as a symptom of state collapse, rising sectarianism, political opportunism of adjacent countries, and trenchant regional rivalries, ISIS's destruction will ultimately require a comprehensive political strategy that credibly mitigates the security dilemma created by these underlying factors." Because the US-led international response to ISIS was deficient, which becomes apparent when "one considers the regional dynamics that continually undermine efforts to destroy the organization" (Banai 2018:157).

According to Kevin Martin (2018), the United States and its allies have failed to achieve a number of policy objectives, including the preservation and enhancement of Western influence in the region, and the shaping of Turkey's behavior. As a result, Iran could exploit the instability to transform itself into a more influential regional power, while Russia's military intervention on behalf of the Assad regime has altered the calculus of regional players. As Martin concludes, the Iranian-allied regimes in Damascus and Baghdad will remain, Kurdish aspirations for autonomy in northern Syria will be thwarted, and Western influence in the Middle East region will be diminished further. Meanwhile, the Islamic State will almost certainly preserve its operational capacity to carry out terrorist attacks (Martin 2018:109).

Lars Erslev Andersen (2017) concluded that the way in which the so called "war against terrorism" has been organized and conducted in the Middle East partly explains what keeps al-Qaeda and Islamic State going. Andersen compares the fight against these terrorist groups to a 'Whack-A-Mole' game, where moles just keep popping up while the player tries to hit as many as possible, pointing out that in this game you cannot really win. This "game" is accompanied by the power struggle between the regional actors, and particularly the SunniShia conflict orchestrated by Saudi Arabia and Iran, which is tearing the region apart. The war against al-Qaeda, the Taliban, Saddam Hussein, and Muammar Gaddafi has fueled the Middle Eastern conflict. What started as a bombing of al-Qaeda's training camps in Afghanistan continued later with other armed conflicts in Iraq, Libya, Syria, and Yemen. Furthermore, the Islamic State has spread further in the region, and even beyond (Andersen 2017).

\subsection{Theoretical and Practical Implications}

As the 2003 invasion of Iraq had significant impacts on regional geopolitical developments, world politics, and the field of International Relations, it is necessary to address here some of the theoretical implications. Based on earlier studies, the following subchapters offer an overview of the revision of the hegemonic stability theory (HST), the concept of preventive 
war and deterrence, intervention, the balance of power theory and the issue of growing uncertainty.

\subsubsection{The Hegemonic Stability Theory and the Iraq War}

As Raymond Hinnebusch (2006:283) noted, borrowing an expression first used by Michael Hudson (1996), the Iraq War was mainly about the United States "playing the world hegemon", and in its aftermath America's global role had to be reconsidered. According to realists like Gilpin (1999), the anarchic world system was vulnerable to disorder, thus there must be a hegemon who can provide security with its predominant military power and economic resources and has legitimacy as well. This is the basic principle of the hegemonic stability theory, which began as an explanation for the maintenance of free trade, and eventually become a fundamental theoretical question of world politics. However, states can accept the existence of such a hegemon only as long as it defends a world order that the others benefit from more than the hegemon itself. As Hinnebusch (2006:283-284) highlighted, the Iraq War exposed all the weaknesses of the hegemonic stability theory, which fails to take into account that a hegemon can be a source of global disorder as well.

According to the liberal version of HST, hegemony is benign by nature, hence liberal thinkers see the US hegemon as benign as well, based on post-World War II experience, when the United States provided security, ensured free trade and liquidity, exported investments, and kept open its markets (Kindleberger 1981:247). However, this liberal approach of HST has not remained without criticism. The idea of a benign hegemon goes against the core concepts of the realist school, which would rather expect that large asymmetries of power will lead to similarly large maldistributions of the benefits. In addition, classical realism sees a balance of power as the key to avoiding the domination of a hegemon, which can lead to war because of the concentration of power. Many critics argued that the liberal approach of HST is too generalized and gave an overly benign interpretation to a particular episode of American leadership in world history. ${ }^{108}$ However, the realist versions of HST always acknowledged that the hegemon follows its own interests. According to Organski (1958), the hegemonic order excludes states just as well as it includes some of them, which means that there will be always dissatisfied states with little benefits from the newly formed order, particularly states of the third world. Organski argues that a number two power eventually will challenge the hegemon for control of the international system by getting together the deprived periphery states. As Hinnebusch (2006:285) notes, maybe a benign hegemony is

\footnotetext{
${ }^{108}$ For critiques of the liberal HST see for instance Grunberg (1990), Strange (1988), Calleo (1987).
} 
only viable if there is a sufficient balance of power to constrain the hegemon, similarly to the situation under the bipolar world order. In contrast, in an "unipolar moment" when the United States feels free to act on its own as it sees fit, there is little to prevent it from becoming a predatory world power.

Another problem of the realist approach of hegemonic stability is its insistence that a hegemon is needed for international cooperation, however, liberal thinkers have demonstrated that complex interdependence will result in growing cooperation among states in order to reap absolute gains (Keohane 2005). The realist version of HST exaggerates the need for a hegemon to facilitate cooperation and even ignores the possibility that it may even obstruct cooperation rather than help it. So, all things considered, the central claims of the hegemonic stability theory that hegemony is both benign and necessary in the international system seems to be overstated at least. As Hinnebusch (2006:287) put it, the US hegemon has turned malign, and the 2003 invasion of Iraq signaled a turn toward a "coercive empire in place of hegemonic leadership by consent."

The Iraq War exposed the weaknesses of both the liberal (benign hegemon) and the realist (which sees the hegemon as a unitary rational actor) approaches of hegemonic stability theory. According to Ikenberry (2001), US hegemony is benign because US power is not threatening, it plays the role of an "off-shore balancer", it is predictable and self-restraining, and it is constrained by mutually agreed rules since its power is exercised through multinational institutions. However, as Hinnebusch noted, considering the experience of the Iraq War, predictability, self-restraint, and multilateralism no longer hold, because the United States has become a partisan actor in the Middle East region, rather than a balancer, which even seeks indirect territorial control. In contrast, the coercive hegemony of the United States has made the Middle East more unstable, put global energy security at risk and increased terrorism (Hinnebusch 2006:305-306; 2007:213).

The case of the Iraq War suggests that for a hegemon to be benign, there must be a challenger state that could check the power of the hegemon (Organski 1958), and the foreign policy of the hegemon cannot serve narrow political interests (Hinnebusch 2006:306). Under unipolarity, the problem of hegemony is that excessive power may make it malign. ${ }^{109}$ According to Kenneth Waltz (2000), hegemons eventually overextend themselves, and their misuse of power provokes a balancing against them, while Birthe Hansen (2001) sees flocking (bandwagoning) and free-riding with the hegemon as the natural behavior under

\footnotetext{
${ }^{109}$ As Kennetz Waltz notes, "unbalanced power is a threat, no matter who wields it" (Hinnebusch [2006:306] quoted Waltz [2000]).
} 
unipolarity. From a balance of power perspective, in the aftermath of the Iraq War, weak states in the region could not afford to balance against the Gulf states, Jordan or Egypt, thus they accommodated themselves to the invasion, except Syria which opposed it.

As Hinnebusch argues, the Gulf War was merely a piece of a US policy that had locked the world hegemon into a pattern of repeated interventions in the Middle East that tended to further inflame regional hostility. He also listed several cases where a US action was followed by a strategic blowback ${ }^{110}$, starting with the US Central Intelligence Agency overthrow of Iran's Mossadeq government in 1953 which ultimately led to Khomeini's Islamic revolution in 1979, and noting that then Saddam Hussein was built up by the United States and the West to counter Iran. According to Hinnebusch, the most unexpected blowback was 9/11, since al-Qaeda, which was initially sponsored by the United States against the threat of the Soviet Union in Afghanistan, was turned against its US patron because of US policies followed by the Gulf War: a large military presence in Saudi Arabia, a continued intervention in Iraq and sanctions, and the double standards which the United States applied to defend Israel in the United Nations (Hinnebusch 2006:290). Hinnebusch (2006:290) quoted Slavoj Zizek (2009), who said that "it is as if some invisible hand of destiny repeatedly ensures that US intervention only makes more likely the outcomes the United States sought most to avoid."

As an unintended consequence, in the post-Saddam Iraq anti-US sentiment increased and the country become more open to Iranian influence. In addition, Iraq become a new generator of terrorism in just a few years, rather than making Americans more secure. Robert Jervis (2003b) warned that while the United States has the military power to overthrow weak regimes, the post-intervention phase is likely to prove costly and can result in continuing intervention.

\subsubsection{Preventive War and Deterrence}

Many analysts argue that the George W. Bush administration's foreign policy towards the Middle East and the Iraq War marked a qualitative escalation in the character of US foreign policy, as the government saw the region as the main threat to US global hegemony and reserved its right to preventive war, which was the key to the hegemonic project (Hinnebusch 2006:291). In this regard, the 2003 invasion of Iraq can be seen as the manifestation of the Bush Doctrine, according to which a state's domestic regime determines its foreign policy;

\footnotetext{
110 "Blowback" is a CIA term first used in March 1954 in a declassified report on the 1953 operation to overthrow the government of Mohammed Mossadegh in Iran. The term is used to describe the unintended consequence and unwanted side-effects of a covert operation (Johnson 2001).
} 
the opportunity has finally come to transform international politics; great threats can be defeated only by preventive war; the state should act unilaterally if it is necessary; and peace and stability require the United States to assert its primacy (Jervis 2003b). So, the 9/11 terror attacks provided an opportunity for the Bush administration to mobilize forces for a "war on terrorism" that could help realize the hegemonic project, while the issue of the WMDs were raised merely because the government believed this would help to get the most support for its plan (Usborne 2013). Energy security considerations (oil supplies, oil prices) provide another alternative explanation for the question why Iraq was targeted (Duffield 2012:291-298).

Simply put, the Iraq War was supposed to be the test case of the concept of preventive war and the neoconservatives' theory that superior military power can be translated into regional hegemony, but the intelligence failures and the manipulation of public opinion undermined the credibility of the doctrine of preemption right from the beginning. ${ }^{111}$ In addition, believing that the military force against Saddam Hussein would be welcomed by "democracy-craving" Iraqis also turned out to be false, and was never likely actually (Trofimov \& King 2003).

The invasion of Iraq was one of the most controversial American foreign policy decisions of the last few decades. Since Iraq posed little threat to the United States - which was already known even before the war -, even mainstream theories of International Relations proved inadequate in providing explanations for the war (Hinnebusch 2007:209). The Bush administration was convinced that Saddam Hussein cannot be deterred, thus preventive war is justified against his regime. In contrast, some defensive realists like Stephen Walt, and even offensive realists like John Mearsheimer argued that Saddam is deterrable, and that the United States can contain Iraq effectively even if Saddam obtains nuclear weapons. ${ }^{112}$ As Mearsheimer and Walt (2009) highlighted, nuclear blackmail can be feasible only if the blackmailer has nuclear weapons but neither the target state nor its allies do. If both opposing sides have nuclear weapons, then the blackmailer's threat is an empty one because the

\footnotetext{
111 The Iraq War was based on faulty and distorted intelligence which undermined the credibility of intelligence services and analysts. As David Kay, who was the United Nations Chief Weapons Inspector following the first Gulf War, and the leader of the Iraq Survey Group's search for weapons of mass destruction following the 2003 invasion of Iraq pointed out in a TV interview with Fox News: "If you cannot rely on good, accurate intelligence that is credible to the American people and to others abroad, you certainly cannot have a policy of pre-emption. Pristine intelligence - good, accurate intelligence - is a fundamental bench stone of any sort of policy of preemption to even be thought about" (Fox News 2004).

${ }^{112}$ Stephen Walt believes that security threats shape foreign policies (Walt 1985, 1987). John Mearsheimer argues that competition for hegemony is confined to a state's own region, and global hegemony is unattainable (Mearsheimer, 2001).
} 
blackmailer cannot carry out the threat without the certain nuclear retaliation which can result his own destruction.

Furthermore, according to Waltz's argument, the spread of nuclear weapons brings stability, regardless of the characteristics of the regime and its leader (Waltz 1981). In regard of giving nuclear weapons to al-Qaeda, it was highly unlikely that Saddam would even have considered sharing his most valuable weaponry with a terrorist organization, losing all control over when and where they would be used. Not to mention that the transfer could have not gone unnoticed. Hence, Mearsheimer and Walt (2009) concluded that a policy of vigilant containment would have worked, because the United States and its regional allies were stronger than Saddam's Iraq. Similarly, Jervis (2003a) also argued that Saddam's behavior did not indicate that he was undeterrable, and the Bush-administration's endorsement of preventive war may partly be explained by its broader foreign policy goals.

The Bush Doctrine conforms to the realist approach that a state's interest will expand as its power does, and offensive realism can explain what the United States has done because it sees states as always wanting more power in order to increase their security in the midst of uncertainty. ${ }^{113}$ Jervis (2003a) argues that the main concern for the United States was with extended deterrence, namely deterring Saddam from coercing his neighbors, and this concern arose from Glenn Synder's stability-instability paradox, which states that under conditions of Mutual Assured Destruction (MAD), neither side can launch a nuclear war because that would result in its own devastation (Synder 1965). And while this certainty and stability is desirable, it also permits either side to engage in adventures at a lower level of violence, such as attacking allies with conventional weapons for instance. Hence, the Bush administration's concerns that even a small Iraqi nuclear force would undermine American extended deterrence was not baseless. In this regard, as Betts (1995) noted, it was not that deterrence was not operating, but that the United States would have found itself deterred instead of Iraq.

This does not mean that Iraqi nuclear weapons would not have changed anything, since the distribution of material power and capabilities is a central factor of international outcomes (as realism argues). An Iraqi nuclear capability would have made a foreign invasion, or any attempt of regime change unlikely. But, as Jervis (2003a:324) noted, even if we believe that a strategy would work under particular conditions, when policymakers reject

\footnotetext{
113 Jervis reminds that many arguments about foreign policy are descriptive and explanatory on the one hand and prescriptive on the other. According to Jervis, the actors can have their own different theories, and it is hard to explain something that we consider foolish when our theories do not incorporate foolishness. If a player is incompetent, game theory models will not work either (Jervis, 2003a:316).
} 
the idea, the theory has no chance to be applied, and we will eventually end up with a selffulfilling prophecy.

\subsubsection{Balance of Power Theory and Growing Uncertainty}

In regard of the applicability of the balance of power theories, it must be noted here that a relative stable security environment makes it much easier to make any analysis, since calculations depend on a minimum level of predictability. The bipolar world order during the Cold War made these kinds of assessments easier, as the competition between the superpowers (the United States and the Soviet Union) could be simplified as a zero-sum game. However, in today's nonpolar, unipolar, or disordered world balance of power calculations have become more complicated. As Christopher Bolan (2017) puts it, the uprisings and regime changes of the Arab Spring, and the civil wars in Libya, Syria, and Yemen signal the dawn of a new uncertain era in the Middle East. However, the increasing number of variables and growing uncertainties will certainly not make any balance-of-power calculations more convincible or far-reaching.

\subsection{Changing Regional Balance of Power After 2003}

Frederic M. Wehrey et al. published a report titled The Iraq Effect sponsored by the United States Air Force in 2010, describing how the Iraq War transformed the Middle East. In Chapter Two the report considers how the Iraqi invasion has affected regional alignments, how has the balance of power shifted, to what extent has the removal of Saddam Hussein altered Iran's regional influence and can the balance of power approach even describe the complex regional alignments. As Wehrey et al. (2010:17) pointed out, Iran gained the most from the 2003 invasion of Iraq, but this does not mean that there are no limits of the growing Iranian influence in the region.

During the Cold War, the traditional Middle East regional order could be described as a competition among Iran and the Arab powers like Iraq, Saudi Arabia, Egypt, and Syria, while these regional rivals received foreign support from external powers like the United States and the Soviet Union to avoid the potential rise of a regional hegemon power. Worth to note that before the Islamic Revolution 1979, the United States supported both Iran and Saudi Arabia as regional balancers to Soviet-backed states, more precisely to the Baathist Iraq. But after the revolution, Tehran become an enemy of Washington and the United States began to support Baghdad to counter the growing Iranian influence and remained on Saddam Hussein's side during the Iran-Iraq War in the 1980s. After the 1991 Gulf War, the United States 
changed its offshore balancing strategy and become a direct regional balancer state through building up its military presence in the GCC countries, following a dual-containment policy against both Iran and Iraq (Wehrey et al. 2010:18-19).

According to Wehrey et al., after the 2003 invasion of Iraq, the regional balance of power shifted to non-Arab states, creating a new strategic environment, even if just perceptually (see Figure 3. for the regional CINC-score comparison graph). Analysts argued that Iraq has never served as a real buffer state against Iran, especially during the 1990s because of the international sanctions against Baghdad that had a crippling effect on the state's capabilities (Eisenstadt 1996:11-16). But even if Iraq could not be and was not even a balancer against Iran, the regime change and the rise of a Shia-dominated government with links to Iran has changed the perception of the "Iranian threat" in the region. The other important change from a regional balance of power perspective was that due to its significant military presence on the ground, the United States turned into a de facto regional power, which led to a situation when two non-Arab actors, the US and Iran became the major players in the region. Next to the United States and Iran, a third non-Arab state, Turkey also has become a more and more active actor in the Middle East, mainly due to Ankara's concerns about Kurdish separatism. This process of increasing non-Arab regional dominance were strengthened by the lack of an Arab balancer against Iran, thus the regional balance of power has shifted from Arab states to non-Arab ones, while the perceptions of Iran's role in the Middle East also shifted (Wehrey et al. 2010:20-21).

Figure 3. Regional CINC-score comparison graph, 1990-2012

(Singer, Bremer \& Stuckey, 1972; Singer, 1987).

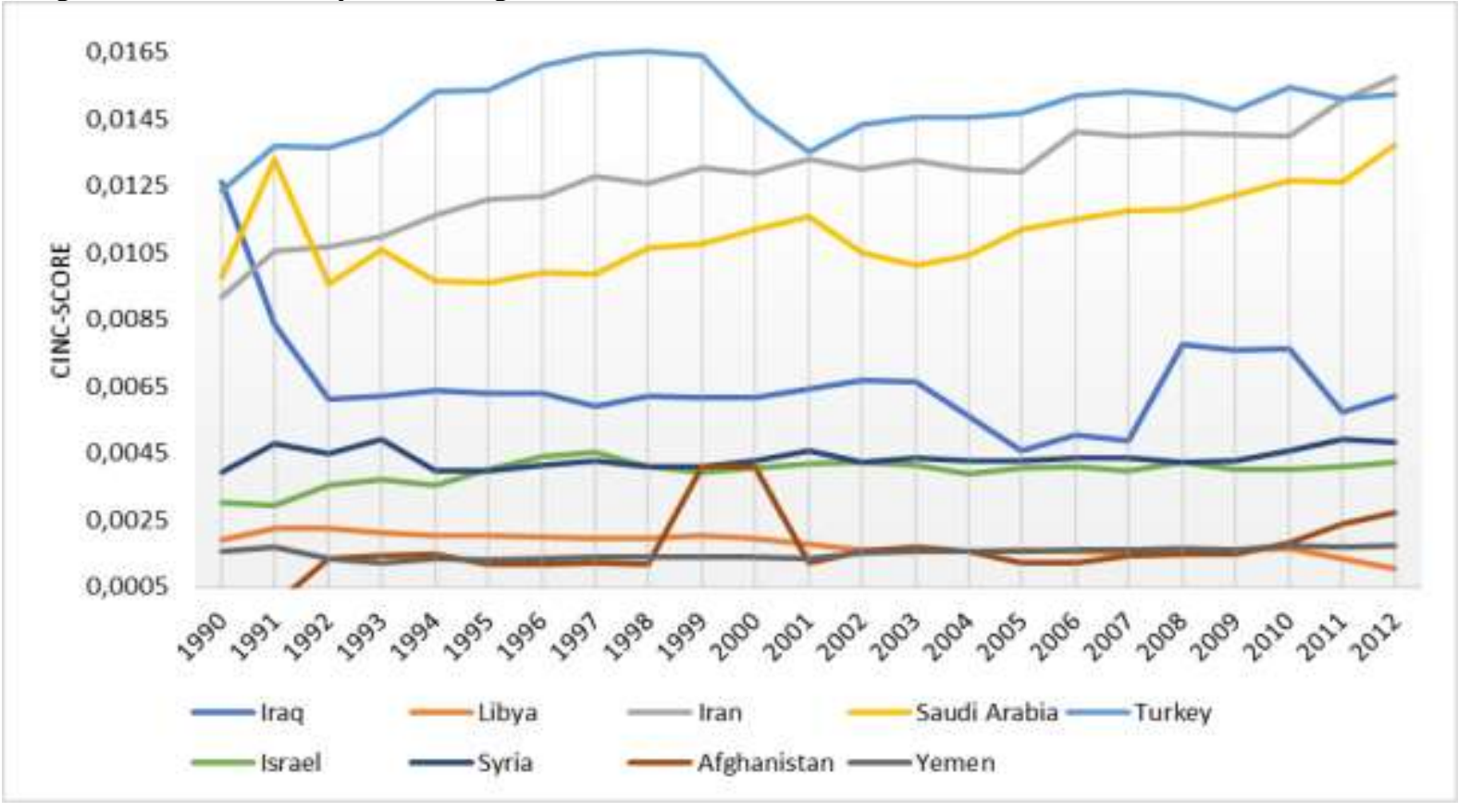




\subsubsection{Opposing Iran's Growing Influence}

Iraq long has been the most important arena for Iranian foreign policy. After 1979, the Shia majority Iraq was the first target for exporting the Islamic Revolution, particularly because the Shia's suffered under various Sunni-dominated regimes since 1920. It also must be mentioned that Iraq is also home to the Shia's four holy cities (namely Najaf, Karbala, Kadhimiya, and Samarra). In addition, there was a strategic rivalry between the Baathist Iraq and the Shia Islamic Republic, and we must also not forget that the Iraqi border is Iran's longest land border with its $1450 \mathrm{~km}$, which is a source of border disputes.

After the Iran-Iraq war in 1988, Iran was forced to agree to a ceasefire, without any gain, and this urged Tehran to increase its influence in its neighbor. Furthermore, the territorial integrity of Iraq was also important to the Islamic Republic of Iran, as a possible secession of the Kurdish region in the north would encourage its own Kurdish minority to press for independence. Tehran opposed the invasion in 2003, and for a while, even feared that Iran would be next in line. However, later became clear that Iran was the main beneficiary from this war because the fall of Saddam Hussein ended a bitter rivalry, and finally prompted a shift of power in Iraq to the favor of the Shia majority. Nonetheless, this does not mean that Iran has not faced difficulties in increasing its influence in Iraq. The ethnic tension between Arabs and Iranians still poses a challenge, and Turkey as a regional rival also creates difficulties in Iraq, since Ankara has its own hegemonic ambitions as the leader of the Sunnis. This led to a situation where Iran supported the Shia government, while Turkey protected the Sunni minority, and for a period even entered into an alliance with the Iraqi Kurds (Litvak, Landau \& Kam 2018:41-45).

After the Iraq War between 2003 and 2011, the growing influence of Iran and its controversial nuclear program has become a central issue of the new Middle East. Many previous studies described Iran's increasing role in Iraqi politics ${ }^{114}$, as well as that Iran's Islamic Revolutionary Guard Corps (IRGC) trained militias and supplied Iraqi insurgents (Katzman 2009). There is a widespread concern since then, that in the last less than two decades Iran's influence has expanded beyond its natural sphere of influence, from Iraq to the Eastern Mediterranean region, which some describe as the "Shia Crescent". Iran's influence is most visible when we take a look at those militant groups that receive Tehran's support, such as the Palestinian Hamas, the Lebanese Hezbollah, the Yemeni Houthis, and through its

\footnotetext{
${ }^{114}$ Some emerging Shia political factions had long-standing ties to Iran before the war (International Crisis Group 2005).
} 
missile development, and its controversial nuclear program. ${ }^{115}$ Although Iran has some threatening naval capabilities which could impede maritime access in the Strait of Hormuz, its nuclear ambitions are contributed partly by the inferiority of its conventional military capabilities (Wehrey et al. 2010:22-23). In addition, Iran also applies soft power projection to increase its influence (Slavin 2008).

It is important to note that the Iraq War changed threat perceptions for Iran as well, mainly because of the close military presence of the United States in its neighborhood. Moreover, while to some extent instability in Iraq can be useful for Iran for keeping US forces distracted, an uncontained instability could threaten even Iran due to a potential spillover effect. There were some exacerbated transnational threats (ethnic separatism, Sunni radicalism) that were affecting Iran's security, while the increasing Kurdish challenge has become particularly concerning for Tehran. The point in short is that Iran had and still has strong incentives to increase its influence to stay a key regional player while the uncertainty of the strategic environment reinforces both the threat perceptions and the regional ambitions of Iran (Wehrey et al. 2010:24-25).

Wehrey et al. (2010) described the Arab world's attitude towards Iran as twofold, which sometimes rapidly fluctuating between a "bad" Iran image and a "good" one, even on the question of Iran's nuclear ambitions. ${ }^{116}$ The authors of the cited RAND report noted that their interviews suggested a complex understanding of the Iranian challenge which can party explain the drive of Iranian regional behavior. The bad Iran image reflects Tehran's influence in Iraq and its meddling with Shia groups in the region, and it is most prevalent among state officials - but can be found in Arab public opinion as well -, while the good image of an Islamic Republic of Iran which defies the West and Israel resonates more with the Arab publics. However, even when the "bad Iran" image prevails, the United States' support does not grow in the region, as Arab publics often see American influence as equally harmful than that of Iran's in Iraq (Wehrey et al. 2010:26-31).

While the rise of the Islamic State in Iraq and Syria posed a threat to Iran as well, it also provided new opportunities. As ISIS has become the most serious regional security threat, and Iran were seen as a stable country that could serve as a potential partner in the fight

\footnotetext{
${ }^{115}$ According to Ali Akbar Velayati, Ali Khamenei's international affairs adviser, the cooperation between Iran, Iraq, and Syria serves as a "chain of resistance" and it was essential to save the region from the United States and "the Zionist regime" (Islamic Republic News Agency 2016; Goodarzi 2020).

116 The "bad" Iran image is about Tehran's growing influence in Iraq and its challenge to the Arab Sunni identity, while the "good" Iran image is characterized by defying the West, opposing Israel, and criticizing the corrupt Arab regimes. Wehrey et al. cites an interview with a Jordanian journalist in 2008, where this characterization was made (Wehrey et al. 2010:26).
} 
against the Salafi jihadist group, the Obama administration softened its position in the negotiations on the Iranian nuclear program. The threat posed by ISIS resulted in a partial confluence of interests and even indirect cooperation between Tehran and Washington, while it also helped Iran increasing its influence over the Iraqi government and over the Kurds (Litvak, Landau \& Kam 2018:45).

\subsubsection{A Potential Anti-Iranian Alliance with Israel and Saudi-Arabia}

If we look at the particular states' stances in regard of balancing or containing Iranian influence, what comes in sight is the region wide ambivalence toward both Iran and the United States, while it is highly unlikely that even a fully independent Iraqi government would return to the hostile anti-Iranian position without a radical shift in the country. Meanwhile, relations between the US and Iraq have been strained in recent years, particularly after Iranian General Qassem Soleimani and Iraqi militia leader Abu Mahdi al-Muhandis were killed in a US drone strike just outside the Baghdad airport in January 2020. Washington and Baghdad are currently in talks to withdraw the remaining 2,500 US troops from Iraq (AFP, France 24 2021).

Turkey's shared interests with Iran in opposing Kurdish independence and in defeating the Islamic State makes hard for Ankara to be part of a containment strategy against the Islamic Republic of Iran, though Turkish-Iranian tensions were rising recently over Turkey's ongoing military operations against Kurdish militants in northern Iraq. ${ }^{117}$ In the past few years, Turkish-Iranian relations have often been characterized by cooperation, but their interests are increasingly divergent. Their competition probably will intensify in the future, though a direct confrontation between them remains unlikely (Cengiz 2021).

Syria maintains close political and military ties with Iran, especially since the Arab Spring, and now Damascus and Tehran are close strategic allies, as Iranian security forces are advising and assisting the Syrian military in order to keep Bashar al-Assad on power (Saban 2020). Jordan can be put among the moderate countries opposing Iran, but the middle class of the country does not believe that Iran represents a dangerous threat. United States policymakers believe that Saudi Arabia would be the most viable "Arab balancer" state against Iran, but not everyone shares this view, worrying that the empowerment of Riyadh as a regional proxy against Iran could prove destabilizing. Consequently, Iran's Arab neighbors and especially the smaller GCC member states have pursued a mixed approach toward Iran. In

\footnotetext{
117 Tensions were rising between Turkey and Iran in March 2021, as Ankara threatened to expand its Iraqi operations to a strategically important region used by an Iranian-backed militia (Jones 2021).
} 
the years after the Iraq War, an Arab diplomatic strategy emerged toward Iran, consisting of engagement in the Gulf region, containment in Iraq, and rollback in the Eastern Mediterranean (Wehrey et al. 2010:32-36).

For Israel, Iran's regional ambitions and the regime's hostility has long been serious security threats (Porter 2015). After the 2003 invasion of Iraq, Israeli leaders have become more concerned about the perceptions of rising Iranian influence in the region, and Tehran's controversial nuclear program. Israeli experts believe that Iran is actively seeking regional hegemony, and if Tehran acquires a nuclear option, it will be more aggressive in pursuing its strategy to become the leading power of the Middle East (Inbar 2021). From an Israeli perspective, the 2003 invasion of Iraq and its aftermath exacerbated this Iranian threat, partly due to the erosion and limitations of American power in the region, which was one of the consequences of the war. It is in Israel's interest for the United States to remain able to intervene in the region at any time if necessary, and for Washington to have a political will to do so. However, a prolonged American military presence in the region or a total troop withdrawal from Iraq would weaken US capabilities and its regional influence. According to the Israeli neoconservative thinking, a US withdrawal would be a disaster for America, harming its image and decreasing its regional influence (Fuller 2020). Nevertheless, some Israelis saw potential opportunities in context of a US withdrawal from Iraq, referring to the possibility that Saudi Arabia could play a more-constructive role in regional security and could even cooperate with Israel (Siddiqa, Hassan \& Khan 2019). After the Iraq War, Israel has become more and more aligned with Arab states, such as Saudi Arabia and Egypt, in a common concern about growing Iranian influence (Wehrey et al. 2010:38-43).

\subsubsection{Turkey's Perspective}

The aftermath of the Iraq War and the fight against ISIS also led to increasing Kurdish activism in the region and resulted a push by Iraqi Kurds for increased autonomy. ${ }^{118}$ The issue of the Kurds deeply concerns Damascus, Tehran, and Ankara as well, compelling them to strengthen their intelligence and operational cooperation. For Turkey, a weakened and

\footnotetext{
${ }^{118}$ In 2016 Kurdish President Masoud Barzani suggested to hold an independence referendum once the ongoing battle to liberate Mosul from ISIS was complete, though calls for Kurdish independence had been going on for years. The United States, the United Kingdom, and Russia urged the Kurdistan Regional Government to at least postpone the vote, while Turkey, Iran, and Syria were concerned that the independence referendum would boost the secessionist sentiment among their own Kurdish populations. This time, despite all the Iraqi and regional objections, the independence referendum took place as planned, on September 25, 2017. The turnout was 72 percent, and 92 percent of the voters supported the Kurdish independence. However, the decision to hold the referendum has backfired, as the Kurds' overwhelming support of independence had pressured Baghdad to reassert its control (BBC News 2017; Morris 2017).
} 
destabilized Iraq is a serious security threat because of its Kurdish challenge. If Iraq stays destabilized, that could lead to the emergence of an independent Kurdish state on Turkey's southern border, which could encourage Turkey's own Kurdish population to fight for secession and increase terrorist activities. Thus, Ankara remains concerned about the threat of the PKK, which the United States, NATO and the European Union consider a terrorist organization as well. Many believe in Turkey that the United States is responsible for the increasing Kurdish violence and criticized the US for its reluctance to deal with the PKK because the Iraqi and Syrian Kurds have proven to be reliable allies for Washington (Karadeniz \& Gumrukcu 2017). Thus, Turkey decided to use unilateral military action against the PKK, beginning with incursions into northern Iraq in 2007-2008, and continuing later with more military operations against the Kurds in Northern Syria as well. In part the resurgent Kurdish challenge has led to increasing Turkish activism in the region and now continues to be a source of tension in the US-Turkish and the Turkish-Iranian relations as well (Wehrey et al. 2010:43-45).

\subsection{Summary}

In the 2000s a fluid strategic environment emerged with complex regional threat perceptions and balancing behaviors, which characterized the 2010s as well. The United States and Iran have emerged as the major players, which means that non-Arab states (the United States, Iran, and Turkey) have become the main regional actors in the Middle East. Analyzing the aftermath of the Iraq War, the Arab Spring, and the fight against ISIS, using the conventional balance of power approach can lead one to the conclusion that the region can be divided between a rising Iran and an opposing bloc of Sunni Arab states in cooperation with Israel (Wehrey et al. 2010).

The 2003 invasion of Iraq, and the removal of Saddam Hussein upset the traditional balance of power in the region by giving Iran increased latitude to project its influence across the region, though Iran has been more and more active even before the Iraq War, supporting Hamas in the Gaza Strip and the Lebanese Hezbollah for instance. Moreover, some analysts doubt that Saddam's Iraq ever really served as a viable balancer state against Iran (Eisenstadt 1996). So, Tehran had some strategic gains as a consequence of the Iraq War, but also faced obstacles to expanding its influence. The perceived rise of Iran has not produced a clear consensus of opposition from Sunni Arab regimes, while Arab states responded in diverse ways, balancing and bandwagoning. Since there was no viable Arab balancer state to Iran, the 
emerging regional powers have become non-Arab states, namely the United States, Iran, Turkey, and Israel. Furthermore, the United States disengagement from the region has increased the influence of other foreign powers, particularly Russia and China, while the local states have become more receptive to their assistance. It is always worth to note that threat perceptions always vary everywhere, and sometimes significantly. In this case the perception of eroding US regional influence has resulted a growing involvement of other foreign actors in the regional affairs (Wehrey et al. 2010:143).

It must be emphasized, that the rise of the Islamic State in the 2010s was an important element of the complex regional developments that can be seen as a partial consequence of the changing strategic environment since the 2003 invasion of Iraq. The Iraq War and later the Arab Spring has clearly offered an opportunity for jihadist groups to gain momentum. Thus, during the last ten years - in the "era of the Arab Spring" - the threat of increasing Iranian influence in Iraq and in the region have been superseded by more-pressing concerns, such as the fight against Salafi jihadist militants, and the civil wars in Libya, Syria, and Yemen. ${ }^{119}$

In regard of Iranian behavior and adapting to shifts in the regional balance of power, namely to Iran's increasing influence, the United States found itself in a hard situation where its efforts to form an anti-Iranian regional alliance of the "moderate" Arab states (GCC, Jordan, Egypt) to counter Iranian influence remained futile for long. Such an alliance seemed unrealistic, and some analysts argued that it could even escalate regional tensions by bolstering Iranian hard-liners, hence the United States should avoid the impression that it is attempting to create a collective security organization arrayed against Iran, or an "Arab NATO” (Wehrey et al. 2010:143-153). However, the Pentagon's announcement in January 2021 to bring Israel inside to US Central Command alongside the Arab states suggests that something similar is happening right now (Everstine 2021). For Israel, this can result a more formal alliance with Arab states against Iran and make possible closer cooperation with ambivalent states (Cook 2021).

The United States has tried three times since 1990 to disengage its military from Iraq. First, in the immediate aftermath of the 1991 Gulf War, when the US military withdrew and left behind only residual defense elements in Saudi Arabia and Kuwait. A few years later, the United States was once again engaged in military operations in Iraq. The second time the

\footnotetext{
${ }^{119}$ Given that the events of the so called Arab Spring sparked anti-government protests in many Middle Eastern countries, which in several cases led to a protracted crisis, a regime change, or an internationalized civil war, perhaps it is not an exaggeration to consider the last 10 years as the era of the Arab Spring. The Arab Spring highlighted the challenges facing the countries of the region, most of which remain unresolved to this day, thus are still a source of social tension.
} 
United States attempted to withdraw from Iraq was in the wake of the 2003 invasion, but ultimately the American forces remained to help counter a growing insurgency. Finally, in 2011, policymakers believed that stability seemed feasible, and ordered a withdrawal. Three years later the Iraqi Army suffered serious blows from the Islamic State, and US forces were engaged in active military operations in Iraq yet again. Until recently, Iraq has been one of only three countries in the world - next to Syria and Afghanistan - where several thousand American military forces were engaged in sustained combat support operations. But in 2021, President Joe Biden's administration and Baghdad have finally agreed on the withdrawal of all remaining US and coalition combat troops deployed to fight ISIS, after US bases in Iraq have come under frequent rocket attacks attributed to Shia militias linked to Iran (Al Jazeera 2021a). ${ }^{120}$

According to some analysts, a full withdrawal might lead to the rebirth of the Islamic State or the growth of a successor violent extremist group; might result in the self-fulfillment of the so-called Shia Crescent across Iran, Iraq, Syria, and Lebanon; could give even more space to Russia and China in the ongoing competition for Iraqi partnership; or may even lead to a future requirement of costly military deployments in the future, which could be prevented by a smaller lasting military presence. As Ben Connable (2020:10) points out, since the risks of disengagement are too great, "Iraq is a strategic inevitability", which "will constantly draw the United States back in, even if American policy makers seek disengagement." Nevertheless, an allied Iraq and an enduring commitment to Baghdad should bring significant strategic benefits to the United States. Even maintaining a small military presence should help expanding the United States' alliance network in the region, which could also contain Iran's rising influence. This would also make easier to prevent the rebirth of the Islamic State, reduce the threat of international terrorism, and would help the United States compete with Russia and China in the region. At the same time, it should be kept in mind that Iran is effectively using Iraq as a buffer against US strategic influence, and where Russia and China succeed in gaining access, the United States will probably lose influence (Connable 2020:10, 18-22).

\footnotetext{
${ }^{120}$ Calls for a US withdrawal from Iraq grew after the killing of Iran's elite Quds Force commander, General Qassem Soleimani, and deputy of Iraq's Hashd al-Shaabi, Abu Mahdi al-Muhandis, in a US drone strike near Baghdad airport in January 2020. Days after that incident, the Iraqi parliament voted in favour of a complete withdrawal of all foreign troops as Iran-backed Shia militias (PMFs) vowed to avenge the killings (Al Jazeera 2021a).
} 


\title{
5. ORDER IN A DISORDERED REGION? ${ }^{121}$
}

\author{
"Much is included in an analysis; little is included in a \\ theory. Theories are sparse in formulation and beautifully \\ simple. Reality is complex and often ugly. [...] A theory is an \\ instrument used in attempting to explain "the real world" \\ and perhaps to make some predictions about it." \\ (Waltz 1996:56)
}

As Schweller put it, "at its essence, balance of power is a type of international order" (Schweller 2016:9). Moreover, according to classical and neoclassical realists, the balance of power is a basic value of international relations and world politics, as a "desirable institution and a good thing to strive for because it prevents hegemonic world domination by any great power" (Jackson \& Sørensen 2010:70).

However, the normal operation of a regional balance of power system, as a type of international order is still unclear. We might say that the regional balance of power system of the Middle East region is an automatic one by default. However, considering the recent increase in the number of foreign interventions and the question of proxy wars, it can be considered rather as a semi-automatic system.

If we take into consideration the nine conditions that Schweller offered as the conditions of an effectively performing balance of power system, it is ascertainable that there are sufficient number of regional powers under anarchic conditions. States in the region are vigilant, that is very sensitive to changes in the distribution of capabilities, and the main actors are able to respond quickly and decisively to these changes in the balance of power. ${ }^{122}$ Additionally, states tend to flock to the weaker or less threatening side of a conflict, the regional powers are able to project power, war is a legitimate tool of statecraft, and the states in the region tend to pursue moderate war aims and to avoid eliminating main actors. One problematical condition in the case of the Middle East, is the one which requires continuous and easy alliance formation. However, considering the fact that the Israel-Saudi relations are

\footnotetext{
${ }^{121}$ An earlier version of this chapter was published as an article in AARMS - Academic and Applied Research in Military and Public Management Science (Selján 2021).

${ }^{122}$ As Spykman (1942:20) noted: "It is obvious that a balance of power policy is in the first place a policy for the Great Powers. The small states, unless they can successfully combine together, can only be weights in a balance used by others. Regional power can be defined as a power that is effective in its own region, but has limited global effect, while can have an impact on the policies of great powers. Additionally, regional power could be defined as a state that has a hegemonic function and potential in its region (Buzan \& Wæver 2003:37). It worth noting that regional powers have less autonomy than great powers, however, it is often the latter that undertake policies that preserve or upset regional balances (Paul, Wirtz \& Fortmann 2004:7).
} 
getting warmer in recent years - which was unthinkable a few years ago -, maybe we can conclude that today there are no "alliance handicaps" in the region. ${ }^{123}$

A system exhibits order when there is an identifiable pattern in the relationship of its actors, or rather some discernible organizing principle. When the operation of a system is highly predictable, order prevails, while disorder is a condition of randomness. The degree of order is partly a function of stability, which is the property of a system that causes it to return to its original condition after it has been disturbed from a state of equilibrium. Some orders are durable, while others are unstable. Especially complex and delicately balanced systems, which may appear orderly at one moment but can become unpredictable and disorderly quiet unexpectedly (Schweller 2016:9).

According to Hedley Bull's definition of social order, international orders vary according to the amount of order displayed; whether the order is purposive or unintended; and the type of mechanisms that provide order (Bull 2002:3-22). On the one hand, there is rulegoverned, purposive order, while on the other hand, there is an international order with entirely unintended recurrent patterns. ${ }^{124}$ Here, in the case of a regional balance of power system, international order is spontaneously generated and mainly self-regulating since balance of power arises though none of the actors may seek actual equality of power. All states may seek greater power than the others, but their power maximizing actions produces the unintended consequence of a balance of power. As Schweller (2016:10) puts it, "the actors are constrained by a system that is the unintended product of their coactions." The predictability of a social system partly depends on its degree of complexity. The operation of a balance of power system is relatively automatic and predictable, since it only requires states seeking to survive through pursuing power and security in an anarchic, self-help international system (Betts 1992:11-12). However, a balance of power system does not function always properly and predictably, as balancing behavior can be late, uncertain, or practically nonexistent.

\footnotetext{
${ }^{123}$ See Benjamin Netanyahu Israeli prime minister's speech before the 2018 UN General Assembly, where he made a confession admitting that "the Iran deal has had one positive consequence, an unintended one but a positive consequence by empowering Iran, it brought Israel and many Arab states closer together than ever before in an intimacy and friendship" (Haaretz 2018; Marcus 2018).

124 There are three types of international orders: a negotiated or rule-based order, an imposed or non-voluntary order among unequal actors, and a spontaneously or automatically generated self-regulating order, which is an unintended consequence of actors seeking only to maximize their power (Schweller 2016:10-11).
} 


\subsection{Balancing Behaviors in the Middle East}

As Walt notes, alliances are usually viewed as a response to threats, yet there is still no agreement on what that response will be. States may either balance, that is ally in opposition to the main source of danger, or ally with the state that poses the major threat, in one word, bandwagon. Walt argues that if balancing is more common than bandwagoning, then states are more secure because aggressors will face combined opposition. But if bandwagoning is more prevalent, then security is scarce because aggression is rewarded. Walt in his 'Alliance Formation and the Balance of World Power' presents each hypothesis in its simplest form and then revises them, arguing that balancing prevails over bandwagoning (Walt 1985). On the other hand, other scholars claim that states have bandwagoned with or hid from threats far more often than they have balanced against them. Robert Powell (1999:196) finds that balancing is relatively rare, since balances of power sometimes form, but there is no general tendency toward this outcome. States frequently wait, bandwagon, or, much less often, balance. Additionally, the theory of the broader phenomenon of underbalancing behavior must be mentioned, which includes buck-passing, distancing, hiding, waiting, appeasement, bandwagoning, incoherent half-measures, civil war, revolution, and state disintegration.

While most of the earth's people live in developing countries or, according to Cold War terminology, in Third World countries, the foreign policy of these states and especially why they align as they do, is still unclear. ${ }^{125}$ David (1991) suggests, that the theory of "omnibalancing" can be applied in the case of the developing world, since it draws upon the key assumptions of balance of power while also correcting those elements that make it inapplicable to these regions. As he notes, omnibalancing agrees with the core assumption of balance of power, that threats will be resisted. But, whereas balance of power focuses on the state's need to counter threats from other states, omnibalancing considers both internal and external threats to the leadership. The theory of omnibalancing combines the need of leaders to appease secondary adversaries, as well as to balance against both internal and external threats in order to survive in power, taking into consideration the common conditions of the developing countries that leaders are generally weak and illegitimate and that the stakes for

\footnotetext{
${ }^{125}$ During the Cold War, the Third World referred to the developing countries of Asia, Africa and Latin America, the nations not aligned with either NATO or the Communist Bloc. Since the end of the Cold War, this terminology has been used less and less, and it is being replaced with terms such as developing countries or least developed countries. We prefer the term developing countries, however, its definition is not universally agreed upon, and there is also no clear agreement on which countries fits this category. According to the International Monetary Fund's World Economic Outlook Database of October 2018, the following are considered developing economies of the Greater Middle East region: Afghanistan, Algeria, Bahrain, Djibouti, Egypt, Iran, Iraq, Jordan, Kuwait, Lebanon, Libya, Mauritania, Morocco, Oman, Pakistan, Palestine, Qatar, Saudi Arabia, Somalia, South Sudan, Sudan, Syria, Tunisia, Turkey, United Arab Emirates, Yemen (International Monetary Fund 2018).
} 
domestic politics are usually high. This theory assumes that the most important determinant of alignment is the drive of these weak and illegitimate leaders to ensure their political and physical survival (David 1991:233, 236).

At present, there are no studies confirming the overall applicability of omnibalancing to the countries of the Greater Middle East, and only an in-depth analysis of the region's alignment decisions could do that. However, in regard of the role of foreign interventions in the balance of power system of the Middle East, the logic of omnibalancing theory may provide a better guide or additional explanation for foreign policy decisions.

Despite important differences among the states considered as developing states of the region in question, there are fundamental similarities among them, like their situation in which internal threats are far more likely to challenge their leader's hold on power than external threats from other countries. The leaders of developing countries must pay more attention to retaining their hold on power, especially in the face of domestic challenges, while internal threats are more prevalent in these countries due to their special characteristics. The great majority of them had been colonies out of which foreign powers created states where none had existed, thus many began and remain more as an artificial construct than a coherent unit, while in many cases the state is often simply just the representative of a group that holds power in the capital. In consideration of this, legitimacy is likely to be weaker for the leaders of developing countries. It is also important to note, that since the consequence of loss of power in the developing countries of the Middle East region is often loss of life, leaders are understandably more aggressive than other leaders in their efforts to maintain their hold on power. Most of these states are governed by authoritarian rule, which also means that decisions in foreign policy are usually made by a single individual or by a narrow elite (David 1991:238-240).

One of the unique characteristics of the Middle East region is the interrelationship between internal and external threats, since leaders and insurgents in the region commonly seek outside support to advance their interests, and their requests for help are often granted by outside states (Tillema 1989:179-185; Einsiedel et al. 2017). Internal threats are so prevalent in these countries that they represent an ideal vehicle for advancing the interests of foreign actors and outside states. Since the leadership of these states is often determined by the outcome of internal threats and conflicts, foreign actors with a special interest in the state's affairs may seek to influence that outcome. This generalization about the developing countries of the Greater Middle East region is not intended to suggest that all of them share these characteristics equally, since we all aware that different states manifest different strengths and 
weaknesses. It is important to note that in this region what really matters when comes to the question of foreign policy - and particularly alignment -, is the orientation of the authoritarian elite, since the interests of this elite are not necessarily the same as of the state. The elites often have their own interests, the most important of which is to stay in power (David 1991:239-244).

\subsection{The Post-Cold War Regional Power Structure}

Currently, the Middle East is suffering from armed conflicts involving virtually all the regional states as well as the United States and Russia and many different non-state actors. While Russia and the United States are still engaged in the region's conflicts, the transformation ongoing today is mostly driven by local and regional factors, like the Arab Spring and the ongoing civil wars as the drivers of an emerging new regional political order in the Middle East (Lynch 2016).

According to Ross Harrison (2018), the current power dynamics in the Middle East can be traced back to the onset of the Cold War and the simultaneous emergence of many of the Arab countries from the rule of European colonialism into independence. He argues that it was the collapse of the global Cold War system nearly four decades later that set the Middle East on its current course. The end of the Cold War, and the period of American unipolarity that followed, led to a regional power imbalance, which the Middle East is still contending with today. However, as Harrison points out, the conflict in the Middle East is more than just about revisionist and status quo powers, since the civil wars turned the region into a tripartite system, consisting of a struggle for power between Iranian, Arab, and Turkish nationalisms (Harrison 2018:14).

The advent of the Cold War and the security and economic needs of independent Arab states resulted in a situation that started to mimic the bipolar structure of the international system, dividing the Arab world into two camps. The Cold War period engendered a Middle East political order that persisted from the 1940s until the collapse of the Soviet Union in the early 1990s, which ultimately resulted in significant global geopolitical changes that contributed to the current power struggles we see in the Middle East today. This geopolitical transformation created a new power structure for the region, consisting of states tilted towards the United States like Israel, Saudi Arabia, Jordan, the United Arab Emirates, and Egypt on one side, and a revisionist front on the other side with Iran in the lead (Hubbard, Kershner \& Barnard 2018), along with Syria, tilted towards Russia, and with non-state actors like 
Hezbollah and Hamas, that have arrayed themselves to resist US influence in the Middle East. However, it is important to note that the political order of the Cold War started to disintegrate even before the formal collapse of the Soviet Union in 1991, with Egypt's President Anwar Sadat forging a peace treaty with Israel in 1978, with the Islamic revolution in Iran in 1979 and with Saddam Hussein's invasion of Kuwait in 1990, which in effect was a test of the strength of the prevailing regional order (Harrison 2018:5-8).

The formal collapse of the Soviet Union in 1991 delivered a final blow to the Cold War regional order of the Middle East. There were several important effects of this event for all states. For instance, once Soviet allies like Syria, Iraq, Libya, and Yemen had to reconfigure their economic and political establishment, as well as their foreign policies. Additionally, former Soviet allies also lost their security umbrellas and their ideological source, while the end of the Cold War upended the regional power balance (Harrison 2018:6).

After the collapse of the Soviet Union, the United States remained the sole superpower, pursuing the policy of dual containment towards Iraq and Iran, in effect imposing a "Pax Americana" on the Middle East in the absence of a global rival (Gause 1994), only a couple years after it defeated Saddam Hussein in his bid to annex Kuwait, and later even imposed tougher sanctions on Iran (The New York Times 1995). Years later in the immediate wake of terrorist attacks of September 11, 2001, when the United States brooked no active resistance by Middle Eastern regimes, this unipolarity translated into military invasions of both Afghanistan and Iraq (Feith 2009). By then it became more and more obvious, that the unity of the Arab world has been finally broken, and the Israeli-Palestinian conflict remained its only common cause. These events turned out to be good opportunities for Iran to build deterrence against possible US and Israeli invasions and to develop the wherewithal to push back against the regional influence of the United States (Barzegar 2008).

The so-called Arab Spring, that is the series of pro-democracy uprisings that enveloped several largely Muslim countries, including Tunisia, Egypt, Libya, Yemen, Syria, and Bahrain, signaled a new era for the Middle East (N. Rózsa 2011; 2015:237-253). Eventually, the American unipolarity led to a new rivalrous power structure in the region, defined by competing Sunni and Shia sectarian identities, and Iranian and Arab nationalisms, while during the Cold War, the Middle East reflected the simple bipolarity of the international system (Harrison 2018:9). ${ }^{126}$

\footnotetext{
${ }^{126}$ Bipolarity refers to the distribution of power among states after World War II, which accounts for both the antagonism that developed between the United States and the Soviet Union, and the fact that this antagonism did not lead to major war between them but remained "cold" instead (Wagner 1993:77).
} 
It is also important to note, that according to Wagner's theory of international system "tightness", a tight distribution of power forces states to take sides and align in particular camps because failing to do so leaves them vulnerable. However, since the end of the Cold War, a loose distribution has emerged, which might account for the general loosening and strategic drift amongst once firmly aligned states (Wagner 1993:103).

\subsection{A Multilayered and Dysfunctional Power System}

Burhanettin Duran and Nuh Yilmaz published an article on the new balance of power following the Arab Spring in 2013, focusing on the foreign policies of the four leading states - Iran, Saudi Arabia, Turkey, and Egypt - and their political and religious models. According to Duran any Yilmaz, the Iranian model legitimizes itself as the basis of an "axis of resistance" against the United States and Israel, which aims for a radical change in the regional status quo, while pursues pragmatic politics when necessary. Saudi Arabia sees itself as Custodian of the Two Holy Mosques, Sunnism, and Islam, envisioning an authoritarian model in favor of the status quo. The Iranian model follows a polarizing and sectarian Shiite theo-political policy, in contrast to the Saudi model, which follows a Sunni one. The Turkish model aims for economic integration, preferring the gradual transformation of the status quo. Finally, there is a potential fourth, Egyptian model, which is still evolving. As Duran and Yilmaz note, the Arab Spring forced all the regional powers to manage this revolution and to try to find a new Middle Eastern order. In their search for this new order, Saudi Arabia and Iran are acting on their claims to regional leadership, keeping in mind their national interests and foreign policy priorities. ${ }^{127}$

As Duran and Yilmaz point out, "after the US invasion of Iraq, Iran's increasing power projection in the region has increased its area of influence through its support for the pro-Iranian Shia in Iraq, the Shia opposition in Bahrain and the increased activity of the Shia population in western Saudi Arabia, through the mobilization of the Zaydis of Yemen against the Saudi-backed Yemeni government, and the conversion of Alawites to Shi'ism in Syria." Additionally, we must mention the Iranian support for the Shia Hazara people in Afghanistan, Lebanon's Hezbollah and the Palestinian Hamas in the Gaza Strip. And here comes into the picture the theory of the "Shia Crescent", which is the result of polarizing sectarian rhetoric, and based on the Shia taking power in Iraq, and Iran's growing influence on Shia population

\footnotetext{
${ }^{127}$ Duran and Yilmaz intentionally used the concept of "theo-political" policy instead of political theology. According to their argument, political theology refers to secularized versions of theological concepts in the realm of politics after centuries of struggle, while Theo-politics is the re-theologisation of modern political concepts in a contemporary political context (Duran \& Yilmaz 2013:165, 140-141).
} 
in Iraq, Syria and Lebanon. In the last two decades Iran has built its regional alliances by promoting itself as an "axis of resistance", while also pursuing a nuclear program as a critical element to increase internal national solidarity, as well as to bolster its claim for regional leadership in a new order. At the beginning of the Arab Spring, Iran supported the protest movements, as the reaction of Muslim peoples against "the Western-supported secular dictators". The Iranian model views the US as an external power who constantly trying to interfere in the affairs of the Middle East, excluding Israel as an actor that was implanted in the region by Western powers (Duran \& Yilmaz 2013:143-147).

Saudi Arabia is one of the most important countries in the Middle East, as a close ally of the United States, a supporter of various Salafist movements, and a leading state of the "Sunni bloc" against Iran. Riyad supported Sunni groups first during the Afghan War in the 1980s against the Soviet Union and later in Iraq against Iran, which has contributed to the strengthening of Saudi Arabia's regional position. The Saudi model represents a conservative Wahhabi authoritarian regime. Even though it is a pro-status quo model, it still has an important role in shaping the new regional order. Saudi Arabia provided asylum to the fallen leader of Tunisia, supported Mubarak and the coup d'état in Egypt, and sent troops of the Gulf Cooperation Council to Bahrain to maintain the regional status quo. However, Saudi Arabia supported the forces of the Arab Spring when the revolts appeared in favor of Riyad in Libya, Syria, and partially Yemen, even though they threatened the regional status quo. Saudi Arabia follows sectarian and polarizing policies by utilizing the "Iranian threat" to gain the leadership role of its "Sunni bloc". Saudi Arabia's basic role, as a leading member state of the GCC, was the protector of the Gulf monarchies against Iraqi and Iranian influence, and Riyad still wishes to be the guardian of the status quo (Duran \& Yilmaz 2013:147-148).

While Iran's rise appears to be altering the regional balance of power by expanding its capabilities and the United States and several its allies have moved to balance and contain Iran, many analysts remain puzzled by the fact that Turkey does not seem to be balancing Iran along the US and Saudi Arabia at all. Despite an expanded US presence in the region, Iran's main regional threats - Saddam's Iraq and the Taliban in Afghanistan - have been neutralized while its influence spread and capabilities improved. As a result of this, many states in the Middle East - particularly Israel and the Gulf region -, have begun balancing Iran by both internal and external means, while the United States has also begun to work on forming a formal political alliance to counterbalance a nuclear-capable Iran aligned with Syria and their proxies. While one would expect Turkey to align itself with the US strategy, as Sameer 
Lalwani (2010) points it out, there appears to be a noticeable Turkish departure from Washington's balancing strategy towards Iran (Ekşi 2017).

The civil wars in Yemen, Syria, and Iraq turned into hotly contested proxy battles between formerly coexisting regional powers, and these wars created security vacuums that presented good opportunities for Saudi Arabia, Iran, and Turkey to project their power into. As Harrison argues, these regional powers are pulled into these armed conflicts by "vertical contagion", which means that conflicts do not just spread across borders horizontally to vulnerable neighboring states, but also vertically to stronger and larger regional powers (Harrison 2018:9; Forsberg 2016). This vertical contagion phenomenon has two important aspects. On the one hand, there is the "bad neighbor effect" that can draw regional powers into the region's civil wars, and the political and economic effects of the fighting that are being exported. On the other hand, there is the fact that the civil wars in Syria, Iraq, Yemen, and Libya have transformed into a regional conflict among the major regional powers, "a vicious competition for short-term regional dominance completely overshadows longer-term shared interests of a stable and prosperous Middle East". This regional level civil war is more about establishing a balance of power, or about the dominance of the region, while the country-level wars are about which elites govern the state (Harrison 2018:10).

The Russian military intervention in the Syrian civil war has added a layer of complexity to the distribution of power in the Middle East, turning the region into a threelayered power system. As Harris points out, the first layer is the battle for the state being fought between the rebels and government in each civil war in question. The second layer is the battle for regional dominance being waged between Iran, Saudi Arabia, and Turkey (Miller 2013:55). And the third is the competition mainly between Washington, and Moscow together with China on the same side in Syria and the broader region. ${ }^{128}$ Today the main element of the regional power-politics is the contest between Iran, Saudi Arabia, and Turkey, playing out in the region's civil wars along indigenous ideological lines, while this time the United States and Russia shares some common interests in the Middle East, such as regional stability, counterterrorism and the cooperative management of the refugee crisis. "While this is a multi-layered system consisting of local, regional and international actors, it is far more complex than the Cold War system of the past" (Harrison 2018:11).

Through its military intervention in Syria, Russia become perhaps the most consequential external actor in the region, while former US President Donald Trump has

\footnotetext{
${ }^{128}$ On the role of global actors in the region see Csicsmann, N. Rózsa \& Szalai (2017).
} 
withdrawn support from the Syrian rebels in 2017 (Sanger, Schmitt \& Hubbard 2017), and one year later pulled out of the Iran nuclear deal (Landler 2018a), which reinforced the view that the United States was an unreliable actor in the region (Walt 2018). ${ }^{129}$ However, the Middle East is still an interconnected regional system, and in spite of its dysfunctionality and instability, it is nonetheless a system of interdependence. Turkey, Iran, Saudi Arabia, and Israel together have the potential to deescalate the civil wars. The current disputes between Iran and Saudi Arabia ${ }^{130}$, and Israel and Iran, are over each other's regional behavior, and not over territory, rooted in concrete grievances, which definitely would make their resolution more difficult. There are also shared interests among the regional powers, such as regional stability.

\subsection{Summary}

The competitive relations between Iran and Saudi Arabia reflect the classical balance of power theory, which in the narrow and simple sense can be described as a condition and structure with no hegemonic power among states and where states have relatively equal or similar powers. The balance of power also offers a structural approach, according which bipolar or multipolar balance of power structures emerge in the international regional system. In regard of the Middle East region, it is probable to notice a multipolar structure in the region, while the balance of power could be established either bilaterally or multilaterally.

The balance of power is fundamentally related to the international distribution of power. If the theoretical concept is adopted to the Middle East, there is a simple balance of power between Iran and Saudi Arabia in the narrow sense, while the complex balance of power - which refers to the condition of more than two rivalries - may include Iran, Saudi Arabia, Turkey, and Israel as regional powers. According to Davutoğlu (2016:319-321), in the

\footnotetext{
${ }^{129}$ As Dennis Ross notes, perceptions matter more than mere power: The Russians are seen as willing to use power to affect the balance of power in the region, while the United States is not (Ross 2016). In January 2019 Trump announced that the terrorist organization ISIS had been defeated in Syria and the 2,000 US troops there would withdraw. Later, months of political pressure from US lawmakers, allies and defense officials has forced him to backtrack on his decision and has agreed to leave roughly 400 troops in Syria (Mitchell 2019).

${ }^{130}$ It is worth to note that Saudi Arabia and Iran cut ties in 2016 after Iranian protesters attacked Saudi diplomatic missions following the kingdom's execution of a revered Shia cleric. However, as a mark of the changing political atmosphere, Saudi Crown Prince Mohammed bin Salman (MBS) in April 2021 has struck a conciliatory tone towards Iran, saying he sought "good" relations after reports the rivals held secret talks on April 9 in Baghdad. He also noted that Riyadh was working with regional and global partners to find solutions to Tehran's "negative behaviour", mentioning Tehran's nuclear and programmes and support for proxies around the Middle East. This changing tone can be considered the result of shifting power dynamics as US President Joe Biden set out to revive the 2015 Iran nuclear deal (JCPOA) that was abandoned by his predecessor Donald Trump, while additional signs made clear for everyone that the United States is serious about shifting its focus away from the Middle East (Al Jazeera 2021c; Motamedi 2021; Parsi 2021).
} 
Middle East, three-component equilibriums create a diverse chess game in which alliances are generally interest-based and only temporary. And what is at stake in these chess games is the leading position in the Arab world. Davutoğlu argues, that the basic geopolitical balancing mechanisms of the Middle East can be found in the Egyptian-Turkish-Iranian external regional equilibrium triangle. In his view, cooperation between these three countries is essential for long-term peace in the region. The balance relations of the external strategic triangle form a complex network of relations with the internal triangle of Iraq-Syria-Saudi Arabia and the even smaller or passive Jordan-Palestine-Lebanon triangle. The invasion of Kuwait by Iraq in 1990 made necessary the re-setting of these strategic balances.

Muharrem Ekşi (2017:138) argues that Iran and Saudi Arabia started their struggle of balance of power after the Arab Spring, while they also escalated their regional hegemonic rivalry, which manifests itself today in the form of a proxy war (Miller 2013). According to Karl Deutsch (1964), proxy war can be defined briefly as an international conflict between two countries in a third country, while Andre Mumford (2013a-b) defines proxy war to be a way of conflict where one state uses proxies in indirect engagements through secret destructive operations against the other. ${ }^{131}$ Thus, we can say that a proxy war is a way of conflict that takes place indirectly and secretly in another country through the use of proxies. Historically, proxy war emerged as the product of the Cold War as a way of struggle between the United States and the Soviet Union. However, the concept is getting popular as a way of conflict within the struggle between countries in the $21^{\text {st }}$ century (Towle 1981:21-26). The change of balance of power and power distributions in the international system, particularly after the Cold War, reveals the fact of proxy war again (Ekşi 2017:138-139). The proxy wars in the Middle East started in 2003 with the US invasion of Iraq and spread through the 2011 Arab Spring process, which in the end resulted a weakened Iraq, which became the field of proxy war between the United States and Iran (Joscelyn 2007). Later, after the start of the Syrian civil war in 2011 Syria has become an area of proxy war for the great and regional powers.

Besides the option of regional cooperation, some suggests that "offshore balancing" activity would ensure the regional security in the Middle East (Layne 1997:113). According to Mearsheimer and Walt (2016), by pursuing a strategy of offshore balancing, "instead of policing the world, the United States would encourage other countries to take the lead in

\footnotetext{
${ }^{131}$ Deutsch termed proxy wars 'an international conflict between two foreign powers, fought out on the soil of a third country; disguised as a conflict over an internal issue of that country; and using some of that country's manpower, resources and territory as a means for achieving preponderantly foreign goals and foreign strategies (Deutsch 1964:102, Mumford 2013a:12-17, 41).
} 
checking rising powers, intervening itself only when necessary" ${ }^{132}$ The general idea behind this theory is that external actors weigh in on an unproportioned regional competition on the side of the weaker party, with the goal of restoring the region to a healthy balance of power. As Harris notes, in a way, that is what the Trump administration was trying to do by siding with Saudi Arabia and Israel in their struggle against what they saw as a rising Iran. Although some argues that Mohammed bin Salman and Benjamin Netanyahu have exploited Trump's indulgence and done next to nothing to reciprocate unilateral American concessions (Diehl 2018; Landler 2018b; Landler \& Wong 2019). Saudi Arabia and Israel have military superiority over Iran even without the United States, while Iran's advantages are rooted in its unconventional hybrid warfare capabilities, perfectly suited for projecting influence into Syria, Iraq, and Yemen. In addition, Iran can turn to Russia, China for support any time (Harrison 2018:13-14).

${ }^{132}$ As Mearsheimer and Walt (2016) note, promoting peace or halt genocides is not among the aims of this realist grand strategy, and the United States should not commit military forces for this sole purpose. However, adopting this strategy would not preclude such operations. 


\section{CONCLUSIONS}

The main goal of this project was to analyze the changes in the balance of power of the Middle East applying the concept of foreign intervention and the theory of the balance of power as analytical tools. In order to be able to take on such a complicated task, we designed a framework based on the possible applicability of the balance of power theory in the contemporary Middle East, while we also noted the known and anticipated limits of the design. Influence, power, the use of force, foreign intervention, threat perception, and alliance formation are key interconnected concepts of International Relations. Using the balance of power theory as an analytical concept can help to evaluate and put into context international events and processes in world politics.

The balance of power theory can still be applied as an analytical tool. However, it must be noted that as uncertainty grows, and the number of variables increases in the international system it can only provide limited results. Calculations based on the balance of power theory have become much more complicated since the end of the bipolar order of the Cold War, which was relatively easy in contrast of the case of today's "nonpolar" world and the "disordered" Middle East region. Therefore, in case of an unstable security environment, great caution must be exercised when applying the balance of power theory - especially in the Middle East -, and it must be kept in mind that uncertainties can make one's calculations even irrelevant or transient.

Foreign military interventions are key since the use of regular military forces of one state within the territory of another country represents a convention-breaking action in order to influence the conflict process in that country. In addition, unlike proxy war, where one state uses proxies in indirect engagements in another country, a direct foreign military intervention shows the strongest commitment of the intervener to that particular alliance or political goal. Moreover, regarding the methodological challenges of measuring power in the international system, the use of force, that is foreign military intervention is also an indicator of an actor's power in the international arena, or as Moul (1989) put it, it is the fighting power itself that needs to be measured. In other words, in addition to the components of national capabilities, other qualitative factors are relevant in determining power. The CINC score itself is inadequate for measuring changes in the balance of power, however, as a quantitative methodological tool it makes possible to monitor processes and to perform comparative analyzes. Moreover, a proxy-type indirect involvement tends to have only a limited influence 
over a given actor, and this influence is not equal to the power manifested in the direct use of military force. This is a significant qualitative difference, which is important to keep in mind even when applying a broader definition of intervention.

Our main research question was whether a foreign military intervention can induce notable shifts in the regional balance of power through the redistribution of the national capabilities among states? In case of large-scale military interventions, their negative impact regarding the national capabilities can be easily identified, while earlier studies have concluded already that during a post-war period the redistribution of capabilities occurs (Ikenberry 2001). Depending on its extent, an external intervention can be system-wide, which can change the whole system, or it can be an in-system intervention with limited impact that does not change the system itself. This differentiation can be made in case of Iraq, where the 2003 invasion as a regime-changing military intervention can be considered a balance-of-power system-altering military action due to the removal of one of the main actors of the system. However, the military interventions in Iraq cannot be assessed in isolation as unrelated events, as each has played a role in shaping the changing strategic environment.

Our additional research questions regarding the impact of foreign military intervention on threat perception, alliance formation, and the activities of non-state actors proved to be key in understanding the context of the regional strategic landscape. Based on previous studies and as a partial result of this research project, the relationship between foreign interventions and threat perception can be reasonably assumed, while as Walt argued, threat perception is a key driver of alliance formation. Thus, it can be stated that the relative changes of national capabilities can influence the threat perceptions of other actors in the international system, while perceived or real threats are important drivers of alliance formation processes. In addition, the story of the Islamic State provides enough evidence for us to say that due to decreasing national capabilities and increasing anarchic patterns, non-state actor activity can increase as well, as the target state cannot maintain its monopoly on the legitimate use of violence.

Iraq has seen the most foreign military intervention by powerful states in the last three decades, while its central location alone would be enough to be considered a state of great importance in the region. Thus, if we want to understand the current security challenges of the Middle East and the changes of the strategic environment in the region, Iraq is the starting point, because what happened there can help a lot to place everything into context for an observer. 
The example of Iraq is a good illustration of how external intervention can influence the development of regional threat perceptions, and thus alliance formation as well. The Gulf War took place after the Iraq-Iran war weakened Saddam Hussein's position during the 1980s and the United States did not prevent him from invading Kuwait in 1990. He acted as a rational actor and should not necessarily have foreseen a coalition forming against him to restore the status quo and thus the regional balance of power. Although Saddam Hussein remained in power after the Gulf War, and Iraq could maintain some of its military strength, the state's serious economic problems also remained. Moreover, the imposition of sanctions and two no-fly zones caused further significant damage to both the economy and state institutions during the 1990s.

The Gulf War was the first major military operation by the United States after the end of the Cold War, which is an example of an internationally supported military intervention to restore the status quo and the regional balance of power. The 2003 invasion of Iraq can be seen as a continuation of the Gulf War, as the US was effectively in a low-intensity conflict with Iraq from 1991 through 2003. During this period, economic sanctions began to take effect, state institutions started to decline, hyperinflation set in, and poverty rates increased. In contrast of the Gulf War, the 2003 Iraq War marked a major deviation from the international norms, as it was the first preemptive war in a century, which later turned out to be waged on the basis of false intelligence reports. However, this unnecessary war had wide implications and serious regional consequences, as the removal of Saddam Hussein was followed by a long occupation, a violent insurgency, and a challenging state building process.

We can classify the examined external military interventions according to their role from a regional balance of power perspective. The Gulf War can be considered as a balancing intervention, in the sense that it was carried out to restore the status quo and the regional balance of power, with international support. In contrast, the invasion of Iraq in 2003 can be seen more as a disruptive intervention, as it upset the regional order by breaking with international norms. The international response against the Islamic State in Iraq can also be seen as an asymmetric balancing intervention, as it was carried out with the consent of the Iraqi government by external actors in the name of the fight against terrorism, that is, against a non-state actor.

Iraq has been in focus of US national security policy since decades, and today, this centrally located state can be considered as the main battleground for regional influence against Iran, as it long has been the most important arena for Iranian foreign policy as well. The 2003 invasion of Iraq contributed to the change of the regional balance of power, which 
shifted to non-Arab states, namely to the United States, Turkey, and Iran. Due to these changes in the balance of power, Iran had strategic gains, and was able to increase its regional influence. However, it must be noted that Iran was very active in the region even before the Iraq War, and increasing its influence was not without any obstacles. The strategic winner of the external military interventions in Iraq was Iran, which assessed the situation as a rational regional player and increased its influence in the region as such. In line with the changing threat perceptions, there has been a corresponding rapprochement between Israel and Saudi Arabia. Meanwhile, without a comprehensive security sector reform, threats rooted in state failure will persist in Iraq. Non-state actors and terrorist organizations will be able to find the opportunity to operate, while the Iraqi state remains vulnerable to the meddling of external actors.

In addition, further conclusions can be drawn from this research project. It is worth noting that changes in the balance of power or in the formation of alliances will not necessarily be proportional to the changes in national capabilities due to external intervention. Moreover, even a small-scale external intervention can lead to significant changes in the balance of power, through its impact on threat perception.

The use of the CINC score system may necessitate the differentiation of external interventions according to whether they may reduce (negative) or increase (positive) national capabilities. However, solely applying the CINC score as a quantitative methodological tool is inadequate for distinguishing between positive and negative interventions in the target state. This is because even a large-scale military intervention on the side of the government does not necessarily lead to a notable increase in the state's national capabilities, while it is a clear signal of alliance tightness, which can have a significant impact on threat perceptions, and that can induce significant changes in the balance of power.

The operation of the balance of power can be presumed if there is no preponderance of power in the international or regional system. In case of hegemony, eventually a balancing alliance must form against the hegemon, or an emerging dissatisfied power must question the status quo, and make an attempt to change it, according to the power transition theory. The theory of the balance of power may become irrelevant in the event of the emergence of hegemony, and especially in the absence of an actor questioning the status quo. In this case, the international order described by the theory cannot prevail, the system is organized hierarchically, and its operation is ensured by the power of the hegemon.

The increase in the number of internationalized armed conflicts is partly due to the destabilization of the regional order as some states in the system have collapsed or become 
failed states, at least in the sense of the central government in these states not functioning properly. As a result, both uncertainty and the number of variables increased, while the deteriorating security environment is forcing the rational actors to act, as the realist thinking would suggest. However, this process fosters the emergence of a "pre-Westphalian" hybrid regional system in which state sovereignty is not complete since the state does not have a monopoly on the legitimate use of violence. Thus, external, and non-state actors become the actual determinants of the regional order. But, in this pre-Westphalian order the balance of power theory must be applied with caution. Since the realist school considers states to be the main actors in the international system, it goes without saying that the classical theory of the balance of power disregards non-state actors.

The regional order can be shaped by large-scale external military interventions through the redistribution of power capabilities, at least among democracies, as Ikenberry (2001) put it earlier. In case of partly democratic or authoritarian regimes, while the redistribution of power capabilities can take place in a similar way, establishing and maintaining a regional order becomes harder. 


\section{Bibliography}

AFP, France 24 (2021): US pledges Iraq troop withdrawal but without timeline. Available at: https://www.france24.com/en/live-news/20210407-us-pledges-iraq-troop-withdrawalbut-without-timeline.

Al Jazeera (2020): Who is Mustafa al-Kadhimi, Iraq's new prime minister? Available at: https://www.aljazeera.com/news/2020/5/7/who-is-mustafa-al-kadhimi-iraqs-newprime-minister.

Al Jazeera (2021a): No timeline as US to move remaining combat troops out of Iraq. Available at: https://www.aljazeera.com/news/2021/4/7/us-agrees-to-move-remainingcombat-troops-from-iraq.

Al Jazeera (2021b): Iran nuclear talks: What you need to know. Available at: https://www.aljazeera.com/news/2021/4/15/irans-nuclear-talks-explained.

Al Jazeera (2021c): Saudi crown prince strikes conciliatory tone towards rival Iran. Available at: https://www.aljazeera.com/news/2021/4/28/mbs-us-and-riyadh-strategic-partnerswith-few-differences.

Alghafli, A. (2018): The Islamic Military Alliance to Fight Terrorism: Structure, Mission, and Politics. Journal of Regional Security, 12(2), pp. 157-185. DOI:10.11643/issn.2217995X172SPA70.

Al-Istrabadi, F., \& Ganguly, S. (Eds.). (2018): The Future of ISIS: Regional and International Implications. Washington, D.C.: Brookings Institution Press.

Altfeld, M. (1984): The Decision to Ally: A Theory and Test. The Western Political Quarterly, 37(4), pp. 523-544.

Andersen, L. (2017): The Mole and the Mallet: Islamic State and al-Qaeda in the 'Thirty Years' War' in the Middle East. Connections, 16(1), pp. 7-24.

Anderson, C., Mitchell, S. and Schilling, E. (2016): Kantian Dynamics Revisited: TimeVarying Analyses of Dyadic IGO-Conflict Relationships. International Interactions, 42(4), pp. 644-676.

Andor, L., Tálas, P. and Valki, L. (2008): Irak - Háborúra ítélve. Budapest: Zrínyi Kiadó.

Arango, T. and Gordon, M. (2017): Iraqi Prime Minister Arrives in Mosul to Declare Victory Over ISIS. The New York Times, p. A1. Available at: https://www.nytimes.com/2017/07/09/world/middleeast/mosul-isis-liberated.html.

Arango, T. and Schmidt, M. (2011): Last Convoy of American Troops Leaves Iraq. The New York Times, p.A6. Available at: https://www.nytimes.com/2011/12/19/world/middleeast/last-convoy-of-americantroops-leaves-iraq.html.

Arany, A., N. Rózsa, E. and Szalai, M. (2016): Az Iszlám Állam Kalifátusa: Az átalakuló Közel-Kelet. Budapest: Osiris Kiadó - Külügyi és Külgazdasági Intézet.

Archive.nytimes.com. (2003): Q\&A: What Is the "Coalition of the Willing?". Available at: https://archive.nytimes.com/www.nytimes.com/cfr/international/slot1_032803.html?m cubz. 
Associated Press (2008): A Timeline of Iraq War, Troop Levels. Available at: https://web.archive.org/web/20141023033147/.

Aydin, A. (2010): Where Do States Go? Strategy in Civil War Intervention. Conflict Management and Peace Science, 27(1), pp. 47-66.

Balch-Lindsay, D. and Enterline, A. (2000): Killing Time: The World Politics of Civil War Duration, 1820-1992. International Studies Quarterly, 44(4), pp. 615-642.

Balch-Lindsay, D., Enterline, A., \& Joyce, K. (2008): Third-Party Intervention and the Civil War Process. Journal of Peace Research, 45(3), pp. 345-363.

Baldwin, D. (1979): Power Analysis and World Politics: New Trends versus Old Tendencies. World Politics, 31(2), pp. 161-194.

Banai, H. (2018): International and Regional Responses: An Appraisal. In: Al-Istrabadi, F., \& Ganguly, S. (Eds.).: The Future of ISIS: Regional and International Implications (pp. 151-172). Washington, D.C.: Brookings Institution Press.

Bannelier-Christakis, K. (2016): Military Interventions against ISIL in Iraq, Syria and Libya, and the Legal Basis of Consent. Leiden Journal of International Law, 29(3), pp. 743 775. DOI:10.1017/S0922156516000303.

Barnett, M., \& Levy, J. (1991): Domestic Sources of Alliances and Alignments: The Case of Egypt, 1962-73. International Organization, 45(3), pp. 369-395.

Barzegar, K. (2008): Iran's Foreign Policy in Post-Invasion Iraq. Middle East Policy, 15(4), pp.47-58. Available at:

https://www.belfercenter.org/sites/default/files/files/publication/Barzegar_Middle_Eas t_Policy_Winter_2008.pdf.

Bayar, M. and Ertan, S. (2016): The Impact of Military Interventions on the Integration of Muslim Immigrants in Western Countries, 1990-2013. Global Society, 30(4), pp. 624641.

BBC News (1998): Containment: The Iraqi no-fly zones. Available at: http://news.bbc.co.uk/2/hi/events/crisis_in_the_gulf/forces_and_firepower/244364.stm

BBC News (2011): Iraq war in figures. Available at: https://www.bbc.com/news/worldmiddle-east-11107739.

BBC News (2017): Iraqi Kurds decisively back independence in referendum. Available at: https://www.bbc.com/news/world-middle-east-41419633.

BBC News (2019): Iraq unrest: PM Abdul Mahdi to resign after bloodiest day in protests. Available at: https://www.bbc.com/news/world-middle-east-50600495.

BBC News. (2018): Myanmar Rohingya: What you need to know about the crisis. Available at: https://www.bbc.com/news/world-asia-41566561.

Bell, S. and Long, A. (2016). Trade Interdependence and the Use of Force: Do Issues Matter? International Interactions, 42(5), pp. 750-773.

Bell, S., Frank, R. and Macharia, P. (2013): Passenger or Driver? A Cross-National Examination of Media Coverage and Civil War Interventions. International Interactions, 39(5), pp. 646-671.

Bennett, D. and Stam, A. (2003): The Behavioral Origins of War. Ann Arbor: University of Michigan Press. 
Betts, R. K. (1992): Systems for Peace or Causes of War? Collective Security, Arms Control, and the New Europe. International Security, 17(1), pp. 5-43.

Betts, R. K. (1995): What Will It Take to Deter the United States? Parameters, 25(1), pp. 7079, https://press.armywarcollege.edu/parameters/vol25/iss 1/12.

Blainey, G. (1988): The Causes of War. New York: Free Press.

Boehmer, C., Gartzke, E. and Nordstrom, T. (2004): Do Intergovernmental Organizations Promote Peace? World Politics, 57(1), pp. 1-38.

Bolan, C. J. (2017): The US Balance-of-Power Strategy in the Gulf is Collapsing. But It Never Had a Chance Anyway. Defense One. Available at: https://www.defenseone.com/policy/2017/08/us-balance-power-strategy-gulfcollapsing-it-never-had-chance-anyway/140005/.

Borger, J. (2004): There were no weapons of mass destruction in Iraq. The Guardian. Available at: https://www.theguardian.com/world/2004/oct/07/usa.iraq1.

Brandt, P., Mason, T., Gurses, M., Petrovsky, N. and Radin, D. (2008): When and How the Fighting Stops: Explaining the Duration and Outcome of Civil Wars. Defence and Peace Economics, 19(6), pp. 415-434.

Brooks, S., \& Wohlforth, W. (2008): World Out of Balance: International Relations and the Challenge of American Primacy. Princeton; Oxford: Princeton University Press.

Brown, D. (2018): 15 years ago, the US invaded Iraq — here's how it changed the Middle East country. Business Insider. Available at: https://www.businessinsider.com/usinvasion-iraq-anniversary-how-it-changed-middle-east-country-2018-3.

Bucher, L. (1887): Über politische Kunstausdrücke. II. Politisches Gleichgewicht. Deutsche Revue, XII, pp. 333-39.

Bull, H. (2002): Anarchical Society. 3rd ed. Houndmills: Palgrave Macmillan.

Bunzel, C. (2015): From Paper State to Caliphate: The Ideology of the Islamic State. The Brookings Project on U.S. Relations with the Islamic World, Center for Middle East Public Policy, Analysis Paper, No 19. Washington, D.C.: Brookings Institution. Available at: https://www.brookings.edu/wp-content/uploads/2016/06/The-ideologyof-the-Islamic-State-1.pdf.

Butterfield, H. and Wight, M. (1968): Diplomatic Investigations: Essays in the Theory of International Politics. Cambridge: Harvard University Press.

Butterworth, R. and Scranton, M. (1976): Managing Interstate Conflict, 1945-74. Pittsburgh: University Center for International Studies, University of Pittsburgh.

Buzan, B. and Wæver, O. (2003): Regions and Powers; the Structure of International Security. Cambridge: Cambridge University Press.

Calleo, D. P. (1987): Beyond American Hegemony. New York: Basic Books.

Callimachi, R. (2019): Described as Defeated, Islamic State Punches Back With Guerrilla Tactics. The New York Times, p.A7. Available at: https://www.nytimes.com/2019/01/21/world/middleeast/isis-syria-attack-iraq.html.

Cengiz, S. (2021): Turkey, Iran flex muscles in tacit regional power struggle. Arab News, Available at: https://www.arabnews.com/node/1816456. 
Chacha, M. and Stojek, S. (2016): Colonial Ties and Civil Conflict Intervention: Clarifying the Causal Mechanisms. Conflict Management and Peace Science, 36(1), pp. 42-62.

Choi, S. (2011): Does U.S. Military Intervention Reduce or Increase Terrorism? Annual Meeting Paper. American Political Science Association.

Choi, S. and Powers, M. (2010): Military Interventions and Transnational Terrorism: An Intense Relationship. Annual Meeting Paper. American Political Science Association.

Christensen, T. (1996): Useful Adversaries: Grand Strategy, Domestic Mobilization, and Sino-American Conflict, 1947-1958. Princeton, N.J.: Princeton University Press.

Chulov, M. (2012): Iraq's growing power vacuum leaves the door open for al-Qaida. The Guardian. Available at: https://www.theguardian.com/world/2012/jul/23/iraqvacuum-terrorism-alqaida-islamists.

Clarke, R. A. (2004): Against All Enemies. New York: Free Press.

Claude, I. L. Jr. (1962): Power and International Relations. New York: Random House, p. 393.

Claude, I. L. Jr. (1989): The Balance of Power Revisited. Review of International Studies, 15(2), pp. 77-85.

Clausen, M. (2019): Breaking the cycle: Iraq following the military defeat of Islamic State. DIIS Report, No 2, ISBN 978-87-7605-942-2. Copenhagen: Danish Institute for International Studies.

Cline, R. (1975): World Power Assessment: A Calculus of Strategic Drift. Washington, D.C.: Georgetown University, The Center for Strategic and International Studies.

Clodfelter, M. (2001): Warfare and Armed Conflicts: A Statistical Reference to Casualty and Other Figures, 1500-2000. Jefferson, N.C.: McFarland.

Cockburn, P. (1997): Revealed: how the West set Saddam on the bloody road to power. The Independent. Available at: https://www.independent.co.uk/news/world/revealed-howthe-west-set-saddam-on-the-bloody-road-to-power-1258618.html.

Coker, M. and Hassan, F. (2017): Iraq Prime Minister Declares Victory Over ISIS. The New York Times, p. A14. Available at:

https://www.nytimes.com/2017/12/09/world/middleeast/iraq-isis-haider-al-abadi.html.

Colaresi, M., \& Thompson, W. (2002): Hot Spots or Hot Hands? Serial Crisis Behavior, Escalating Risks, and Rivalry. The Journal of Politics, 64(4), 1175-1198.

Collings, S. (2019): Desert Storm: A Look Back. U.S. Department of Defense. Available at: https://www.defense.gov/Explore/Features/story/Article/1728715/desert-storm-a-lookback/.

Collinson, S. (2014): Obama sends 1,500 troops to Iraq. CNN. Available at: https://edition.cnn.com/2014/11/07/politics/obama-sends-troops-to-iraq/index.html.

Connable, B. (2020): An Enduring American Commitment in Iraq: Shaping a Long-Term Strategy with Iraqi Army Partners. Santa Monica, CA: RAND Corporation. DOI: https://doi.org/10.7249/PE353

Cook, J. (2021): Why Israel is joining the Pentagon's 'Arab Nato'. Middle East Eye. Available at: https://www.middleeasteye.net/opinion/why-israel-joining-pentagon-arab-nato. 
Correlatesofwar.org. (2019): Data Sets - Correlates of War. [online] Available at: http://www.correlatesofwar.org/data-sets.

Cox, R. W. (1981): Social Forces, States and World Orders: Beyond International Relations Theory. Millennium, 10(2), pp. 126-155. DOI:10.1177/03058298810100020501.

Csicsmann, L., N. Rózsa, E. and Szalai, M. (2017): The MENA Region in the Global Order: Actors, Contentious Issues and Integration Dynamics. Methodology and Concept Papers. [online] Middle East and North Africa Regional Architecture (MENARA): Mapping Geopolitical Shifts, Regional Order and Domestic Transformations. Available at: http://www.menaraproject.eu/wpcontent/uploads/2017/11/menara_cp_4.pdf.

Dahl, R. A. (1957): The Concept of Power. Behavioral Science, 2(3), pp. 201-215. Available at: https://welcometorel.files.wordpress.com/2008/08/conceptpower_r-dahl.pdf.

Danilovic, V. (2002): When the Stakes Are High: Deterrence and Conflict among Major Powers. Ann Arbor: University of Michigan Press, pp. 71-97.

Darwich, M. (2018): The Saudi Intervention in Yemen: Struggling for Status. Insight Turkey, 20(2), pp. 125-142.

David, S. R. (1991): Explaining Third World Alignment. World Politics, 43(2), pp. 233-256.

Davutoğlu, A. (2016): Stratégiai mélység - Törökország nemzetközi helyzete. Budapest: Antall József Tudásközpont.

Daxecker, U. E. (2011): Rivalry, Instability, and the Probability of International Conflict. Conflict Management and Peace Science, 28(5), pp. 543-565.

De Mesquita, B. (1975): Measuring Systemic Polarity. The Journal of Conflict Resolution, 19(2), pp. 187-216.

De Mesquita, B. (1985): The War Trap Revisited: A Revised Expected Utility Model. The American Political Science Review, 79(1), pp. 156-177. DOI:10.2307/1956125.

Dearden, L. (2016): Former US military adviser David Kilcullen says there would be no Isis without Iraq invasion. The Independent. Available at: https://www.independent.co.uk/news/world/middle-east/iraq-war-invasion-causedisis-islamic-state-daesh-saysus-military-adviser-david-kilcullen-a6912236.html.

DeRouen, K. (2000): Presidents and the Diversionary Use of Force: A Research Note. International Studies Quarterly, 44(2), pp. 317-328.

Deutsch, K. (1964): External Involvement in Internal Wars. In: H. Eckstein, ed., Internal War: Problems and Approaches. New York: Free Press of Glencoe.

Devlin, J. F. (1991): The Baath Party: Rise and Metamorphosis. The American Historical Review, 96(5), pp. 1396-1407.

Diehl, J. (2018): Trump's Middle East ambitions have been exposed as misguided fantasies. The Washington Post. Available at: http://www.washingtonpost.com/opinions/global-opinions/trumps-middle-eastambitions-have-been-exposed-as-misguided-fantasies/2018/10/14/5e007bc8-cd6911e8-920f-dd52e1ae4570_story.html.

Diehl, P. F., \& Goertz, G. (1988): Territorial Changes and Militarized Conflict. The Journal of Conflict Resolution, 32(1), pp. 103-122. 
Dixon, J. (2013): Civil War Termination in the Middle East and North Africa, 1816-2012. Annual Meeting Paper. American Political Science Association.

Dodge, T. (2006): War and Resistance in Iraq: From Regime Change to Collapsed State. In: Fawn, R. and Hinnebusch, R. (2006): The Iraq War: Causes and Consequences. Boulder, London: Lynne Reinner Publishers.

Dodge, T. (2012): Iraq: From War to a New Authoritarianism. London: Routledge.

Doyle, M. W. (1997): Ways of War and Peace. New York: W. W. Norton.

Duffield, J. S. (2012): Oil and the Decision to Invade Iraq. Political Science Faculty Publications. 27. Available at: https://core.ac.uk/download/pdf/214061761.pdf.

Duncan, G., \& Siverson, R. (1982): Flexibility of Alliance Partner Choice in a Multipolar System: Models and Tests. International Studies Quarterly, 26(4), pp. 511-538.

Dunér, B. (1981): Proxy Intervention in Civil Wars. Journal of Peace Research, 18(4), pp. 353-361.

Duran, B. and Yilmaz, N. (2013): Islam, Models and the Middle East: The New Balance of Power Following the Arab Spring. Perceptions, 18(4), pp.139-170. Available at: http://sam.gov.tr/pdf/perceptions/Volume-XVIII/winter-2013/Duran_Yilmaz.pdf.

Einsiedel, S. (2017): Civil War Trends and the Changing Nature of Armed Conflict. Occasional Paper 10. Tokyo: United Nations University Centre for Policy Research.

Eisenstadt, M. (1996): Target Iraq's Republican Guard. Middle East Quarterly, 3(4), pp. 1116.

Ekşi, M. (2017): Regional Hegemony Quests in the Middle East from the Balance of Power System to the Balance of Proxy Wars: Turkey as Balancing Power for the Iran - Saudi Rivalry. Journal of Gazi Academic View, 11(21), pp. 133-156. DOI: 10.19060/gav.379597

Elbadawi, I. and Sambanis, N. (2000): External Interventions and the Duration of Civil Wars. Policy Research Working Paper 2433. Washington D.C.: The World Bank, Development Research Group, Public Economics.

Enterline, A. (1998): Regime Changes, Neighborhoods, and Interstate Conflict, 18161992. The Journal of Conflict Resolution, 42(6), pp. 804-829.

Eriksson, M., Wallensteen, P. and Sollenberg, M. (2003): Armed Conflict, 19892002. Journal of Peace Research, 40(5), pp. 593-607.

Everstine, B. W. (2021): Pentagon Shifts Israel to CENTCOM Responsibility. Air Force Magazine. Available at: https://www.airforcemag.com/pentagon-shifts-israel-tocentcom-responsibility/.

Falk, R. (1964): The Legitimacy of Legislative Intervention by the United Nations. In: R. Stanger, ed., Essays on Intervention. Columbus: Ohio State University Press, pp. 3161.

Fang, S., Johnson, J. and Leeds, B. (2014): To Concede or to Resist? The Restraining Effect of Military Alliances. International Organization, 68(4), pp. 775-809.

Fawn, R. and Hinnebusch, R. (2006): The Iraq War: Causes and Consequences. Boulder, London: Lynne Reinner Publishers. 
Fearon, J. D. (1994): Domestic Political Audiences and the Escalation of International Disputes. The American Political Science Review, 88(3), pp. 577-592.

Fearon, J. D. (1995): Rationalist Explanations for War. International Organization, 49(3), pp. $379-414$.

Feith, D. (2009): War and Decision. New York: HarperCollins.

Ferris, W. H. (1973): The Power Capabilities of Nation-States: International Conflict and War. Lexington, Mass: Lexington Books.

Findley, M., \& Teo, T. (2006): Rethinking Third-Party Interventions into Civil Wars: An Actor-Centric Approach. The Journal of Politics, 68(4), pp. 828-837.

Fisher, I. and Wong, E. (2004): The Reach of War: The Insurgency; Iraq's Rebellion Develops Signs Of Internal Rift. The New York Times, p.1001001. Available at: https://www.nytimes.com/2004/07/11/world/the-reach-of-war-the-insurgency-iraq-srebellion-develops-signs-of-internal-rift.html.

Forsberg, E. (2016): Transnational Dimensions of Civil Wars: Clustering, Contagion, and Connectedness. In: T. Mason and S. Mitchell, ed., What Do We Know about Civil Wars? Lanham, Boulder, New York, London: Rowman \& Littlefield, pp.75-90.

Foster, D. and Keller, J. (2014): Leaders' Cognitive Complexity, Distrust, and the Diversionary Use of Force. Foreign Policy Analysis, 10(3), pp. 205-223.

Fox News (2004): Transcript: David Kay on 'Fox News Sunday. Available at: https://www.foxnews.com/story/transcript-david-kay-on-fox-news-sunday.

Fox, J., James, P., \& Li, Y. (2009): Religious Affinities and International Intervention in Ethnic Conflicts in the Middle East and Beyond. Canadian Journal of Political Science / Revue Canadienne De Science Politique, 42(1), pp. 161-186.

Friedberg, A. (2010): The Weary Titan. Princeton, N.J.: Princeton University Press.

Friedman, B. (2012): Battle for Bahrain: What One Uprising Meant for the Gulf States and Iran. World Affairs, 174(6), pp. 74-84.

Fuller, A. L. (2020): Israel and the Neoconservatives: Zionism and American Interests. London: Lexington Books.

Gaddis, J. (1986): The Long Peace: Elements of Stability in the Postwar International System. International Security, 10(4), pp. 99-142.

Gartzke, E. and Westerwinter, O. (2016): The Complex Structure of Commercial Peace Contrasting Trade Interdependence, Asymmetry, and Multipolarity. Journal of Peace Research, 53(3), pp. 325-343.

Gause, F. (1994): The Illogic of Dual Containment. Foreign Affairs, 73(2), pp. 56-66.

Gee, J. (2006): From Sanctions to Occupation: The US Impact on Iraq. In: Fawn, R. and Hinnebusch, R. (2006): The Iraq War: Causes and Consequences. Boulder, London: Lynne Reinner Publishers.

Gent, S. (2008): Going in When It Counts: Military Intervention and the Outcome of Civil Conflicts. International Studies Quarterly, 52(4), pp. 713-735.

Gentz, (1806): Fragmente aus der neutsten Geschichte des politischen Gleichgewichts in Europa. St. Petersburg, pp. 1-8. 
George, A. (1979): Case Studies and Theory Development: The Method of Structured, Focused Comparison. In: P. Lauren, ed., Diplomacy: New Approaches in History, Theory, and Policy. New York: Free Press.

George, A. and McKeown, T. (1985): Case Studies and Theories of Organizational Decisionmaking. In: Advances in Information Processing in Organizations, vol. 2. JAI Press.

Ghosn, F., Palmer, G., \& Bremer, S. (2004): The MID3 Data Set, 1993-2001: Procedures, Coding Rules, and Description. Conflict Management and Peace Science, 21(2), pp. 133-154.

Gibbons-Neff, T. (2021): U.S. Military Begins Final Withdrawal From Afghanistan. The New York Times. Available at: https://www.nytimes.com/2021/04/25/world/asia/usamilitary-withdrawal-afghanistan.html.

Gibler, D. and Vasquez, J. (1998): Uncovering the Dangerous Alliances, 14951980. International Studies Quarterly, 42(4), pp. 785-807.

Gilovich, T., Griffin, D. and Kahneman, D. (2002): Heuristics and Biases: The Psychology of Intuitive Judgment. Cambridge: Cambridge University Press.

Gilpin, R. (1999): War and Change in World Politics. Cambridge: Cambridge University Press.

Gleditsch, N., Christiansen, L. and Hegre, H. (2007): Democratic Jihad? Military Intervention and Democracy. Post-Conflict Transitions. Washington, DC: World Bank.

Gleditsch, N., Wallensteen, P., Eriksson, M., Sollenberg, M. and Strand, H. (2002): Armed Conflict 1946-2001: A New Dataset. Journal of Peace Research, 39(5), pp. 615-637.

Goldstein, J. (2012): Winning the War on War: The Decline of Armed Conflict Worldwide. New York: Penguin Group.

Goldstone, J., Bates, R., Epstein, D., Gurr, T., Lustik, M., Marshall, M., . . W Woodward, M. (2010): A Global Model for Forecasting Political Instability. American Journal of Political Science, 54(1), pp. 190-208.

Gooch, G. (1939): European Diplomacy Before the War in the Light of the Archives. International Affairs (Royal Institute of International Affairs 1931-1939), 18(1), pp. 77-102.

Goodarzi, J. (2020): Iran and the Syrian civil war: To the bitter end. Confluences Méditerranée, 113(2), pp. 177-191. DOI:10.3917/come.113.0177.

Greig, J. and Enterline, A. (2017): Correlates of War Project National Material Capabilities (NMC) Data Documentation Version 5.0. Denton: University of North Texas: Department of Political Science. Available at: http://www.correlatesofwar.org/datasets/national-material-capabilities/nmc-codebook-v5-1/at_download/file.

Grunberg, I. (1990): Exploring the "Myth" of Hegemonic Stability. International Organization, 44(4), pp. 431-477.

Gulick, E. (1943): The Balance of Power. Philadelphia: Pacifist Research Bureau, pp. 14-15.

Gulick, E. (1982): Europe's Classical Balance of Power. Westport: Greenwood Press. 
Haaretz (2018): FULL TEXT: Prime Minister Benjamin Netanyahu's 2018 UN General Assembly Speech. Haaretz. Available at: https://www.haaretz.com/israel-news/fulltext-benjamin-netanyahu-s-2018-un-general-assembly-speech-1.6513185.

Haas, E. (1953): The Balance of Power: Prescription, Concept, or Propaganda. World Politics, 5(4), pp. 442-477.

Hansen, B. (2001): Unipolarity and the Middle East. New York: St. Martin's Press.

Harkavy, R. (1982): Great Power Competition for Overseas Bases: The Geopolitics of Access Diplomacy. New York: Pergamon Press.

Harrison, R. (2018): Shifts in the Middle East Balance of Power: An Historical Perspective. Mecca: Aljazeera Centre for Studies. Available at:

http://studies.aljazeera.net/en/reports/2018/09/shifts-middle-east-balance-powerhistorical-perspective-180902084750811.html.

Hart, J. (1976): Three Approaches to the Measurement of Power in International Relations. International Organization, 30(2), pp. 289-305.

Hegre, H. (2014): Democracy and Armed Conflict. Journal of Peace Research, 51(2), pp. $159-172$.

Hensel, P. (1994): One Thing Leads to Another: Recurrent Militarized Disputes in Latin America, 1816-1986. Journal of Peace Research, 31(3), pp. 281-297.

Hermann, M., \& Kegley, C. (1996): Ballots, a Barrier Against the Use of Bullets and Bombs: Democratization and Military Intervention. The Journal of Conflict Resolution, 40(3), pp. 436-459.

Hermann, M., \& Kegley, C. (2001): Democracies and Intervention: Is There a Danger Zone in the Democratic Peace? Journal of Peace Research, 38(2), pp. 237-245.

Herz, J. (1950): Idealist Internationalism and the Security Dilemma. World Politics, 2(2), pp. 157-180.

Hinnebusch, R. (2006): Hegemonic Stability Theory Reconsidered: Implications of the Iraq War. In: Fawn, R. and Hinnebusch, R.: The Iraq War: Causes and Consequences (pp. 283-322). Boulder, London: Lynne Reinner Publishers.

Hinnebusch, R. (2007): The US Invasion of Iraq: Explanations and Implications. Critique: Critical Middle Eastern Studies, 16(3), pp. 209-228.

DOI:10.1080/10669920701616443.

Hirst, D. (1968): Ba'athists now put Iraq first. The Guardian. Available at: https://www.theguardian.com/world/1968/jul/18/iraq.davidhirst.

Hoffmann, S. (1968): Balance of Power. In: D. Sills, ed., International Encyclopedia of the Social Sciences, Vol. 1. New York: Macmillan.

Hoffmann, S. (1971): International Law and the Control of Force. In: K. Deutsch and S. Hoffmann, ed., The Relevance of International Law. Garden City: Anchor Books, pp. 34-66.

Holbraad, C. (1990): Conclusion: Hedley Bull and International Relations. In: J. Miller and R. Vincent, ed., Order and Violence: Hedley Bull and International Relations. Oxford: Clarendon Press, pp. 186-204. 
Holsti, K. (1998): International Relations Theory and Domestic War in the Third World: The Limits of Relevance. In: S. Neuman, ed., International Relations Theory and the Third World. New York: St. Martin's Press.

Holsti, O., Hopmann, P. and Sullivan, J. (1985): Unity and Disintegration in International Alliances: Comparative Studies. Lanham, Md: University Press of America.

Howard, M. (1984): The Causes of Wars. The Wilson Quarterly, 8(3), pp. 90-103.

Hrw.org. (2019): Rohingya Crisis. Available at: https://www.hrw.org/tag/rohingya-crisis.

Hubbard, B., Kershner, I. and Barnard, A. (2018): Iran, Deeply Embedded in Syria, Expands 'Axis of Resistance'. The New York Times. Available at: https://www.nytimes.com/2018/02/19/world/middleeast/iran-syria-israel.html.

Hudson, D. (2014): President Obama: "We Will Degrade and Ultimately Destroy ISIL". Obama White House. Available at: https://obamawhitehouse.archives.gov/blog/2014/09/10/president-obama-we-willdegrade-and-ultimately-destroy-isil.

Hudson, M. C. (1996): To Play the Hegemon. Middle East Journal, 50(3), pp. 329-343.

Hume, D. (1777): Of the Balance of Power. In: D. Hume and E. Miller, ed., Essays, Moral, Political, and Literary. Indianapolis: Liberty Fund, pp. 337-338.

Ibrahim, A. (2019): Muhasasa, the political system reviled by Iraqi protesters. Al Jazeera. Available at: https://www.aljazeera.com/news/2019/12/4/muhasasa-the-politicalsystem-reviled-by-iraqi-protesters.

Icpsr.umich.edu. (2019): Search Variables. Available at: https://www.icpsr.umich.edu/icpsrweb/ICPSR/ssvd/series/232/variables.

Ikenberry, G. J. (1999): Liberal hegemony and the future of American postwar order. In: T. V. Paul and J. Hall, ed., International Order and the Future of World Politics. Cambridge: Cambridge University Press, pp. 123-145.

Ikenberry, G. J. (2001): After Victory. New Jersey: Princeton University Press.

Ikenberry, G. J. (2001): American power and the empire of capitalist democracy. Review of International Studies, 27(5), pp. 191-212. DOI:10.1017/S0260210501008087.

Ikenberry, G. J. (2007): America Unrivaled: The Future of the Balance of Power. Ithaca, New York: Cornell University Press.

Inbar, E. (2021): Iran and Israel: The Inevitable War? The Jerusalem Institute for Strategy and Security. Available at: https://jiss.org.il/en/inbar-iran-and-israel-the-inevitable-war/.

International Crisis Group (2005): Iran in Iraq: How Much Influence? Middle East Report No. 38. Available at: https://d2071andvip0wj.cloudfront.net/38-iran-in-iraq-howmuch-influence.pdf.

International Monetary Fund (2018): World Economic Outlook October 2018, Challenges to Steady Growth. World Economic and Financial Surveys. Washington, DC.:

International Monetary Fund. Available at: https://www.imf.org/ /media/Files/Publications/WEO/2018/October/English/mainreport/Text.ashx.

Ireland, M., \& Gartner, S. (2001): Time to Fight: Government Type and Conflict Initiation in Parliamentary Systems. The Journal of Conflict Resolution, 45(5), pp. 547-568. 
Islamic Republic News Agency (2016): Velayati: Syria is golden ring in line of resistance. Available at: https://en.irna.ir/news/82080242/Velayati-Syria-is-golden-ring-in-lineof-resistance.

Izmirlioglu, A. (2017): The Correlates of War Dataset. Journal of World-Historical Information, [online] 4(1). DOI: 10.5195/jwhi.2017.49

Jackson, R. and Sørensen, G. (2010): Introduction to International Relations. 4th ed. Oxford: Oxford University Press.

Jervis, R. (1976): Perception and Misperception in International Politics. Princeton: Princeton University Press.

Jervis, R. (1978): Cooperation Under the Security Dilemma. World Politics, 30(2), pp. 167214.

Jervis, R. (1985): From Balance to Concert: A Study of International Security Cooperation. World Politics, 38(1), pp. 58-79.

Jervis, R. L. (2003a): The Confrontation between Iraq and the US: Implications for the Theory and Practice of Deterrence. European Journal of International Relations, 9(2), pp. 315-337. DOI:10.1177/1354066103009002006.

Jervis, R. L. (2003b): Understanding the Bush Doctrine. Political Science Quarterly, 118(3), pp. 365-388.

Jessup, J. (1989): A Chronology of Conflict and Resolution, 1945-1985. New York: Greenwood Press.

Johnson, C. (2001): Blowback. The Nation. Available at: https://www.thenation.com/article/archive/blowback/.

Johnston, P., Shapiro, J., Shatz, H., Bahney, B., Jung, D., Ryan, P. and Wallace, J. (2016): Foundations of the Islamic State: Management, Money, and Terror in Iraq, 20052010. California: RAND Corporation.

Joint Comprehensive Plan of Action (JCPOA), Vienna, 14 July 2015. Available at: https://www.europarl.europa.eu/cmsdata/122460/full-text-of-the-iran-nuclear-deal.pdf.

Jones, D. (2021): Turkey-Iran Tensions Rise as Ankara Expands Operations in Iraq. Voice of America. Available at: https://www.voanews.com/middle-east/turkey-iran-tensionsrise-ankara-expands-operations-iraq.

Jones, D., Bremer, S. and Singer, J. (1996): Militarized Interstate Disputes, 1816-1992: Rationale, Coding Rules, and Empirical Patterns. Conflict Management and Peace Science, 15(2), pp. 163-213.

Joscelyn, T. (2007): Iran's Proxy War Against America. National Security Studies. The Claremont Institute. Available at: http://www.aina.org/reports/ipwaa.pdf.

Kaeber, E. (1906): Die Idee des Europäischen Gleichgewichts in der publizistischen Literatur vom 16. bis zur Mitte des 18. Jahrhunderts, Berlin, pp. 22-35.

Kafala, T. (2003): The Iraqi Baath party. BBC News. Available at: http://news.bbc.co.uk/2/hi/middle_east/2886733.stm.

Kaplan, M. (1957): System and Process in International Policies. Chicago: University of Chicago Press. 
Kaplan, M. (1964): Intervention in Internal War: Some Systemic Sources. In: J. Rosenau, ed., International Aspects of Civil Strife. Princeton, N. J.: Princeton University Press, pp. 92-121.

Karadeniz, T. and Gumrukcu, T. (2017): Turkey warns U.S. of blowback from decision to arm Kurdish fighters in Syria. Reuters. Available at: https://www.reuters.com/article/us-mideast-crisis-usa-turkey-idUSKBN1860SG.

Kathman, J. (2011): Civil War Diffusion and Regional Motivations for Intervention. The Journal of Conflict Resolution, 55(6), pp. 847-876.

Kathman, J. and Wood, R. (2011): Managing Threat, Cost, and Incentive to Kill: The Shortand Long-Term Effects of Intervention in Mass Killings. The Journal of Conflict Resolution, 55(5), pp. 735-760.

Katzman, K. (2009): Iran's Activities and Influence in Iraq. Washington, D.C.: Congressional Research Service. Available at: https://apps.dtic.mil/dtic/tr/fulltext/u2/a501453.pdf.

Keesing's Record of World Events 1987-2000. London: Longman.

Keller, J. (2005): Leadership Style, Regime Type, and Foreign Policy Crisis Behavior: A Contingent Monadic Peace? International Studies Quarterly, 49(2), pp. 205-232.

Keller, J. and Foster, D. (2012): Presidential Leadership Style and the Political Use of Force. Political Psychology, 33(5), pp. 581-598.

Keller, J. and Foster, D. (2016): Don't Tread on Me: Constraint-Challenging Presidents and Strategic Conflict Avoidance. Presidential Studies Quarterly, 46(4), pp. 808-827.

Kende, I. (1977): Dynamics of Wars, of Arms Trade and of Military Expenditure in the 'Third World', 1945-1976. Instant Research on Peace and Violence, 7(2), pp. 59-67.

Kende, I. (1978): Wars of Ten Years (1967-1976): Journal of Peace Research, 15(3), pp. $227-$ 241.

Kennedy, P. (1989): The Rise and Fall of the Great Powers: Economic Change and Military Conflict from 1500-2000. New York: Vintage Books.

Keohane, R. (2005): After Hegemony. Princeton etc.: Princeton University Press.

Kindleberger, C. P. (1981): Dominance and Leadership in the International Economy: Exploitation, Public Goods, and Free Rides'. International Studies Quarterly, 25(2), pp. 242-254.

Kirdar, M. J. (2011): Al Qaeda in Iraq. Washington, D.C.: Center for Strategic and International Studies, AQAM Futures Project Case Study Series, No 1. Available at: https://csis-website-prod.s3.amazonaws.com/s3fspublic/legacy_files/files/publication/110614_Kirdar_AlQaedaIraq_Web.pdf.

Kisangani, E. F. and Pickering, J. (2008): International Military Intervention, 1989-2005. Data Collection No 21282. Ann Arbor: University of Michigan: Inter-University Consortium for Political and Social Research. Retrieved from https://www.kstate.edu/polsci/intervention/index.html.

Kisangani, E. F. and Pickering, J. (2011): Democratic Accountability and Diversionary Force: Regime Types and the Use of Benevolent and Hostile Military Force. The Journal of Conflict Resolution, 55(6), pp. 1021-1046.

Kisangani, E. F. and Pickering, J. (2015): The Human Consequences of Foreign Military Intervention. Defence and Peace Economics, 28(2), pp. 230-249. 
Kisangani, E.F. and Pickering, J. (2009): The Dividends of Diversion: Mature Democracies' Proclivity to Use Diversionary Force and the Rewards They Reap from It. British Journal of Political Science, 39(3), pp. 483-515.

Knorr, K. (1975): The Power of Nations. New York: Basic Books.

Koga, J. (2011): Where Do Third Parties Intervene? Third Parties' Domestic Institutions and Military Interventions in Civil Conflicts. International Studies Quarterly, 55(4), pp. 1143-1166.

Krain, M. (2005): International Intervention and the Severity of Genocides and Politicides. International Studies Quarterly, 49(3), pp. 363-387.

Krause, K. (2016): From Armed Conflict to Political Violence: Mapping \& Explaining Conflict Trends. Daedalus, 145(4), pp. 113-126.

Krause, P. (2018): A State, an Insurgency, and a Revolution: Understanding and Defeating the Three Faces of ISIS. In: Al-Istrabadi, F., \& Ganguly, S. (Eds.).: The Future of ISIS: Regional and International Implications (pp. 223-246). Washington, D.C.: Brookings Institution Press.

Kreps, S. (2008): Multilateral Military Interventions: Theory and Practice. Political Science Quarterly, 123(4), pp. 573-603.

Kristof, N. D. (2003): Missing in Action: Truth. The New York Times. Available at: https://www.nytimes.com/2003/05/06/opinion/missing-in-action-truth.html.

Krugman, P. (2004): The Awful Truth. The New York Times. Available at: https://www.nytimes.com/2004/01/13/opinion/the-awful-truth.html.

K-state.edu. (2010): International Military Intervention Data - 1946-2005. Available at: https://www.k-state.edu/polsci/intervention/about.html.

Kupchan, C. (1998): After Pax Americana: Benign Power, Regional Integration, and the Sources of a Stable Multipolarity. International Security, 23(2), pp. 40-79.

Lacina, B. and Gleditsch, N. (2005): Monitoring Trends in Global Combat: A New Dataset of Battle Deaths. European Journal of Population, 21(2-3), pp. 145-166.

LaFeber, W. (2009): The Rise and Fall of Colin Powell and the Powell Doctrine. Political Science Quarterly, 124(1), pp. 71-93.

Lai, B. and Slater, D. (2006): Institutions of the Offensive: Domestic Sources of Dispute Initiation in Authoritarian Regimes, 1950-1992. American Journal of Political Science, 50(1), pp. 113-126.

Lalwani, S. (2010): Why Isn't Turkey Balancing Iran? Explaining Balance-of-Power and Alliance Behavior in Response to Nuclear Proliferation. International Security Studies Section Annual Conference, Providence, RI, October 14-16, 2010. Available at: http://sameerlalwani.com/wp-content/uploads/2018/09/110916_Lalwani.pdf.

Landler, M. (2018a). Trump Abandons Iran Nuclear Deal He Long Scorned. The New York Times, p. A1. Available at:

https://www.nytimes.com/2018/05/08/world/middleeast/trump-iran-nuclear-deal.html.

Landler, M. (2018b): In Extraordinary Statement, Trump Stands With Saudis Despite Khashoggi Killing. The New York Times, p.A1. Available at: https://www.nytimes.com/2018/11/20/world/middleeast/trump-saudi-khashoggi.html. 
Landler, M. and Wong, E. (2019): In Golan Heights, Trump Bolsters Israel's Netanyahu but Risks Roiling Middle East. The New York Times, p. A1. Available at: https://www.nytimes.com/2019/03/21/us/politics/golan-heights-trump.html.

Lasswell, H. (1965): World Politics and Personal Insecurity. New York: Free Press.

Layne, C. (1997): From Preponderance to Offshore Balancing: America's Future Grand Strategy. International Security, 22(1), pp. 86-124.

Layne, C. (2004): The War on Terrorism and the Balance of Power: The Paradoxes of American Hegemony. In: T. V. Paul, J. Wirtz and M. Fortmann, ed., Balance of Power: Theory and Practice in the 21 st Century. Stanford: Stanford University Press, pp. 103-126.

Lebow, R. (1994): The Long Peace, the End of the Cold War, and the Failure of Realism. International Organization, 48(2), pp. 249-277.

Leckie, G. (1817): An Historical Research Into the Nature of the Balance of Power in Europe. London: Taylor \& Hessey.

Leffler, M. (2007): A Preponderance of Power. Stanford CA: Stanford University Press.

Leung, R. (2004): Bush Sought 'Way' to Invade Iraq? CBS News. Available at: https://www.cbsnews.com/news/bush-sought-way-to-invade-iraq/.

Levy, J. S and Mabe, W. (2004): Politically Motivated Opposition to War. International Studies Review, 6(4), pp. 65-83.

Levy, J. S. (2004): What Do Great Powers Balance Against and When? In: T. V. Paul, J. Wirtz and M. Fortmann, ed., Balance of Power: Theory and Practice in the 21st Century. Stanford: Stanford University Press, pp. 29-51.

Lieber, K. and Alexander, G. (2005): Waiting for Balancing: Why the World Is Not Pushing Back. International Security, 30(1), pp. 109-139.

Linebarger, C. and Enterline, A. (2016): Third Party Intervention and the Duration and Outcomes of Civil Wars. In: T. Mason and S. Mitchell, ed., What Do We Know About Civil Wars? Lanham, MD: Rowman and Littlefield, pp. 93-108.

Liska, G. (1957): International Equilibrium. Cambridge, Mass.: Harvard University Press.

Liska, G. (1962): Nations in Alliance: The limits of interdependence. Baltimore: Johns Hopkins Press.

Litvak, M., Landau, E., \& Kam, E. (Eds.). (2018): Iran in a Changing Strategic Environment. Institute for National Security Studies, Memorandum No 173, INSS, Tel-Aviv, pp. 4152.

Lounsbery, M. O., Pearson, F. and Talentino, A. (2011): Unilateral and Multilateral Military Intervention: Effects on Stability and Security. Democracy and Security, 7(3), pp. 227-257. DOI:10.1080/17419166.2011.600585.

Lynch, M. (2016): The New Arab wars: Uprisings and Anarchy in the Middle East. New York: Public Affairs.

MacAskill, E. and Burkeman, O. (2003): Power vacuum that has taken US by surprise. The Guardian. Available at: https://www.theguardian.com/world/2003/apr/11/usa.iraq.

MacFarlane, S. (1984): Africa's Decaying Security System and the Rise of Intervention. International Security, 8(4), pp. 127-151. 
Malik, H. (2017): What role will Iran-linked militias play once IS leaves Iraq? Al-Monitor. Available at: https://www.al-monitor.com/originals/2017/03/pmu-iraq-shiite-militiasiran-syria-golan-israel.html.

Mandelbaum, M. (1993): The Fate of Nations. Cambridge: Cambridge University Press.

Mansfield, E. and Pollins, B. (2009): Economic Interdependence and International Conflict. Ann Arbor: University of Michigan Press.

Mansour, R. and Jabar, F. A. (2017): The Popular Mobilization Forces and Iraq's Future. Beirut: Carnegie Middle East Center.

Maoz, Z. (1996): Domestic Sources of Global Change. Ann Arbor: University of Michigan Press.

March, J. and Olsen, J. (1989): Rediscovering Institutions: The Organizational Basis of Politics. New York: Free Press.

Marcus, J. (2018): Israel and Saudi Arabia: The relationship emerging into the open. $B B C$. Available at: https://www.bbc.com/news/world-middle-east-43632905.

Martin, K. W. (2018): Syria and Iraq ISIS and Other Actors in Historical Context. In: AlIstrabadi, F., \& Ganguly, S. (Eds.).: The Future of ISIS: Regional and International Implications (pp. 89-118). Washington, D.C.: Brookings Institution Press.

Mattes, M. and Rodríguez, M. (2014): Autocracies and International Cooperation. International Studies Quarterly, 58(3), pp. 527-538.

Mattis, J. N. (2018): Summary of the 2018 National Defense Strategy of the United States of America: Sharpening the American Military's Competitive Edge. Washington, D.C.: U.S. Department of Defense. Available at: https://dod.defense.gov/Portals/1/Documents/pubs/2018-National-Defense-StrategySummary.pdf.

McGinnis, M. (1990): A Rational Model of Regional Rivalry. International Studies Quarterly, 34(1), pp. 111-135.

McGowan, P. and Rood, R. (1975): Alliance Behavior in Balance of Power Systems: Applying a Poisson Model to Nineteenth-Century Europe. The American Political Science Review, 69(3), pp. 859-870.

Mearsheimer, J. and Walt, S. (2016): The Case for Offshore Balancing. Foreign Affairs, (July/August): Available at: https://www.foreignaffairs.com/articles/unitedstates/2016-06-13/case-offshore-balancing.

Mearsheimer, J. J. (2001): The Future of the American Pacifier. Foreign Affairs, 80(5), pp. 46-61. Available at: https://www.foreignaffairs.com/articles/united-states/2001-0901/future-american-pacifier.

Mearsheimer, J. J. and Walt, S. M. (2009): An Unnecessary War. Foreign Policy. Available at: https://foreignpolicy.com/2009/11/03/an-unnecessary-war-2/.

Meernik, J. (1996): United States Military Intervention and the Promotion of Democracy. Journal of Peace Research, 33(4), pp. 391-402.

Melander, E., Pettersson, T. and Themnér, L. (2016): Organized Violence, 19892015. Journal of Peace Research, 53(5), pp. 727-742. 
Miller, B. (2013): The International Order and the Arab Spring. Annual Meeting Paper. American Political Science Association. Available at: https://ssrn.com/abstract=2300096.

Mitchell, E. (2019): Trump Backs Off Total Syria Withdrawal. The Hill. Available at: https://thehill.com/policy/defense/431289-trump-backs-off-total-syria-withdrawal.

Modelski, G. (1974): World Power Concentrations: Typology, Data, Explanatory Framework. New Jersey: General Learning Press.

Moon, B. (1983): The Foreign Policy of the Dependent State. International Studies Quarterly, 27(3), pp. 315-340.

Moon, B. (1985): Consensus or Compliance? Foreign-Policy Change and External Dependence. International Organization, 39(2), pp. 297-329.

Moore, J. (1924): International Law and Some Current Illusions. New York: MacMillan.

Moravcsik, A. (1997): Taking Preferences Seriously: A Liberal Theory of International Politics. International Organization, 51(4), pp. 513-553. Available at: https://www.princeton.edu/ amoravcs/library/preferences.pdf.

Morgenthau, H. and Thompson, K. (2006): Politics Among Nations: The Struggle for Power and Peace. New York: Random House.

Morris, J. (2017): Military coup in Iraq ousts monarchy - archive, 1958. The Guardian. Available at: https://www.theguardian.com/world/2017/jul/26/iraq-revolution-oustsmonarchy-1958.

Morris, L. (2017): How the Kurdish independence referendum backfired spectacularly. The Washington Post. Available at: https://www.washingtonpost.com/world/how-thekurdish-independence-referendum-backfired-/2017/10/20/3010c820-b371-11e7-9b93b97043e57a22_story.html.

Morris, R. (2003): A Tyrant 40 Years in the Making. The New York Times, p.A00029. Available at: https://www.nytimes.com/2003/03/14/opinion/a-tyrant-40-years-in-themaking.html.

Motamedi, M. (2021): Iran says open to talks with Saudi Arabia after media reports. Al Jazeera. Available at: https://www.aljazeera.com/news/2021/4/19/iran-says-open-totalks-with-saudi-arabia-after-media-reports.

Moubayed, S. (2015). Under the Black Flag: At the Frontier of the New Jihad. London, New York: I.B. Tauris. DOI:10.5040/9780755609123.

Moul, W. (1989): Measuring the 'Balances of Power': A Look at Some Numbers. Review of International Studies, 15(2), pp. 101-121.

Moul, W. (2003): Power Parity, Preponderance, and War between Great Powers, 18161989. The Journal of Conflict Resolution, 47(4), pp. 468-489.

Mullenbach, M. and Matthews, G. (2008): Deciding to Intervene: An Analysis of International and Domestic Influences on United States Interventions in Intrastate Disputes. International Interactions, 34(1), pp. 25-52.

Mumford, A. (2013a): Proxy Warfare and the Future of Conflict. The RUSI Journal, 158(2), pp. 40-46.

Mumford, A. (2013b): Proxy Warfare. Cambridge: Polity Press. 
Murdie, A., \& Peksen, D. (2013): The Impact of Human Rights INGO Shaming on Humanitarian Interventions. The Journal of Politics, 76(1), pp. 215-228.

N. Rózsa, E. (2011): Új világrend a Közel-Keleten? Nemzet és Biztonság: Biztonságpolitikai Szemle, 4(2), p. 2.

N. Rózsa, E. (2015): Az arab tavasz: A Közel-Kelet átalakulása. Budapest: Osiris Kiadó Külügyi és Külgazdasági Intézet.

Nicholson, M. (1996): The Continued Significance of Positivism? In: S. Smith, K. Booth and M. Zalewski, ed., International Theory: Positivism and Beyond. Cambridge: Cambridge University Press, pp. 128-146.

Nome, M. (2012): Transnational Ethnic Ties and Military Intervention: Taking Sides in Civil Conflicts in Europe, Asia and North Africa, 1944-99. European Journal of International Relations, 19(4), pp. 747-771.

North, D. (2002): Institutions, Institutional Change and Economic Performance. Cambridge, Mass: Cambridge University Press.

Oakes, A. (2012): Diversionary War: Domestic Unrest and International Conflict. Stanford, California: Stanford University Press.

Okuducu, I. (2016): Peshmerga forces don't get orders from Iraq army: KRG. Anadolu Agency. Available at: https://www.aa.com.tr/en/middle-east/peshmerga-forces-don-tget-orders-from-iraq-army-krg/632056.

Olson, M. (1971): The Logic of Collective Action: Public Goods and the Theory of Groups. Cambridge, Mass: Harvard University Press.

Organski, A. and Kugler, J. (1980): The War Ledger. Chicago and London: The University of Chicago Press.

Organski, A. F. K. (1958): World Politics. New York: Alfred A. Knopf.

Owen, J. (2001): Transnational Liberalism and U.S. Primacy. International Security, 26(3), pp. 117-152.

Owsiak, A. (2012): Signing Up for Peace: International Boundary Agreements, Democracy, and Militarized Interstate Conflict1. International Studies Quarterly, 56(1), pp. 51-66.

Palmer, G., D'Orazio, V., Kenwick, M. and Lane, M. (2015): The MID4 dataset, 2002-2010: Procedures, coding rules and description. Conflict Management and Peace Science, 32(2), pp. 222-242. DOI: 10.1177/0738894214559680

Parsi, T. (2021): Why Mohammed bin Salman Suddenly Wants to Talk to Iran. Foreign policy. Available at: https://foreignpolicy.com/2021/04/29/saudi-arabia-iran-uaemohammed-bin-salman-secret-talks-biden-withdrawal-pivot-middle-east/.

Paul, T. V. (2005): Soft Balancing in the Age of U.S. Primacy. International Security, 30(1), pp. 46-71.

Paul, T. V. and Hall, J. (1999): International Order and the Future of World Politics. Cambridge: Cambridge University Press.

Paul, T. V., Wirtz, J. and Fortmann, M. (2004): Balance of Power: Theory and Practice in the 21 st Century. Stanford (Calif.): Stanford University Press.

Pearson, F. and Baumann, R. (1993): International Military Intervention, 1946-1988

(Codebook), [online] Ann Arbor, Michigan: Inter-university Consortium for Political 
and Social Research, p.4. Available at: https://nanopdf.com/download/imi-codebook1993-kansas-state-university_pdf.

Pearson, F. S. and Baumann, R. A. (1993): International Military Intervention, 1946-1988. Data Collection No 6035. Ann Arbor: University of Michigan: Inter-University Consortium for Political and Social Research. Available at: https://www.kstate.edu/polsci/intervention/index.html.

Peceny, M. (1999): Forcing Them to Be Free. Political Research Quarterly, 52(3), pp. 549582.

Peceny, M. and Beer, C. (2003): Peaceful Parties and Puzzling Personalists. American Political Science Review, 97(2), pp. 339-342.

Peksen, D. (2011): Foreign Military Intervention and Women's Rights. Journal of Peace Research, 48(4), pp. 455-468.

Peksen, D. (2012): Does Foreign Military Intervention Help Human Rights? Political Research Quarterly, 65(3), pp. 558-571.

Peksen, D. and Lounsbery, M. (2012): Beyond the Target State: Foreign Military Intervention and Neighboring State Stability. International Interactions, 38(3), pp. 348-374.

Pettersson, T. and Eck, K. (2018): Organized Violence, 1989-2017. Journal of Peace Research, 55(4), pp. 535-547. DOI: 10.1177/0022343318784101

Pettinger, T. (2015): "What Is the Impact of Foreign Military Intervention on Radicalization? Journal for Deradicalization, 5(5), pp. 92-119.

Pickering, J. (1999): The Structural Shape of Force: Interstate Intervention in the Zones of Peace and Turmoil, 1946-1996. International Interactions, 25(4), pp. 363-391.

Pickering, J. (2002): Give Me Shelter: Reexamining Military Intervention and the Monadic Democratic Peace. International Interactions, 28(4), pp. 293-324.

Pickering, J. and Kisangani, E. (2005): Democracy and Diversionary Military Intervention: Reassessing Regime Type and the Diversionary Hypothesis. International Studies Quarterly, 49(1), pp. 23-43.

Pickering, J. and Kisangani, E. (2006): Political, Economic, and Social Consequences of Foreign Military Intervention. Political Research Quarterly, 59(3), pp. 363-376.

Pickering, J. and Kisangani, E. (2009): The International Military Intervention Dataset: An Updated Resource for Conflict Scholars. Journal of Peace Research, 46(4), pp. 589599.

Pickering, J. and Kisangani, E. (2010): Diversionary Despots? Comparing Autocracies' Propensities to Use and to Benefit from Military Force. American Journal of Political Science, 54(2), pp. 477-493.

Pickering, J. and Mitchell, D. (2017): Empirical Knowledge on Foreign Military Intervention. Oxford Research Encyclopedia of Politics. Ed. Available at: https://doi.org/10.1093/acrefore/9780190228637.013.319.

Pickering, J. and Peceny, M. (2006): Forging Democracy at Gunpoint. International Studies Quarterly, 50(3), pp. 539-560.

Pollard, A. (1923): The Balance of Power. Journal of the British Institute of International Affairs, 2(2), pp. 51-64. 
Porter, G. (2015): Israel's Construction of Iran as an Existential Threat. Journal of Palestine Studies, 45(1), pp. 43-62. DOI:10.1525/jps.2015.45.1.43.

Powell, R. (1999): In the Shadow of Power. Princeton, NJ: Princeton University Press.

Powell, W. and DiMaggio, P. (1991): The New Institutionalism in Organizational Analysis. Chicago: University of Chicago Press.

Prio.org. (2019): UCDP/PRIO Armed Conflict Dataset. Available at: https://www.prio.org/Data/Armed-Conflict/UCDP-PRIO/.

Quinlivan, J. (1999): Coup-Proofing: Its Practice and Consequences in the Middle East. International Security, 24(2), pp. 131-165.

Rasler, K. and Thompson, W. (2006): Contested Territory, Strategic Rivalries, and Conflict Escalation. International Studies Quarterly, 50(1), pp. 145-167.

Regan, P. (1996): Conditions of Successful Third-Party Intervention in Intrastate Conflicts. The Journal of Conflict Resolution, 40(2), pp. 336-359.

Regan, P. (2000): Civil Wars and Foreign Powers. Ann Arbor: University of Michigan Press.

Regan, P. (2002): Third-Party Interventions and the Duration of Intrastate Conflicts. The Journal of Conflict Resolution, 46(1), pp. 55-73.

Regan, P. and Meachum, M. (2014): Data on Interventions During Periods of Political Instability. Journal of Peace Research, 51(1), pp. 127-135.

Regan, P., Frank, R., \& Aydin, A. (2009): Diplomatic Interventions and Civil War: A New Dataset. Journal of Peace Research, 46(1), pp. 135-146.

Reiter, D. and Tillman, E. (2002): Public, Legislative, and Executive Constraints on the Democratic Initiation of Conflict. The Journal of Politics, 64(3), pp. 810-826.

Reuveny, R., \& Thompson, W. (2004): World Economic Growth, Systemic Leadership, and Southern Debt Crises. Journal of Peace Research, 41(1), pp. 5-24.

Rhodes, E. (2004): A World Not In the Balance: War, Politics, and Weapons of Mass Destruction. In: T. V. Paul, J. Wirtz and M. Fortmann, ed., Balance of Power: Theory and Practice in the 21st Century. Stanford: Stanford University Press, pp. 150-176.

Richards, D. and Shaikh, S. (2013): Military Interventions in the Broader Middle East: Effects on Nation Building and Education. The Brookings Institution, Brookings Doha Center, October 29, 2013. Event transcript available at: https://www.brookings.edu/wpcontent/uploads/2013/10/military_interventions_middle_east.pdf.

Roberts, D. and Ackerman, S. (2014): US begins air strikes against Isis targets in Iraq, Pentagon says. The Guardian. Available at: https://www.theguardian.com/world/2014/aug/08/us-begins-air-strikes-iraq-isis.

Rose, G. (1998): Review: Neoclassical Realism and Theories of Foreign Policy. World Politics, 51(1), pp. 144-172.

Rosenau, J. (1968): The Concept of Intervention. Journal of International Affairs, 22(2), pp. $165-176$.

Rosenau, J. (1969): Intervention as a Scientific Concept. The Journal of Conflict Resolution, 13(2), pp. 149-171. 
Rosh, R. (1988): Third World Militarization: Security Webs and the States They Ensnare. The Journal of Conflict Resolution, 32(4), pp. 671-698.

Ross, D. (2016): Why Middle Eastern Leaders Are Talking to Putin, Not Obama. Politico. Available at: https://www.politico.com/magazine/story/2016/05/putin-obama-middleeast-leaders-213867.

Rothstein, R. (1963): Alliances and Small Powers. New York: Columbia University Press.

Russett, B., Oneal, J. and Davis, D. (1998): The Third Leg of the Kantian Tripod for Peace: International Organizations and Militarized Disputes, 1950-85. International Organization, 52(3), pp. 441-467.

Ryan, C. (2015): Regional Responses to the Rise of ISIS. Middle East Report, 45(276), pp. $18-23$.

Saban, N. (2020): Factbox: Iranian influence and presence in Syria. Atlantic Council. Available at: https://www.atlanticcouncil.org/blogs/menasource/factbox-iranianinfluence-and-presence-in-syria/.

Salim, M. and El-Ghobashy, T. (2018): After months of deadlock, Iraqis name new president and prime minister. The Washington Post. Available at:

https://www.washingtonpost.com/world/veteran-kurdish-politician-wins-iraqipresidency-as-traditional-alliances-falter/2018/10/02/dac9b788-c5b1-11e8-9c0f2ffaf6d422aa_story.html?utm_term=.6b3280240354.

Sanger, D., Schmitt, E. and Hubbard, B. (2017): Trump Ends Covert Aid to Syrian Rebels Trying to Topple Assad. The New York Times, p. A6. Available at: https://www.nytimes.com/2017/07/19/world/middleeast/cia-arming-syrianrebels.html.

Santora, M., Glanz, J. and Tavernise, S. (2006): Dictator Who Ruled Iraq With Violence Is Hanged for Crimes Against Humanity. The New York Times, p.A1. Available at: https://www.nytimes.com/2006/12/30/world/middleeast/30hussein.html.

Sarkees, M. and Schafer, P. (2000): The Correlates of War Data on War: An Update to 1997. Conflict Management and Peace Science, 18(1), pp. 123-144.

Schmitt, E. and Brinkley, J. (2003): The Struggle for Iraq: Planning; State Dept. Study Foresaw Trouble Now Plaguing Iraq. The New York Times. Available at: https://www.nytimes.com/2003/10/19/world/struggle-for-iraq-planning-state-deptstudy-foresaw-trouble-now-plaguing-iraq.html.

Schroeder, P. (1994): Historical Reality vs. Neo-Realist Theory. International Security, 19(1), pp. $108-148$.

Schuman, F. (1941): International Politics. New York: McGraw-Hill.

Schweller, R. L. (1994): Bandwagoning for Profit: Bringing the Revisionist State Back In. International Security, 19(1), pp. 72-107.

Schweller, R. L. (1997): New Realist Research on Alliances: Refining, Not Refuting, Waltz's Balancing Proposition. The American Political Science Review, 91(4), pp. 927-930.

Schweller, R. L. (2004): Unanswered Threats: A Neoclassical Realist Theory of Underbalancing. International Security, 29(2), pp. 159-201.

Schweller, R. L. (2006): Unanswered Threats: Political Constraints on the Balance of Power. Princeton, NJ: Princeton University Press. 
Schweller, R. L. (2016): The Balance of Power in World Politics. Oxford Research Encyclopedia of Politics. Available at: https://doi.org/10.1093/acrefore/9780190228637.013.119.

Semple, K. (2006): Saddam Hussein Is Sentenced to Death. The New York Times. Available at: https://www.nytimes.com/2006/11/05/world/middleeast/05cnd-saddam.html.

Sheehan, M. (1996): Balance of Power Intervention: Britain's Decisions for or Against War, 1733-56. Diplomacy \& Statecraft, 7(2), pp. 271-289.

Sheehan, M. (2007): The Balance of Power: History and Theory. London: Routledge.

Siddiqa, A., Hassan, M. A., Khan, A. U. (2019): Saudi-Israeli Nexus: Implications for Iran. Center for Iranian Studies in Ankara. Available at:

https://iramcenter.org/d_hbanaliz/Saudi_Y_Israeli_Nexus_Implications_for_Iran.pdf.

Singer, D. and Small, H. (1979): Conflict in the International System, 1816-1977: Historical Trends and Policy Futures. In: C. Kegley and P. McGowan, ed., Challenges to America: US Foreign Policy in the 1980's. Beverly Hills: Sage, pp. 89-115.

Singer, J. (1988): Reconstructing the Correlates of War Dataset on Material Capabilities of States, 1816-1985. International Interactions, 14(2), pp.115-132. DOI: 10.1080/03050628808434695.

Singer, J. and Small, M. (1972): The Wages of War, 1816-1965. New York: Wiley.

Singer, J. and Small, M. (1994): Correlates of War Project: International and Civil War Data, 1816-1992. ICPSR Data Holdings.

Singer, J., and Small, M. (1966): The Composition and Status Ordering of the International System: 1815-1940. World Politics, 18(2), pp. 236-282.

Singer, J., Bremer, S. and Stuckey, J. (1972): Capability Distribution, Uncertainty, and Major Power War, 1820-1965. In: B. Russett, ed., Peace, War, and Numbers. Beverly Hills, California: SAGE Publications.

Sissons, M. and Al-Saiedi, A. (2013): A Bitter Legacy: Lessons of De-Baathifi cation in Iraq. International Center for Transitional Justice. Available at:

https://www.ictj.org/sites/default/files/ICTJ-Report-Iraq-De-Baathification-2013ENG.pdf.

Slavin, B. (2008): Mullahs, Money, and Militias: How Iran Exerts Its Influence in the Middle East. Special Report 206, United States Institute of Peace. Available at: https://www.jstor.org/stable/resrep12368.

Sly, L. (2019): The once vast ISIS 'caliphate' is now reduced to a pair of villages in Syria. The Washington Post. Available at:

https://www.washingtonpost.com/world/the-once-vast-isis-caliphate-is-now-reducedto-a-pair-of-villages-in-syria/2019/01/25/39cbd85c-2015-11e9-a7592b8541bbbe20_story.html.

Small, M., Singer, J. and Bennett, R. (1982): Resort to Arms. Beverly Hills, California: Sage Publications.

Smeltz, D. and Kafura, C. (2020): American Public Support for US Troops in Middle East Has Grown. The Chicago Council on Global Affairs. Available at: https://www.thechicagocouncil.org/sites/default/files/2020-12/report_americansupport-grows-for-american-troops-in-middle-east_20200210.pdf. 
Smith, S. (1997): New Approaches, to International, Theory. In: J. Baylis and S. Smith, eds., The Globalization of World Politics. Oxford: Oxford University Press, pp. 165-190.

Snyder, G. H. (1965): The Balance of Power and the Balance of Terror. In Paul Seabury, ed., The Balance of Power. San Francisco: Chandler, pp. 185-201.

Snyder, G. H. (1997): Alliance Politics. Ithaca: Cornell University Press.

Solomon, E. and Sheppard, D. (2017): Kurds' independence dreams shattered by Iraqi tanks in Kirkuk. Financial Times. Available at: https://www.ft.com/content/7628e416-b28e11e7-aa26-bb002965bce8.

Sousa, R. (2014): External Interventions and Conflicts in Africa after the End of the Cold War. Ph.D. Erasmus University Rotterdam. Retrieved from https://repub.eur.nl/pub/77584/PhD-file-1-Manuscript-FINAL-D.pdf.

Souva, M. and Prins, B. (2006): The Liberal Peace Revisited: The Role of Democracy, Dependence, and Development in Militarized Interstate Dispute Initiation, 1950 1999. International Interactions, 32(2), pp. 183-200.

Spykman, N. (1942): America's Strategy in World Politics: The United States and the Balance of Power. New York: Harcourt, Brace, pp. 21-25.

Stern, A. (1923): Das politische Gleichgewicht. Archiv für Politik und Geschichte, IV, pp. 4849.

Stern, J. (2003): How America Created a Terrorist Haven. The New York Times. Available at: https://www.nytimes.com/2003/08/20/opinion/how-america-created-a-terroristhaven.html.

Stojek, S. and Chacha, M. (2015): Adding Trade to the Equation. Journal of Peace Research, 52(2), pp. 228-242.

Strange, S. (1988): States and Markets. London: Pinter Publishers.

Strassler, R. (1996): The Landmark Thucydides: A Comprehensive Guide to the Peloponnesian War. New York: Free Press.

Sullivan, P. and Karreth, J. (2015): The Conditional Impact of Military Intervention on Internal Armed Conflict Outcomes. Conflict Management and Peace Science, 32(3), pp. 269-288.

Sullivan, P. and Koch, M. (2009): Military Intervention by Powerful States, 1945-2003. Journal of Peace Research, 46(5), pp. 707-718.

Sullivan, P. and Koch, M. (2011): "Replication data for: Military Intervention by Powerful States (MIPS)". DOI:10.7910/DVN/KRUFQH.

Sullivan, P. and Koch, M. (2018): Military Intervention by Powerful States (MIPS) Codebook.

Suskind, R. (2004): The Price of Loyalty. New York: Simon and Schuster.

Tellis, A., Bially, J., Layne, C., Mcpherson, M. and Sollinger, J. (2000): Measuring National Power in the Postindustrial Age: Analyst's Handbook. California: Santa Monica: RAND Corporation. Available at: https://www.rand.org/content/dam/rand/pubs/monograph_reports/2005/MR1110.1.pdf

The New York Times (1995): The Iran Embargo. p. A00020. Available at: https://www.nytimes.com/1995/05/02/opinion/the-iran-embargo.html. 
The New York Times (2006): Key Events in the Life of al-Zarqawi. Available at: https://www.nytimes.com/2006/06/08/world/08timeline-zarqawi.html.

The Washington Post (2003): Text of President Bush's 2003 State of the Union Address. Available at: https://www.washingtonpost.com/wpsrv/onpolitics/transcripts/bushtext_012803.html.

The World Bank (2011): Conflict, Security, and Development. World Development Report. Washington DC: The International Bank for Reconstruction and Development / The World Bank. Available at: http://hdl.handle.net/10986/4389.

Thompson, W. (1993): The Consequences of War. International Interactions, 19(1-2), pp. $125-147$.

Thompson, W. (2003): A Streetcar Named Sarajevo: Catalysts, Multiple Causation Chains, and Rivalry Structures. International Studies Quarterly, 47(3), pp. 453-474.

Thompson, W. and Dreyer, D. (2012): Handbook of International Rivalries, 1494-2010. Los Angeles: SAGE.

Tillema, H. K. (1973): Appeal to Force: American Military Intervention in the Era of Containment. New York: Harper \& Row.

Tillema, H. K. (1989): Foreign Overt Military Intervention in the Nuclear Age. Journal of Peace Research, 26(2), pp. 179-196.

Tillema, H. K. and Van Wingen, J. (1982): Law and Power in Military Intervention: Major States after World War II. International Studies Quarterly, 26(2), pp. 220-250.

Towle, P. (1981): The Strategy of War by Proxy. The RUSI Journal, 126(1), pp. 21-26.

Treaties.un.org. (1945): Charter of the United Nations. Available at: https://treaties.un.org/doc/publication/ctc/uncharter.pdf.

Trifunov, D. (2013): Hassan Rouhani calls for WAVE: 'World against violence and extremism'. The World. Available at: https://www.pri.org/stories/2013-09-24/hassanrouhani-calls-wave-world-against-violence-and-extremism.

Trofimov, Y. and King Jr., N. (2003): U.S. Troops Aren't Welcomed by Everyone in Southern Iraq. The Wall Street Journal. Available at: https://www.wsj.com/articles/SB104846165792087700.

Tucker, R. W. and Hendrickson, D. C. (1992): The Imperial Temptation. New York, Council on Foreign Relations Press.

Tversky, A., Kahneman, D. and Slovic, P. (1982): Judgment Under Uncertainty: Heruistics and Biases. Cambridge: Cambridge University Press.

United Nations Security Council Resolution 678 (1990). Available at: https://digitallibrary.un.org/record/102245/files/S_RES_678\%281990\%29-EN.pdf.

Usborne, D. (2013): WMD just a convenient excuse for war, admits Wolfowitz. Independent. Available at: https://www.independent.co.uk/news/world/middle-east/wmd-justconvenient-excuse-war-admits-wolfowitz-106754.html.

Vagts, A. (1948): The Balance of Power: Growth of an Idea. World Politics, 1(1), pp. 82-101.

Van Dyke, V. (1957): International Politics. New York: Appleton-Century-Crofts. 
Vasquez, J. (1997): The Realist Paradigm and Degenerative versus Progressive Research Programs: An Appraisal of Neotraditional Research on Waltz's Balancing Proposition. The American Political Science Review, 91(4), pp. 899-912.

Vasquez, J. and Elman, C. (2003): Realism and the Balancing of Power. Upper Saddle River: Prentice Hall.

Vasquez, J. and Henehan, M. (2001): Territorial Disputes and the Probability of War, 18161992. Journal of Peace Research, 38(2), pp. 123-138.

Wagner, R. (1986): The Theory of Games and the Balance of Power. World Politics, 38(4), pp. 546-576.

Wagner, R. (1993): What was Bipolarity? International Organization, 47(1), pp. 77-106.

Walt, S. M. (1985): Alliance Formation and the Balance of World Power. International Security, 9(4), pp. 3-43. DOI:10.2307/2538540.

Walt, S. M. (1987): The Origins of Alliances. Ithaca: Cornell University Press.

Walt, S. M. (2018): America Can’t Be Trusted Anymore. Foreign Policy. Available at: https://foreignpolicy.com/2018/04/10/america-cant-be-trusted-anymore/.

Waltz, K. N. (1959): Man, the State and War: A Theoretical Analysis. New York: Columbia University Press.

Waltz, K. N. (1979): Theory of International Politics. Massachusetts: Addison-Wesley.

Waltz, K. N. (1981): The Spread of Nuclear Weapons: More May Better. Adelphi Papers, Number 171. London: International Institute for Strategic Studies.

Waltz, K. N. (1993): The Emerging Structure of International Politics. International Security, 18(2), pp. 44-79.

Waltz, K. N. (2000): Structural Realism After the Cold War. International Security, 25(1), pp. $5-41$.

Weeks, J. (2012): Strongmen and Straw Men: Authoritarian Regimes and the Initiation of International Conflict. The American Political Science Review, 106(2), pp. 326-347.

Wehrey, F., Kaye, D. D., Watkins, J., Martini, J. and Guffey, R. A. (2010): The Iraq Effect: The Middle East After the Iraq War. California: RAND Corporation. Available at: https://www.rand.org/content/dam/rand/pubs/monographs/2010/RAND_MG892.pdf.

Weiss, M. and Hassan, H. (2016): ISIS: Inside the Army of Terror. New York: Regan Arts.

Wendt, A. (1992): Anarchy is What States Make of It: The Social Construction of Power Politics. International Organization, 46(2), pp. 391-425.

Wohlforth, W. C. (1993): The Elusive Balance: Power and Perceptions during the Cold War. Ithaca, N.Y.: Cornell University Press.

Wohlforth, W. C. (2004): Revisiting Balance of Power Theory in Central Eurasia. In: T. Paul, J. Wirtz and M. Fortmann, ed., Balance of Power: Theory and Practice in the 21st Century. Stanford: Stanford University Press, pp. 214-238.

Wohlforth, W., Little, R., Kaufman, S., Kang, D., Jones, C., Tin-Bor Hui, V., Eckstein, A., Deudney, D. and Brenner, W. (2007): Testing Balance-of-Power Theory in World History. European Journal of International Relations, 13(2), pp. 155-185. DOI: $\underline{10.1177 / 1354066107076951 .}$. 
Wolfers, A. (1962): The Balance of Power in Theory and Practice. In: A. Wolfers, ed., Discord and Collaboration. Baltimore: Johns Hopkins University Press, pp. 117-131.

Woodward, B. (2002): Bush at War. New York: Simon and Schuster.

Wright, Q. (1964): A Study of War. Chicago: University of Chicago Press.

Zakaria, F. (1995): Realism and Domestic Politics. In: M. Brown, S. Lynn-Jones and S. Miller, ed., The Perils of Anarchy: Contemporary Realism and International Security. Cambridge: MIT Press, pp. 462-483.

Zakaria, F. (2001): From Wealth to Power. Princeton: Princeton University Press.

Zartman, I. (1967): Africa as a Subordinate State System in International Relations. International Organization, 21(3), pp. 545-564.

Zartman, I. (2000): Ripeness: The Hurting Stalemate and Beyond. In: P. Stern and D. Druckman, ed., International Conflict Resolution After the Cold War. Washington, D.C.: National Academy Press, pp. 225-250.

Zizek, S. (2009): Iraq's False Promises. Foreign Policy. Available at: https://foreignpolicy.com/2009/10/28/iraqs-false-promises/. 


\section{List of the Author's Related Publications}

Selján Péter (2021): The Balance of Power System of the Middle East. AARMS - Academic and Applied Research in Military and Public Management Science, 19(2), pp. 5-17. DOI: 10.32565/aarms.2020.2.1.

Selján Péter (2020): A 2017-2020-as Trump-adminisztráció Közel-Kelet-politikája. Nemzet és Biztonság: Biztonságpolitikai Szemle, 13(2), pp. 45-65. DOI: 10.32576/nb.2020.2.4

Selján Péter (2020): Külső katonai beavatkozás a szíriai polgárháborúba - Oroszország, Irán, Törökország és az Egyesült Államok szerepe. Nemzet és Biztonság: Biztonságpolitikai Szemle, 13(1), pp. 24-46. DOI: 10.32576/nb.2020.1.3

Selján Péter (2018): A külső intervenciók hatása a közel-keleti hatalmi egyensúly alakulására - Szaúd-Arábia és Irán fokozódó rivalizálása. Nemzet és Biztonság: Biztonságpolitikai Szemle, 11(2), pp. 66-86.

Selján Péter (2018): Az intervenciók hatása a célországok nemzeti képességeire és a hatalmi egyensúlyra a Közel-Keleten. Nemzet és Biztonság: Biztonságpolitikai Szemle, 11(1), pp. 75-99.

Selján Péter (2018): Szaúd-Arábia és Irán a Kőolaj-exportáló Országok Szervezetében: Az új OPEC-megállapodás. Nemzet és Biztonság: Biztonságpolitikai Szemle, 10(1), pp. 3246.

Selján Péter (2017): Oroszország és a szíriai polgárháború. Nemzet és Biztonság: Biztonságpolitikai Szemle, 9(5), pp. 14-30.

Selján Péter (2017): A közel-keleti hatalmi egyensúly átalakulása. Nemzet és Biztonság: Biztonságpolitikai Szemle, 9(4), pp. 30-53.

Selján Péter (2015): Új fejezet az iráni atomvitában, avagy Irán szerepe a közel-keleti hatalmi játszmában. Nemzet és Biztonság: Biztonságpolitikai Szemle, 8(4), pp. 70-81.

Selján Péter (2014): Harc az Iszlám Állam ellen. Nemzet és Biztonság: Biztonságpolitikai Szemle, 7(5), pp. 63-74.

Selján Péter (2011): Izrael és egy atomfegyverek nélküli Közel-Kelet esélyei. Nemzet és Biztonság: Biztonságpolitikai Szemle, 4(10), pp. 3-13.

Selján Péter (2010): A nuclear Iran: Fears and Prospects. AARMS - Academic and Applied Research in Military Science, 9(2), pp. 315-326.

\section{Accepted for publication:}

Selján Péter (2021): Líbia, 2021: elhúzódó polgárháború és fokozódó külső beavatkozás. Nemzet és Biztonság: Biztonságpolitikai Szemle, 13(4).

Selján Péter (2021): Military Intervention and Changing Balance of Power in Libya. AARMS - Academic and Applied Research in Military and Public Management Science, 19(3). 


\section{APPENDICES}

\section{A.1. Datasets on Intervention and Armed Conflict}

Understanding the causes of armed conflict continues to be a primary goal of IR. In order to achieve this goal, scholars continue to rely on large scientific datasets of conflict in the international system. In case of third-party intervention, scholars use different data collections to test ideas about what might be broadly construed as foreign military intervention, such as the Militarized Interstate Dispute (Palmer et al. 2015), the International Military Intervention (Kisangani \& Pickering 2008), and the Military Intervention by Powerful States (Sullivan \& Koch 2011) data sets.

\section{A.1.1. Correlates of War Project: Militarized Interstate Disputes, 1816-2010}

The Correlates of War Project was founded in 1963 by J. David Singer, a political scientist at the University of Michigan to collect empirical data on large state conflicts and to systematically build scientific knowledge of war. Joined by historian Melvin Small, the project began its work by assembling a more accurate data set on the incidence and extent of inter-state and extra-systemic war in the post-Napoleonic period. To do this scientifically Singer and Small found they needed to operationally resolve a number of difficult issues such as what is a "state" and what precisely is a "war." Singer and Small published The Wages of War in 1972 and Resort to Arms in 1982, which established a standard definition of war that has guided the research of hundreds of scholars since its publication (Singer \& Small 1972; Small, Singer \& Bennett 1982). Despite the retirement of Singer in the late 1990s, the project has since thrived, becoming the largest and most applied source of data on war for the period 1815-2016. The dataset is currently administered in multiple repositories under the leadership of Zeev Maoz and D. Scott Bennett. The Correlates of War project consists of thirteen individual datasets that provide detailed information on diverse factors that may help us to better understand the nature of conflict among interstate and non-state actors.

Topics addressed by the datasets include state system membership, militarized interstate disputes, militarized interstate dispute geographical locations, national material capabilities, world religion data, formal alliances, national and bilateral trade, and diplomatic representation. ${ }^{133}$ The temporal range of the data is the post-Napoleonic era, with the majority of the datasets covering the early nineteenth century to the early twenty-first century. The

\footnotetext{
${ }^{133}$ See Correlatesofwar.org. (2019). Data Sets - Correlates of War. Available at: http://www.correlatesofwar.org/data-sets.
} 
tabular data in each dataset are organized into subcategories and presented in commaseparated values (CSV) files (and in some cases as MS Excel files), with supplementary information presented in PDF and RTF files. The variables in the CSV files, such as population, conflict duration, number of fatalities in the conflict, and geographic region of conflict, are organized into columns in the tables. There are 395 different variables available within the datasets. ${ }^{134}$

Although it was the first of its kind, COW is no longer the only dataset available on armed conflict. The success of COW, as well some perceived limitations in its definitions, inspired other researchers to collect and maintain empirical data on war. For example, the Uppsala Conflict Data Program (UCDP) began collecting data on low-level conflicts in the 1980 s by focusing on conflicts with an annual fatality limit of 25 (rather than the COW's higher threshold of 1000 annual fatalities). Despite the increasing number of conflict datasets, COW still stands out as a unique benchmark, both in terms of its broad scope and its decentralized structure. The dataset suits the needs of quantitative research far more than those of qualitative research. Consequently, the works that cite COW tend to favor quantitative methodologies and modelling, and it is worth to note that the dataset so far has mainly attracted researchers in International Relations and policy analysis (Izmirlioglu 2017).

The latest iteration of this most widely used dataset on interstate conflicts, is Version 4 of the Militarized Interstate Dispute (MID) data collection, which provides information about conflicts in which one or more states threaten, display, or use force against one or more other states between 1816 and 2010. In 2003, the MID3 dataset ${ }^{135}$ built upon earlier versions of the MID data (MID1 and MID2.1) ${ }^{136}$ by updating the data through 2001 and by developing the new incident-level datasets. The MID4 project furthers this development by updating the MID and incident-level datasets through the year 2010, cleaning older portions of the data, and updating the data-collection procedures. For instance, the MID4 project addressed the issue of data-collection inefficiency by utilizing automated document classification techniques to identify relevant news reports efficiently (Palmer, D’Orazio, Kenwick \& Lane 2015).

\section{A.1.2. Military Intervention by Powerful States, 1945-2003}

The Military Intervention by Powerful States (MIPS) project develops a generalizable measure of the effectiveness of armed force as a policy instrument and applies the measure to

\footnotetext{
${ }^{134}$ Icpsr.umich.edu. (2019). Search Variables. Available at: https://www.icpsr.umich.edu/icpsrweb/ICPSR/ssvd/series/232/variables.

135 Ghosn, Palmer, and Bremer, 2004.

136 Jones, Bremer, and Singer, 1996.
} 
code the outcomes of 126 foreign military interventions conducted by five major powers since the end of World War II. Thus, the MIPS dataset provides thorough data on US, British, Chinese, French, and Russian uses of armed force against both state and non-state targets between 1946 and 2003. The MIPS project particularly focuses on the political objectives strong states pursue through the use of armed force, the human and material cost of their military operations, and measures of intervention outcomes relative to the intervening states' objectives. The authors of the dataset note that this dataset is unique in the depth and comprehensiveness of the data provided for each of the cases (Sullivan \& Koch 2009).

The already mentioned previous efforts to collect data on states' use of armed force are much broader in scope, but do not include detailed information about states' aims or whether their interventions were successful. According to Sullivan and Koch, the Correlates of War MID dataset has huge coverage, but the project codes only four broad revision-type categories, and over $56 \%$ of the disputes in the dataset are coded as ending in stalemate. Similarly, the IMI dataset, as Sullivan and Koch argue, is comprehensive, but does not identify the intervening states' primary aims or evaluate whether the states attained these objectives. The MIPS project defines military intervention success in Clausewitzian terms, by identifying the primary political objective for which a state used armed force and evaluating whether that objective was attained, since states employ military force to attain political objectives. The MIPS dataset also include extensive data on the cost of using armed force in terms of both intervening state and target casualties, troop numbers, type of force employed, and intervention duration. The authors' aim was to keep a balance between breadth and depth, to provide researchers with enough data to draw generalizable conclusions (Sullivan \& Koch 2009:708).

The MIPS dataset defines military intervention as a use of armed force that involves the official deployment of at least 500 regular military personnel to attain immediate-term political objectives through action against a foreign adversary. Sullivan and Koch elaborate on the definition as follows:

- To qualify as a 'use of armed force', the military personnel deployed must either use force or be prepared to use force if they encounter resistance.

- To be 'official', a state's leaders must authorize the deployment of national troops.

- The troop deployment must be intended to attain immediate-term political aims through military action, or the imminent threat of military action, against another actor. Therefore, the authors note that they excluded routine military movements and operations without a defined target, such as training exercises, non-combatant evacuation operations, and disaster relief. 
- Foreign adversaries can be either state or non-state actors, such as insurgent groups and terrorist organizations (Sullivan \& Koch 2009:709).

The researchers of the MIPS project tried to identify all foreign military interventions by the five permanent members of the UN Security Council, referring to them as the 'major powers', between April 1945 and March 2003. In order to collect all possible major power military interventions, they identified potential cases from the earlier datasets mentioned earlier in the previous sections then looked for additional cases that met their case selection criteria in reference books. According to their data, Britain, China, France, Russia/USSR, and the United States conducted 126 military interventions between 1945 and 2003. The US undertook 35 interventions, about $28 \%$ of the total. France was the second most active major power in this regard with 29 operations (23\%), while China was the least active with only 17 interventions in six decades. The primary target is a non-state actor in 61 (48\%) of the major power military interventions from 1945 until 2003. Of these, 31 operations were conducted against insurgents, 16 against civilian rioters, and 4 against terrorist organizations (Sullivan \& Koch 2009:709-710).

Interestingly, as the MIPS data show, major power states are most likely to be successful when they use armed force to overthrow a foreign regime (92\%) or defend an allied government against a threat posed by another state (100\%). On the other hand, major power states are least likely to be successful when they attempt to coerce a foreign government into changing its foreign or domestic policy (29\%) (Sullivan \& Koch 2009:715).

\section{A.1.3. International Military Intervention, 1946-2005}

According to the official website of the project, IMI was begun by Frederic S. Pearson and Robert A. Baumann in the late 1960s. Under their supervision, 667 cases of international military intervention were coded in IMI, from 1946 to 1988 (Pearson \& Baumann 1993). The data collection was deposited in the Inter-University Consortium of Political and Social Research (ICPSR) at the University of Michigan as collection 6035. Later, Jeffrey Pickering and Emizet N. Kisangani (2009) expanded the IMI collection to 2005, adding 449 more cases. The updated data is now housed in ICPSR collection 21282 as well as on the project's official website. ${ }^{137}$

The International Military Intervention data set records events involving "the movement of regular troops or forces (airborne, seaborne, shelling, etc.) of one country into

\footnotetext{
${ }^{137}$ K-state.edu. (2010). International Military Intervention Data - 1946-2005. Available at: https://www.kstate.edu/polsci/intervention/about.html.
} 
the territory or territorial waters of another country, or forceful military action by troops already stationed by one country inside another, in the context of some political issue or dispute." The collection identifies intervener and target states and specifies the starting and ending dates of the intervention. Potential interests in or motives for intervention are also presented, including efforts to affect regional power balances and strategic relations. Information is provided on the direction of the intervention, that is, to support or oppose the government or opposition groups of the target state or third-parties. Other variables are included to show the degree of prior intervention, the alliance or treaty relationship between intervener and target prior colonial status, prior intervention, and measures of intervener and target power size. The intensity measures, such as battle-related casualties are also included. In addition, contiguity information is provided to indicate both whether intervener and target are geographically contiguous, and whether the intervention was launched from contiguous territory (Pearson \& Baumann 1993).

As mentioned above, recognizing that despite the apparent increase in the frequency of foreign military interventions over recent decades, the quantitative literature continues to operate without either a comprehensive or a current inventory of foreign military interventions, Pickering and Kisangani attempted to fill this gap in the field by updating Pearson \& Baumann's (1993) IMI dataset to 2005. As they note, with updated data on foreign military intervention, we can begin to develop systematic knowledge on the use of foreign military intervention as a policy instrument in the post-Cold War era. They also note that the field of quantitative conflict studies lacks cross-national data on the monadic use of military force that are both reliable and current, and that the most commonly used data collection, the MID dataset, is not designed to measure the monadic use of force by state actors. In addition, the authors emphasize that IMI is more inclusive than alternative data collections. While MIDs, Sullivan's MIPS (2009), and Tillema's (1989) military intervention data focus on belligerent military actions against state actors, the IMI collection catalogs any purposeful dispatch of national troops into another sovereign country, whether it opposes the target government, supports it, or is neutral. Thus, the updated IMI data consequently allow researchers to analyze a wider swath of forceful behavior in the international system (Pickering \& Kisangani 2009:589-591).

Another important contribution of the updated IMI dataset is its utility in the reexamination of existing theories. Competing data collections are necessary to confirm the validity of important empirical findings in the literature. If a theoretical proposition that is supported when analyzing MIDs, MIPS, Regans (2002) data on third-party interventions, or 
some other data source is also confirmed when analyzing the data of the IMI collection, confidence in the proposition will grow. According to Pickering and Kisangani, arguably the most important contribution of the IMI dataset is its real world relevance, since it seems that foreign military intervention, not interstate military force, is the type of armed force that will be most common in the coming decades, and non-state actors seem to be one of the largest threats to the security of states across the globe in the present period, while they also appear to be one of the primary targets of state use of force (Pickering \& Kisangani 2009:592).

Pickering and Kisangani note that alternative datasets exist of course, which complement IMI more than they compete with it, and they are better suited to answer certain theoretical questions than IMI. In regard of the MIPS dataset, for instance, they note that it overlooks the huge number of meaningful foreign military interventions launched by smaller states, while in fact, small states initiated the bulk of foreign military interventions in both the Cold War and post-Cold War eras. They argue that MIPS is really valuable for studies of large-scale major power interventions, but IMI will prove a better resource for foreign military interventions initiated by non-major power actors and small-scale missions launched by the five permanent members of the UN Security Council (Pickering \& Kisangani 2009:592).

To ensure consistency, Pickering and Kisangani have followed the operational definitions and coding procedures of the initial IMI dataset by Pearson and Baumann precisely. Paramilitaries, government backed militias, private security forces, and other military units that are not part of the regular uniformed military of the state thus are still not included. Similarly, events must be purposeful, since foreign military interventions are the result of conscious decisions by national leaders, not of accidents. Accordingly, random border crossings are not recorded, nor are unintentional confrontations between fighter planes or naval ships. In all, 1114 cases meeting these criteria are cataloged for the years 1946 to 2005, and twenty-seven separate pieces of information are coded for each case in an attempt to capture multiple dimensions of the intervention (Pickering \& Kisangani 2009:593). 
Figure 4. International Military Interventions, 1946-2005

(Pickering and Kisangani, 2009, p. 597)



According to the updated IMI data, non-major power intervention levels spike in the late 1980s and early 1990s as the Cold War ended (see Figure 4.). They reach a peak of 48 interventions in 1990, but then surge again in 1998 and in 2003. In the Cold War era (194689 ) in sum 690 interventions occurred, against 425 from 1990 to 2005. Overall intervention rates thus seem to have increased in the post-Cold War era, which is consistent with popular conceptions. Approximately 16 external military interventions were launched per year during the 44 years of the Cold War, while 26 interventions per year were initiated during the 16 years of the post-Cold War period for which data is available (1990-2005), which means that major power interventions increased from 4.30 per year during the Cold War to 5.63 per year during the post-Cold War period (see Table 4.). Pickering and Kisangani (2009:596-597) note that US and French military actions account for most of this increase, however Russian intervention levels rise after 1989 as well. The US military operations include the invasions of Afghanistan and Iraq in 2001 and 2003 as well. The increase in non-major power interventions during the post-Cold War era is more marked, despite of the fact that non-major power interventions accounted for a smaller number of total interventions in the post-Cold War era $(58.3 \%)$ than in the Cold War era $(63.8 \%)$. The average number of interventions nonmajor powers launched per year, however, increased by over one-third from the Cold War (10 interventions per year) to the post-Cold War periods (nearly 16 interventions per year). 
Table 4. Interventions by Major Powers, Non-Major Powers and International Organizations, 1946-2005

(Pickering \& Kisangani, 2009:597)

\begin{tabular}{lcccccccc}
\hline & \multicolumn{3}{c}{ Cold War $(N=690)$} & & \multicolumn{3}{c}{ Post-Cold War $(N=425)$} \\
\cline { 2 - 3 } & Number & Percent & Per year & & Number & Percent & Per year \\
\hline Major powers & 193 & 27.9 & 4.30 & & 90 & 21.2 & 5.63 \\
USA & 74 & 10.7 & 1.68 & & 35 & 8.2 & 2.18 \\
United Kingdom & 38 & 5.5 & .86 & & 13 & 3.1 & .81 \\
France & 35 & 5.1 & .79 & & 31 & 7.3 & 1.93 \\
Soviet Union/Russia & 25 & 3.6 & .56 & & 10 & 2.4 & .63 \\
China & 21 & 3.0 & .47 & & 1 & .2 & .06 \\
Non-major powers & 440 & 63.8 & 10.00 & & 248 & 58.3 & 15.50 \\
International organizations & 57 & 8.3 & 1.20 & & 87 & 20.5 & 5.43 \\
\hline
\end{tabular}

Table 5. Interventions by Region, 1946-2005

(Pickering \& Kisangani 2009:598)

\begin{tabular}{lcccccccc}
\hline & \multicolumn{3}{c}{ Cold War $(N=690)$} & & \multicolumn{3}{c}{ Post-Cold War $(N=425)$} \\
\cline { 2 - 3 } & \multicolumn{2}{c}{ Number } & Percent & Per Year & & Number & Percent & Per Year \\
\hline Middle East & 173 & 25.1 & 3.43 & & 48 & 11.3 & 3.00 \\
Asia & 118 & 17.1 & 2.68 & & 52 & 12.2 & 3.25 \\
Western Europe & 96 & 13.9 & 2.18 & & 76 & 17.9 & 4.75 \\
Sub-Saharan Africa & 84 & 12.2 & 1.90 & & 52 & 12.2 & 3.25 \\
North America & 74 & 10.7 & 1.68 & & 40 & 9.4 & 2.50 \\
Latin America & 45 & 6.5 & 1.02 & & 24 & 5.6 & 1.50 \\
Eastern Europe & 37 & 5.4 & .84 & & 32 & 7.5 & 2.00 \\
Oceania & 6 & 0.9 & .13 & & 14 & 3.3 & 0.87 \\
\hline
\end{tabular}

In regard of the question, which regions have witnessed the greatest increases in intervention frequencies in the post-Cold War era, the data shows that the only region to experience declining rates of intervention from the Cold War to the post-Cold War periods is the Middle East, which accounted for $25.1 \%$ of all intervention initiations during the Cold War and only $11.3 \%$ from 1990 to 2005 (see Table 5.). Interestingly, the sharpest increases in intervention activity took place in Western Europe, Eastern Europe, and Oceania (Pickering \& Kisangani 2009:597).

\section{A.1.4. Interventions During Political Instability, 1957-2007}

Regan and Meachum published an article introducing a new dataset on pre-conflict interventions in 2014. Their data identifies states that are at risk of civil war and codes 
instances of third-party military, economic, and diplomatic interventions. They argue, that based on their forecasting models, they are able to identify those states that are most at risk and provide detailed information about interventions that occur in those states. According to their research results, military interventions increase the risk of civil war onset, while economic and diplomatic interventions forestall that particular outcome. Regan and Meachum note that wars begin and continue when actors cannot find an acceptable bargaining range to resolve competing interests. The already mentioned bargaining framework, when applied to the civil war context, puts the focus on domestic politics and the inability of parties to reach agreements short of war. In this sense, in an internal conflict, foreign actors can play a critical role in the supply of arms, money, or diplomatic resources (Regan \& Meachum 2014:127128).

The bargaining framework can be a useful conceptual tool to analyze prewar intervention indeed, however, it is not the only way to think about interventions. Regan and Meachum note that whether one chooses to focus on the bargaining perspective or examine mobilization of groups and their adoption of violent strategies, the ability to test the processes has been constrained by data limitations. They aim to address this limitation by presenting this new dataset on external interventions into countries that are estimated to be at risk of civil war. In other words, they present data on foreign military, economic, and/or diplomatic interventions into a set of countries where political instability is so high that civil war is a real possibility but as yet there has no recourse to organized armed conflict. In this regard, as the authors note, the foreign military interventions can either facilitate the regaining of political instability or help set the process for war in motion (Regan \& Meachum 2014:128).

One of the greatest challenges Regan and Meachum had to solve was the narrowing the potential universe of cases. To generate a sample of countries for which there is a reasonable chance that they might experience armed conflict in the future and there is also a plausible likelihood that a foreign actor would intervene in support of either an opposition group or the government, they relied on estimates of risk derived by Goldstone et al., who developed a model that generates a risk score which indicates the likelihood that a country will experience a civil war onset in two years. ${ }^{138}$

\footnotetext{
${ }^{138}$ Goldstone et al. use the common definition of 1,000 battlefield deaths to code instances of civil war. The risk scores are predicted on a forecasting model that includes four variables such as regime type, infant mortality, whether it is in a conflict ridden neighborhood, and the presence of state-led discrimination. Using these variables Goldstone et al. can forecast civil war onsets with a two-year lead-time with $80 \%$ accuracy. See Goldstone et al. 2010.
} 
To identify interventions, Regan and Meachum employ the above mentioned definition that distinguishes interventions from the normal course of influence in the international system, relying on Rosenau and Regan's basic definition of interventions as third-party actions that are convention-breaking and authority-targeted. Keeping it consistent with earlier work on interventions they code pre-conflict interventions as military, economic, or diplomatic. Applying their methodology, they were able to collect data on all three types of interventions into the most at-risk states from 1957 to 2007, identifying and coding 449 separate interventions. According to their findings, military interventions (230) occur nearly twice as frequently as either economic interventions (109) or diplomatic interventions (110), and nearly $47 \%$ of the interventions supported the opposition, while $22 \%$ were neutral, and $31 \%$ supported the government. Looking at interventions by year the data shows that in the mid-to-late 1990s the number of interventions increased dramatically compared to previous years. At this point the authors note that interventions into at-risk states demonstrate a different pattern, which might suggest an increased interest in or ability to manipulate unstable countries before they influence regional stability. If we look at interventions by region, we can see that, perhaps not surprisingly, sub-Saharan Africa is the most targeted region and military interventions are the most common type of intervention (Regan \& Meachum 2014:129, 131).

This dataset also elucidates patterns regarding the identity of the intervener. Consistent with Regan, Frank, and Aydin (2009), Regan and Meachum (2014) conceive of interveners as distinct political entities, which can be states, international organizations, or private nongovernmental groups. In their data, there are a total of 67 individual interveners of which foreign governments account for the vast majority (91\%). On the other hand, when viewed from the perspective of individual interventions, states account for just over $75 \%$ all interventions. In other words, it seems that the interveners are more likely to be foreign governments than international organizations (IOs). The authors note that this disparity in intervening actors is driven mostly by the behavior of the USA (Regan \& Meachum 2014). ${ }^{139}$

Regarding the application of their new data Regan and Meachum notes that the core idea behind this dataset is that interventions before the onset of a civil war might influence the willingness and ability of opposition groups to challenge their state by force of arms. In other words, their understanding of the onset of a civil war should be viewed through the lens of efforts to forestall the onset of a war or facilitate it. In this regard they note, that in terms of

\footnotetext{
${ }^{139}$ Removing the USA with 104 individual interventions, the distribution of interventions by state actors drops to slightly more than 52\% (Regan \& Meachum 2014:132).
} 
mobilization, as we could observe this dynamic in Libya and in Syria, an influx of weapons or monetary support aiding a particular opposition group could very well serve as the catalyst that encourages a nonviolent group to begin a violent campaign. The results of their analysis suggest that in countries at risk of civil war, external military interventions increase the likelihood of an onset, while diplomatic interventions can forestall the onset of a war. In contrast, interventions may also increase the possibility that an unstable political environment can regain stability without recourse to armed conflict. Put it differently, interventions can be used effectively to lessen a possible resort to arms. In this regard, their results suggest that economic interventions can increase the chances for regaining stability, while diplomatic interventions have no apparent impact. In sum, the dataset presented by Regan and Meachum (2014:134) offer the opportunity to gain a better understanding of civil war onset by allowing for the influence of external actors in the process of moving from groups in contention to groups involved in armed rebellion.

\section{A.1.5. Uppsala Conflict Data Program: Organized Violence, 1989-2017}

The Uppsala Conflict Data Program (UCDP) at the department of Peace and Conflict Research, Uppsala University and the Centre for the Study of Civil War at the Peace Research Institute Oslo (PRIO) have collaborated in the production of a dataset of armed conflicts in the period 1946 to 2017. The dataset is described in detail in the "Armed Conflict 1946-2001: A New Dataset" by Gleditsch et al. (2002). Until 2002 the conflict data from Uppsala University had only covered the years from 1989 and onwards. The joint project of UCDP and PRIO extended the armed conflict list back to $1946 .{ }^{140}$ Earlier the already mentioned Correlates of War project has served as the main supplier of reliable data used in longitudinal studies of armed conflict for decades, using the relatively high threshold of 1,000 battledeaths for its datasets on war. The Uppsala dataset on armed conflict however has a lower threshold. As the authors note, no dataset of this kind will ever be 'final', but today probably this dataset is the best one available for the period. Gleditsch et al. (2002:615-616) note that regional pattern of armed conflict in 2001 varied little from earlier years, since most of the conflicts were in Africa (14) or Asia (13), while the Middle East continued as the most conflict-prone region, measured as the probability that a given country will be in conflict.

An armed conflict is defined by the UCDP as a contested incompatibility that concerns government or territory or both where the use of armed force between two parties, of

\footnotetext{
${ }^{140}$ See Prio.org. (2019). UCDP/PRIO Armed Conflict Dataset. Available at: https://www.prio.org/Data/ArmedConflict/UCDP-PRIO/.
} 
which at least one is the government of a state, results in at least 25 battle-related deaths. A state is defined as an internationally recognized sovereign government controlling specified territory, or a non-recognized government whose sovereignty is not disputed by another internationally recognized sovereign government previously controlling the same territory. ${ }^{141}$

In the Uppsala dataset armed conflict is divided into three subsets:

- Minor Armed Conflict: at least 25 battle-related deaths per year and fewer than 1,000 battle-related deaths during the course of the conflict.

- Intermediate Armed Conflict: at least 25 battle-related deaths per year and an accumulated total of at least 1,000 deaths, but fewer than 1,000 in any given year.

- War: at least 1,000 battle-related deaths per year.

The dataset differentiates conflicts also by type, following the definitions of the COW project:

- Interstate armed conflict occurs between two or more states.

- Extrastate armed conflict occurs between a state and a non-state group outside its own territory.

- Internationalized internal armed conflict occurs between the government of a state and internal opposition groups with intervention from other states.

- Internal armed conflict occurs between the government of a state and internal opposition groups without intervention from other states (Gleditsch et al. 2002:619).

Pettersson and Eck (2018) published an article in which they reported on trends in organized violence from data collected by the UCDP. According to their assessment, 2017 saw a decrease for the third consecutive year to a level $32 \%$ lower than the latest peak in 2014. They point out that this declining trend of organized violence is driven by state-based armed conflict, particularly by the Syrian Civil War. The overall decrease in fatalities supports the claim that conflict deaths are in decline and that the world is increasingly peaceful. Pettersson and Eck emphasize that this trend holds even more strongly when controlling for increases in world population. On the other hand, non-state conflict has increased, since a new peak of 82 active non-state conflicts was recorded in 2017 and fatalities have increased concurrently. The authors note that much of this is due to escalating violence in DR Congo and the Central African Republic.

UCDP presents trends in state-based armed conflict, non-state conflict and one-sided violence in an annual update. They aggregate these three mutually exclusive categories of armed conflict as 'organized violence' and use the same intensity cut-off for inclusion for all

${ }^{141}$ See at https://www.pcr.uu.se/research/ucdp/definitions [Accessed 19 May 2021]. 
of them, which is 25 fatalities in a calendar year. State-based armed conflict includes violence where at least one of the parties is the government of a state, namely, violence between two states and violence between the government and a rebel group. ${ }^{142}$ Non-state conflict is the use of armed force between two organized groups, neither of which is the government of a state, ${ }^{143}$ while one-sided violence covers violence by the government of a state or by a formally organized group targeting unarmed civilians (Pettersson \& Eck 2018:535).

\section{A.1.5.1. State-based Conflict Between 1946-2017}

According to the data of UCDP, since 1946, 614 dyads ${ }^{144}$ have been active in 285 conflicts in 157 locations, while for the post-Cold War period (1989-2017) the numbers are 371 dyads in 176 conflicts in 94 locations. In 2017 forty-nine conflicts were active, down from 53 in the previous year, which was the peak year of the entire 1946-2017 period. In the early 1990s there has been a similar increase in the number of state-based conflict, right after the end of the Cold War. The recent trend has been driven by the growth of the Islamic State (ISIS), as the group has tried to expand its territory resulting in a number of new conflicts. During 2017, both Iraq and Syria reported the defeat of ISIS, and the group has now lost all but a fraction of the land it once held in the region while many of its leaders have been killed. However, according to different estimates, in 2019 ISIS still had 20,000 to 30,000 members in Iraq and Syria, and it has made a tactical shift to a guerrilla strategy (Callimachi 2019; Sly 2019). Nonetheless, ISIS was involved in 15 conflicts during 2017, a full $31 \%$ of the total number of conflicts. ${ }^{145}$ As Pettersson and Eck (2018:536) note this is both the highest absolute number, and the highest percentage recorded since the group announced its caliphate in 2014.

Interestingly, of the 48 intrastate conflicts, as many as 19 , or $40 \%$, were internationalized, in other words, troops from external states supported one or both sides in the conflict. Again, the authors note that both the absolute number and the percentage are high for the post-1946 period - second only to 2015 , with 20 conflicts. It is worth to note that with

\footnotetext{
${ }^{142}$ For instance, the conflict between Ethiopia and Eritrea until their peace treaty was signed in 2018, and the conflict between the Taliban and the Afghan government.

${ }^{143}$ Non-state conflict is defined by UCDP and PRIO as: "the use of armed force between two organized armed groups, neither of which is the government of a state, which results in at least 25 battle-related deaths in a year". For example, fighting between the Islamic State (ISIS) and Tahrir al-Sham in Syria. See at https://www.pcr.uu.se/research/ucdp/definitions.

${ }^{144}$ According to the definitions used by UCDP and PRIO: "A dyad is made up of two armed and opposing actors. In state-based conflicts a dyad is defined as two actors, with one or more being the government, that have a stated incompatibility. In a non-state conflict, a dyad is constructed by at least two organized actors, of which none is the government of a state, that oppose each other with arms. In non-state conflicts it is possible for an alliance of non-state actors to enter into a dyad with either an opposing group, or an alliance of opposing groups." See at https://www.pcr.uu.se/research/ucdp/definitions.

${ }^{145}$ For more on the Islamic State see Arany, N. Rózsa and Szalai (2016).
} 
troops in seven internationalized intrastate conflicts, the United States was involved in more conflicts as a secondary warring party than any other country in 2017 (Pettersson \& Eck 2018:537).

In regard of battle-related deaths in state-based conflict, the numbers show that the decrease in fatalities continued for the third year in a row. ${ }^{146}$ However, despite the overall decline, violence in Iraq and Afghanistan escalated in 2017, with Afghanistan experiencing its most violent year in the post-Cold War period and Iraq its second most violent year. It is worth mentioning that while the past years have witnessed high levels of fatalities compared to most years since the end of the Cold War, wars of the $21^{\text {st }}$ century, however, have been nowhere near as lethal as the large-scale wars of the $20^{\text {th }}$ century, such as the Chinese Civil War, Korea, Vietnam, and the two World Wars (Lacina \& Gleditsch 2005). Overall, the data shows that battle-deaths are in decline and that the world today is increasingly peaceful (Pettersson \& Eck 2018:537-538; Goldstein 2012).

\section{A.1.5.2. Non-state Conflict 1989-2017}

According to the data of UCDP 670 non-state conflicts have been recorded since 1989, with a yearly average of 37 active conflicts. The increase in non-state conflict since 2010 was reversed in 2016, however, it rose again significantly in 2017, reaching a new peak number of 82 active conflicts. Similarly to the previous years, Syria and Mexico dominated this category, together responsible for $28 \%$ of the total number of non-state conflicts. It is worth mentioning, however, that number of active conflicts was also on the rise in the Democratic Republic of Congo (DRC) and the Central African Republic (CAR). In addition, Africa saw a large increase in the number of non-state conflicts in 2017, up by two from 2016. Similarly to the case in 2016, the vast majority of the conflicts in the Middle East in 2017 took place in Syria, and two non-state conflicts were recorded in Asia in 2017, both of them in Afghanistan. The Americas had 11 active non-state conflicts in 2017, an increase from 8 in 2016 (Pettersson \& Eck 2018:538).

The sharp increase in the number of non-state conflicts was accompanied by a rise in the number of fatalities from this type of violence. The data shows a new peak in fatalities in 2017, with more than 13,500 people killed in non-state conflict. As Pettersson and Eck (2018:538-539) point out much of this is due to the conflict between ISIS and the Kurdishdominated Syrian Democratic Forces (SDF) in Syria, which was the most lethal non-state

\footnotetext{
${ }^{146}$ According to the definitions used by UCDP and PRIO: "Counted as battle-related deaths is the use of armed force between warring parties in a conflict dyad, be it state-based or non-state, resulting in deaths." See at https://www.pcr.uu.se/research/ucdp/definitions [Accessed 19 May 2019].
} 
conflict during 2016 and 2017. In these years the Middle East was the region where most fatalities in non-state conflicts were incurred. The overall increase in deaths, however, was also caused by escalating violence in Africa. Although fatalities in non-state conflict peaked in 2017 , they remain but $15 \%$ of the total number of fatalities in organized violence.

\section{A.1.5.3. One-sided Violence 1989-2017}

UCDP has recorded 266 actors engaged in one-sided violence since 1989, with a yearly average of 33 active actors, while the number of actors carrying out one-sided violence increased substantially from 27 to 33 . According to the estimates of UCDP a state or a formally organized group targeted and killed almost 7,000 civilians in 2017. One widely known case of one-sided violence during 2017 took place in Myanmar (Burma), where the government targeted and executed civilians mainly belonging to the Muslim Rohingya ethnic minority (Hrw.org 2019; BBC News 2018). Although the killings of civilians by the Burmese government constituted one of the most lethal cases of one-sided violence in 2017, non-state actors caused the vast majority of the global fatalities from one-sided violence. Since 1989, with a few exceptions this has been the case for most years, and in only seven out of 29 years were governments responsible for more deaths than non-state groups. ISIS continued to be the actor responsible for most one-sided violence - around 35\% of the total number of deaths however, the killings carried out by the group decreased substantially from 2016 (Pettersson \& Eck 2018:539-540). 


\section{A.2. Graphs and Tables}

Table 6. CINC scores of Iraq: A comparative table of pre-intervention and post-intervention periods

Source: Correlates of War CINC score, National Material Capabilities data set

\begin{tabular}{|c|c|c|c|c|c|c|c|c|}
\hline Conflict & Year & $\begin{array}{c}\text { Military } \\
\text { expenditures }^{147}\end{array}$ & $\begin{array}{c}\text { Military } \\
\text { personnel }^{148}\end{array}$ & $\begin{array}{l}\text { Iron and steel } \\
\text { production }\end{array}$ & $\begin{array}{c}\text { Energy } \\
\text { consumption }\end{array}$ & Population & $\begin{array}{c}\text { Urban } \\
\text { population }\end{array}$ & $\begin{array}{l}\text { CINC } \\
(2011)\end{array}$ \\
\hline \multirow{3}{*}{ The Gulf War } & 1988 & 12870000 & 1390 & 0 & 1390 & 16882 & 12594 & 0.0109068 \\
\hline & 1990 & 8610000 & 1390 & 0 & 32036 & 18078 & 13294 & 0.012605 \\
\hline & 1992 & 2500000 & 407 & 0 & 33544 & 18898 & 14016 & 0.0061309 \\
\hline \multirow{3}{*}{$\begin{array}{c}\text { Invasion of } \\
\text { Iraq }\end{array}$} & 2001 & 1372000 & 424 & 0 & 46675 & 24813 & 17451 & 0.006409 \\
\hline & 2003 & -9 & 389 & 0 & 45829 & 25960 & 11673 & 0.006640 \\
\hline & 2005 & -9 & 180 & 0 & 45137 & 27377 & 12060 & 0.004558 \\
\hline
\end{tabular}

${ }^{147}$ Defense spending shows the country's total (gross) annual military budget in US dollars, focusing on military capabilities, excluding military-controlled non-military (e.g. police) capabilities and civilian spending. Missing values are indicated by the code -9 . The primary sources of data are the issues of the Military Balance, published annually by the International Institute for Strategic Studies (IISS). See Greig, J. and Enterline, A. (2017). Correlates of War Project National Material Capabilities (NMC) Data Documentation Version 5.0. [online] Denton: University of North Texas: Department of Political Science, pp. 23-29. Available at: http://www.correlatesofwar.org/datasets/national-material-capabilities/nmc-codebook-v5-1/at download/file [Accessed 19 May 2021].

${ }^{148}$ Military personnel are defined as troops under the command of the national government, including only active, regular military units of the land, naval, and air components, and excluding the military forces of foreign military forces, semi-autonomous states and protectorates, and insurgent troops. These figures reflect the project's best judgment on which forces were intended for combat with foreign parties. The precise numbers of active forces remain uncertain in a conceptual basis. Missing values are indicated by -9 . Ibid., pp. 13-22. 
Figure 5. Regional CINC-score comparison graph, 1945-2012

(Singer, Bremer \& Stuckey, 1972; Singer, 1987)

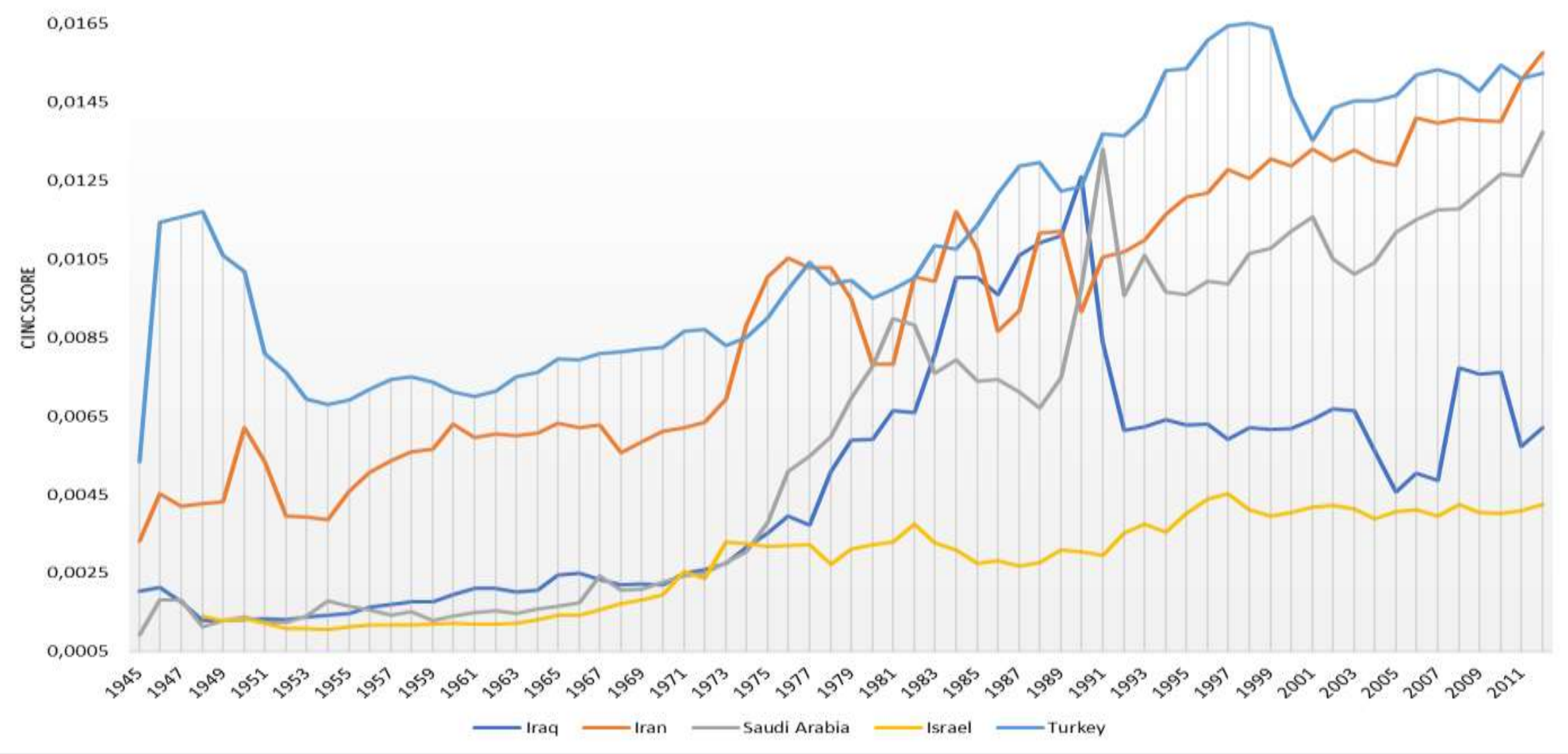


Table 7. CINC-score comparison table

\begin{tabular}{|c|c|c|c|c|c|}
\hline Year & Iraq & Iran & $\begin{array}{l}\text { Saudi } \\
\text { Arabia }\end{array}$ & Israel & Turkey \\
\hline 1945 & 0,0020499 & 0,00332 & 0,0009225 & & 0,00534 \\
\hline 1946 & 0,0021282 & 0,0045245 & 0,0018056 & & 0,011434 \\
\hline 1947 & 0,0017747 & 0,0042104 & 0,0018122 & & 0,011582 \\
\hline 1948 & 0,001297 & 0,0042677 & 0,0011293 & 0,001414 & 0,011723 \\
\hline 1949 & 0,0012939 & 0,0043231 & 0,0012833 & 0,001288 & 0,010601 \\
\hline 1950 & 0,0013108 & 0,0062025 & 0,0013792 & 0,001332 & 0,010197 \\
\hline 1951 & 0,0013278 & 0,0053488 & 0,0012478 & 0,001225 & 0,008091 \\
\hline 1952 & 0,0013117 & 0,0039461 & 0,001255 & 0,001098 & 0,007616 \\
\hline 1953 & 0,0013845 & 0,0039396 & 0,001411 & 0,001086 & 0,006925 \\
\hline 1954 & 0,0014358 & 0,0038649 & 0,0017959 & 0,00107 & 0,006806 \\
\hline 1955 & 0,0014816 & 0,0045821 & 0,0016605 & 0,001128 & 0,006902 \\
\hline 1956 & 0,0016339 & 0,0050572 & 0,0015756 & 0,001186 & 0,007192 \\
\hline 1957 & 0,001691 & 0,0053636 & 0,001427 & 0,001181 & 0,007434 \\
\hline 1958 & 0,0017766 & 0,0055935 & 0,0015082 & 0,001189 & 0,007513 \\
\hline 1959 & 0,0017597 & 0,0056616 & 0,0012976 & 0,001192 & 0,007359 \\
\hline 1960 & 0,0019411 & 0,0062873 & 0,001404 & 0,001217 & 0,00712 \\
\hline 1961 & 0,0021218 & 0,0059514 & 0,0015025 & 0,00121 & 0,006992 \\
\hline 1962 & 0,0021011 & 0,0060581 & 0,0015496 & 0,001205 & 0,007132 \\
\hline 1963 & 0,0020268 & 0,005997 & 0,0014775 & 0,001214 & 0,007512 \\
\hline 1964 & 0,0020568 & 0,006063 & 0,001578 & 0,001304 & 0,007605 \\
\hline 1965 & 0,0024435 & 0,0063259 & 0,0016511 & 0,001427 & 0,007947 \\
\hline 1966 & 0,0025025 & 0,0061971 & 0,0017438 & 0,001427 & 0,00794 \\
\hline 1967 & 0,0023475 & 0,0062846 & 0,0024324 & 0,001557 & 0,008104 \\
\hline 1968 & 0,0022052 & 0,0055705 & 0,0020692 & 0,001732 & 0,008151 \\
\hline 1969 & 0,0022238 & 0,0058392 & 0,0020811 & 0,001813 & 0,008212 \\
\hline 1970 & 0,0022001 & 0,0061196 & 0,0022656 & 0,001956 & 0,008243 \\
\hline 1971 & 0,0024966 & 0,0062166 & 0,0024192 & 0,002534 & 0,008661 \\
\hline 1972 & 0,0025821 & 0,0063509 & 0,0025048 & 0,002361 & 0,008708 \\
\hline
\end{tabular}




\begin{tabular}{|c|c|c|c|c|c|}
\hline 1973 & 0,0027432 & 0,0069416 & 0,002764 & 0,003292 & 0,00829 \\
\hline 1974 & 0,0031538 & 0,0088231 & 0,0030445 & 0,00325 & 0,008508 \\
\hline 1975 & 0,003516 & 0,0100492 & 0,0037922 & 0,003178 & 0,008999 \\
\hline 1976 & 0,0039433 & 0,0105288 & 0,0051023 & 0,003204 & 0,009738 \\
\hline 1977 & 0,0037324 & 0,0102733 & 0,0054758 & 0,003215 & 0,010418 \\
\hline 1978 & 0,0050907 & 0,0102895 & 0,0059736 & 0,002734 & 0,009864 \\
\hline 1979 & 0,0058809 & 0,0094861 & 0,0069553 & 0,003112 & 0,009968 \\
\hline 1980 & 0,0059016 & 0,0078179 & 0,0077669 & 0,003222 & 0,009503 \\
\hline 1981 & 0,0066345 & 0,0078229 & 0,0089855 & 0,003287 & 0,009722 \\
\hline 1982 & 0,0065825 & 0,0100467 & 0,008832 & 0,003756 & 0,010019 \\
\hline 1983 & 0,0080654 & 0,0099378 & 0,0076035 & 0,003267 & 0,010851 \\
\hline 1984 & 0,0100267 & 0,0117157 & 0,0079308 & 0,003087 & 0,010747 \\
\hline 1985 & 0,0100262 & 0,0107252 & 0,0073919 & 0,002739 & 0,011364 \\
\hline 1986 & 0,0095884 & 0,008658 & 0,0074389 & 0,002821 & 0,01216 \\
\hline 1987 & 0,0105868 & 0,0091912 & 0,007109 & 0,002669 & 0,012878 \\
\hline 1988 & 0,0109068 & 0,0111667 & 0,0067087 & 0,002768 & 0,012956 \\
\hline 1989 & 0,0111034 & 0,0112109 & 0,007484 & 0,003099 & 0,012234 \\
\hline 1990 & 0,012605 & 0,0091591 & 0,0097885 & 0,003045 & 0,012359 \\
\hline 1991 & 0,0083689 & 0,01055 & 0,0133136 & 0,002957 & 0,013693 \\
\hline 1992 & 0,0061309 & 0,0106825 & 0,0095651 & 0,003531 & 0,013639 \\
\hline 1993 & 0,006231 & 0,0109832 & 0,0105903 & 0,003738 & 0,014127 \\
\hline 1994 & 0,0064014 & 0,0116459 & 0,009654 & 0,003547 & 0,01531 \\
\hline 1995 & 0,0062761 & 0,0120869 & 0,0096013 & 0,004018 & 0,015361 \\
\hline 1996 & 0,0062988 & 0,0121789 & 0,0099269 & 0,004391 & 0,016079 \\
\hline 1997 & 0,0059131 & 0,0127905 & 0,0098686 & 0,004522 & 0,01645 \\
\hline 1998 & 0,0062035 & 0,0125535 & 0,0106328 & 0,004112 & 0,016514 \\
\hline 1999 & 0,0061649 & 0,0130514 & 0,0107827 & 0,003947 & 0,016382 \\
\hline 2000 & 0,0061786 & 0,0128793 & 0,0112029 & 0,004054 & 0,014657 \\
\hline 2001 & 0,0064085 & 0,0133085 & 0,0115701 & 0,00418 & 0,013527 \\
\hline
\end{tabular}




\begin{tabular}{|lrrrrr|}
\hline $\mathbf{2 0 0 2}$ & 0,0066789 & 0,0130174 & 0,0105053 & 0,004232 & 0,014344 \\
\hline $\mathbf{2 0 0 3}$ & 0,0066403 & 0,013277 & 0,0101286 & 0,004145 & 0,014537 \\
\hline $\mathbf{2 0 0 4}$ & 0,0056035 & 0,0130136 & 0,0104053 & 0,003879 & 0,014539 \\
\hline $\mathbf{2 0 0 5}$ & 0,0045582 & 0,0128966 & 0,011185 & 0,004075 & 0,014679 \\
\hline $\mathbf{2 0 0 6}$ & 0,0050392 & 0,0141106 & 0,0115048 & 0,004119 & 0,015189 \\
\hline $\mathbf{2 0 0 7}$ & 0,0048718 & 0,013973 & 0,0117657 & 0,003958 & 0,015324 \\
\hline $\mathbf{2 0 0 8}$ & 0,007738 & 0,0140784 & 0,0117789 & 0,004253 & 0,01518 \\
\hline $\mathbf{2 0 0 9}$ & 0,0075736 & 0,0140388 & 0,0122051 & 0,004035 & 0,014774 \\
\hline $\mathbf{2 0 1 0}$ & 0,0076158 & 0,0140014 & 0,0126661 & 0,004017 & 0,015432 \\
\hline $\mathbf{2 0 1 1}$ & 0,0057172 & 0,0150526 & 0,0126323 & 0,004084 & 0,015107 \\
\hline $\mathbf{2 0 1 2}$ & 0,0062019 & 0,0157625 & 0,0137426 & 0,00425 & 0,015239 \\
\hline & & & & & \\
\hline
\end{tabular}


Table 8. Strategic international military interventions targeting Iraq, 1989-2005

Source: IMI Kisangani \& Pickering 1989-2005, Excel spreadsheet.




Table 9. IMI Dataset variables explained

Source: ICPSR Codebook - Kisangani \& Pickering 1989-2005 Data, pp. 6-10.

Variable Number

VAR 001

VAR 002

VAR 003

VAR 004

VAR 005

VAR 006

VAR 007

VAR 008

VAR 009
Column(s) Variable Name and/or Description

Intervener Country Code using COW Country codes and ICOW international organization codes.

B Target Country Code using COW Country codes.

C Starting Date: year/month/day. This is an eight (8) digit number. For example, 19890101 stands for January 1, 1989.

D Ending Date: year/month/day. This is also an eight (8) digit number. For example, 20051231 stands for December 31, 2005; if month is unknown, last month of the year coded ; if date unknown, 99999999; if ongoing, 88888888 .

Source of Intervention

1. Nation crossing border or demarcation line.

2. Nation whose troops are already present in the country participating in the intervention.

9. Not ascertained.

Direction of Intervener Supporting Action

0 . Non-supportive or neutral intervention

1. Support government (including immediate restoration to abort coup)

2. Oppose rebels or opposition groups

3. Oppose government

4. Support rebel or opposition groups

5. Support or oppose $3^{\text {rd }}$ party government

6. Support or oppose rebel groups in sanctuary

9. Not ascertained.

Troop Activity (outside bases-code highest level)

$0 . \quad$ None

1. Evacuation of troops or personnel (any nationality) in context or dispute.

2. Transport or negotiate-observe

3. Patrol/guard/defend (SAMS)

4. Intimidation

5. Combat

9. Not ascertained.

Amount of Troop Incursion (code at highest level)

$0 . \quad$ None

1. $1-1,000$

2. $1,001-5,000$

3. $5,001-10,000$

4. $10,000+$

9. Not ascertained

Air Incursion (note: reconnaissance flights are not included - code at highest level)

0 . None

1. Evacuation of troops or personnel

2. Transport troops or personnel -supply/support

3. Act of intimidation/air defense/patrol

4. Bombing or strafing, firing (offense) 
VAR 010

VAR 011

VAR 012

VAR 013

VAR 014

VAR 015

VAR 016
9. Not ascertained.

Naval Incursion (code at highest level)

0 . None

1. Evacuation of troops or personnel.

2. Transport troops or launch forces inside territorial waters for combat or application of force

3. Laying or removing mines in territorial waters/commando raid

4. Act of intimidation or patrol in territorial waters or disputed waters already occupied

5. Shelling/firing

9. Not ascertained.

Size of Naval Force Employed (within territorial waters of target)

1. Small forces (1-4 ships)

2. Large force (5 or more ships)

9. Not ascertained.

Firing (by artillery, guns, or ships) by the intervener from outside the target

1. No

2. Yes

9. No report; no information; not ascertained; not applicable.

Number of Battle (military) Casualties to the

Intervener (whenever possible include number

killed + number wounded) Associated with the

Intervention.

0 . None

998. At least 998 casualties (exact number uncertain)

9999999. Not ascertained

Note that the original IMI collection used 999 to indicate that casualty figures could not be ascertained. Coding for 1989-2005 provides the exact number of casualties reported, including those exceeding 999.

Since more than 1 million casualties were the direct result of some international interventions, 9999999 indicates that casualty figures could not be ascertained.

$\mathrm{N}$

Number of Battle (military) Casualties to the Target

Associated with this Intervention

0 . None

998. At least 998 (exact number uncertain) 9999999. Not ascertained.

O Total Civilian Casualties on both Sides (killed/ wounded)

0. None

998. At least 998 (exact number uncertain) 9999999. Not ascertained

Intervener Takes Sides in a Domestic Dispute

$0 . \quad$ No

1. Yes

9. Not ascertained; not applicable 
VAR 017

VAR 018

VAR 019

VAR 020

VAR 021

VAR 022

VAR 023

VAR 024

VAR 025
$\mathrm{R}$
Affect Policies or Conditions in Target

0 . No

1. Yes

9. Not ascertained; not applicable

Social Protective Intervention (e.g. to protect a socio-ethnic faction(s) or minority of the target country)

$0 . \quad$ No

1. Yes

9. Not ascertained; not applicable

Pursue Rebel or Terrorist Forces across Border or into Sanctuary

$0 . \quad$ No

1. Yes

9. Not ascertained; not applicable

Economic Protective Intervention (intervener attempts to protect economic or resource interests of self or others)

$0 . \quad$ No

1. Yes

9. Not ascertained; not applicable Strategic Intervention (e.g., regional power balances, stability, or ideological issues mentioned by the intervener or clearly connected to the intervention)

$0 . \quad$ No

1. Yes

9. Not ascertained; not applicable

Humanitarian Intervention (e.g., to save lives, relieve suffering, distribute foodstuffs to prevent starvation and so forth) apart from protection of a minority group, see variable 18 .

0 . No

1. Yes

9. Not ascertained; not applicable.

Territorial Intervention (acquisition or retention of territory, delineation of frontiers, or specification of sovereign status).

$0 . \quad$ No

1. Yes - intervention in established territory

2. Yes - intervention in disputed territory under other state's control

9. Not ascertained; not applicable Intervention to Protect own Military and/or Diplomatic Interests and Property inside or outside the Target (e.g., military property; diplomats; diplomatic property)

0 . No

1. Yes

9. Not ascertained; not applicable Are Intervener and Target Neighboring Contiguous Countries?
$0 . \quad$ No
1. Yes
2. Less than or Equal to 150 Miles of Water 
VAR 026

VAR 027

between borders

9. Not ascertained; not applicable

Z

Does Intervention Come from Neighboring

Contiguous Country or Countries?

0 . No

1. Yes

9. Not ascertained; not applicable

Description/Source of Intervention 